A Simplified Technique for

Thermal Analysis of a Fenestration system with a Venetian Blind

by

Hidayat Ullah Shahid

Bachelor of Engineering

Department of Mechanical, Aerospace and Industrial Engineering

Ryerson University

Toronto, Ontario, Canada, 2003

\author{
A thesis \\ presented to Ryerson University \\ in partial fulfillment of the \\ requirements for the degree of \\ Master of Applied Science \\ in the Program of \\ Mechanical Engineering
}

Toronto, Ontario, Canada, 2003

'Hidayat Ullah Shahid 2003 
UMI Number: EC53408

\section{INFORMATION TO USERS}

The quality of this reproduction is dependent upon the quality of the copy submitted. Broken or indistinct print, colored or poor quality illustrations and photographs, print bleed-through, substandard margins, and improper alignment can adversely affect reproduction.

In the unlikely event that the author did not send a complete manuscript and there are missing pages, these will be noted. Also, if unauthorized copyright material had to be removed, a note will indicate the deletion.

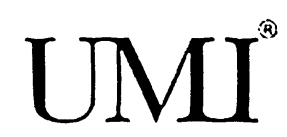

\section{UMI Microform EC53408 \\ Copyright 2009 by ProQuest LLC}

All rights reserved. This microform edition is protected against unauthorized copying under Title 17, United States Code.

ProQuest LLC

789 East Eisenhower Parkway

P.O. Box 1346

Ann Arbor, MI 48106-1346 



\section{AUTHOR'S DECLARATION}

I hereby declare that I am the sole author of this thesis. I authorize Ryerson University to lend this thesis to other institutions or individuals for the purpose of scholarly research.

Signature:

I further authorize Ryerson University to reproduce this thesis by photocopying or by other means, in total or in part, at the request of other institutions or individuals for the purpose of scholarly research.

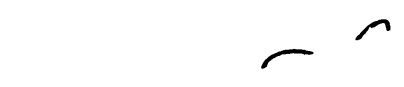

Signature: 


\section{BORROWER'S PAGE}

Ryerson University requires the signatures of all persons using or photocopying this thesis.

Please sign below, and give address and date. 


\title{
A SIMPLIFIED TECHNIQUE FOR THERMAL ANALYSIS OF A FENESTRATION SYSTEM WITH A VENETIAN BLIND
}

\author{
Hidayat Ullah Shahid \\ Master of Applied Science \\ Department of Mechanical \& Industrial Engineering \\ Ryerson University, Toronto, Ontario, Canada, 2003
}

\begin{abstract}
A simplified 1-D numerical model of a window and horizontal Venetian blind assembly has been developed. This model provides a realistic estimate of the advantage of using blinds to control the window heat gain or loss. The free convective heat transfer rate from an isothermal vertical surface adjacent to a set of horizontal louvers has been studied numerically. This configuration is an approximate model of an indoor window glazing with a Venetian-type blind. Knowledge of the effect of blinds on the free convection at the indoor window surface is important for understanding and predicting the impact of shading devices on the overall thermal performance of a window. The convective heat transfer results are used in the onedimensional model of the complete fenestration system to study the effect on key performance parameters. The results show that louvered blinds can have a significant beneficial effect on window thermal performance.
\end{abstract}




\section{ACKNOWLEDGEMENTS}

In the name of the Most Gracious, the Most Merciful, the only Helper, the Giver of best rewards who gives the wisdom and knowledge to those whomsoever He chooses.

I would like to thank my parents and family members for their support and encouragement. Special thanks are due to my mother and father for their kindness, prayers and support that proved to be a major factor in personal accomplishments.

I would like to acknowledge the research work of Alan Machin, Jeff Phillips and others that led to this thesis. I would also like to gratefully thank Dr. P.H. Oosthuizen, Dr. S.J. Harrison at Queen's University and Dr. J. Wright at University of Waterloo. Their support and insights have been valuable throughout this thesis.

I would like to gratefully thank my teachers for their contributions. Special thanks are due to Dr. Greg Kawall (the best teacher I ever had!), Dr. David Naylor, Dr. Marc Rosen, Dr. Jacob Friedman, Dr. Shudong Yu and Prof. R.S. Budny for making the learning process easy.

I would also like to thank Leah Stanwyck and Gerald Bootes at Ryerson for their valuable time and support. I would like to acknowledge NSERC for providing partial financial support for this project. 
Finally, I would like to express my deepest appreciation to Dr. David Naylor for his support, encouragement and guidance. In fact, without his enthusiasm and persistence this thesis would not have been possible.

May God bless us all and increase us in knowledge! 


\section{TABLE OF CONTENETS}

Page

TITLE PAGE

.. $\mathrm{i}$

AUTHOR'S DECLARATION ....................................................................................... iii

BORROWER'S PAGE ............................................................................................... iv

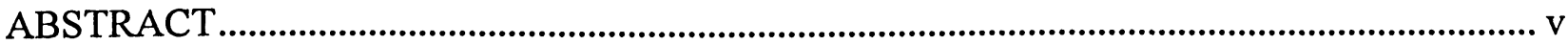

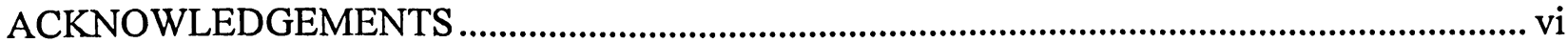

TABLE OF CONTENTS.......................................................................................... vii

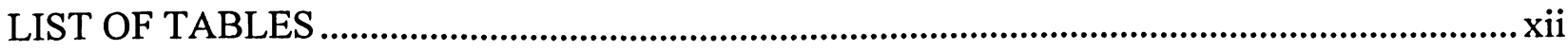

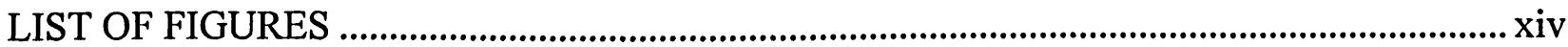

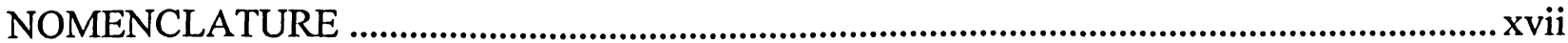

\section{CHAPTER 1: INTRODUCTION AND LITERATURE REVIEW}

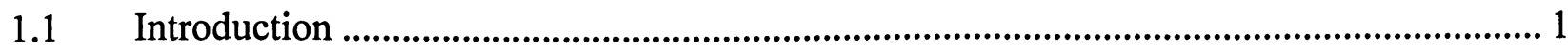

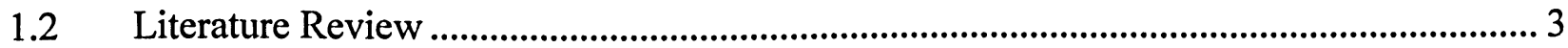

1.2.1 Fenestration Thermal Analysis with No Blind/Shading Device ............................... 4

1.2.2 Studies of Laminar Natural Convection from an Isothermal Plate ............................ 6

1.2.3 Studies of Natural Convection in a 2-D Rectangular Cavity ...................................8

1.2.4 Studies of the Effects of a Venetian Blind on Window Energy Performance ........... 10

1.3 Problem Statement and Scope of Research ............................................................. 16

\section{CHAPTER 2: NUMERICAL MODEL AND SOLUTION PROCEDURES}

2.1 Introduction 


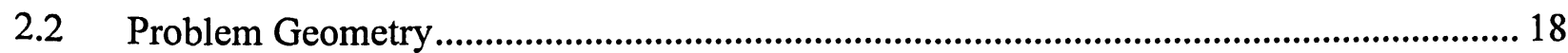

2.3 Thermal Resistance Model of an Unshaded Window ...................................................... 20

2.4 Simplified Numerical Model for the Window/Blind System and Solution Procedure ..... 26

2.5 Computations of Thermal Radiation Exchange between an Indoor Glazing and a

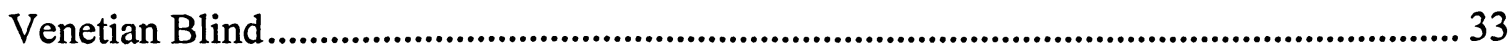

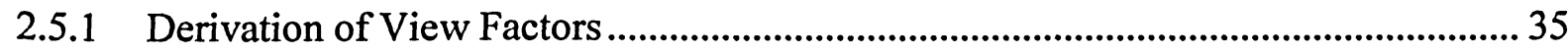

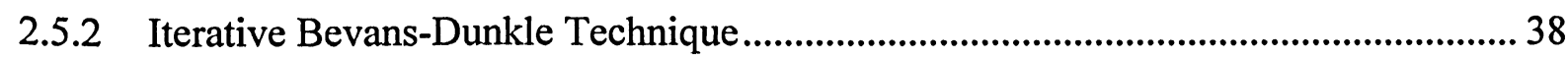

2.6 Convection Heat Transfer Correlations for the Outdoors and Window Cavity ................ 40

2.7 Computations of Free Convection Exchange between an Indoor Glazing and a Venetian

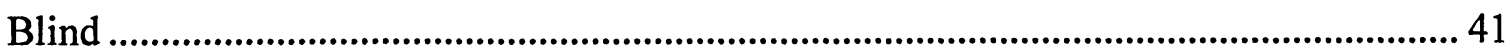

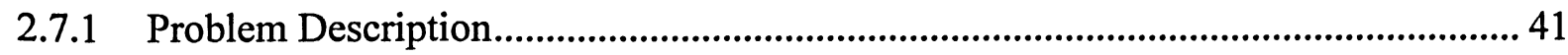

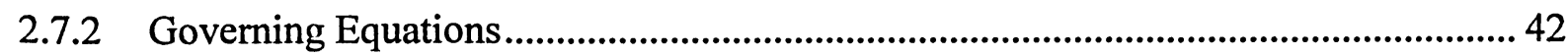

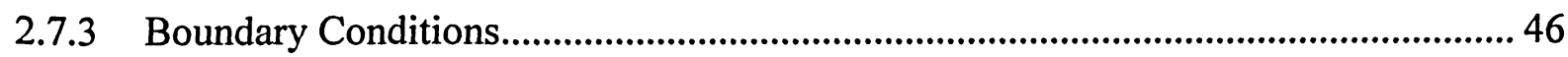

2.7.4 Non-dimensionalization Scheme and Solution Procedure ........................................... 48

2.7.5 Validation Study of the Free Convection Numerical Model..........................................5 53

2.7.6 Far Field Boundary and Grid Sensitivity Study ............................................................5

\section{CHAPTER 3: PRESENTATION OF RESULTS}

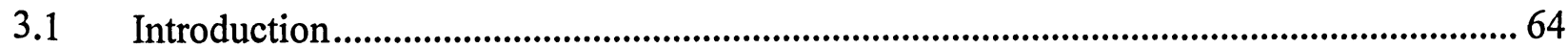

3.2 Presentation of Results pertaining to the Finite Element Free Convection Model ........... 65

3.2.1 Effect of Rayleigh Number on the Convective Heat Transfer ...................................... 66

3.2.2 Effect of Blind tip-to-window Spacing on the Convective Heat Transfer from the Indoor Glazing surface. 
3.2.3 Effect of Blind tip-to-window Spacing on the Convective Heat Transfer from the Blind 83

3.2.4 Effect of Blind Angle on the Convective Heat Transfer.......................................... 85

3.3 Energy Performance Assessments of a Window with a Venetian Blind ............................ 88

3.3.1 Baseline Data and Design Conditions ....................................................................... 89

3.3.2 Effects of Blind on the U-value of a Single/Double Glazed Window ....................... 90

3.3.3 Effect of Blind Emissivity on the Center of Glass U-value ...................................... 98

3.3.4 Effect of Blind on the Thermal Comfort of the Occupant ........................................ 99

3.3.5 Effect of Blind Emissivity on Thermal Comfort of the Occupant ............................ 103

3.3.6 Effect of Blind on the Thermal Performance of an Energy Efficient Window with

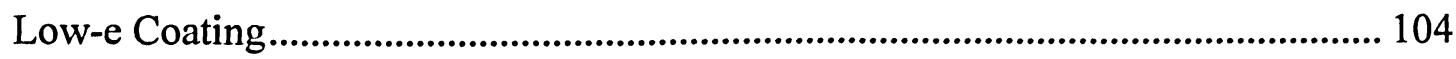

3.3.7 On the Optimum Performance of a Window and Blind system................................ 105

3.3.8 On the Accuracy of 1-D Thermal Resistance Model ................................................... 107

\section{CHAPTER 4: CONCLUSIONS AND RECOMMENDATIONS}

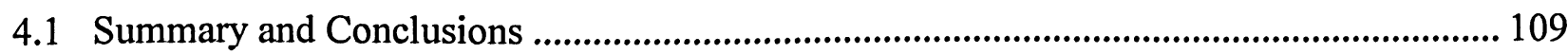

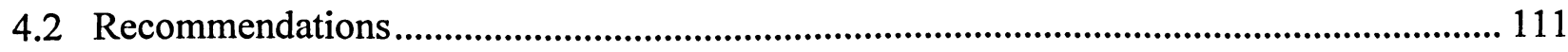

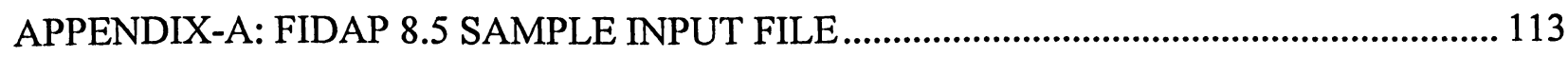

APPENDIX-B: FIDAP 8.5 SAMPLE OUTPUT FILE ............................................................... 124

APPENDIX-C: SELECTED FREE CONVECTION SOLUTION DATA................................. 125

APPENDIX-D: C-PROGRAM FOR A DOUBLE GLAZED WINDOW WITH A BLIND..... 145 
APPENDIX-E: SAMPLE OUTPUT FROM 1-D THERMAL RESISTANCE MODEL OF

BLIND AND WINDOW SYSTEM …........................................................ 154

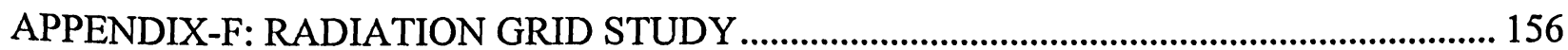

APPENDIX-H: SAMPLE STREAMLINE AND TEMPERATURE CONTOURS PLOTS..... 157

REFERENCES

165 


\section{LIST OF TABLES}

Table 3.1: Window specifications used in the current study. 89

Table 3.2: ASHRAE Design Conditions for summer and winter [4] 90

Table 3.3: $U$-value $\left(\mathrm{U}_{\mathrm{NB}}\right)$ and radiation heat flux to the indoor surroundings $\left(\mathrm{Q}_{\mathrm{R} 4, \mathrm{NB}}\right)$ for the unshaded window.

Table 3.4: Summer U-value ratio (U/ $\left.\mathrm{U}_{\mathrm{NB}}\right)$ Present 1-D model compared to CFD study [54]. $\mathrm{d} / \mathrm{L}=0.043, \varepsilon_{\mathrm{b}}=0.8, \mathrm{~W} / \mathrm{ps}=1.14$. 108

Table C-1: Average Nusselt number data for the indoor window surface, $\phi=0^{\circ}$. 125

Table C-2: Average Nusselt number data for the indoor window surface, $\phi=45^{\circ}$ 125

Table C-3: Average Nusselt number data for the indoor window surface, $\phi=90^{\circ}$ 126

Table C-4: Average heat flux $\left(\mathrm{q}_{\mathrm{i}, \text { avg }}\right.$ ) data for the individual blind louver, $\phi=0^{\circ}, \mathrm{T}_{\mathrm{b}}{ }^{*}=0.1$, $\mathrm{d} / \mathrm{L}=0.043$.

Table C-5: Average heat flux $\left(\mathrm{q}_{\mathrm{i}, \mathrm{avg}}\right)$ data for the individual blind louver, $\phi=0^{\circ}, \mathrm{T}_{\mathrm{b}}{ }^{*}=0.2$, $\mathrm{d} / \mathrm{L}=0.043$

Table C-6: Average heat flux $\left(\mathrm{q}_{\mathrm{i}, \mathrm{avg}}\right)$ data for the individual blind louver, $\phi=0^{\circ}, \mathrm{T}_{\mathrm{b}}{ }^{*}=0.3$, $\mathrm{d} / \mathrm{L}=0.043$.

Table C-7: Average heat flux $\left(\mathrm{q}_{\mathrm{i}, \mathrm{avg}}\right)$ data for the individual blind louver, $\phi=0^{\circ}, \mathrm{T}_{\mathrm{b}}{ }^{*}=0.4$, $\mathrm{d} / \mathrm{L}=0.043$

Table C-8: Average heat flux $\left(\mathrm{q}_{\mathrm{i}, \text { avg }}\right.$ ) data for the individual blind louver, $\phi=45^{\circ}, \mathrm{T}_{\mathrm{b}}{ }^{*}=0.2$, $\mathrm{d} / \mathrm{L}=0.043$

Table C-9: Average heat flux $\left(\mathrm{q}_{\mathrm{i}, \text { avg }}\right)$ data for the individual blind louver, $\phi=45^{\circ}, \mathrm{T}_{\mathrm{b}}{ }^{*}=0.3$, $\mathrm{d} / \mathrm{L}=0.043$

Table C-10: Average heat flux ( $\mathrm{q}_{\mathrm{i}, \text { avg }}$ ) data for the individual blind louver, $\phi=45^{\circ}, \mathrm{T}_{\mathrm{b}}{ }^{*}=0.4$, $\mathrm{d} / \mathrm{L}=0.043$

Table C-11: Average heat flux ( $\mathrm{q}_{\mathrm{i} \text {,avg }}$ ) data for the individual blind louver, $\phi=90^{\circ}, \mathrm{T}_{\mathrm{b}}{ }^{*}=0.2$, $\mathrm{d} / \mathrm{L}=0.043$

Table C-12: Average heat flux ( $\left.\mathrm{q}_{\mathrm{i}, \mathrm{avg}}\right)$ data for the individual blind louver, $\phi=90^{\circ}, \mathrm{T}_{\mathrm{b}}{ }^{*}=0.3$, $\mathrm{d} / \mathrm{L}=0.043$. 
Table C-13: Average heat flux ( $\left.\mathrm{q}_{\mathrm{i}, \mathrm{avg}}\right)$ data for the individual blind louver, $\phi=90^{\circ}, \mathrm{T}_{\mathrm{b}}{ }^{*}=0.4$, $\mathrm{d} / \mathrm{L}=0.043$

Table C-14: Average heat flux ( $\left.\mathrm{q}_{\mathrm{i}, \mathrm{avg}}\right)$ data for the individual blind louver, $\phi=90^{\circ}, \mathrm{T}_{\mathrm{b}}{ }^{*}=0.5$, $\mathrm{d} / \mathrm{L}=0.043$

Table C-15: Average heat flux ( $\mathrm{q}_{\mathrm{i}, \text { avg }}$ ) data for the individual blind louver, $\phi=0^{\circ}$, $\mathrm{T}_{\mathrm{b}}{ }^{*}=0.2, \mathrm{~d} / \mathrm{L}=0.012$

Table C-16: Average heat flux ( $\left.\mathrm{q}_{\mathrm{i}, \mathrm{avg}}\right)$ data for the individual blind louver, $\phi=90^{\circ}$, $\mathrm{T}_{\mathrm{b}}{ }^{*}=0.3, \mathrm{~d} / \mathrm{L}=0.012$ 138

Table C-17: Average heat flux ( $\mathrm{q}_{\mathrm{i}, \text { avg }}$ ) data for the individual blind louver, $\phi=0^{\circ}$, $\mathrm{T}_{\mathrm{b}}{ }^{*}=0.4, \mathrm{~d} / \mathrm{L}=0.012$

Table C-18: Average heat flux ( $\mathrm{q}_{\mathrm{i}, \text { avg }}$ ) data for the individual blind louver, $\phi=0^{\circ}$, $\mathrm{T}_{\mathrm{b}}{ }^{*}=0.5, \mathrm{~d} / \mathrm{L}=0.012$

Table C-19: Average heat flux ( $\left.\mathrm{q}_{\mathrm{i}, \mathrm{avg}}\right)$ data for the individual blind louver, $\phi=90^{\circ}$, $\mathrm{T}_{\mathrm{b}}{ }^{*}=0.2, \mathrm{~d} / \mathrm{L}=0.012$

Table C-20: Average heat flux $\left(\mathrm{q}_{\mathrm{i}, \text { avg }}\right)$ data for the individual blind louver, $\phi=90^{\circ}$, $\mathrm{T}_{\mathrm{b}}{ }^{*}=0.4, \mathrm{~d} / \mathrm{L}=0.012$

Table C-21: Average heat flux ( $\mathrm{q}_{\mathrm{i}, \mathrm{avg}}$ ) data for the individual blind louver, $\phi=90^{\circ}$, $\mathrm{T}_{\mathrm{b}}{ }^{*}=0.5, \mathrm{~d} / \mathrm{L}=0.012$ 


\section{LIST OF FIGURES}

Figure 2.1 Problem geometry showing the side view of a double glazed window with a horizontal louvered Venetian blind

Figure 2.2 Side view of an unshaded double glazed window with thermal resistance representation

Figure 2.3 The solution algorithm 31

Figure 2.4 Hottel Crossed string method [49] for view factor calculations................................... 36

Figure 2.5 Variation in the Window-to-Ambient View factors with Louver Angle $(\phi) \ldots \ldots . . . . . . . . .37$

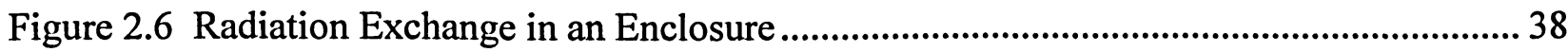

Figure 2.7 Problem geometry and Coordinate System ................................................................... 42

Figure 2.8 Computational Domain and Coordinate system ......................................................... 45

Figure 2.9 Dimensionless Computational Domain.................................................................... 51

Figure 2.10 Variation in the local Nusselt number for an un-shaded window. ............................. 54

Figure 2.11 Variation in the average Nusselt number with Rayleigh number for an unshaded window

Figure 2.12 Comparison of numerical isotherms with interferogram of Machin et al. [42] for $\mathrm{b} / \mathrm{L}=0.066, \phi=0^{\circ}, 45^{\circ}, \mathrm{Ra}_{\mathrm{L}}=3.05 \times 10^{7}, \mathrm{Pr}=0.71$.

Figure 2.13 Comparison of numerical stream functions with flow visualization of Machin et al. [42] for $\mathrm{b} / \mathrm{L}=0.066, \phi=0^{\circ}, \mathrm{Ra}_{\mathrm{L}}=3.05 \times 10^{7}, \mathrm{Pr}=0.71$

Figure 2.14 Comparison of local Convective Nusselt Number Distribution with the Experimental data [42] for $\phi=0^{\circ}, \mathrm{Ra}_{\mathrm{L}}=3.05 \times 10^{7}, \mathrm{~b} / \mathrm{L}=0.066$ 58

Figure 2.15 Comparison of the average Nusselt number of the indoor window glazing for three different test grids. 63

Figure 2.16 Comparison of the average convective Nusselt number on the indoor window glazing for the far field test solutions 63

Figure 3.1 Variation of the average indoor glazing surface Nusselt number with Rayleigh number, $\mathrm{d} / \mathrm{L}=0.043$, Louver angle $\phi=0^{\circ}$ 
Figure 3.2 Effect of Rayleigh number on isotherms for $\phi=0^{\circ}, \mathrm{d} / \mathrm{L}=0.043$, dimensionless blind temperature $\mathrm{T}_{\mathrm{b}}{ }^{*}=0.3,(\mathrm{a}) \mathrm{Ra}_{\mathrm{L}}=10^{5},(\mathrm{~b}) \mathrm{Ra}_{\mathrm{L}}=10^{6},(\mathrm{c}) \mathrm{Ra}_{\mathrm{L}}=10^{8},(\mathrm{~d}) \mathrm{Ra}_{\mathrm{L}}=5 \times 10^{8}$

Figure 3.3 Effect of Rayleigh number on the flow field for $\phi=0^{\circ}, \mathrm{d} / \mathrm{L}=0.043$, dimensionless blind temperature $\mathrm{T}_{\mathrm{b}}{ }^{*}=0.3,(\mathrm{a}) \mathrm{Ra}_{\mathrm{L}}=10^{5},(\mathrm{~b}) \mathrm{Ra}_{\mathrm{L}}=10^{6},(\mathrm{c}) \mathrm{Ra}_{\mathrm{L}}=5 \times 10^{8}$

Figure 3.4 Variation of the average convective heat transfer rate from the blind with Rayleigh number, $\mathrm{d} / \mathrm{L}=0.043$, louver angle $\phi=0^{\circ}$

Figure 3.5 Variation of the local blind Nusselt number with Rayleigh number, $d / L=0.043$, dimensionless blind temperature $\mathrm{T}_{\mathrm{b}}{ }^{*}=0.3$, Louver angle $\phi=0^{\circ}$

Figure 3.6 Variation of the average indoor glazing surface Nusselt number with Rayleigh number, $d / L=0.012$, Louver angle $\phi=0^{\circ}$

Figure 3.7 Interference of the blind with (a) the temperature and (b) the velocity fields for $\phi=$ $0^{\circ}, \mathrm{d} / \mathrm{L}=0.012, \mathrm{~T}_{\mathrm{b}}{ }^{*}=0.3, \mathrm{Ra}_{\mathrm{L}}=5 \times 10^{8}$

Figure 3.8 Variation of the average convective heat transfer rate from the blind with Rayleigh number, $\mathrm{d} / \mathrm{L}=0.012$, Louver angle $\phi=0^{\circ}$

Figure 3.9 Variation of the average indoor glazing surface Nusselt number with Rayleigh number, (a) $d / L=0.043$, (b) $d / L=0.012$, Louver angle $\phi=45^{\circ}$

Figure 3.10 Variation of the average indoor glazing surface Nusselt number with Rayleigh number, (a) $d / L=0.043$, (b) $d / L=0.012$, Louver angle $\phi=90^{\circ}$

Figure 3.11 Variation of the average convective heat transfer rate from the blind with Rayleigh number, (a) $d / L=0.043$, (b) $d / L=0.012$, Louver angle $\phi=90^{\circ}$. 84

Figure 3.12 Variation of the dimensionless average indoor glazing surface Nusselt number with Rayleigh number, dimensionless blind temperature $\mathrm{T}_{\mathrm{b}}{ }^{*}=0.3$

Figure 3.13 Variation of the average convective heat transfer rate from the blind with Rayleigh number, dimensionless blind temperature $T_{b}{ }^{*}=0.3$

Figure 3.14 Variation of $U$-value ratio with louver angle and blind tip-to-window spacing for a single glazed window for summer and winter conditions $\left(\mathrm{W} / \mathrm{ps}=1.14, \varepsilon_{\mathrm{b}}=0.8\right) \ldots . . .91$

Figure 3.15 Variation of U-value ratio with louver angle and blind tip-to-window spacing for a double glazed window for summer and winter conditions $\left(\mathrm{W} / \mathrm{ps}=1.14, \varepsilon_{\mathrm{b}}=0.8\right) \ldots . . .91$

Figure 3.16 Effect of the presence of the blind on the radiative heat transmission from a single glazed window for summer and winter conditions $\left(\mathrm{W} / \mathrm{ps}=1.14, \varepsilon_{\mathrm{b}}=0.8\right)$ 94

Figure 3.17 Effect of the presence of the blind on the radiative heat transmission from a double 
glazed window for summer and winter conditions $\left(\mathrm{W} / \mathrm{ps}=1.14, \varepsilon_{\mathrm{b}}=0.8\right)$

Figure 3.18 Effect of the blind on the convective heat transmission from a single glazed window for summer and winter conditions $\left(\mathrm{W} / \mathrm{ps}=1.14, \varepsilon_{\mathrm{b}}=0.8\right)$ .97

Figure 3.19 Effect of the blind on the convective heat transfer from a double glazed window for summer and winter conditions $\left(\mathrm{W} / \mathrm{ps}=1.14, \varepsilon_{\mathrm{b}}=0.8\right)$.

Figure 3.20 Variation of U-value ratio with louver angle for a double glazed window for summer conditions $\mathrm{d} / \mathrm{L}=0.043$

Figure 3.21 Effect of the blind on the ambient radiation heat flux ratio for a single glazed window $\left(\mathrm{W} / \mathrm{ps}=1.14, \varepsilon_{\mathrm{b}}=0.8\right)$

Figure 3.22 Effect of the blind on the indoor ambient radiation heat flux ratio for a double glazed window $\left(\mathrm{W} / \mathrm{ps}=1.14, \varepsilon_{\mathrm{b}}=0.8\right)$

Figure 3.23 Variation of ambient radiation heat flux ratio for a double glazed window for summer condition $\mathrm{d} / \mathrm{L}=0.043$

Figure 3.24 Variation of U-value ratio with louver angle for a low-e double glazed window for summer conditions $\left(\mathrm{d} / \mathrm{L}=0.043, \mathrm{~W} / \mathrm{ps}=1.14, \varepsilon_{\mathrm{b}}=0.8\right)$ 

A Surface area $\left(\mathrm{m}^{2}\right)$
b
Blind center-to-window spacing (m)
$\mathrm{C}_{\mathrm{p}} \quad$ Specific heat capacity $(\mathrm{J} / \mathrm{kg} \cdot \mathrm{K})$
d Blind tip-to-window spacing (m)
E Emissive power $\left(\mathrm{W} / \mathrm{m}^{2}\right)$
F View factors
G Irradiation $\left(\mathrm{W} / \mathrm{m}^{2}\right)$
g
Acceleration due to gravity $\left(\mathrm{m} / \mathrm{s}^{2}\right)$
Gr Grashof number
$\mathrm{h}$
Heat transfer coefficient $\left(\mathrm{W} / \mathrm{m}^{2} . \mathrm{K}\right)$
Surface radiosity $\left(\mathrm{W} / \mathrm{m}^{2}\right)$
$\mathrm{k}$
Thermal conductivity (W/mK)
L Window height (m)
n
Total number of blind slats
$\mathrm{N}$
Total number of surfaces in enclosure
$\mathrm{Nu} \quad$ Nusselt number
p Pressure $\left(N / \mathrm{m}^{2}\right)$
p' $\quad$ Pressure defect $\left(\mathrm{N} / \mathrm{m}^{2}\right)$
P Dimensionless pressure
ps $\quad$ Louver pitch (m)
Pr Prandtl number 


$\begin{array}{ll}\mathrm{q} & \text { Heat transfer rate per unit area }\left(\mathrm{W} / \mathrm{m}^{2}\right) \\ \mathrm{Q} & \text { Heat transfer rate }(\mathrm{W} / \mathrm{m}) \\ \mathrm{Q}_{\mathrm{amb}} & \text { Net radiative heat flux to the ambient }\left(\mathrm{W} / \mathrm{m}^{2}\right) \\ \mathrm{R} & \text { Thermal resistance }(\mathrm{K} / \mathrm{W}) \\ \mathrm{Ra} & \text { Rayleigh number } \\ \mathrm{s} & \text { Window cavity width }(\mathrm{m}) \\ \mathrm{t} & \text { Glazing thickness }(\mathrm{m}) \\ \mathrm{T} & \text { Temperature }(\mathrm{K}) \\ \mathrm{T}_{\mathrm{b}} & \text { Blind temperature }(\mathrm{K}) \\ \mathrm{T}_{\mathrm{b}}{ }^{*} & \text { Dimensionless blind temperature } \\ \mathrm{T}_{\mathrm{w}} & \text { Indoor glazing surface temperature }(\mathrm{K}) \\ \mathrm{T}_{\infty} & \text { Room ambient temperature }(\mathrm{K}) \\ \mathrm{u}, \mathrm{v} & \text { Velocity components }(\mathrm{m} / \mathrm{s}) \\ \mathrm{U}, \mathrm{V} & \text { Dimensionless velocity } \\ \mathrm{U}-\mathrm{value} & \text { Thermal conductance }\left(\mathrm{w} / \mathrm{m}^{2}\right) \\ \mathrm{W} & \text { Louver width (m) }\end{array}$

\section{Greek Symbols}

$\begin{array}{ll}\alpha & \text { Thermal diffusivity }\left(\mathrm{m}^{2} / \mathrm{s}\right) \\ \beta & \text { Thermal expansion coefficient }\left(\mathrm{K}^{-1}\right) \\ \gamma & \text { Window cavity aspect ratio } \\ \delta & \text { Kronecker Delta } \\ \varepsilon & \text { Emissivity }\end{array}$


$\zeta \quad$ Constant

$\mu \quad$ Dynamic viscosity $\left(\mathrm{Ns} / \mathrm{m}^{2}\right)$

$v \quad$ Kinematics viscosity $\left(\mathrm{m}^{2} / \mathrm{s}\right)$

$\rho \quad$ Density $\left(\mathrm{kg} / \mathrm{m}^{3}\right)$

$\sigma \quad$ Stefan-Boltzmann constant $\left(\mathrm{W} / \mathrm{m}^{2} \cdot \mathrm{K}^{4}\right)$

$\phi \quad$ Blind louver angle (degrees)

\section{Subscripts}

\begin{tabular}{ll} 
avg & Average \\
$\mathrm{b}$ & Blind \\
$\mathrm{C}, \mathrm{con}$ & Convection \\
$\mathrm{C}, \mathrm{NB}$ & Convection with no blind \\
cond & Conduction \\
$\mathrm{F}$ & Fluid \\
$\mathrm{fg}$ & Fill gas \\
$\mathrm{film}$ & Film temperature \\
$\mathrm{gl}$ & Glazing \\
$\mathrm{i}$ & Index, $\mathrm{i}=1,2, \ldots$. \\
$\mathrm{j}$ & Index, $\mathrm{j}=1,2, \ldots$. \\
$\mathrm{k}$ & Index, $\mathrm{k}=1,2, \ldots$. \\
$\mathrm{NB}$ & No blind \\
$\mathrm{o}$ & Outdoor ambient \\
$\mathrm{R}, \mathrm{rad}$ & Radiation \\
\hline
\end{tabular}


R, NB Radiation with no blind

w Window

1-4 Window glazing surface

$\infty \quad$ Indoor ambient 


\section{CHAPTER 1: INTRODUCTION AND LITERATURE REVIEW}

\subsection{INTRODUCTION}

Clear or shaded glass windows are an integral part of all commercial and residential buildings. These windows, glass doors, skylights and other such transparent devices are collectively called fenestration systems. In the design and operation of such fenestration systems, energy performance is not the only thing that matters. On the basis of elegance and beauty alone, fenestration systems are a vital part of our daily lives. However, the addition of improperly designed fenestration systems to the buildings can increase the energy waste and result in higher heating and air conditioning costs. In most cases, windows add to the energy costs through conduction and convection heat losses in winter and radiant heat gains in the summer. However, in some cases with their proper design, fenestration systems perform better than an insulated opaque wall [1]. In order to improve the energy performance of such fenestration systems great effort has been invested. The technology of fenestration systems has advanced greatly in last twenty years. The major area of interest has been focused to reduce building heat losses in winter and trap sunlight as heat in a room. However, in summer one focus has been on the reduction of solar heat gains using thermochromism, photochromism and electrochromism [2].

Most fenestrations have some type of internal shading to provide privacy and aesthetic effects, as well as to give varying degrees of sun control [3]. In general, the effectiveness of any internal shading device depends on its ability to reflect incoming solar radiation back 
through the fenestration before it can be absorbed and converted into heat within the building. The ideal fenestration system would permit optimum light, heat, ventilation and visibility. It would minimize moisture and sound transfer between the exterior and the interior of a building. At present, instantaneous energy performance indices (U-value, solar heat gain coefficient SHGC, air infiltration rates etc.) are typically used to compare fenestration systems under a fixed set of conditions. However, these indices alone are not good indicators of the annual energy performance attributable to the fenestration. Furthermore, fenestration energy performance is very difficult to quantify because of the dynamic response that occurs between the fenestration and the environment in which it is installed. The four major mechanisms of fenestration energy performance are thermal heat transfer, solar heat gains, air leakage and day lighting. The energy performance of a fenestration can only be determined when a large number of variables are considered. Shading devices, building types, trees and location of windows are some of the major variables that affect the thermal performance of a fenestration system.

The present study examines just one aspect of window energy performance. The objective of this study is to quantify the effects of horizontal Venetian blinds on the thermal performance of a window. The effects of a blind on the occupant thermal comfort are also examined. In this study, a simplified mathematical model of the centre-of-glass region of a window and blind assembly has been developed to compute a realistic estimate of the advantage of using blinds to control the window heat gains or losses. The conjugate heat transfer between the window and the blind is solved for summer and winter "nighttime" conditions. The solution also applies to the daytime conditions with zero incident solar heat flux. In addition, the convection 
coefficients on the window and the Venetian blind are computed for three different blind louver angles and blind tip-to-window spacings. In order to calculate the window and the blind convection coefficients, a two-dimensional finite element numerical model has been developed.

\subsection{LITERATURE REVIEW}

Heat transfer in fenestration systems is a complex physical problem. It requires simultaneous calculation of radiative and convective heat transfer that is governed by nonlinear equations. For example, for a double glazed window the coupling between the radiative and free convective heat transfer occurs in the insulated glazing unit and at the indoor glazing surface. The problem is further complicated with the exposure of fenestration exterior surfaces to forced convection. A closed form analytical solution to this problem is not known. This complex physical problem is often solved with a one-dimensional thermal resistance model approach. This approach heavily relies on empirical correlations.

Three main areas relevant to this thesis have been reviewed. In section 1.2.1 relevant studies related to unshaded fenestration are briefly reviewed. In section 1.2.2, the relevant literature related to free convection from an isothermal vertical plate is discussed. In section 1.2.3, a very brief overview of the literature on the convection in a $2-\mathrm{D}$ window cavity is presented. Finally in section 1.2.4, a review of all relevant studies regarding the effects of Venetian blinds on the thermal performance of windows are presented. 


\subsubsection{Fenestration Thermal Analysis with No Blind/Shading Device}

In the literature, the analysis of unshaded fenestration systems is well documented. A comprehensive literature survey on the performance of many fenestration products is given in [4]. This survey covers the standards and simplified procedures of calculating energy flows through fenestration systems. The algorithms to solve coupled modes of convective, conductive and thermal radiation heat transfer between a window and its environment are well established. In order to analyze the energy performance characteristics of a window, the window is divided into two sections. The first section is the window frame that may be composed of many different materials, geometry and construction arrangements. The second section is the glass portion of the window, which is further broken into two regions namely centre-of-glass and edge-of-glass regions. The centre-of-glass region is the middle area of the window, which is nearly isothermal. The edge-of-glass region is the glazing area that surrounds the centre-of-glass region.

According to ASHRAE [4] guidelines, the centre-of-glass region is approximately 6.35 centimetres (2.5 inches) away from the frame of the window. Recently, Curcija and Goss [5-7] carried out numerical investigations for windows with different frame construction and arrangements. They conducted a two-dimensional CFD study [5] of the natural convection from an indoor surface of a window. In this study [5], a correlation for the indoor convection coefficients was obtained. The indoor convection coefficient correlation was then used in more complex two and three-dimensional numerical models of a double glazed window. Curcija and Goss [6,7] calculated the heat transfer rates through a double glazed window. It was found that 
non-isothermal conditions and significant variations in the heat transfer existed as much as 4inches from the window frame. They argued that the 6.35 centimetres ( 2.5 inches) criterion [4] could be misleading and the centre-of-glass region of the window should be at least 10.2 centimetres (4-inches) away from the window frame.

In order to simplify window design, simulation software programs such as VISION [8], WINDOW [9], WinTherm [10] and FRAME [11] have been developed. These programs analyze and solve window glazing unit heat transfer for a wide range of glazing construction and arrangements. VISION [8] and WINDOW [9] analyze the centre-of-glass region of the window. WinTherm [10] and FRAME [11] can be used to calculate the heat transfer rate through the edge-of-glass and the window frame. These programs are widely used in window design and to determine Energy Rating (ER). The National Fenestration Rating Council uses WINDOW [9] and the Canadian Standards Association uses VISION [8].

VISION [8] has been used as the basis of a variety of studies including the development of a simplified thermal performance calculation method and the comparison of various glazing systems [12]. VISION [8] is used to calculate the energy transfer through the centre-of-glass region of a glazing system for different environmental conditions. These energy flows are due to heat transfer driven by the indoor/outdoor temperature difference and energy gain due to incident solar radiation. It quantifies these quantities by calculating two indices: $U$-value and solar heat gain coefficient (SHGC). The U-value represents the thermal conductance and is used to calculate the overall heat transfer rate across the glazing. The steady state rate of heat transfer through the window per unit area is calculated by multiplying the U-value and the 
indoor/outdoor temperature difference across the window. The SHGC is a measure of the solar heat gain that a glazing system delivers. In VISION [8], the user specifies the window geometry and the weather conditions and it calculates the steady state rate of heat transfer

through the window. At present, VISION [8] and other programs $[9,10,11]$ are restricted for the analysis of window with no shading devices attached. Present work involves the development of a simplified numerical model of the centre-of-glass region of a window and Venetian blind assembly.

\subsubsection{Studies of Laminar Natural Convection from an Isothermal Plate}

The centre-of-glass region of a window is nearly isothermal. It is a standard practice to estimate the convective heat transfer from the indoor glazing using the convection heat transfer coefficient for a vertical isothermal plate. In the literature, the classical problem of laminar natural convection from an isothermal vertical flat plate has been studied extensively. A comprehensive review of the early development of analytical and experimental work is given by Ede [13]. The governing equations were derived using conservation of mass, momentum and energy. Two outstanding and significant early studies were the analytical studies of Oberbeck [14] and Lorenze [15]. They attempted to solve the continuity, momentum and energy equations for a vertical isothermal surface assuming laminar and steady state conditions. Lorenze's solution led to the following expression for the Nusselt number:

$$
\mathrm{Nu}_{\mathrm{L}}=0.548\left(\mathrm{Gr}_{\mathrm{L}} \cdot \mathrm{Pr}\right)^{\frac{1}{4}}
$$

where $L$ is the length of the vertical surface, $G_{L}$ is the Grashof number based on the length $L$ and $\operatorname{Pr}$ is the fluid Prandtl number. This result was astonishingly close to the experimental data. However, this solution failed to provide the local heat transfer distribution. Their work was 
further extended with the studies of Pohlhausen in collaboration with Schmidt and Beckmann [16]. Pohlhausen attempted to solve the continuity, momentum and energy equations using Prandtl's boundary layer approximations assuming the effects of free convection were confined to a thin layer of fluid adjacent to the heated surface. He introduced the stream function and then sought a solution with similarity transformations that reduced the governing equations to two ordinary differential equations. He attempted a series solution and encountered convergence difficulties that forced him to use temperature and velocity boundary conditions obtained from the experimental work of Schmidt and Beckmann [16]. He solved this problem for a single value of Prandtl number $\operatorname{Pr}=0.733$, which is an appropriate value for air. Pohlhausen's solution led to the following expressions for the local and average Nusselt number:

$$
\begin{aligned}
& \mathrm{Nu}=0.39\left(\mathrm{Gr}_{\mathrm{y}} \cdot \mathrm{Pr}\right)^{\frac{1}{4}} \\
& \mathrm{Nu}_{\mathrm{L}}=0.52\left(\mathrm{Gr}_{\mathrm{L}} \cdot \mathrm{Pr}\right)^{\frac{1}{4}}
\end{aligned}
$$

Saunders and Suhuh $[17,18]$ sought further solutions to this problem. However, Ostrach [19] virtually concluded the study of Schmidt and Beckmann [15], and his work is arguably the most significant and is regarded as the benchmark. Ostrach [19] used a computer to solve the two ordinary differential equations previously attempted by Pohlhausen. He obtained solutions for eight different values of Prandtl number covering the range of $\operatorname{Pr}=0.01$ to 1000 . His solution led to the following expressions for the local and average Nusselt number:

$$
\begin{aligned}
& \mathrm{Nu}=\left(\frac{3 \zeta}{4}\right)\left(\mathrm{Gr} r_{y} \cdot \operatorname{Pr}\right)^{\frac{1}{4}} \\
& \mathrm{Nu}_{\mathrm{L}}=\zeta\left(\mathrm{Gr}_{\mathrm{L}} \cdot \mathrm{Pr}\right)^{\frac{1}{4}}
\end{aligned}
$$


where $\zeta$ is a function of the Prandtl number. Ostrach presented a tabulated solution that could cover many engineering applications. For example, by interpolating for $\operatorname{Pr}=0.7$ corresponding to air in Ostrach's tabulated solution, the local and average Nusselt number can be written as:

$$
\begin{aligned}
& \mathrm{Nu}=0.386\left(\mathrm{Ra}_{\mathrm{y}}\right)^{\frac{1}{4}} \\
& \mathrm{Nu}_{\mathrm{L}}=0.515\left(\mathrm{Ra}_{\mathrm{L}}\right)^{\frac{1}{4}}
\end{aligned}
$$

where $\mathrm{Ra}$ is the Rayleigh number.

With the work of Ostrach [19], the classical convection problem of an isothermal vertical plate may be regarded as completely solved. However, many experimental and numerical studies have been performed since his work. For example, Sugawara and Michiyoshi [20], Sparrow et al. [21], Gebhart [22] and Le Fevre [23] carried out calculations of the same type for different Prandtl number ranges. The majority of the remaining numerical and experimental studies yield comparable results to those of Ostrach [19]. For this reason, those studies are not included in this review and the results of Ostrach [19] are used for comparative and numerical model validation purposes throughout this study. The benchmark similarity solution of Ostrach [19] is used to validate the free convection finite element model. Also, extensive comparisons have been made to demonstrate the effects of Venetian blinds on the local and average heat transfer from the indoor glazing.

\subsubsection{Studies of Natural Convection in a 2-D Rectangular Cavity}

A rectangular cavity, where the temperature difference between the vertical walls drives a convective flow, is another classical heat transfer problem. This problem has many 
practical applications. One of these applications is the convection inside the cavities of a multiglazed window. An abundance of information about rectangular cavities is available in the literature. For example, Wright and Sullivan [24] give a comprehensive review of the literature relevant to rectangular cavities with particular attention given to window applications. They reviewed more than 90 publications covering analytical, numerical and experimental studies. Among those studies the most relevant to this thesis are the measurements of Elsherbiny [25]. His measurements comprised the most suitable data source for window applications. He carried out measurements of convective heat transfer over a wide range of Rayleigh numbers. Elsherbiny's [25] data showed that the aspect ratio strongly influenced the heat transfer for low aspect ratios. His experimental data was used to develop a set of design correlations [26]. This work was further extended with the studies of Shewen [27], Lee and Korpela [28] and Wright and Sullivan [29]. Based on this research and a detailed review, Wright [8] adopted new design correlations. These new correlations are used in VISION [8] to quantify the convective heat transfer through the glazing cavities. The design correlations are expressed as:

$$
\begin{array}{ll}
\mathrm{Nu}=0.0673838 \mathrm{Ra}^{\frac{1}{3}} & \mathrm{Ra}>5 \times 10^{4} \\
\mathrm{Nu}=0.028154 \mathrm{Ra}^{0.4134} & 10^{4}<\mathrm{Ra} \leq 5 \times 10^{4} \\
\mathrm{Nu}=\operatorname{MAX}\left(1+1.7596678 \times 10^{-10} \mathrm{Ra}^{2.2984755}, 0.242\left(\frac{\mathrm{Ra}}{\gamma}\right)^{0.272}\right) & \mathrm{Ra} \leq 10^{4}
\end{array}
$$

where $\mathrm{Nu}$ is the average Nusselt number, $\gamma$ is the window height to cavity width aspect ratio and the Rayleigh number $\mathrm{Ra}$ is based on the cavity width. The intention of the present study is to develop a numerical model that may be incorporated in VISION [8]. For this reason, these correlations are used to calculate the convective heat transfer rate across the window cavity. 


\subsubsection{Studies of the Effects of a Venetian Blind on Window Energy Performance}

It is well known that unshaded fenestration products become sources of radiant heat by transmitting short-wave solar radiation and by emitting long wave radiation to dissipate some of the absorbed energy. In winter, the glass temperature is usually less than the indoor air temperature, which results in heat loss due to thermal radiation. Thermal radiation also causes thermal discomfort for the occupants. However, in summer solar radiation and high indoor window surface temperatures result in heat gains. Previous studies have shown that Venetian blinds can have a significant beneficial effect on window thermal performance. The blind reduces thermal radiation from the window surface and it provides a thermal shield for individuals who are seated next to window. This radiation shielding effect tends to decrease the heat transmission rate through the window and can substantially improve occupant thermal comfort. Although these effects are well known, there has been relatively little work done to quantify and perhaps optimize the benefits of the window shading devices.

Some of the early work on the solar heat gain through a double glazed window with an interior Venetian blind was conducted by Pennington et al. [30]. In this study, a theoretical model of the solar heat gain was developed and experiments were conducted using a calorimeter. In subsequent years, Rubin et al. [31] investigated the feasibility of energy saving operations using interior Venetian blinds. They speculated that on a hot sunny day, the usage of a Venetian blind on a south-facing window would substantially reduce the heat gain. They suggested that manipulating the slat angle could control the reduction in the heat gain. Their calculations indicated $50 \%$ reduction in the heat gain for a slat angle of $45^{\circ}$ and $75 \%$ when the slats were fully closed. They predicted $10 \%-15 \%$ reduction in heat transmission for the winter 
months. In another study, Mills and McCluney [32] performed theoretical calculations of solar heat gain for a fenestration system with interior shades and Venetian blinds. They concluded that significant reduction in solar heat gain would be realized if the shades or Venetian blinds are controlled and adjusted several times a day.

Some of the previous work pertaining to louvered blinds has been done for a horizontal blind sealed between the panes of an Insulated Glazing Unit (IGU). For example, both analytical [33] and experimental [34] investigations of Rheault and Bilgen fall into this category. They used typical Canadian summer and winter climate conditions and determined the heat transmission through such IGU configurations. Their geometry consisted of an aluminium horizontal louvered blind sealed between the panes of the window. In their analytical work, the blind tip-to-window spacing was kept large enough to assume that the presence of the blind did not affect the cavity flow except when the blind slats were fully closed. For the fully closed position, the blind was treated as a dividing wall between the two cavities. They performed the radiation and convection calculations across the window and blind system by neglecting the thermal gradients and conduction effects inside the blind. Their calculations indicated that in winter months, the presence of the blind could reduce the heating load by up to $36 \%$. Their results also showed that during summer the presence of the blind could reduce the auxiliary cooling load by up to $47 \%$. These numerical predictions were later verified through experimental work.

In another study, Cho et al. [35] approached this problem using both experimental and numerical techniques. This study [35] was very similar to those of Reheault and Bilgen [33,34] 
except different climate conditions were used. In this study, typical South Korean (Seoul) weather conditions were used. The results indicated that using a window and blind system, the heating and cooling loads of a building could be reduced by as much as $5 \%$ and $30 \%$, respectively.

Similar blind configurations within a sealed insulated glazing unit (IGU), were also studied by Garnet et al. [36] and Fang \& Ge [37]. Garnet et al. [36] conducted an experimental study using a guarded hot plate apparatus to determine the thermal performance of an IGU with an aluminium blind sealed between the panes. They investigated the effects of the louver angle for small blind tip-to-window spacing. They measured the $U$-values by raising and lowering the blind within the enclosure. They observed that when the louvers were at horizontal position, the U-value of the window and blind system was higher than in the no blind case. They speculated that the domination of conduction through the aluminium blind slats increased the $U$-value. This dominance diminished as the louver angle was increased and the U-value dropped below the no blind case. They concluded that more analytical and experimental work was required to determine the relative roles of conduction, convection and radiation in the measured U-values.

Fang and Ge [37] conducted an experimental study by placing a Venetian blind on the inside of a single and double glazed window. They measured the U-value of the windows using a hot box set up. In this study [37], the spacing between the inside glazing and the middle of the large louvers was fixed. The louvers were covered with aluminium foil and the temperature difference across the window for different louver angles was varied. The results showed that 
the $U$-value varied with the louver angle $\phi$ and temperature difference. The variation in the $U$ value for one and two panes was shown as, respectively:

$$
\begin{aligned}
& \mathrm{U}=0.227(1.95+0.32 \sin \phi) .(\Delta \mathrm{T})^{0.42} \\
& \mathrm{U}=0.535(2.34+0.73 \sin \phi) .(\Delta \mathrm{T})^{0.25}
\end{aligned}
$$

Fang and Ge [37] went on to apply the correction factors for the outdoor wind velocity and different fame effects. The corrected $U$-value was expressed as:

$$
\mathrm{U}^{\prime}=\mathrm{C}_{1} \mathrm{C}_{2} \mathrm{U}
$$

where $C_{1}$ and $C_{2}$ are the frame and wind velocity correction factors, respectively.

More recently, several studies have examined the inward-flowing fraction of absorbed solar irradiation from a Venetian blind (Klems and Kelley [38], Collins and Harrison $[39,40,41]$. These studies do not fall into the scope of this thesis and are not closely related to the present work. For this reason, the details of these studies are not included in this review.

Previous studies that are closely related to the current work are those of Machin et al. [42], Ye [43] and Phillips et al. [44]. Machin et al. [42] carried out an experimental study and demonstrated the effects of a horizontal louvered aluminium blind on the local convective heat transfer from an indoor glazing. They used an isothermal vertical plate to approximate the centre-of-glass region of an indoor glazing. They obtained temperature and flow field images using a Mach-Zhender interferometer and flow visualization. They measured the local and average heat transfer rate from the isothermal plate for three different blind centre-to-plate spacings and four different blind angles. They observed that the presence of a Venetian blind had a strong effect on the buoyancy driven flow next to the isothermal plate. They found that 
for small blind-to-window spacing, the local convective heat transfer rates from the plate were substantially different than a no-blind case. They compared their results with the isolated vertical plate and reported a small decrease in the average convective heat transfer rate with the presence of a Venetian blind. This study [42] is most applicable to the present work and it provides an excellent source of experimental data. It has been used for the validation of present numerical work and will be referred to extensively throughout this thesis.

Ye [43] carried out a numerical investigation and developed a two-dimensional convection model of an isothermal surface with a horizontal louvered Venetian blind. The isothermal surface was used to simulate the centre-of-glass region of the window and the solution was obtained using the finite element method. In this study [43], the blind louvers were treated as zero thickness baffles with no curvature and conduction effects through the louvers were neglected. The solution was obtained for different blind centre-to-window spacings and different louver angles. The numerical results showed similar trends to those observed by Machin et al. [42]. Ye [43] reported that the numerical predictions of the convection heat transfer coefficients were lower than the experimental results of Machin et al. [42]. She concluded that conduction effects through the aluminium Venetian blind used by Machin et al. [42] increased the local convection coefficients in the regions near the inside tip of each louver. The numerically predicted convection coefficients were lower because these conduction effects were ignored.

The work of Machin et al. [42] and Ye [43] was further extended with the finite element CFD study of Phillips et al. [44]. They developed a conjugate heat transfer numerical 
model of a Venetian blind adjacent to an isothermal plate. They carried out numerical investigations to understand the roles of both convection and radiation heat exchange between the blind and the isothermal plate for different louver angles and blind emissivity. They modelled ten louvers of a horizontal Venetian blind with a typical pitch ratio of $7 / 8$. Their numerical predictions were in excellent agreement with the experimental results of Machin et al. [42]. They found that the blind had only a small effect on the convection from the window, except when the blind louvers were almost touching the window. This conclusion was in agreement with an interferometric study of Machin et al. [42]. Phillips et al. [44] also found that the radiation shielding effect of the blind could be substantial. They reported significant reductions in the radiative heat transfer from the isothermal plate. At a Rayleigh number based on the window height of $\mathrm{Ra}_{\mathrm{L}}=10^{8}$, the radiation heat transfer rate from the indoor glazing surface was reduced by as much as $33 \%$, even when the louvers were fully open.

In a recent study by Shahid and Naylor [45], the previous work on the effects of blind was further extended and a simplified numerical model of a complete fenestration (i.e. window/blind) assembly was developed. A simplified one-dimensional thermal resistance model approach was used to solve the thermal interactions between a complete fenestration system and a vertical blind for its centre-of-glass region under summer and winter "nighttime" conditions. In order to obtain the solution, the convective heat transfer coefficients on the indoor glazing and the blind were required. Unfortunately, the convective heat transfer coefficients for the blind were not available. For this reason, the blind to indoor window spacing was fixed such that the blind and window thermal boundary layers did not merge together and the convective heat transfer rates were calculated using the similarity solution for 
a vertical isothermal surface given by Ostrach [19]. Therefore, only the thermal radiative interaction between the blind and the window was considered and convective interaction was ignored. It was shown that for most of the commercially available blinds, the curvature of the blind had a very small effect $(<1.7 \%)$ on its view factors. Therefore, for simplification purposes, these effects were ignored. It was found that the presence of a blind had a significant effect on the heat transfer from a window. For summer conditions, the blind reduced the Uvalue of a single-glazed window up to $25 \%$. For the most commercial installations, the blind tip-to-window spacing could be small and the blind and window might interact convectively. Because of possible blind-to-blind and blind-to-window convective interaction the results could be quite different. Therefore, for more realistic and accurate calculations, the convection coefficients for the blind and the indoor glazing surface must be known.

\subsection{PROBLEM STATEMENT AND SCOPE OF RESEARCH}

The objective of present work is to develop a simplified numerical model for a window with a horizontal Venetian blind. This one-dimensional thermal resistance model calculates the radiative and the convective heat exchange between the centre-of-glass region of a window and the blind. It is used to determine more realistic estimates of the U-value of a window for different weather conditions with zero incident solar flux. In this study, the window and the blind convective interactions are considered and the convective coefficients on the indoor glazing and a horizontal Venetian blind for different blind tip-to-window spacings and different louver angles are calculated. 
In order to calculate the convection coefficients, a two-dimensional finite element model for an indoor window glazing and a horizontal louvered Venetian blind is developed. The convection coefficients are used in the one-dimensional thermal resistance model and the thermal performance of the overall fenestration is determined. This simplified mathematical model of a window and blind combination provides a realistic estimate of the advantage of using blinds to control the unwanted window heat gains or losses. Additionally, this model may be incorporated in commercial fenestration analysis programs $[8,9]$ that are currently restricted to the thermal analysis of windows without shading devices. The improved understanding of the benefits of the Venetian blinds may lead to better designs of window/shading systems. 


\section{CHAPTER 2: NUMERICAL MODEL AND SOLUTION PROCEDURES}

\subsection{INTRODUCTION}

In this chapter a one-dimensional thermal resistance model of a window and horizontal Venetian blind assembly is developed. The equations governing the thermal radiation exchange between the indoor glazing, the room and the Venetian blind are developed. Assumptions are made to simplify the computation of view factors and the thermal radiation exchange. This chapter also describes how the convective heat exchange between the indoor glazing, the Venetian blind and the room surroundings was computed. A two-dimensional numerical model of this convective heat exchange has been developed. The equations governing fluid flow and the appropriate boundary conditions are described. The non-dimensionalization scheme is outlined and applied over the computational domain. The grid sensitivity and far field boundary study is performed. The numerical model is validated using the experimental convective heat transfer data from the work of Machin et al. [42]. Detailed comparisons of the temperature and flow field are made with the interferograms and the flow visualization photographs of Machin et al. [42]. Finally, the convection coefficients on the indoor glazing and the Venetian blind are computed.

\subsection{PROBLEM GEOMETRY}

The objective of this work is to develop a simplified numerical model of window/blind thermal interaction that could easily be incorporated into commercial fenestration analysis programs, such as VISION [8]. The problem geometry for a double glazed window with a 
horizontal Venetian blind adjacent to the indoor glazing is illustrated in Figure 2.1. This figure shows a side view of the center-of-glass region of a window and blind assembly. The window is of length $\mathrm{L}$ and the panes are separated by a distance $\mathrm{s}$. The window cavity is filled with a gas (air or Argon) and is sealed at the both ends. The Venetian blind consists of a set of louvers of width $\mathrm{W}$, spaced at pitch ps. The louvers are positioned at a distance $\mathrm{d}$ from the window that may be rotated through the horizontal axis to an angle $\phi$. In this figure, $T_{0}$ and $T_{\infty}$ are the outdoor and the indoor temperature, respectively. The window glazing surface designation numbers 1 through 4 are shown, which will be used to establish the thermal resistance model.

Outdoor

Temperature $T_{0}$

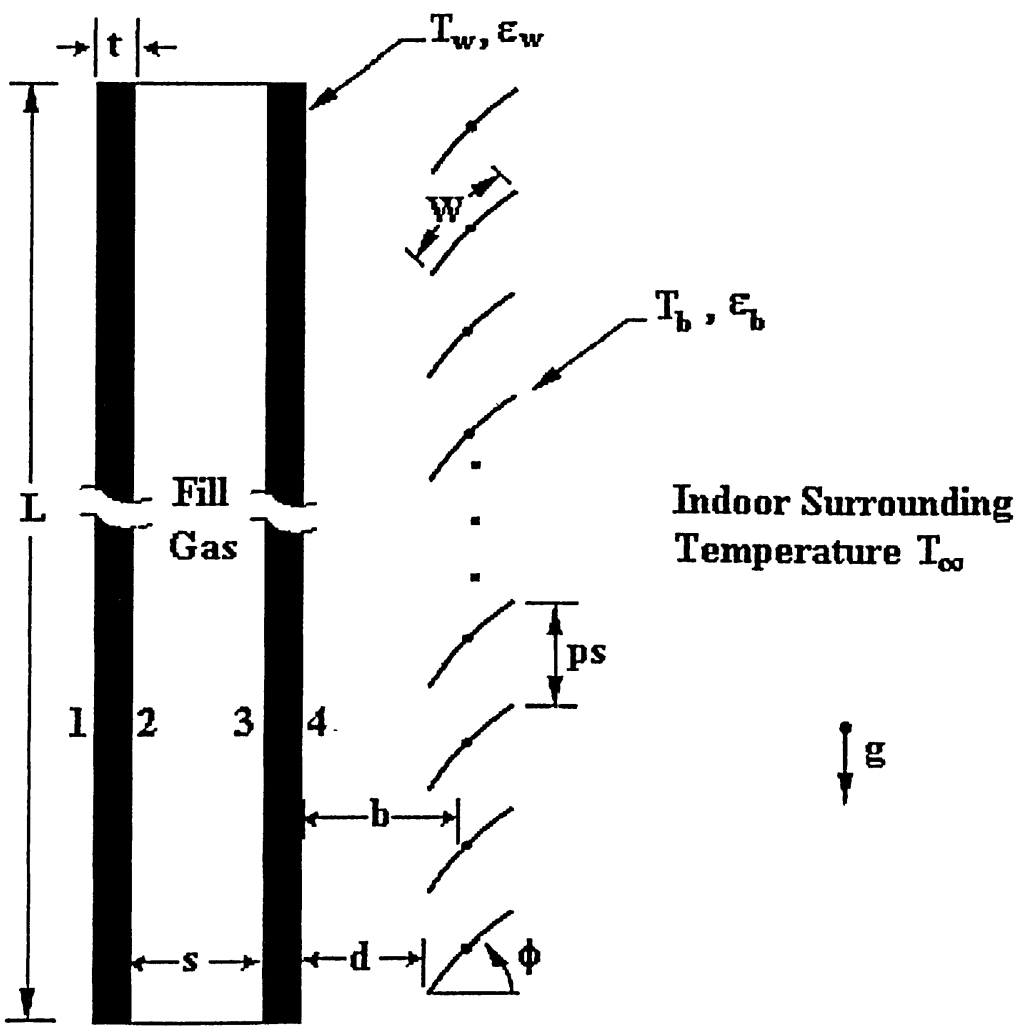

Figure 2.1 Problem geometry showing the side view of a double glazed window with a horizontal louvered Venetian blind. 


\subsection{THERMAL RESISTANCE MODEL OF AN UNSHADED WINDOW}

In the development of the present numerical model, a one-dimensional thermal resistance algorithm [8] is used. First, a numerical model of an unshaded window is developed and then this model is modified to incorporate the indoor Venetian blind and shades. The energy flows through any standard window are due to conduction, convection, long wave thermal radiation and incident solar radiation. The energy flows through the centre-of-glass region of a window can be calculated using a one-dimensional thermal resistance approach. In this approach, all modes of heat transfer are assumed to be associated with a thermal resistance, which is very similar to an electrical resistance that is associated with the conduction of electricity. Thermal resistance network representations provide a very useful tool for both conceptualization and quantifying heat transfer problems.

The centre-of-glass region of a window can be represented with a thermal resistance network. Thermal resistance representation of a double glazed window is depicted in Figure 2.2. This model considers all modes of heat transfer that occur across the window glazing. In

this model, all surfaces are assumed to be gray, perfectly diffuse and opaque. The indoors, the outdoors and the glazing surface temperatures are represented with different temperature nodes, which represent the thermal potentials that drive the energy flows. Thermal interaction between the outdoors and the window surface (1) involves two modes of heat transfer. The first mode is the mixed (forced and natural) convection and the second mode is thermal radiation exchange. The convection is due to the random molecular motion (diffusion) and the bulk motion of the air. The forced convection is caused by the atmospheric wind and natural (or free) convection is due to buoyancy forces, which arise from density differences caused by 
Outdoor

Temperature $T_{\text {。 }}$

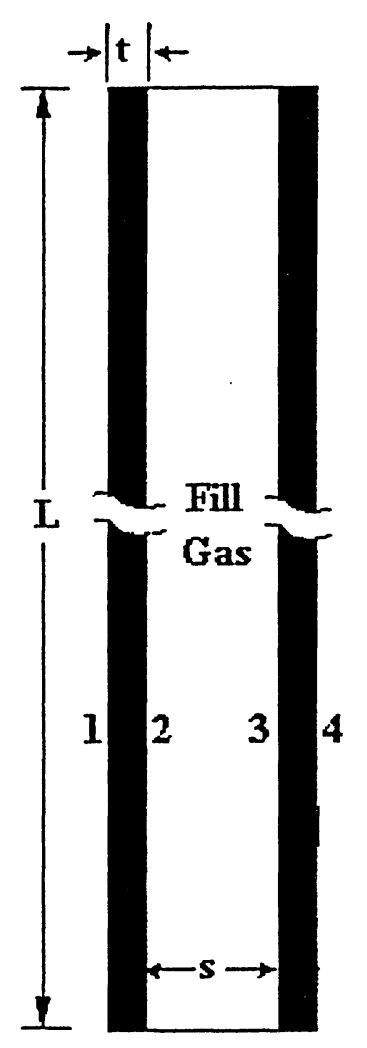

Indoor Surrounding

Temperature $T_{\infty}$
$R_{\text {ram }}=\frac{1}{h_{0} A}$

$R_{\text {can, gap }}=\frac{1}{h_{\operatorname{cop} A}}$

$R_{\text {can }}=\frac{1}{h_{i} A}$
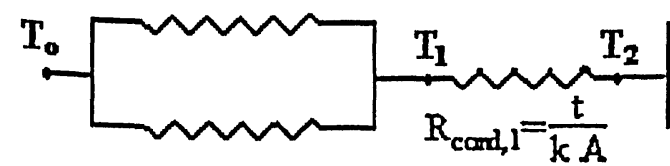

$\mathrm{R}_{n d}=\frac{1}{\mathrm{~h}_{\mathrm{r}, \mathrm{f}} \mathrm{A}}$

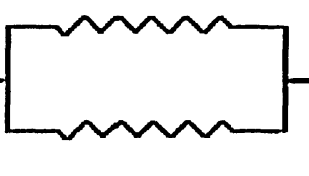

$R_{\text {rd, gap }}=\frac{1}{h_{\text {gap }} A}$

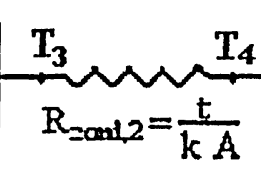

$R_{=\operatorname{con} 12}=\frac{t}{\mathrm{kA}}$

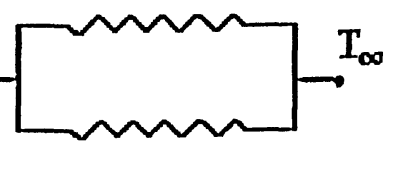

$\mathrm{R}_{\mathrm{zdd}}=\frac{1}{\mathrm{~h}_{\mathrm{r}, 4} \mathrm{~A}}$

Figure 2.2 Side view of an unshaded double glazed window with thermal resistance representation.

temperature variations in the fluid (in this case air). The convection heat exchange between the outdoors and the glazing surface (1) is calculated using Newton's law of cooling:

$$
\mathrm{Q}_{\text {con }}=\mathrm{h}_{\mathrm{o}} \mathrm{A}\left(\mathrm{T}_{\mathrm{o}}-\mathrm{T}_{1}\right)
$$

where $h_{0}$ is the external convection coefficient, $T_{0}$ is the outdoor temperature, $T_{1}$ is the outdoor glazing surface temperature and $\mathrm{A}$ is the window surface area. From this expression, the 
outside thermal resistance for the convection heat transfer can be written as:

$$
\mathrm{R}_{\text {con }}=\frac{\left(\mathrm{T}_{\mathrm{o}}-\mathrm{T}_{1}\right)}{\mathrm{Q}_{\text {con }}}=\frac{1}{\mathrm{~h}_{\mathrm{o}} \mathrm{A}}
$$

Thermal radiation is energy emitted by matter as electromagnetic waves in the thermal wavelength band. Thermal radiation exchange between any two surfaces depends on various properties that are associated with the two surfaces. There exists a special case, which involves radiation exchange between a small surface and an infinitely large surface. In our case, the outdoors can be considered as a very large diffuse surface and the outdoor glazing is very small as compared to the outdoor envelope. Therefore, the net rate of gray diffuse radiation exchange between the two surfaces can be expressed as:

$$
\mathrm{Q}_{\mathrm{rad}}=\varepsilon_{1} \sigma \mathrm{A}\left(\mathrm{T}_{\mathrm{o}}^{4}-\mathrm{T}_{1}^{4}\right)
$$

where $\varepsilon_{1}$ is the emissivity of glazing surface(1) and $\sigma$ is the Stefan-Boltzmann constant. $(\sigma=$ $5.67 \times 10^{-8} \mathrm{~W} / \mathrm{m}^{2} \mathrm{~K}^{4}$ ). This expression gives the difference between the thermal energy released due to radiation emission and that gained due to radiation absorption. For convenience, this expression can be expressed as:

$$
Q_{\mathrm{rad}}=\mathrm{h}_{\mathrm{r}} A\left(\mathrm{~T}_{\mathrm{o}}-\mathrm{T}_{1}\right)
$$

where the radiation heat transfer coefficient $h_{r}$ is:

$$
h_{r}=\varepsilon_{1} \sigma\left(T_{o}^{2}+T_{1}^{2}\right)\left(T_{o}+T_{1}\right)
$$

Using above expressions, the outdoor thermal radiation resistance can be expressed as:

$$
\mathrm{R}_{\mathrm{rad}}=\frac{\left(\mathrm{T}_{\mathrm{o}}-\mathrm{T}_{1}\right)}{\mathrm{Q}_{\mathrm{rad}}}=\frac{1}{\mathrm{~h}_{\mathrm{r}} A}
$$

The next heat exchange occurs within the window glazing and it involves pure conduction. The thermal conduction resistance for the window glazing can be written as: 


$$
\mathrm{R}_{\text {cond }, 1}=\frac{\left(\mathrm{T}_{1}-\mathrm{T}_{2}\right)}{\mathrm{Q}_{\text {cond }}}=\frac{\mathrm{t}}{k A}
$$

where $T_{2}$ is the glazing surface(2) temperature, " $t$ " is the thickness of the glass and $k$ is the thermal conductivity of the glass. Similarly, the thermal conduction resistance between surface (3) and surface (4) can be expressed as:

$$
\mathrm{R}_{\text {cond }, 2}=\frac{\left(\mathrm{T}_{3}-\mathrm{T}_{4}\right)}{\mathrm{Q}_{\text {cond }}}=\frac{\mathrm{t}}{k A}
$$

where $T_{3}, T_{4}$ are the temperatures of surface (3) and surface (4), respectively. The heat transfer between surface (2) and surface (3) is due to convection and thermal radiation exchange. The gap convection resistance can be written as:

$$
\mathrm{R}_{\text {con }}=\frac{\left(\mathrm{T}_{2}-\mathrm{T}_{3}\right)}{\mathrm{Q}_{\text {con }}}=\frac{1}{\mathrm{~h}_{\text {gap }} A}
$$

where $h_{\text {gap }}$ is the gap heat transfer convection coefficient. The thermal radiation exchange between two large gray and diffuse parallel planes (surface (2) \& surface (3)) can be calculated as:

$$
\mathrm{Q}_{\mathrm{rad}}=\frac{\sigma \mathrm{A}\left(\mathrm{T}_{2}^{4}-\mathrm{T}_{3}^{4}\right)}{\frac{1}{\varepsilon_{2}}+\frac{1}{\varepsilon_{3}}-1}
$$

where $\varepsilon_{2}, \varepsilon_{3}$ are the emissivity of surface(2) and surface(3), respectively. Using the above expressions, the gap thermal radiation resistance can be expressed as:

$$
\mathrm{R}_{\mathrm{rad}}=\frac{\left(\mathrm{T}_{2}-\mathrm{T}_{3}\right)}{\mathrm{Q}_{\mathrm{rad}}}=\frac{1}{\mathrm{~h}_{\mathrm{r}, \mathrm{gap}} \mathrm{A}}
$$

where $h_{r, \text { gap }}$ is the gap radiation heat transfer coefficient. 


$$
\mathrm{h}_{\mathrm{r}, \text { gap }}=\frac{\sigma\left(\mathrm{T}_{2}^{2}+\mathrm{T}_{3}^{2}\right)\left(\mathrm{T}_{2}+\mathrm{T}_{3}\right)}{\frac{1}{\varepsilon_{2}}+\frac{1}{\varepsilon_{3}}-1}
$$

Without any shading devices, the thermal interaction between window glazing surface (4) and the indoor is relatively simple. The free/natural convection heat exchange can be calculated as:

$$
\mathrm{Q}_{\text {con }}=\mathrm{h}_{\mathrm{i}} \mathrm{A}\left(\mathrm{T}_{4}-\mathrm{T}_{\mathrm{i}}\right)
$$

where $h_{i}$ is the free convection coefficient and $T_{i}$ is the indoor room temperature. Once again, the indoor thermal resistance for convection can be expressed as:

$$
\mathrm{R}_{\text {con }}=\frac{\left(\mathrm{T}_{4}-\mathrm{T}_{\mathrm{i}}\right)}{\mathrm{Q}_{\text {con }}}=\frac{1}{\mathrm{~h}_{\mathrm{i}} \mathrm{A}}
$$

Finally, the net rate of gray diffuse radiation exchange between the surface (4) and the indoor surroundings can be expressed as:

$$
\mathrm{Q}_{\mathrm{rad}}=\varepsilon_{4} \sigma \mathrm{A}\left(\mathrm{T}_{4}^{4}-\mathrm{T}_{\mathrm{i}}^{4}\right)
$$

where $\varepsilon_{4}$ is the emissivity of surface(4). This expression provides the difference between thermal energy released due to radiation emission and that gained due to radiation absorption. For convenience, this expression can be expressed as:

$$
\mathrm{Q}_{\mathrm{rad}}=\mathrm{h}_{\mathrm{r}} \mathrm{A}\left(\mathrm{T}_{4}-\mathrm{T}_{\mathrm{i}}\right)
$$

where the radiation heat transfer coefficient $h_{r}$ is

$$
h_{r}=\frac{Q_{r a d}}{A\left(T_{4}-T_{i}\right)}
$$

Using the above expressions, the indoor thermal radiation resistance can be witten as:

$$
\mathrm{R}_{\mathrm{rad}}=\frac{\left(\mathrm{T}_{4}-\mathrm{T}_{\mathrm{i}}\right)}{\mathrm{Q}_{\mathrm{rad}}}=\frac{1}{\mathrm{~h}_{\mathrm{r}} A}
$$


In order to obtain energy flows through a double glazed window, surface temperatures $T_{1}, T_{2}$, $T_{3}$ and $T_{4}$ must be specified. However, these temperatures are not known a priori and must be calculated. These temperatures depend on the energy balance at each surface. The energy balance at each surface requires that the overall heat transfer rate between the glazings must be equal. Mathematically,

$$
\left(\mathrm{Q}_{\text {total }}\right)_{01}=\left(\mathrm{Q}_{\text {total }}\right)_{12}=\left(\mathrm{Q}_{\text {total }}\right)_{23}=\left(\mathrm{Q}_{\text {total }}\right)_{34}=\left(\mathrm{Q}_{\text {total }}\right)_{4 \infty}
$$

In order to determine correct surface temperatures, an iterative technique is used. This iterative process can easily be implemented in various computer software programs. For this iterative process, outdoor velocity, outdoor/indoor temperatures, window dimensions, convection coefficients and other properties are specified. To initialize this process, all surface temperatures are guessed and the overall heat transfer rate is calculated as:

$$
Q_{\text {total }}=\frac{\left(T_{0}-T_{i}\right)}{R_{\text {total }}}
$$

where

$$
\mathrm{R}_{\text {total }}=\left(\frac{\mathrm{R}_{\text {con }} \cdot \mathrm{R}_{\mathrm{rad}}}{\mathrm{R}_{\text {con }}+\mathrm{R}_{\mathrm{rad}}}\right)_{01}+\left(\mathrm{R}_{\text {cond }}\right)_{12}+\left(\frac{\mathrm{R}_{\text {con }} \cdot \mathrm{R}_{\mathrm{rad}}}{\mathrm{R}_{\text {con }}+\mathrm{R}_{\mathrm{rad}}}\right)_{23}+\left(\mathrm{R}_{\text {cond }}\right)_{34}+\left(\frac{\mathrm{R}_{\text {con }} \cdot \mathrm{R}_{\mathrm{rad}}}{\mathrm{R}_{\text {con }}+\mathrm{R}_{\mathrm{rad}}}\right)_{4 \infty}
$$

It must be noted that the convection and the radiation resistances depend on the temperature differences between the adjacent surfaces. Therefore, the thermal resistance needs to be updated in each new iteration. The surface temperatures can be updated as:

$$
\begin{aligned}
& T_{1}^{(j)}=T_{0}-Q_{\text {total }}^{(j-1)}\left(\frac{R_{\text {con }} \cdot R_{\text {rad }}}{R_{\text {con }}+R_{\text {rad }}}\right)_{01} \\
& T_{2}^{(j)}=T_{1}-Q_{\text {total }}^{(j-1)}\left(R_{\text {cond }}\right)_{12} \\
& T_{3}^{(j)}=T_{2}-Q_{\text {total }}^{(j-1)}\left(\frac{R_{\text {con }} \cdot R_{\text {rad }}}{R_{\text {con }}+R_{\text {rad }}}\right)_{23}
\end{aligned}
$$




$$
\mathrm{T}_{4}^{(\mathrm{j})}=\mathrm{T}_{3}-\mathrm{Q}_{\text {total }}^{(\mathrm{j}-1)}\left(\mathrm{R}_{\text {cond }}\right)_{34}
$$

Where $\mathrm{j}=1,2,3 \ldots . . \mathrm{n}$. The overall heat transfer is calculated and the energy balance at each surface is performed. This iterative process is stopped when $\frac{Q_{\text {total }}^{(j)}-Q_{\text {total }}^{(j-1)}}{Q_{\text {total }}^{(j)}} \leq 0.01 \%$. In other words, the process is terminated when there is no change in the overall heat transmission in the new and the old iteration. This also implies that in the new iteration, all surface temperatures do not change significantly. When the correct surface temperatures are known, all other desired parameters such as convection, radiation components and the U-value can be calculated easily. The U-value measures the overall thermal conductance of the window and is calculated as:

$$
U-\text { value }=\frac{\left(T_{0}-T_{i}\right)}{Q_{\text {total }}}=\frac{1}{R_{\text {total }}}
$$

In this thesis, the effects of a horizontal Venetian blind on the thermal performance of a fenestration will be demonstrated by comparing the centre-of-glass U-value of a window with the U-value of an unshaded window.

\subsection{SIMPLIFIED NUMERICAL MODEL FOR THE WINDOW/BLIND SYSTEM AND SOLUTION PROCEDURE}

In the previous section of this chapter, a simplified one-dimensional thermal resistance model of the centre-of-glass region of an unshaded window was established. In addition, an iterative scheme to solve the heat transfer rates through the window was described. In this section, the simplified one-dimensional thermal resistance model of an unshaded window will be modified. This modified model will incorporate the interior Venetian blinds. It should be noted that the thermal resistance model of the centre-of-glass region of a double glazed 
window with an interior Venetian blind adjacent to the indoor glazing is very similar to that shown in Figure 2.2.

The only difference between the thermal resistance model of an unshaded and shaded window arises from different convection and radiation heat transfer coefficients on the indoor glazing surface. In the absence of the Venetian blind, the computation of the indoor radiative heat transfer coefficient is straightforward and the indoor convective heat transfer coefficient is easily calculated using the similarity correlation of Ostrach [19]. In the presence of an interior Venetian blind, the determination of the indoor convective and radiative heat transfer coefficients is more complex than for a no-blind case. In this case, the heat transfer coefficients depend on the convective and the radiative heat exchange between the indoor glazing, the blind and the indoor surroundings.

In order to incorporate the Venetian blind, a new procedure of calculating the heat transfer coefficients on the indoor glazing must be developed and implemented in the simplified model of an unshaded window. The implementation of a new procedure in the thermal resistance model of an unshaded window will result in a new numerical model that will describe the thermal behaviour of the window and blind system.

In order to develop the new procedure of calculating the radiative and convective heat transfer coefficients on the indoor glazing, one must understand and formulate the laws that govern the radiative and the convective heat exchange between the indoor glazing, the blind and its surroundings. For the purpose of this study, an attempt has been made to simplify the 
complex physical problem as much as possible. To formulate the laws that govern the radiative heat exchange, certain assumptions regarding the energy flows and the optical characteristics of the window and blind system have been made. The simplifying assumptions are the following:

* All surfaces including the window and the blind are assumed to perfectly opaque, diffuse and gray.

* The energy flows are assumed to be steady and one-dimensional.

* All surfaces including the window and the blind are represented by a single average temperature. Temperature gradients are assumed to exist along a single coordinate direction.

* The outdoor and the indoor surroundings are treated as very large black bodies. Only long wave thermal radiation exchange is considered.

All assumptions inherent to the one-dimensional thermal resistance model of an unshaded window are assumed to be true.

Recall that, in order to calculate the energy flows through an unshaded double glazed window, the glazing surface temperatures $T_{1}, T_{2}, T_{3}$ and $T_{4}$ were needed. These temperatures were calculated using the iterative process that was described in Section 2.2. In the case of a window and blind system, the presence of the blind would also influence the window glazing temperatures and these temperatures cannot be determined unless the blind temperature $T_{b}$ is known or specified. Unfortunately, the blind temperature is not known a priori and it depends on the energy balance between the indoor glazing surface (4), the blind and the indoor surroundings. To be more specific, the temperature of the blind $T_{b}$ depends on the balance 
between the net radiative heat flux to/from the blind and the rate of heat loss or gain from the ambient surroundings by convection.

In order to predict the correct blind temperature $T_{b}$, the net radiation heat flux to the blind and the convective coefficient on the blind must be known. An extensive search of the literature has indicated that the convective coefficients on the blind and the indoor glazing are not available. Therefore, one objective of the current work is to calculate the blind and the indoor glazing convective heat transfer coefficients for different blind and window configurations. A second objective is to use these convective coefficients to predict the correct glazing temperatures and assess the energy performance of the window and blind system. In this study, the convective heat transfer coefficients are computed by developing a twodimensional finite element model of an indoor glazing and Venetian blind assembly. The mathematical formulation and the solution procedure for the window and blind convection model will be discussed in the next few sections of this chapter.

As discussed earlier, the correct temperature of the blind $T_{b}$ can be predicted only if the radiative heat flux to the blind and the convective heat transfer coefficient $h_{b}$ are known. The radiative heat flux to the blind depends on the radiative heat exchange between the indoor glazing surface (4), the blind and the indoor surroundings. In this study, the radiation heat exchange between the indoor glazing surface (4), the blind and the indoor surroundings is calculated using an iterative scheme developed by Bevan and Dunkle [46]. The mathematical formulation and the solution procedure for the radiative heat exchange between a window and blind system will be presented in Section 2.4. 
For the purpose of this section, let us assume that for a given indoor glazing surface temperature $T_{4}$, the radiative and the convective heat flux to the blind is known. The correct blind temperature of $T_{b}$ can be predicted by adjusting the blind temperature until the radiative and the convective heat flux to blind are balanced. Mathematically, it can be expressed as:

$$
\mathrm{Q}_{\mathrm{R}, \mathrm{b}}=\mathrm{Q}_{C, \boldsymbol{b}}
$$

where $Q_{R, b}$ and $Q_{C, b}$ are the blind radiative and convective heat fluxes, respectively. When the correct blind temperature is known, thermal radiation exchange for the window and blind system can be calculated using Bevans-Dunkle's technique [46]. If the convective heat transfer coefficient on the indoor glazing surface is also known, the convective heat transfer from the indoor glazing surface (4) can be calculated. With this information, a modified thermal resistance between the indoor glazing and its surroundings can be calculated. The modified thermal resistance can be used to calculate the overall heat transfer through the window and blind system.

In this study, a program in C-language was developed which was used to compute the heat transfer through the window and blind system. This program has been included in Appendix-D. The solution procedure used in this program is illustrated in Figure 2.3. The solution procedure is as follows:

1. The weather condition, window dimension and louver angle $(\phi)$ are specified.

2. The window glazing temperatures $T_{1}, T_{2}, T_{3}, T_{4}$ are guessed.

3. The heat transfer rates for the glazing surface (1) through (3) are computed using the outdoor and the window cavity correlations. 


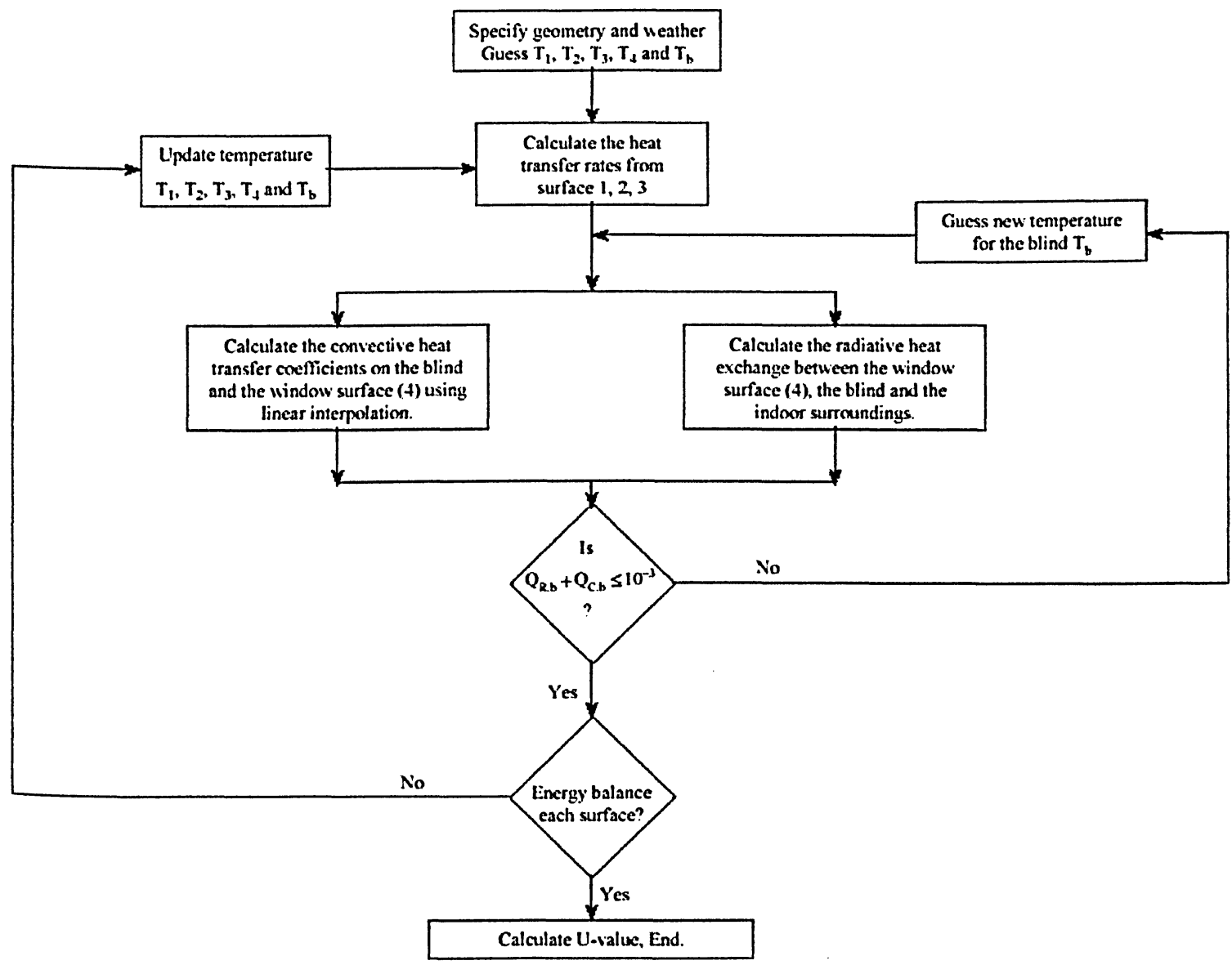

Figure 2.3 Solution procedures.

4. For the $1^{\text {st }}$ iteration, the blind temperature $T_{b}$ is set equal to the indoor surrounding temperature $T_{\infty}$.

5. The glazing surface (4) and blind convective coefficients are obtained from the results of the finite element study described in Section 2.6. The convective heat transfer coefficients are calculated using linear interpolation between the convective heat transfer data. A sample of the convective heat transfer data is given in the Appendix-C. To calculate the convective heat transfer coefficients, linear interpolations are performed between the blind temperature $\left(T_{b}\right)$, Rayleigh number $\left(\mathrm{Ra}_{\mathrm{L}}\right)$ and the louver angle $(\phi)$. 
6. Thermal radiation exchange between the indoor glazing surface (4), the blind and the indoor surroundings is computed using Bevans-Dunkle's technique given in Section 2.5.2.

7. The net radiative and convective heat fluxes to the blind are computed. If the net radiative heat flux is balanced by the convective heat flux (i.e., equation 2.24 is satisfied and $\left(Q_{R, b}-h_{b}\left(T_{b}-T_{\infty}\right) \leq 10^{-4}\right)$ then the present blind temperature is correct.

8. If this criterion is not satisfied, the blind temperature is increased in very small intervals and steps 4-7 are repeated until the net radiative heat flux is balanced by the convective heat flux.

9. When the correct blind temperature is determined, the thermal radiation heat transfer coefficient on the glazing surface (4) is calculated as:

$$
\mathrm{h}_{\mathrm{r}, 4}=\frac{\mathrm{Q}_{\mathrm{R}, 4}}{\mathrm{~A}_{\mathrm{w}}\left(\mathrm{T}_{4}-\mathrm{T}_{\infty}\right)}
$$

10. The total thermal resistance and the overall heat transfer through the window and blind system are calculated as:

$$
\begin{gathered}
\mathrm{R}_{\text {total }}=\left(\frac{\mathrm{R}_{\text {con }} \cdot \mathrm{R}_{\mathrm{rad}}}{\mathrm{R}_{\text {con }}+\mathrm{R}_{\mathrm{rad}}}\right)_{01}+\left(\mathrm{R}_{\text {cond }}\right)_{12}+\left(\frac{\mathrm{R}_{\text {con }} \cdot \mathrm{R}_{\mathrm{rad}}}{\mathrm{R}_{\text {con }}+\mathrm{R}_{\mathrm{rad}}}\right)_{23}+\left(\mathrm{R}_{\text {cond }}\right)_{34}+\left(\frac{\mathrm{R}_{\text {con }} \cdot \mathrm{R}_{\mathrm{rad}}}{\mathrm{R}_{\text {con }}+\mathrm{R}_{\mathrm{rad}}}\right)_{400} \\
\mathrm{Q}_{\text {total }}=\frac{\left(\mathrm{T}_{\mathrm{o}}-\mathrm{T}_{\infty}\right)}{\mathrm{R}_{\text {total }}}
\end{gathered}
$$

11. Now, the energy balance is performed at each surface. If the total heat transfer at each surface is within $0.01 \%$ of the overall heat transfer $Q_{\text {total }}$ then the U-value of the window is calculated as:

$$
\mathrm{U}-\text { value }=\frac{\left(T_{0}-T_{i}\right)}{Q_{\text {total }}}=\frac{1}{R_{\text {total }}}
$$


12. If the energy balance described in step 11 is not achieved then the steps $3-11$ are repeated by updating the glazing surface temperatures as:

$$
\begin{aligned}
& \mathrm{T}_{1}^{(\mathrm{j})}=\mathrm{T}_{\mathrm{o}}-\mathrm{Q}_{\text {total }}^{(\mathrm{j}-1)}\left(\frac{\mathrm{R}_{\text {con }} \cdot \mathrm{R}_{\mathrm{rad}}}{\mathrm{R}_{\text {con }}+\mathrm{R}_{\mathrm{rad}}}\right)_{\mathrm{ol}} \\
& \mathrm{T}_{2}^{(\mathrm{j})}=\mathrm{T}_{1}-\mathrm{Q}_{\text {total }}^{(j-1)}\left(\mathrm{R}_{\text {cond }}\right)_{12} \\
& \mathrm{~T}_{3}^{(\mathrm{j})}=\mathrm{T}_{2}-\mathrm{Q}_{\text {total }}^{(\mathrm{i}-1)}\left(\frac{\mathrm{R}_{\text {con }} \cdot \mathrm{R}_{\mathrm{rad}}}{\mathrm{R}_{\text {con }}+\mathrm{R}_{\mathrm{rad}}}\right)_{23} \\
& \mathrm{~T}_{4}^{(j)}=\mathrm{T}_{3}-\mathrm{Q}_{\text {total }}^{(\mathrm{j}-1)}\left(\mathrm{R}_{\text {cond }}\right)_{34}
\end{aligned}
$$

Where $\mathrm{j}$ is the iteration number and $\mathrm{j}=1,2,3 \ldots . . \mathrm{n}$. The energy balance condition is achieved when $\frac{\mathrm{Q}_{\text {total }}^{(\mathrm{j})}-\mathrm{Q}_{\text {total }}^{(\mathrm{j}-1)}}{\mathrm{Q}_{\text {total }}^{(i)}} \leq 0.01 \%$ and the iteration process terminates when all surface temperatures do not change significantly.

\subsection{COMPUTATIONS OF THERMAL RADIATION EXCHANGE BETWEEN AN INDOOR GLAZING AND A VENETIAN BLIND}

Thermal radiation exchange between two or more surfaces depends strongly on the surface geometries and orientations, as well as on their radiative properties and temperatures. In this study, the steady-state thermal radiation exchange between the indoor window glazing, the blind and the indoor surroundings was treated as a classical multi-surface enclosure problem with surfaces separated by a non-participating medium. The blind and the indoor glazing surface were assumed to be perfectly diffuse, gray and opaque. This means that emissivity and absorptivity are independent of the wavelength. Also, by Kirchoff's law [47], the emissivity equals the absorptivity. For a diffuse surface, the reflectivity and emission are 
independent of the outgoing or incoming directions. The Net Radiation Method describes thermal radiation exchange between the window, the blind and the indoor surroundings. Siegel and Howell [48] have discussed this method in detail. This method assumes that each radiating surface in an enclosure has a uniform temperature and is characterized by uniform radiosity and irradation. The governing equation is expressed as:

$$
\sum_{j=1}^{N}\left(\frac{\delta_{j, k}}{\varepsilon_{j}}-F_{j, k} \frac{1-\varepsilon_{j}}{\varepsilon_{j}}\right) Q_{R j}=\sigma \sum_{j=1}^{N}\left(\delta_{j, k}-F_{j, k}\right)\left(T_{j}^{4}\right)
$$

where $Q_{R j}$ is the net radiative heat transfer rate from the $j^{\text {th }}$ surface, $\varepsilon_{j}$ is the emissivity of the $j^{\text {th }}$ surface, $F_{j, k}$ is the view factor from the $\mathrm{j}^{\text {th }}$ to $\mathrm{k}^{\text {th }}$ surface, $\mathrm{N}$ is the total number of surfaces in the enclosure, $\delta_{\mathrm{j}, \mathrm{k}}$ is the Kronecker delta and $\sigma$ is the Stefan-Boltzmann constant. For N surfaces, equation (2.32) gives $\mathrm{N}$ simultaneous equations in $\mathrm{Q}_{\mathrm{R} 1}, \mathrm{Q}_{\mathrm{R} 2}, \ldots . \mathrm{Q}_{\mathrm{RN}}$.

In the current study, thermal gradients inside the blind louvers were assumed to be negligible for thermal radiation exchange calculations. The length of the window (L) and the array of louvers were assumed to be infinite. It should be noted that for an infinite array of louvers, the window has no view of the ambient through the gap between the blind and the window, i.e., at the top and bottom of the window. This view approaches zero as the number of louvers and window length increases, and thermal radiation exchange between the window and the blind does not depend on the blind tip-to-window spacing $d$. Therefore, the effect of blind tip-to-window spacing $\mathrm{d}$ was neglected for radiation calculations.

The radiative heat transfer rates were computed for a very small section of the window that consisted of the gap between two blind louvers. It was hypothesized that a four surface 
enclosure model would be sufficient for the radiative heat exchange between the window, blind and the indoor surroundings. This hypothesis was verified through a radiation grid study. In the grid study, the radiating surfaces, i.e. the window and the blind were broken into small surfaces and radiation computations were performed. A sample of results pertaining to this radiation grid study can be found in Appendix-F.

In order to compute thermal radiation exchange between the window, the blind and the indoor surroundings, view factors for each surface were required. An extensive search of the literature indicated that the view factors for this configuration were not available. These view factors were derived using Hottel's Crossed String Method [49].

\subsubsection{Derivation of View Factors}

To compute the radiation exchange between two or more surfaces, one must calculate the view factors for each surface. The view factor $F_{k j}$ is defined as the fraction of the radiation leaving surface $k$ that is intercepted by surface $j$. The view factors can be computed by defining the geometric properties of each radiating surface.

Hottel [49] has shown that for two-dimensional systems, the view factors are related to the lengths of imaginary crossed and uncrossed "strings". For example, this method is illustrated in Figure 2.4. The view factor for surface $A_{1}$ and surface $A_{2}$ can be determined by drawing four "strings" stretched between the end points of each surface. To determine the view factor between surface $A_{1}$ and surface $A_{2}$, imaginary "strings" are stretched between the end 
points (A, B, C, D). These "strings" are shown as dashed lines. The view factors are related to the length of the crossed and uncrossed 'strings" as follows:

$$
\begin{aligned}
A_{1} F_{1,2}=A_{2} F_{2,1} & =\frac{\text { Length of }(\text { crossed }- \text { uncrossed }) \text { strings }}{2} \\
& =\frac{|(A D+B C)-(A B+C D)|}{2}
\end{aligned}
$$

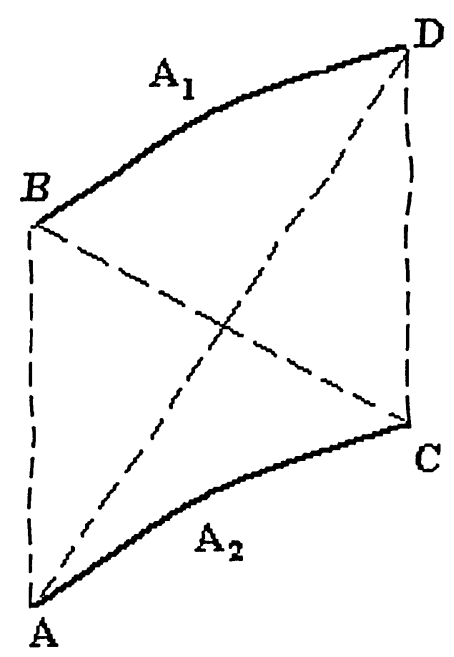

Figure 2.4 Hottel Crossed string method [49] for view factor calculations.

This method was applied to an infinite array of blind louvers and window assembly. The view factors for each radiating surface were computed by rotating the blind louvers from $0^{\circ}$ to $90^{\circ}$. The profile of many commercially available Venetian blinds is slightly curved for aesthetic reasons and to increase the resistance to axial buckling. In order to assess the effect of the curvature on the view factors, calculations were performed for flat and curved blind louvers. The window-to-ambient view factors for the flat and curved blind were compared. For this comparison, a typical value of 2.27 for the radius of curvature to louver pitch ratio was used. The variation of the window-to-ambient view factor with louver angle $(\phi)$ is shown in 
Figure 2.5. It can be seen that the window-to-ambient view factors for flat and curved louvers were approximately equal. The curvature had the maximum effect when the louvers were fully open (i.e. $\phi=0^{\circ}$ ). At this louver angle (i.e. $\phi=0^{\circ}$ ), the view factor for the curved case was approximately $1.7 \%$ lower than the flat case. Given the small effect of the curvature, in the remainder of this thesis thermal radiation calculations were carried out neglecting the curvature of the blind louvers.

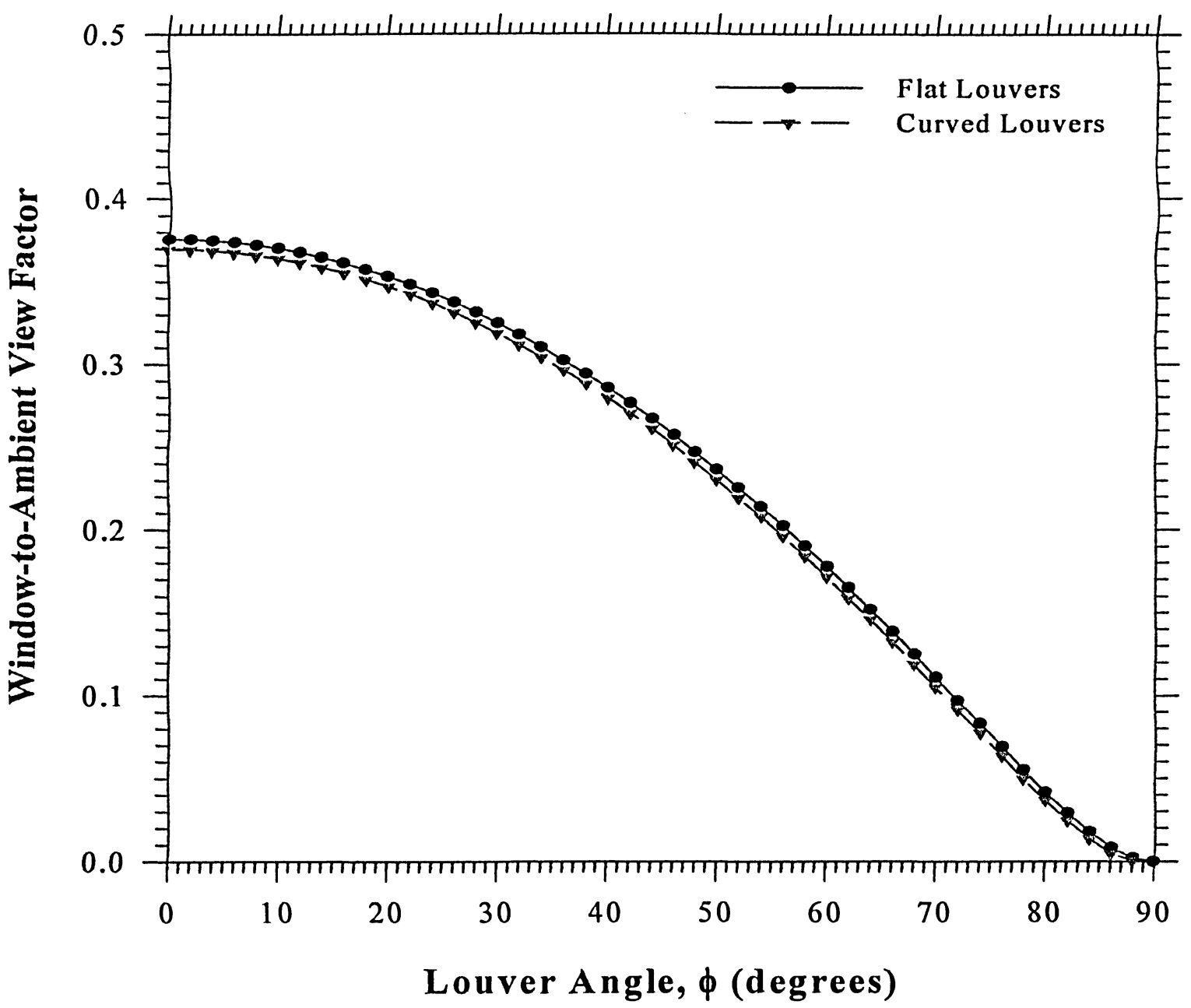

Figure 2.5 Variation in the Window-to-Ambient View factors with Louver Angle $(\phi)$. 


\subsubsection{Iterative Bevans-Dunkle Technique}

In this study, thermal radiation exchange computations were carried out using an iterative method developed by Bevans and Dunkle [46]. This method determines the net radiative heat flux for each surface in the enclosure. To illustrate this method, an enclosure with $\mathrm{N}$ surfaces is depicted in Figure 2.6.

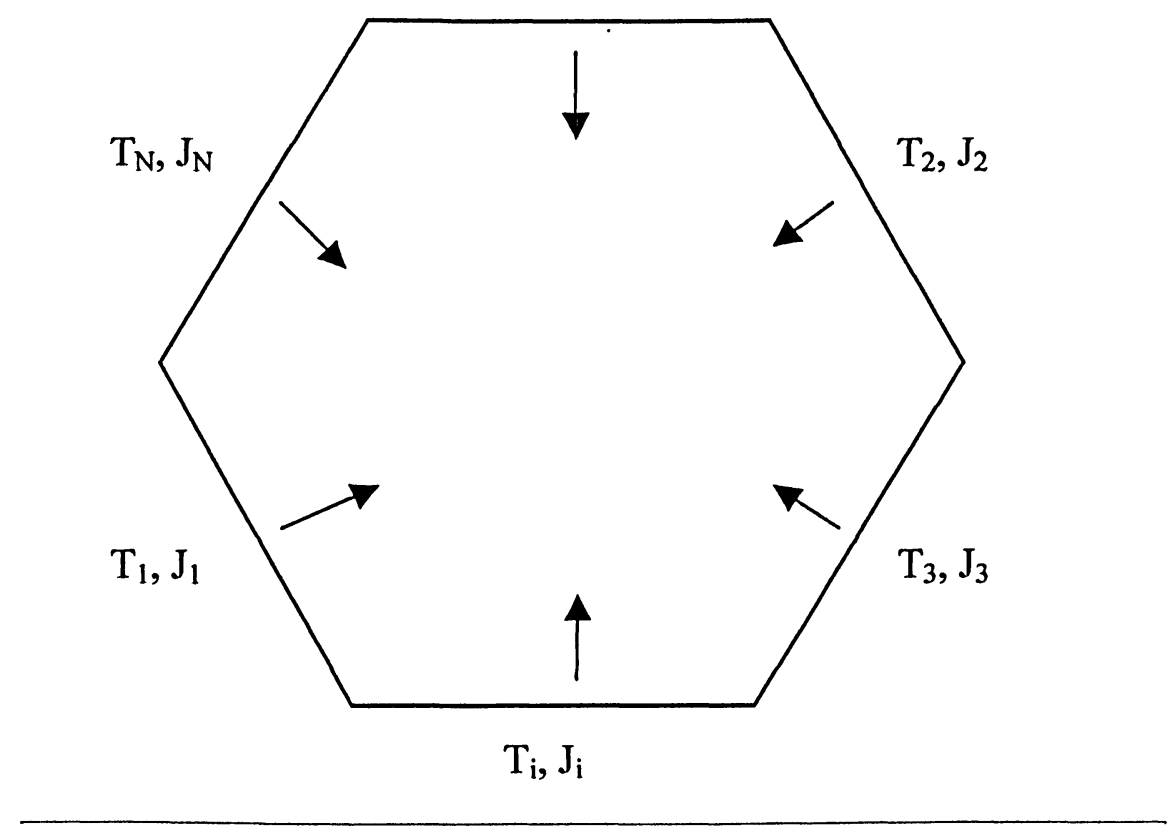

Figure 2.6 Radiation Exchange in an Enclosure

The net rate at which radiation leaves the $\mathrm{i}^{\text {th }}$ surface, represents the net effect of radiative interactions occurring at the $\mathrm{i}^{\text {th }}$ surface. It is equal to the difference between the surface radiosity $J_{i}$ and irradiation $G_{i}$ and may be expressed as:

$$
Q_{R i}=A_{i}\left(J_{i}-G_{i}\right)
$$


By definition, the total radiosity of the $\mathrm{i}^{\text {th }}$ surface includes the emitted portion of radiation and the reflected portion of irradiation. Realizing the opaque and gray surface assumption, the total radiosity can be expressed as:

$$
J_{i}=\varepsilon_{i} E_{i}+\left(1-\varepsilon_{i}\right) G_{i}
$$

The irradiation of surface i can be evaluated from the radiosities of all the surfaces in the enclosure. In particular, from the definition of the view factor, it follows that the total rate at which radiation reaches surface i from all surfaces, is:

$$
G_{i}=\frac{\sum_{j=1}^{N} F_{j, i} A_{j} J_{j}}{A_{i}}=\sum_{j=1}^{N} F_{i, j} J_{j}
$$

Equation (2.36) makes use of the reciprocity relation $A_{i} F_{i j}=A_{j} F_{j i}$. Substituting the total irradiation relation given in equation (2.36) into equation (2.35), a new expression can be obtained for the total radiosity at surface $\mathrm{i}$ :

$$
J_{i}=\varepsilon_{i} E_{i}+\left(1-\varepsilon_{i}\right) \sum_{j=1}^{N} F_{i, j} J_{j}
$$

Substituting equations (2.36) and (2.37) into (2.34), the net radiative heat transfer rate from the $\mathrm{i}^{\text {th }}$ surface can be written as:

$$
Q_{R i}=A_{i} \varepsilon_{i}\left(E_{i}-\sum_{j=1}^{N} F_{i, j} J_{j}\right)
$$

The Bevans-Dunkle iterative method solves the total radiosity equation for all surfaces in the enclosure. The radiosity at each surface is computed using an iterative process. Guessing the total radiosity associated with each surface initializes the iteration process. Then, the total radiosity at each surface is computed using equation (2.37). Iterations are performed until the 
radiosity of at each surface does not change significantly. In this study, the following convergence criterion was specified:

$$
\frac{\mathrm{J}_{i}^{k}-\mathrm{J}_{i}^{k-1}}{\mathrm{~J}_{i}^{k-1}} \leq 0.01 \%
$$

where $\mathrm{k}$ is the $\mathrm{k}^{\text {th }}$ iteration for the total radiosity at surface $\mathrm{i}$. When this criterion was met, the net heat transfer rates from each surface were calculated using equation (2.38).

\subsection{CONVECTION HEAT TRANSFER CORRELATIONS FOR THE OUTDOORS AND WINDOW CAVITY}

To compute the overall heat transfer through a window and Venetian blind assembly, the convective heat transfer coefficients for the outdoor window surface and window cavity must be specified. Since, the intention of present study is to develop a numerical model that may be incorporated in VISION [8], therefore, the following correlations were used to calculate convective heat transfer rates across the window cavity:

$$
\begin{array}{ll}
\mathrm{Nu}=0.0673838 \mathrm{Ra}^{\frac{1}{3}} & \mathrm{Ra}>5 \times 10^{4} \\
\mathrm{Nu}=0.028154 \mathrm{Ra}^{0.4134} & 10^{4}<\mathrm{Ra} \leq 5 \times 10^{4} \\
\mathrm{Nu}=\operatorname{MAX}\left(1+1.7596678 \times 10^{-10} \mathrm{Ra}^{2.2984755}, 0.242\left(\frac{\mathrm{Ra}}{\gamma}\right)^{0.272}\right) \quad \mathrm{Ra} \leq 10^{4}
\end{array}
$$

Where Rayleigh number $\mathrm{Ra}$ is based on the cavity width s. In this study, the outdoor convective heat transfer coefficients were obtained from the correlations developed by Lokmanhekim [50]. These correlations depend on the outdoors air velocity $V_{0}$ and are expressed as: 


$$
\begin{array}{lll}
\mathrm{h}_{\mathrm{o}}=8.07 V_{o}^{0.605} \frac{\mathrm{W}}{\mathrm{m}^{2} K} & \mathrm{~V}_{\mathrm{o}}>2 \frac{m}{\mathrm{~s}} \\
\mathrm{~h}_{\mathrm{o}}=12.27 & \frac{\mathrm{W}}{\mathrm{m}^{2} K} & \mathrm{~V}_{\mathrm{o}} \leq 2 \frac{m}{s}
\end{array}
$$

\subsection{COMPUTATIONS OF FREE CONVECTION EXCHANGE BETWEEN AN INDOOR GLAZING AND A VENETIAN BLIND}

In order to compute the heat transfer rates through a window and blind system, the convective heat transfer coefficients on the indoor glazing and the blind must be known. Unfortunately, the convective coefficients for a window and blind system are not known. In this study, the convection coefficient for a window and blind system are computed using a finite element method. A two-dimensional CFD model of a window and blind system has been developed. The full description of this convection model is given in the next few sections of this chapter.

\subsubsection{Problem Description}

The convective heat transfer rates depend on the details of the flow and temperature field. To understand the mechanism of the convective heat transfer, the physical problem should be expressed in mathematical terms. The geometry of this free convection problem is illustrated in Figure 2.7. The Venetian blind consists of a set of louvers of width W spaced at pitch ps. The louvers are positioned at a distance $d$ from the window that may be rotated through the horizontal axis to an angle $\phi$. In this figure, $T_{w}$ and $T_{b}$ are the indoor window glazing and the blind temperature, respectively. $T_{\infty}$ is the temperature of the indoor surroundings. 


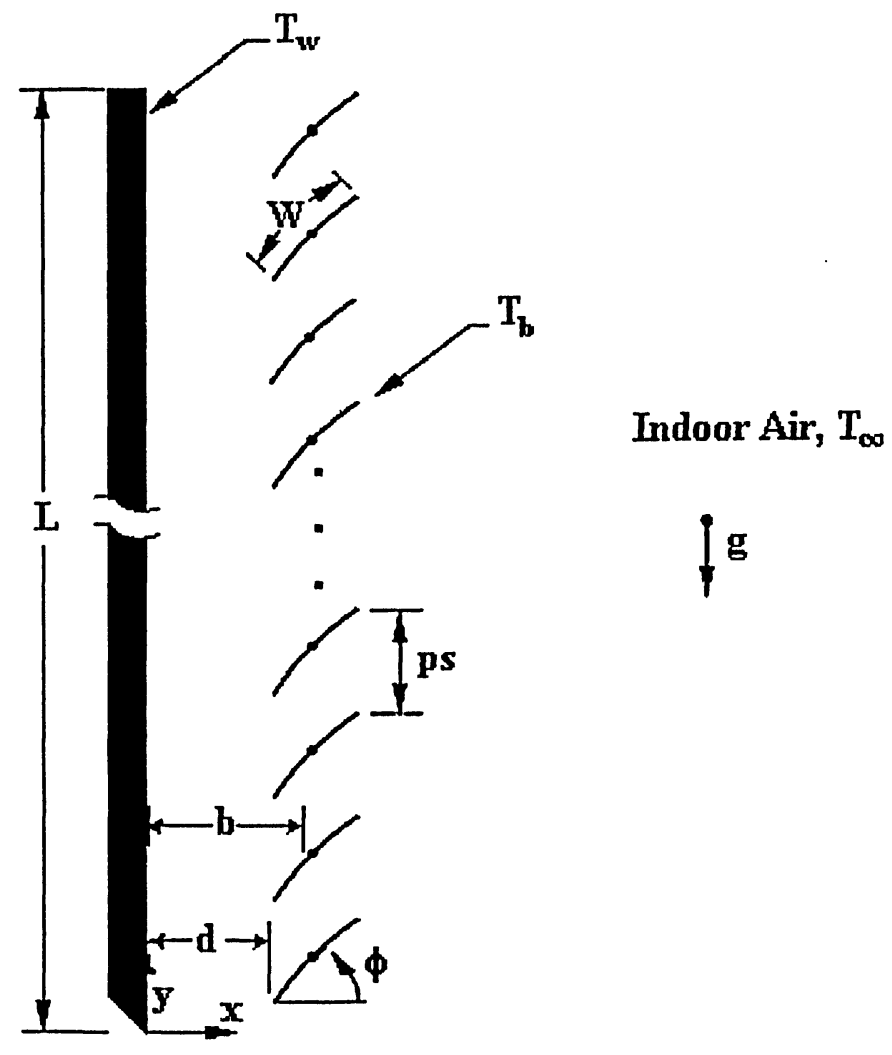

Figure 2.7 Problem geometry and Coordinate System.

\subsubsection{Governing Equations}

In order to predict convective heat transfer rates, the distribution of pressure, velocity and temperature through the flow field must be determined. Once the distributions of these variables are determined, the variations of other desirable quantities such as the convection heat transfer coefficients can be obtained. The distributions of pressure, velocity and temperature are determined using the principle of conservations of mass, momentum and energy. In general, these conservation principles represent mathematical models of the behaviour of the physical problem and they are adequate for the analysis of the vast majority of engineering problems. These conservation principles lead to the so-called continuity, NavierStokes and energy equations. 
The natural convective heat transfer is the heat exchange between a surface and a fluid moving over it, with the fluid motion caused by the buoyancy forces that result from the temperature variations in the flow field. In general, natural convective flows arise due to density gradients in the presence of the gravitational field. In the present study, the natural convective heat transfer between the indoor glazing, the Venetian blind and the indoor surroundings has been assumed to be steady and two-dimensional. The flow field is assumed to be laminar and incompressible. These assumptions are consistent with the numerical work of Phillips et al. [44] that showed excellent agreement with the experimental work of Machin et al. [42]. The continuity, momentum, and energy equations are presented below:

$$
\begin{aligned}
& \frac{\partial u}{\partial x}+\frac{\partial v}{\partial y}=0 \\
& \rho\left(u \frac{\partial u}{\partial x}+v \frac{\partial u}{\partial y}\right)=-\frac{\partial p}{\partial x}+\mu\left(\frac{\partial^{2} u}{\partial x^{2}}+\frac{\partial^{2} u}{\partial y^{2}}\right) \\
& \rho\left(u \frac{\partial v}{\partial x}+v \frac{\partial v}{\partial y}\right)=-\frac{\partial p}{\partial y}+\mu\left(\frac{\partial^{2} v}{\partial x^{2}}+\frac{\partial^{2} v}{\partial y^{2}}\right)+\left(\rho_{\infty}-\rho\right) g \\
& \rho C_{p}\left(u \frac{\partial T}{\partial x}+v \frac{\partial T}{\partial y}\right)=k\left(\frac{\partial^{2} T}{\partial x^{2}}+\frac{\partial^{2} T}{\partial y^{2}}\right)+\Phi
\end{aligned}
$$

A detailed derivation of Eqs. 2.44 through 2.47 can be found in [51]. In the derivation of the momentum equations in the $\mathrm{x}$ and $\mathrm{y}$ directions, the pressure can be measured relative to the local hydrostatic pressure that would exist if there were no heating and no fluid motion. This is known as the pressure defect, which is defined as:

$$
p^{\prime}=p-p_{\infty}
$$


where $\mathrm{p}$ and $\mathrm{p}_{\infty}$ are the local pressures with and without heating/fluid motion, respectively. The last term on the right-hand side of equation (2.46) is the buoyancy force. The buoyancy force arises as a result of the fluid density change with temperature and pressure. In the case of an incompressible flow, the influence of the temperature changes on density changes is significant and the influence of pressure changes on density changes is negligible. Therefore, it is convenient to express the buoyancy force in terms of the temperature difference. This can be achieved by introducing the temperature coefficient of bulk expansion $\beta$, such that

$$
\left(\rho_{\infty}-\rho\right) g \approx \rho g \beta\left(T-T_{\infty}\right)
$$

It should be noted that in the analysis of many free convective flows, the fluid properties can be assumed to be constant except for the density change which produces the buoyancy force. This assumption is, basically, the "Boussinesq approximation" which is reasonable for the problem under study. In this study, all thermo-physical properties have been assumed to be constant except density, which is treated with the Boussinesq approximation. The adoption of Boussinesq approximation substantially simplifies the form of the governing equations to be solved. Further details regarding the Boussinesq approximation can be found in [51]. Finally, the last term on the right-hand side of equation (2.47) is the viscous dissipation, which is important only when the pool of kinetic energy available for possible conversion into thermal energy is significant compared to the transfer of thermal energy due to the temperature difference. In the present study, the velocities encountered are very small and the thermal energy flows due to the temperature difference are relatively large. Therefore, the role of the viscous dissipation in the energy equation can be neglected. Equations (2.44) through (2.47) can be written as: 


$$
\begin{aligned}
& \frac{\partial u}{\partial x}+\frac{\partial v}{\partial y}=0 \\
& \rho\left(u \frac{\partial u}{\partial x}+v \frac{\partial u}{\partial y}\right)=-\frac{\partial p^{\prime}}{\partial x}+\mu\left(\frac{\partial^{2} u}{\partial x^{2}}+\frac{\partial^{2} u}{\partial y^{2}}\right) \\
& \rho\left(u \frac{\partial v}{\partial x}+v \frac{\partial v}{\partial y}\right)=-\frac{\partial p^{\prime}}{\partial y}+\mu\left(\frac{\partial^{2} v}{\partial x^{2}}+\frac{\partial^{2} v}{\partial y^{2}}\right)+\rho g \beta\left(T-T_{\infty}\right) \\
& \rho C_{p}\left(u \frac{\partial T}{\partial x}+v \frac{\partial T}{\partial y}\right)=k\left(\frac{\partial^{2} T}{\partial x^{2}}+\frac{\partial^{2} T}{\partial y^{2}}\right)
\end{aligned}
$$

The solution to the continuity, momentum and energy equations can be obtained using numerical techniques. In this study, equations (2.50) through (2.53) are solved for a twodimensional computation domain, which is shown in Figure 2.8 .

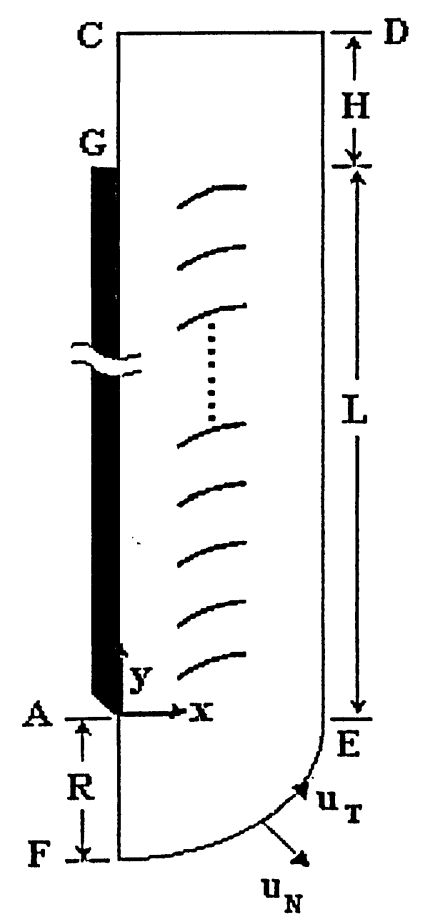

Figure 2.8 Computational Domain and Coordinate system. 


\subsubsection{Boundary Conditions}

To solve the continuity, momentum and energy equations certain boundary conditions were applied. Listed below are the boundary conditions in dimensional form for the computational domain depicted in Figure 2.8.

$$
\begin{array}{lr}
u=v=0, T=T_{w} & \text { for } \mathrm{x}=0,0<\mathrm{y}<(\mathrm{H}+\mathrm{L}) \\
\frac{\partial \mathrm{u}}{\partial \mathrm{y}}=\frac{\partial \mathrm{v}}{\partial \mathrm{y}}=\frac{\partial \mathrm{T}}{\partial \mathrm{y}}=0 & \text { for } 0<\mathrm{x}<\mathrm{R}, \mathrm{y}=(\mathrm{H}+\mathrm{L}) \\
\frac{\partial \mathrm{u}}{\partial \mathrm{x}}=\mathrm{v}=0, \mathrm{~T}=\mathrm{T}_{\infty} & \text { for } \mathrm{x}=\mathrm{w}, 0<\mathrm{y}<(\mathrm{H}+\mathrm{L}) \\
u_{T}=\frac{\partial u_{N}}{\partial N}=0, T=T_{\infty} & \text { On arc of radius } \mathrm{R} \\
\mathrm{u}=\frac{\partial \mathrm{v}}{\partial \mathrm{x}}=\frac{\partial \mathrm{T}}{\partial \mathrm{x}}=0 & \text { for } \mathrm{x}=0,-\mathrm{R}<\mathrm{y}<0
\end{array}
$$

These boundary conditions were chosen from the previous numerical work of Phillips et al. [44]. In this study, no slip/impermeable velocity conditions were applied at the blind boundary. The blind temperature was fixed to decouple the radiation and convection heat transfer. Therefore, finite element radiation modelling was not required. However, calculations were performed to assess the effect of a uniform blind temperature on the accuracy of the free convection solution. It should be noted that when a fixed blind temperature is imposed, thermal gradients inside the blind louvers become irrelevant and can be ignored. Also, many commercially available blinds are fabricated from aluminium and the blind Biot number $\mathrm{Bi}<<0.1$. For these reasons, thermal gradients inside the blind louvers were ignored. 
Boundary AC represents the length of the window where no slip/impermeable boundary conditions were applied. The temperature along boundary AG was set to a constant value to model the isothermal window centre-of-glass region. Inflow boundaries are labelled in Figure 2.7 as sections FE, ED. Fluid was allowed to enter the ED boundary by setting the derivative of the $u$ velocity component to zero. No fluid movement was allowed in the vertical direction to ensure fluid is entrained perpendicular to the window surface. Both FE and ED had the ambient temperature conditions. The curved fluid inflow boundary was used below the leading edge of the window along FE. On this boundary, the tangential velocity was set to zero while the fluid was allowed to flow into the computational domain perpendicular to the boundary. Wright and Gebhart [52] conducted a numerical study of entrainment flow below the leading edge of an isothermal vertical flat plate. They showed that negative motion pressure gradients cause the fluid to entrain perpendicular to an arc approximately centred about the leading edge of the plate. This inflow region was intended to simulate the experimental conditions of Machin et al. [42] as closely as possible. Furthermore, extending the computational domain below the leading edge of the window allowed for upstream diffusion of momentum and heat, which would occur under actual conditions.

Directly below the leading edge of the window, a line of symmetry condition was implemented along FA. This implies that the window was infinitely thin and that the fluid would rise on both sides. This condition was imposed so that the numerical model could be validated against the experimental work of Machin et al. [42] where a vertical isothermal plate was placed in air with no solid window portions below it. In reality, a section of window would exist along FA that would have some sort of temperature distribution extending from the 
edge of the isothermal section to the frame of the window. However, this distribution may vary from window to window depending on the type of frame. Therefore, a line of symmetry was the best available option below the leading edge. In addition, it closely describes the experimental conditions in the work of Machin et al. [42].

In Figure 2.8, boundary $\mathrm{CD}$ represents the problem outflow boundary. At the top of the computational domain, momentum and energy are convected out where a zero derivative condition applies to velocity and temperature. This boundary condition implies that there is no diffusion of momentum and heat at the exit of the computational domain. For significantly high Rayleigh numbers, the diffusion is relatively small compared to convection and this condition is a good approximation.

\subsubsection{Non-Dimensionalization Scheme and Solution Procedure}

In order to predict convective heat transfer rates, one must solve equations (2.50) through (2.53). The variables appearing in the governing equations are the dimensional variables. The solution of the governing equations in the present form would only apply to a specific situation, i.e., to a specific physical situation corresponding to the dimensional variables. The objective of present study is to calculate the convective heat transfer coefficients that can be used for a wide range of window and blind configurations. This objective can be achieved transforming equations (2.50) through (2.53) with the introduction of some nondimensional variables. When the equations are expressed in terms of appropriate nondimensional variables, the solution for a specific non-dimensional situation would be applicable for several different physical situations. However, it should be noted that when the 
equations and the boundary conditions are properly scaled, the numerical solution of the equations in dimensional and dimensionless form is identical.

In this study, the continuity, momentum and energy equations were cast in terms of dimensionless variables. The following dimensionless variables were used and these variables were obtained from [44].

$$
\begin{aligned}
& X, Y=\frac{x, y}{L}, U, V=\frac{u, v}{(\alpha / L)} \\
& P=\frac{p L^{2}}{\mu \alpha}, T^{*}=\frac{T-T_{\infty}}{T_{w}-T_{\infty}}
\end{aligned}
$$

where $T_{w}$ and $T_{\infty}$ are the window and the indoor surroundings temperatures, respectively. $L$ is the height of the window and $\alpha=\left(\mathrm{k} / \rho C_{\mathrm{p}}\right)$ is the fluid thermal diffusivity. It measures the ability of a material to conduct thermal energy relative to its ability to store thermal energy. The substitution of the dimensionless variables into equations (2.50) through (2.53) result in the following form:

$$
\begin{aligned}
& \frac{\partial U}{\partial X}+\frac{\partial V}{\partial Y}=0 \\
& G r^{\frac{1}{2}}\left(U \frac{\partial U}{\partial X}+V \frac{\partial U}{\partial Y}\right)=-\frac{\partial P}{\partial X}+\left(\frac{\partial^{2} U}{\partial X^{2}}+\frac{\partial^{2} U}{\partial Y^{2}}\right) \\
& G r^{\frac{1}{2}}\left(U \frac{\partial V}{\partial X}+V \frac{\partial V}{\partial Y}\right)=-\frac{\partial P}{\partial Y}+\left(\frac{\partial^{2} V}{\partial X^{2}}+\frac{\partial^{2} V}{\partial Y^{2}}\right)+G^{\frac{1}{2}} T^{*} \\
& G^{\frac{1}{2}} \operatorname{Pr}\left(U \frac{\partial T^{*}}{\partial X}+V \frac{\partial T^{*}}{\partial Y}\right)=\left(\frac{\partial^{2} T^{*}}{\partial X^{2}}+\frac{\partial^{2} T^{*}}{\partial Y^{2}}\right)
\end{aligned}
$$


where Pr is the Prandtl number and Gr is the Grashof number. The Prandtl number is the ratio of the momentum diffusivity to the thermal diffusivity and it provides a measure of the relative effectiveness of momentum and energy transport by diffusion in the velocity and thermal boundary layers, respectively. The Grashof number indicates the ratio of buoyancy force to the viscous force acting on the fluid. Mathematically:

$$
\begin{aligned}
& \operatorname{Pr}=\frac{v}{\alpha} \\
& \mathrm{Gr}=\frac{g \beta \rho^{2}\left(\mathrm{~T}_{\mathrm{w}}-\mathrm{T}_{\infty}\right) \mathrm{L}^{3}}{v^{2}}
\end{aligned}
$$

In this study, equations (2.57) through (2.60) were solved using a dimensionless computational domain. The dimensionless computational domain for the present study is illustrated in Figure 2.9. The solution was obtained by applying the boundary conditions, which were also cast into non-dimensional form. The conditions applied at each boundary are listed below:

$$
\begin{aligned}
& \mathrm{U}=\mathrm{V}=0, \mathrm{~T}^{*}=1 \\
& \text { for } X=0,0 \leq Y \leq\left(1+H^{*}\right) \\
& \frac{\partial U}{\partial \mathrm{Y}}=\frac{\partial \mathrm{V}}{\partial \mathrm{Y}}=\frac{\partial \mathrm{T}^{*}}{\partial \mathrm{Y}}=0 \\
& \text { for } 0<\mathrm{X} \leq \mathrm{R}^{*}, \mathrm{Y}=\left(1+\mathrm{H}^{*}\right) \\
& \frac{\partial U}{\partial X}=V=0, T^{*}=0 \\
& \text { for } \mathrm{X}=\mathrm{R}^{*}, 0<\mathrm{Y}<\left(1+\mathrm{H}^{*}\right) \quad(\mathrm{DE}) \\
& \mathrm{U}=\frac{\partial \mathrm{V}}{\partial \mathrm{X}}=\frac{\partial \mathrm{T}^{*}}{\partial \mathrm{X}}=0 \quad \text { for } \mathrm{X}=0,-\mathrm{R}^{*}<\mathrm{Y}<0 \\
& \mathrm{U}_{\mathrm{T}}=\frac{\partial \mathrm{U}_{\mathrm{N}}}{\partial \mathrm{N}}=0, \mathrm{~T}^{*}=0 \quad \text { on arc of radius } \mathrm{R}^{*} \\
& \mathrm{U}=\mathrm{V}=0, \mathrm{~T}_{\mathrm{b}}{ }^{*}=(0.1-0.5) \quad \text { for the blind louver boundary }
\end{aligned}
$$




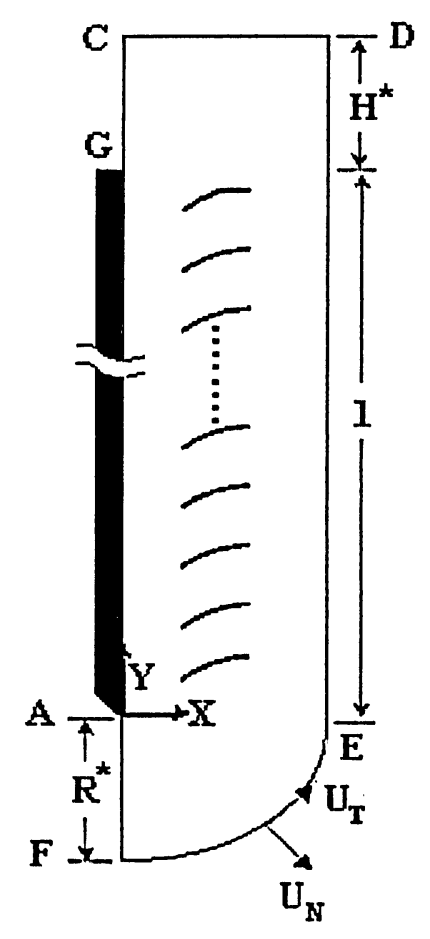

Figure 2.9 Dimensionless Computational Domain.

In this study, the computational field was discretized using nine-node quadrilateral and iso-parametric elements. These types of elements use bi-quadratic interpolation functions to approximate the velocity and temperature components. The finite element method based on Galerkin Weighted Residual method was used to solve the continuity, momentum and energy equations. The penalty formulation was employed and the equations of interest were solved using the Successive Substitution technique. To stabilize the solution process and speed up the convergence, the under-relaxation technique was used. Further details of the solution procedure can be found in FIDAP 8.5 documentation [53].

In this study, the dimensionless blind temperature $\left(\mathrm{T}_{\mathrm{b}}{ }^{*}\right)$ was fixed for a range of $(0.1-$ 0.5). The solution was obtained for different blind tip-to-window spacings and louver angle 
$(\phi)$. For the purpose of this study, all results will be presented in terms of Rayleigh number $\left(R a_{L}\right)$ based on the window height. Dimensionless heat transfer rates from the indoor glazing are presented in the form of local and average Nusselt numbers. The Nusselt numbers for the indoor window surface are defined as:

$$
N u=\frac{q L}{k_{F}\left(T_{w}-T_{\infty}\right)}, \quad N u_{\text {avg }}=\frac{1}{L} \int_{0}^{L} N u d y=\int_{0}^{L} N u d Y
$$

Similarly, the local Nusselt number and the convective coefficient for the blind are defined as follows:

$$
N u_{b, i}=\frac{-q_{i, a v g}(2 W)}{\left(T_{b}-T_{\infty}\right)}, h_{b, i}=\frac{N u_{b, i} k_{F}}{2 W}=\frac{-q_{i, a v g}\left(T_{w}-T_{\infty}\right) k_{F}}{L\left(T_{b}-T_{\infty}\right)}
$$

In equations (2.64) and (2.65), $\mathrm{q}$ is the local heat flux for the indoor glazing and $\mathrm{q}_{\mathrm{i} \text {,avg }}$ is the average heat flux (obtained from FIDAP [53]) for the individual blind slat. The average Nusselt number and the average convective coefficient for the entire blind are defined as follows:

$$
N u_{b, \text { avg }}=\frac{\sum_{i=1}^{n} N u_{b, i}}{n}, \quad h_{b, \text { avg }}=\frac{\sum_{i=1}^{n} h_{b, i}}{n}
$$

Where $i=1,2 \ldots . n$ represents the louver number starting from the lower end of the window. The present study has been restricted to a blind with $n=29$ louvers. The reason for this low number is to avoid unsteady and turbulent conditions. The convective coefficients for the blind will be presented in their dimensional form. These coefficients are calculated for a commercial Venetian blind with a louver pitch ratio $(\mathrm{W} / \mathrm{ps}=1.14)$ and $(\mathrm{W}=25 \mathrm{~mm})$ wide louvers. For a total number of 29 blind louvers, the window height has been calculated as $0.635 \mathrm{~m}$. 


\subsubsection{Validation Study of the Free Convection Numerical Model}

In general, the reliability and accuracy of a numerical solution to a physical problem depends on the careful validation of the numerical model and the solution technique. In this study, numerical modeling work was carried out using a commercial finite element software package, FIDAP 8.5 [53]. This commercial code was tested for its reliability and accuracy by comparing the numerical solution with the benchmark solution of Ostrach [19]. Then, the current free convection numerical model of a window and blind assembly was tested against the experimental work of Machin et al. [42].

To validate the numerical method and the boundary conditions, a finite element solution was obtained initially for an isothermal vertical surface. A two-dimensional free convection model was developed and the full Navier-Stokes/Energy equations were solved. This solution was compared to the similarity solution [19] of boundary layer equations for free convection from an isothermal vertical flat plate. One such comparison is illustrated in Figure 2.10, which shows the local convective Nusselt number distribution obtained from the finite element model and the benchmark similarity solution [19]. The examination of Figure 2.10 reveals that the local convective Nusselt number distribution obtained from the finite element model agrees well with the similarity solution. Only minor differences between the two solutions exist. On average, the present numerical solution is within $0.4 \%$ of the similarity solution.

Similarly, the variation of average Nusselt number with Rayleigh number is illustrated in Figure 2.11. Clearly, the local and average convection Nusselt number distributions obtained 


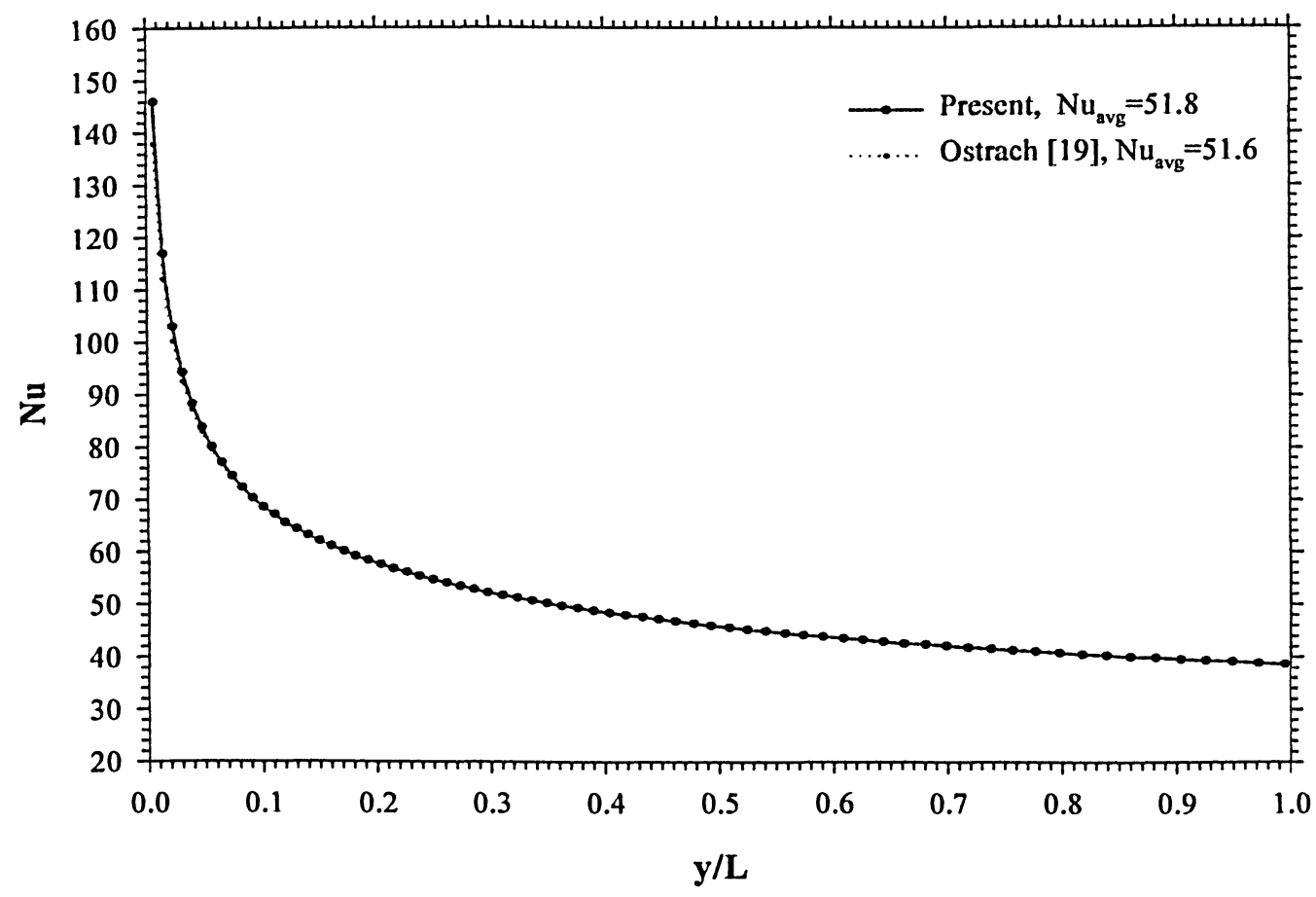

Figure 2.10 Variation in the local Nusselt number for an unshaded window, $\operatorname{Ra}_{L}=10^{8}, \operatorname{Pr}=0.71$.

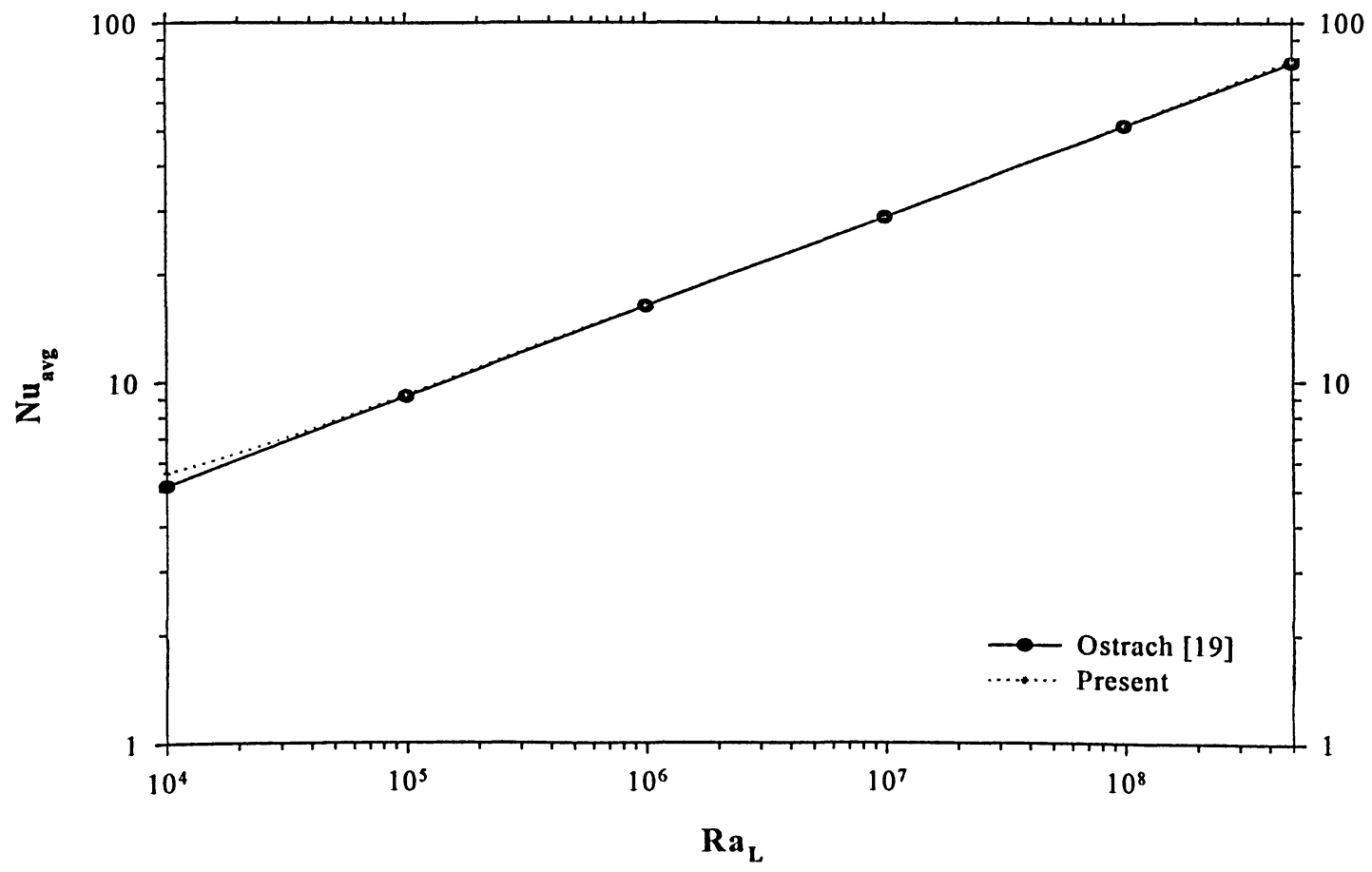

Figure 2.11 Variation in the average Nusselt number with Rayleigh number for an unshaded window. 
numerically agree well with the solutions by Ostrach [19]. On average, at high Rayleigh number, the convective coefficients differ by only $1 \%$. It should be noted that the largest difference of $2.5 \%$ occurs at a very low Rayleigh number $\mathrm{Ra}_{\mathrm{L}}=10^{4}$. This deviation is likely caused by the boundary layer assumption, which was used by Ostrach [19]. The boundary layer assumptions breakdown at low Rayleigh numbers because the diffusion normal to the isothermal surface is of the same order as in the streamwise direction. In this study, full elliptic equations are solved that include the diffusion in both directions. Therefore, the differences between the Ostrach [19] and the present solution are expected to occur at low Rayleigh numbers.

In order to validate the numerical model of an indoor glazing and blind assembly, a numerical model consisting of 17 blind louvers was developed. The purpose of this model was to match the experimental results of Machin et al. [42]. For validation purpose, solutions were obtained by fixing the window and the blind louvers temperature to the same values measured by Machin et al. [42]. In addition, the effects of representing blind louvers with a single average temperature were examined. To assess the effects of an average blind temperature, the blind temperature was fixed using an average value that was calculated from the experimental data [42]. The results obtained from this model were compared to the experimental data [42].

A qualitative comparison of the numerically predicted isotherms to the interferograms of Machin et al. [42] is illustrated in Figure 2.12. Clearly, numerically derived isotherms for two louver angles of $45^{\circ}, 0^{\circ}$ at $\mathrm{Ra}_{\mathrm{L}}=3.05 \times 10^{7}$ agree closely with the experimental results. The important temperature field features such as shape and locations of the isotherms are very 
similar. The numerical solution appears to predict the correct temperature field. Another qualitative comparison has been made between the experimental flow visualization photographs of Machin et al. [42]. Numerically predicted stream function contours and experimental flow visualization photographs are presented in Figure 2.13. This comparison is made for a louver angle of $0^{\circ}$ at Rayleigh number of $3.05 \times 10^{7}$ and a dimensionless blind centre-to-window spacing of 0.066 . Clearly, the cellular structure of the flow between the louvers is the same and the locations of flow features such as separation and reattachment are in close agreement.

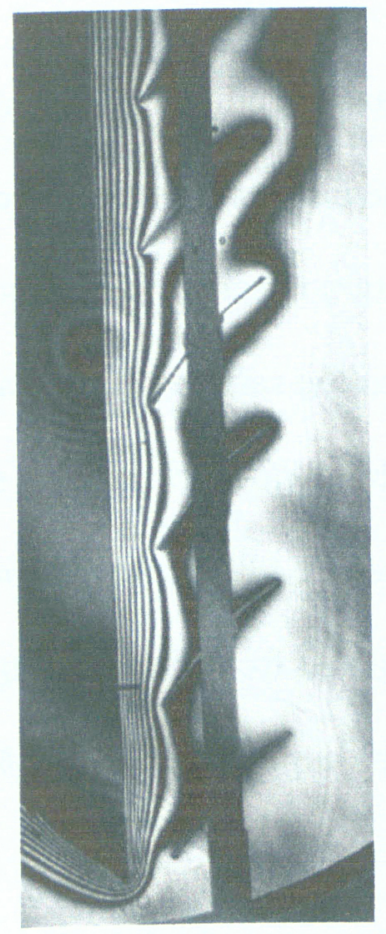

(a)

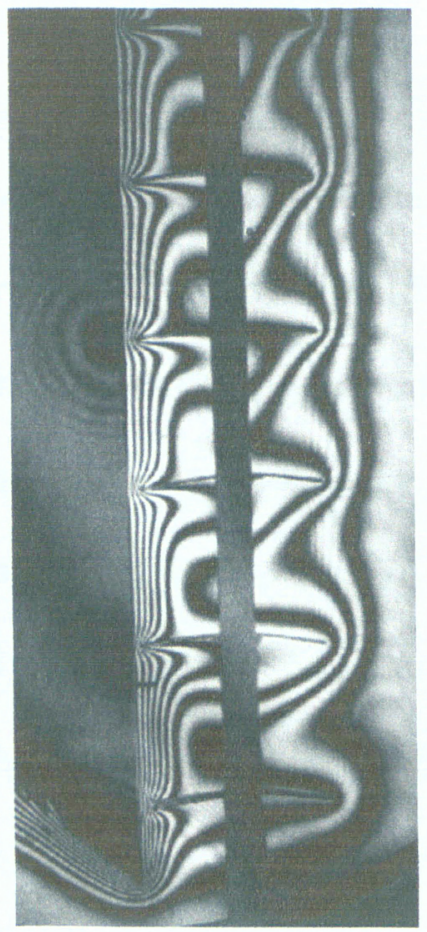

(b)
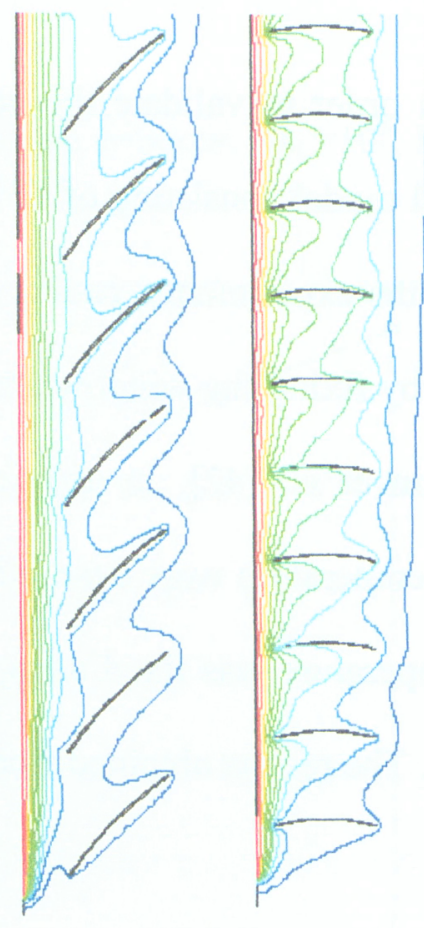

(c)

(d)

Figure 2.12 Comparison of numerical isotherms with interferogram of Machin et al. [42] for $\mathrm{b} / \mathrm{L}=0.066, \phi=0^{\circ}, 45^{\circ}, \mathrm{Ra}_{\mathrm{L}}=3.05 \times 10^{7}, \operatorname{Pr}=0.71$. 
It is interesting to note that the numerical solution is able to capture two eddies between the blind louvers that are rotating in opposite directions. The location of the larger eddy is closer to the indoor glazing surface and is likely caused by the hot air rising from the hot window side. The strength and speed of the hot air arising from the window side is higher than the buoyant air arising from the blind side. The difference between the strength of the buoyant air produces the large eddy, which is forced to rotate in clockwise direction. Once the large eddy is established, it promotes the creation of the smaller eddy. The smaller eddy rotates in the counter clockwise direction and is produced due to the combined effect of the larger eddy, the louver curvature and the flow arising from the indoor side.

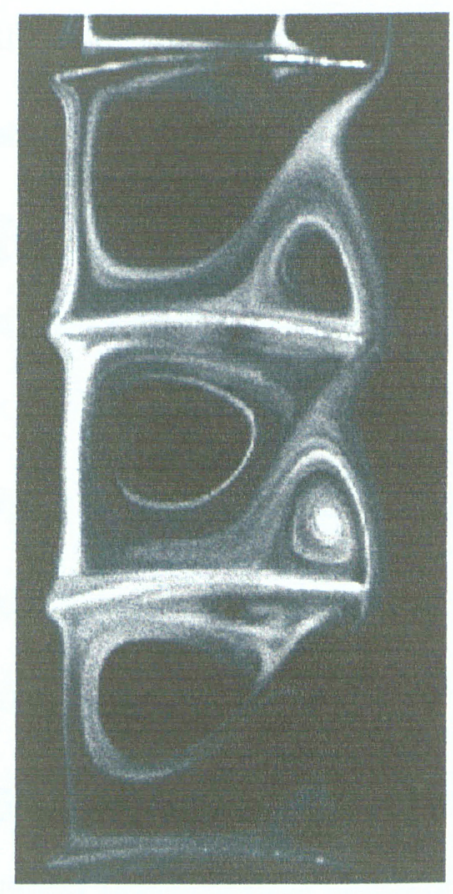

(a)

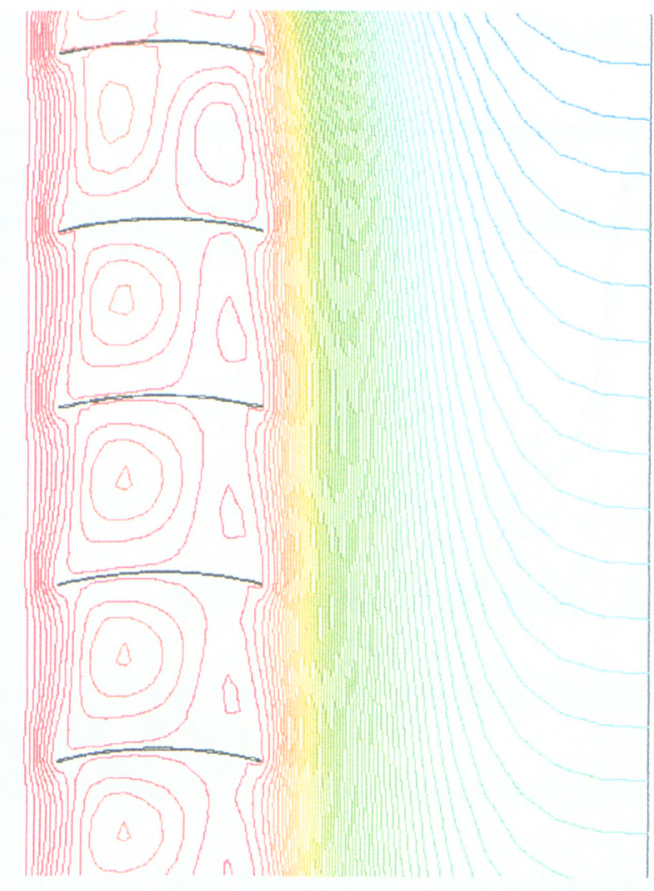

(b)

Figure 2.13. Comparison of numerical stream functions with flow visualization of Machin et al. [42] for $\mathrm{b} / \mathrm{L}=0.066, \phi=0^{\circ}, \mathrm{Ra}_{\mathrm{L}}=3.05 \times 10^{7}, \operatorname{Pr}=0.71$. 
A quantitative comparison has been made in Figure 2.14 between the numerical local convective Nusselt number distribution on the window and the experimental results of Machin et al. [42]. Clearly, the numerical predictions are in good agreement with the experimental convective Nusselt number for a louver angle of $0^{\circ}$ at a Rayleigh number of $3.05 \times 10^{7}$. It is interesting to note at each louver location a peak in the convection Nusselt number occurs. This peak is a result of higher fluid velocities due to reduction in the flow area between the louver tip and the window. The largest difference between the experimental data and numerical predictions occurs at the top and bottom ends where end effects are expected to be present. This figure also shows the convective heat transfer distribution on the window with the blind louvers represented by a single average temperature.

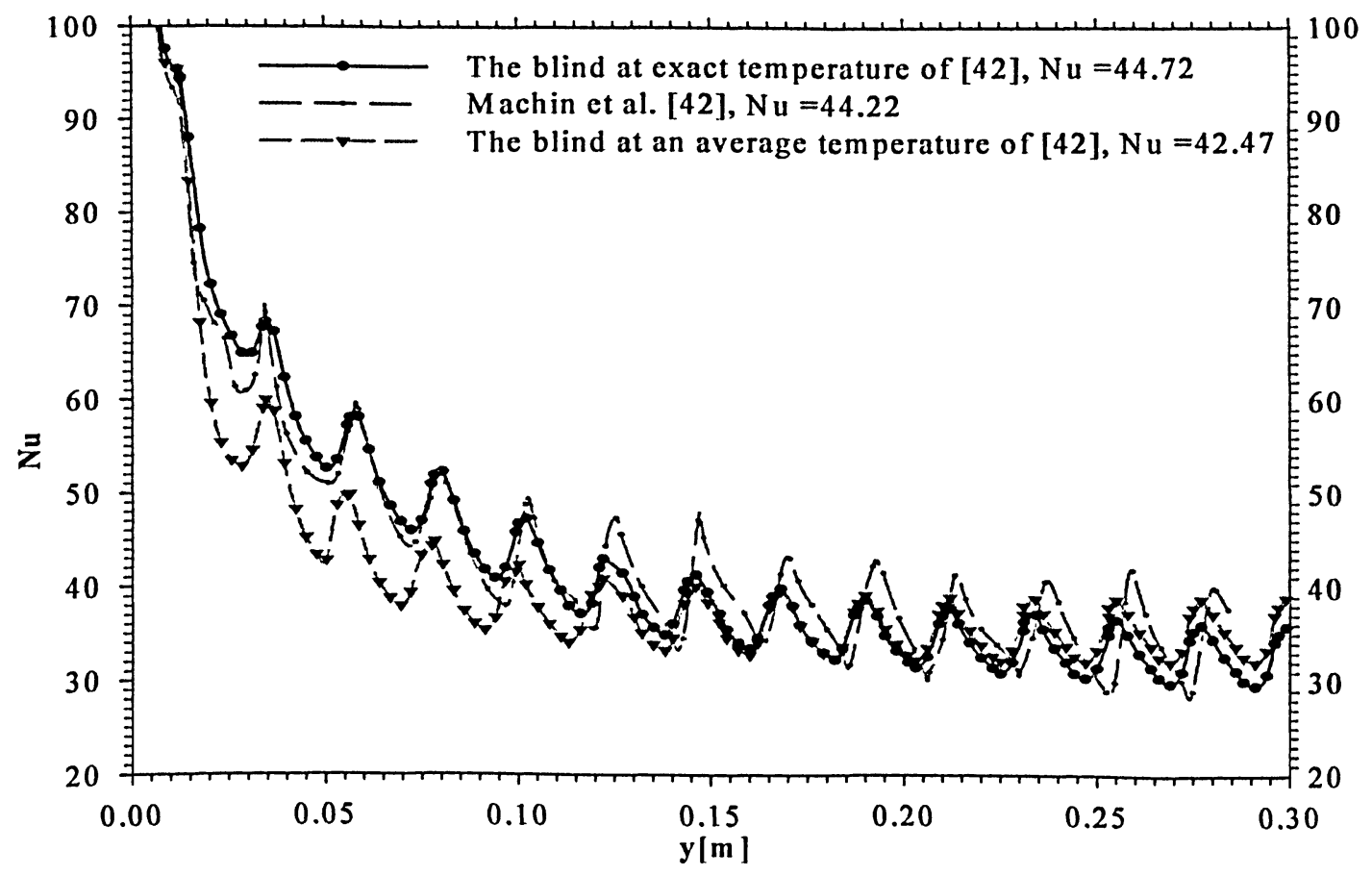

Figure 2.14 Comparison of local Convective Nusselt Number Distribution with the Experimental data [42] for $\phi=0^{\circ}, \mathrm{Ra}_{\mathrm{L}}=3.05 \times 10^{7}, \mathrm{~b} / \mathrm{L}=0.066$. 
It is interesting to note that when the blind louvers are represented with an average blind temperature, the results agree well with the experimental results of Machin et al. [42]. Some differences are noted near the lower edge region of the window where the convective heat transfer for the average blind temperature case is lower than the experimental results [42]. This difference is expected because the actual blind temperature near the leading edge is lower than the average blind temperature. When the average blind temperature boundary condition is imposed on the first few louvers, the local cooling near the leading edge is reduced. It is important to note that the average convective heat transfer rate for all cases were within $5 \%$ of those of Machin et al. [42]. Considering the small differences in the convective heat transfer rates, it was concluded that the blind louvers represented with an average temperature would produce results acceptable for most window design purposes. For this reason, in subsequent modeling, the blind louvers were represented by an average blind temperature. It should be noted that similar results were obtained for a louver angle of $45^{\circ}$. For the sake of brevity, these results are not included in this thesis.

\subsubsection{Far Field Boundary and Grid Sensitivity Study}

In order to ensure the accuracy of the finite element solution, the size of the computational domain should be chosen such that the numerical solution is independent of the grid density and the locations of the outer boundaries. In a previous numerical study, Phillips et al. [44] conducted detailed grid sensitivity and far field boundary studies for an indoor glazing and Venetian blind assembly. This study proved to be an excellent source for the grid density and the far field boundary selection for the problem under study. In this study [44], the computational domain consisted of a vertical isothermal surface with ten blind louvers. Phillips 
et al. [44] varied the number of nodes within the computational domain from 14421 to 29391 and compared the local and average Nusselt number distributions. They noticed that slight numerical instabilities existed for the coarse grid. The numerical instability existed near the tip of the louvers because there were not enough nodes to pick up the large changes occurring in the temperature and velocity. However, the numerical instabilities were not present for the fine grid consisting of 29391 nodes because the grid density was sufficient. Phillips et al. [44] also noticed that despite the slight numerical instabilities, both grids produced almost the same results. The average convective Nusselt numbers for the coarse and fine grid differed by only $0.5 \%$. Based on this comparison, they decided to use the coarse grid with 14421 nodes because it reduced the computation time.

Phillips et al. [44] conducted the boundary study on the computational domain by moving the flow entrainment and top exit boundaries away from the isothermal surface. They carefully added extra nodes in the extended boundaries such that the boundary change was the only variable that could affect the results. They found that any changes in the local and average Nusselt number distributions due to the extension of entrainment and exit boundaries beyond certain locations were minimal. For an isothermal vertical surface of length $22 \mathrm{~cm}$, the location of the appropriate flow entrainment boundaries were approximately $5.5 \mathrm{~cm}$ away from the isothermal surface. Similarly, the top flow exit boundary was approximately $3.3 \mathrm{~cm}$ away from the isothermal surface.

In the current study, the computational domain is very similar to that of Phillips et al. [44]. Therefore, the numerical work of Phillips et al. [44] is used as a general guideline for the 
selection of grid density and the computational domain boundaries. However, the grid and far field boundary sensitivity studies are performed to confirm that the numerical solutions are independent of the grid density and the locations of the outer boundaries. The present numerical model consists of an indoor glazing surface with 29 blind louvers. For this study, the following variables were held constant:

$$
\begin{aligned}
& \mathrm{d} / \mathrm{L}=0.012 \mathrm{~mm} \\
& \phi=0^{\circ} \\
& \mathrm{T}_{\mathrm{b}}^{*}=\frac{\left(\mathrm{T}_{\mathrm{b}}-\mathrm{T}_{\infty}\right)}{\left(\mathrm{T}_{\mathrm{w}}-\mathrm{T}_{\infty}\right)}=0.1
\end{aligned}
$$

In order to ensure grid density independence, the number of nodes within the computational domain was varied from 31660 to 61820 . A comparison of the average Nusselt number variation with the Rayleigh number for three different grid densities is presented in Figure 2.15. Clearly, the average convective heat transfer did not change significantly with the grid density. It should be noticed that doubling the number of nodes from 31660 to 61820 improved the results by less than $0.6 \%$. This study suggested that the coarse grid consisting of 31660 nodes would be sufficient to produce reliable results. However, it was decided to use a fine grid consisting of $45,000-55,000$ nodes because the blind tip-to-window spacing was varied in subsequent studies. When the blind tip-to-window spacing was changed, extra nodes were carefully added between the indoor glazing surface and the blind louvers such that the grid density did not change.

The far field boundary study was performed to confirm that the solution was independent of the location of the flow entrainment and exit boundaries. In this study, numerical solutions for 
two different locations of the flow entrainment and exit boundaries were obtained. The dimensionless locations of the outer boundaries for the test cases are listed below:

Case $1: \mathrm{R}^{*}=0.2, \mathrm{H}^{*}=0.15$

Case $2: \mathrm{R}^{*}=0.25, \mathrm{H}^{*}=0.2$

A comparison of the average Nusselt number variation with the Rayleigh number for the two test cases is presented in Figure 2.16. Clearly, the differences between the two numerical solutions are within less than $0.5 \%$. This shows that the smaller computational domain boundaries were sufficient to impose the appropriate ambient conditions and further extension of boundaries did not affect the solution. Based on these results, it was decided to use the smaller computational domain for the rest of study. 


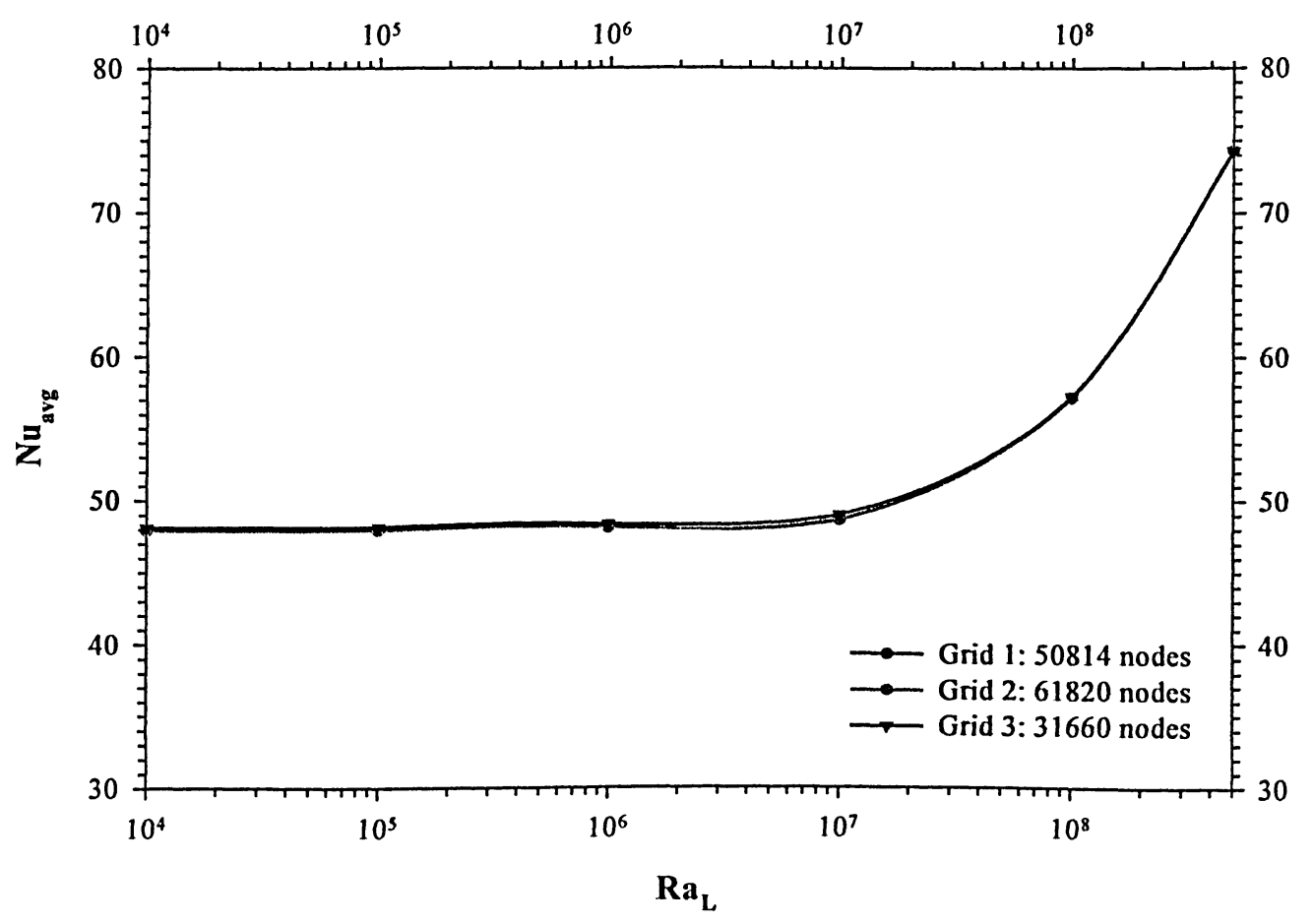

Figure 2.15 Comparison of the average Nusselt number of the indoor window glazing for three

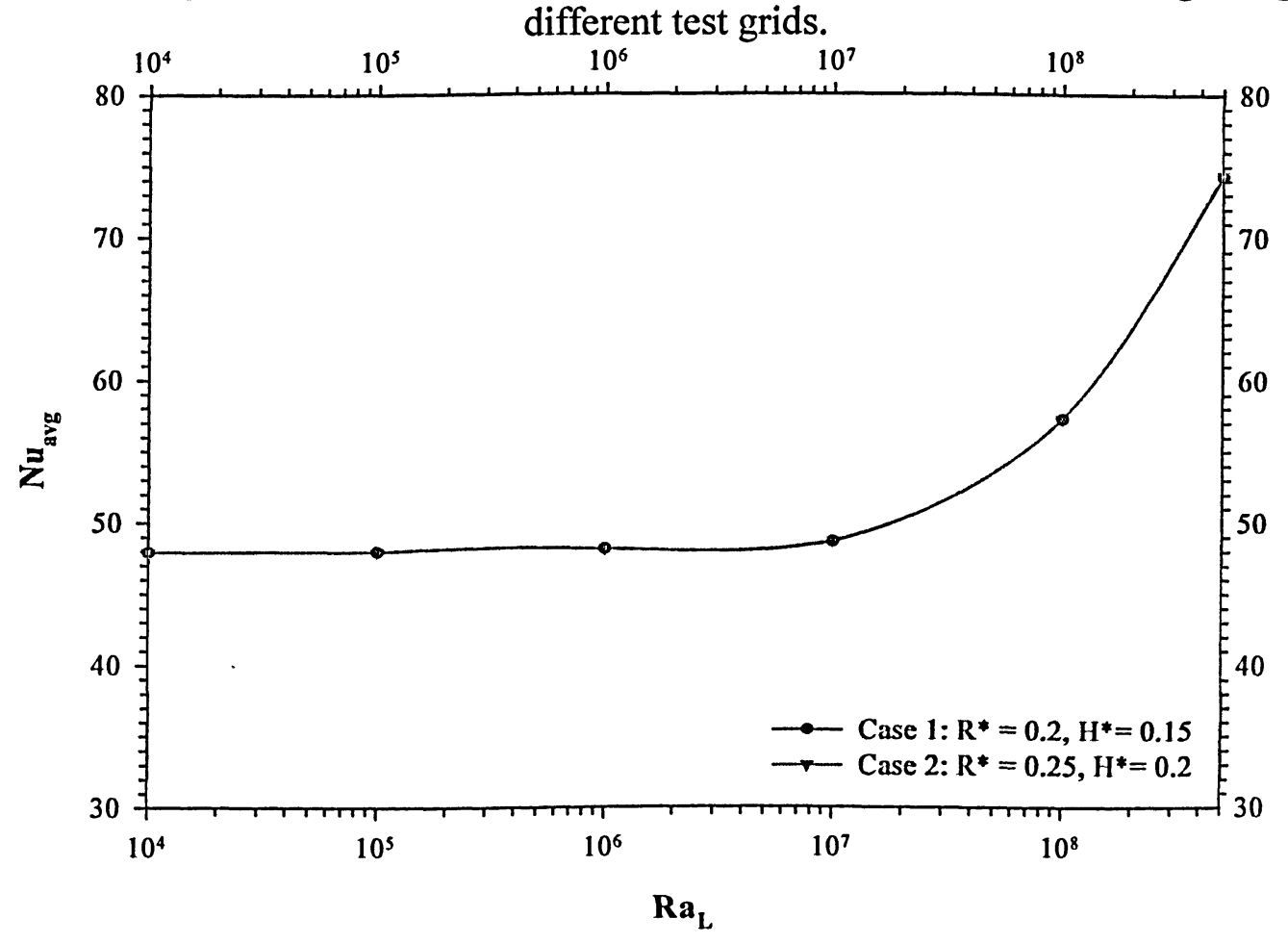

Figure 2.16 Comparison of the average convective Nusselt number on the indoor window glazing for far field test solutions. 


\section{CHAPTER 3: PRESENTATION OF RESULTS}

\subsection{INTRODUCTION}

In this chapter thermal interactions between a Venetian blind and a window will be examined. Numerical solutions will be presented to demonstrate the effect of a horizontal blind on the centre glass heat transmission through a window. In this study, a total of more than 500 individual solutions were obtained. It is very difficult to present all solutions covering the entire range of parameters. For this reason, only selected numerical solutions that highlight the effect of a Venetian blind on the energy performance of a window will be presented.

This chapter has been divided into two main sections. Finite element solutions for the 2-D free convection model of an indoor glazing surface and a Venetian blind are presented in Section 3.2. These solutions are obtained using the commercial CFD software FIDAP [53]. A sample of an input file for this software program is presented in Appendix-A. A sample of an output file for this software program is presented in Appendix-B. Selected numerical solutions pertaining to this study are also presented in tabular form in Appendix-C. The solutions for the 1-D conjugate heat transfer model of a window and blind system are presented in Section 3.3. These solutions were obtained using a C-code that was written specifically for this thesis. A sample of this program can be found in Appendix-D. All solutions are available from the author should the reader wish to obtain further numerical solutions from this study.

Finally, this chapter is concluded with the examination of the accuracy of the numerical solutions obtained using the present simplified 1-D thermal resistance model approach. The 
solutions for the 1-D thermal resistance model are compared with a 2-D, fully conjugate CFD model of a window and blind system. The conjugate (conduction/convection and radiation) finite volume model of a window and blind system, was developed by the author [54]. It should be noted that the finite volume (FV) study [54] is not a central part of this thesis and is only used for the purpose of comparison.

\subsection{PRESENTATION OF RESULTS PERTAINING TO THE FINITE ELEMENT FREE CONVECTION MODEL}

In this study, a 2-D convection model of an indoor glazing surface and blind system was developed. Finite element solutions were obtained to compute the convective heat transfer coefficients on the indoor glazing surface and the blind. The convective coefficients were computed for the following range of parameters:

Louver angle $\phi=0^{\circ}, 45^{\circ}, 90^{\circ}$

* Louver pitch ratio $\mathrm{W} / \mathrm{ps}=1.14$

* Dimensionless average blind temperature $\mathrm{T}_{\mathrm{b}}{ }^{*}=0.1-0.5$

- Rayleigh number $\mathrm{Ra}_{\mathrm{L}}=1 \times 10^{4}-5 \times 10^{8}$

* Prandtl number $\operatorname{Pr}=0.71$

* Blind tip-to-window spacing $\mathrm{d} / \mathrm{L}=0.012,0.043$

* 29 Louvers, $\mathrm{W} / \mathrm{L}=0.04$

The reader is reminded that the blind temperature $\left(\mathrm{T}_{\mathrm{b}}\right)$ was fixed to decouple radiation from convection. In the results that follow, some of the dimensionless blind temperatures $\left(\mathrm{T}_{\mathrm{b}}{ }^{*}\right)$ may correspond to a non-physical situation and some results may not be intuitive. It should be 
noted that in reality, the blind temperature will vary depending on the balance of radiant and convective heat transfer from the blind. The blind temperature corresponding to a physical situation will be determined using the 1-D solution procedure (given in Section 2.4).

\subsubsection{Effect of Rayleigh Number on the Convective Heat Transfer}

To understand the convective heat exchange between an indoor glazing surface and a blind, the effects of the strength of the convective flow must be examined. In this section, the effect of Rayleigh Number on the convective heat transfer from the indoor glazing surface and the Venetian blind is examined. The effect of Rayleigh number on the local blind convective heat transfer is also presented. The effect of Rayleigh number on the local heat transfer distributions on the indoor glazing surface is not presented because this effect has been discussed in details in $[42,44]$. In current study a wide range of geometric configurations are studied. However, results in this section are presented for the louver angle $\phi=0^{\circ}$ and blind tipto-window spacing $\mathrm{d} / \mathrm{L}=0.043,0.012$.

It is well known that the magnitude of the free convective heat transfer rates strongly depends on the Rayleigh number. In this section, the effect of Rayleigh number on the convective heat transfer rate from the indoor glazing surface and the Venetian blind is examined. The first quantity to be examined is the average convective Nusselt number for the indoor glazing surface that is shown in Figure 3.1. In this figure, Ostrach's [19] similarity solution for free convection from a vertical plate is also plotted. The Nusselt numbers corresponding to Ostrach [19], indicate the convective heat transfer from an indoor glazing 
surface of an unshaded window. Any differences between the present solution and the Ostrach [19] solution are attributed to the interaction of the blind with the temperature and flow fields.

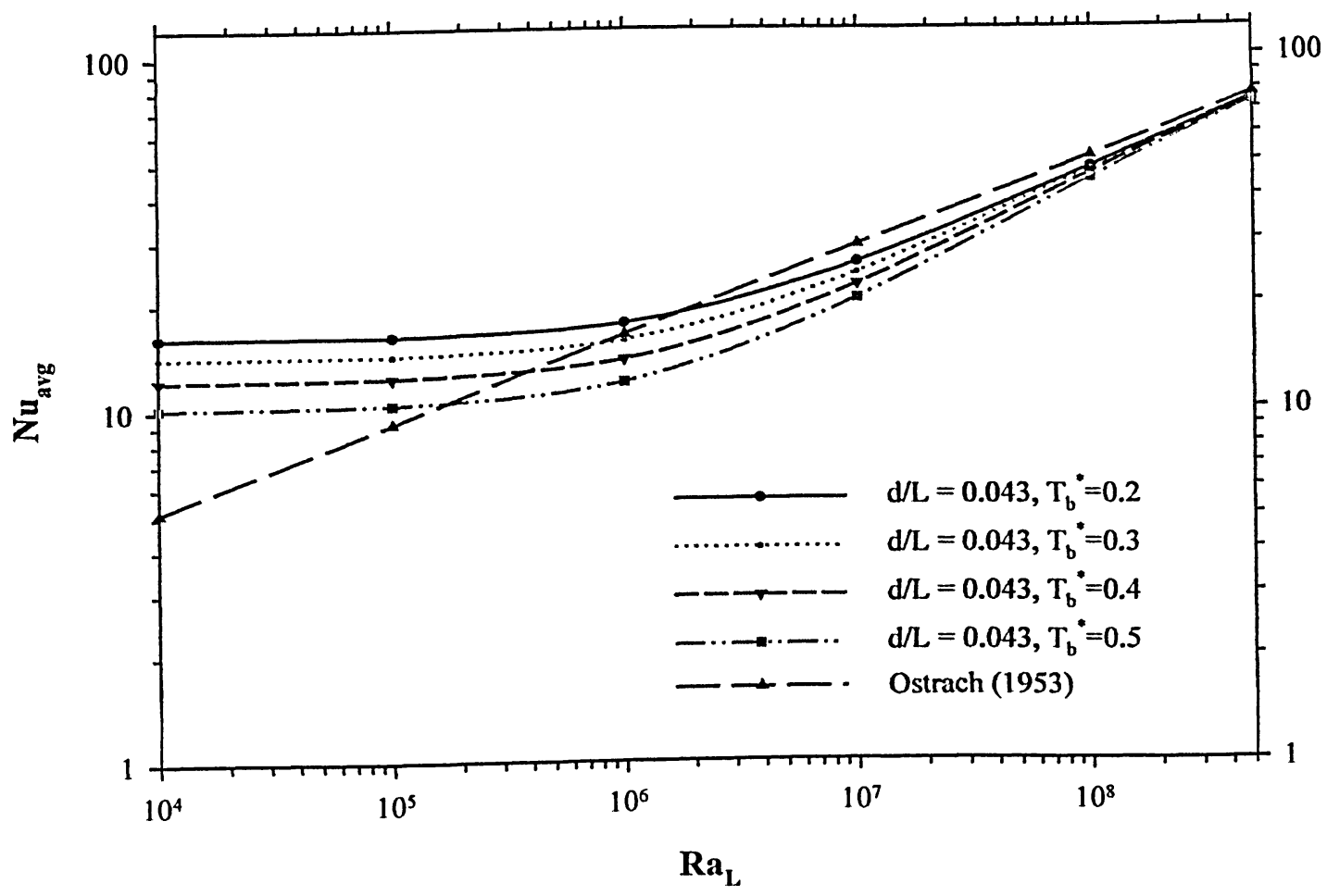

Figure 3.1 Variation of the average indoor glazing surface Nusselt number with Rayleigh number, $\mathrm{d} / \mathrm{L}=0.043$, Louver angle $\phi=0^{\circ}$.

In Figure 3.1, the blind tip-to-window spacing has been fixed to $d / L=0.043$. The sensitivity of the convective heat transfer from the indoor glazing surface to the Rayleigh number can be described by two regimes. The first regime is characterized with the weak dependence of the convective Nusselt number on the Rayleigh number $\operatorname{Ra}_{L} \leq 10^{6}$. The second regime is beyond $\mathrm{R}_{\mathrm{L}} \approx 10^{6}$ and it is characterized by Rayleigh number dependent convective Nusselt numbers. In the first regime, heat from the indoor glazing surface to the fluid is mainly transferred by conduction, and the constant magnitude of the convective Nusselt number indicates weak advection effects. In the second regime, the convective Nusselt number 
increases with the Rayleigh number indicating that buoyancy driven flow has a significant effect on the heat transfer rate.

It is interesting to note that the presence of the blind has a significant effect on the convective heat transfer from the indoor glazing surface for the Rayleigh number between $\mathrm{Ra}_{\mathrm{L}}=10^{4}$ and $10^{7}$. The dimensionless blind temperature has a strong influence on the heat transfer. The indoor glazing surface Nusselt number is significantly different than Ostrach's solution [19]. However, beyond $\mathrm{Ra}_{\mathrm{L}}=10^{7}$, the influence of the blind decreases and the convective heat transfer from the indoor glazing surface asymptotically approaches the Ostrach's similarity solution [19]. In order to understand the major differences between the conduction and the convection dominated regime, one can examine the temperature and flow fields corresponding to different Rayleigh numbers, which are presented in Figure 3.2 and Figure 3.3, respectively.

The first observation to be made regarding Figure 3.2 is the location of isotherms at different Rayleigh number. Notice that at low Rayleigh numbers, 3.2(a) $\operatorname{Ra}_{\mathrm{L}}=10^{5}$ and 3.2(b) $\mathrm{Ra}_{\mathrm{L}}=10^{6}$, thermal gradients near the window surface are smaller than at high Rayleigh numbers, $R a_{L} \geq 10^{8}$. The examination of the flow field shown in Figure 3.3 reveals that at a low Rayleigh number, 3.3(a) $\mathrm{Ra}_{\mathrm{L}}=10^{5}$, the blind is submerged in the warm air adjacent to the indoor glazing surface and there is a very little movement of air. The strength of convective flow corresponding to $3.3(\mathrm{~b}) \mathrm{Ra}_{\mathrm{L}}=10^{6}$ is also weak, since there is a very little movement of air, which implies that heat is not advected away from the window surface. Instead, the heat from the indoor glazing surface is transferred to the fluid and the blind boundaries mainly through the conductive mode of heat transfer. For this reason, the dimensionless blind temperature has 


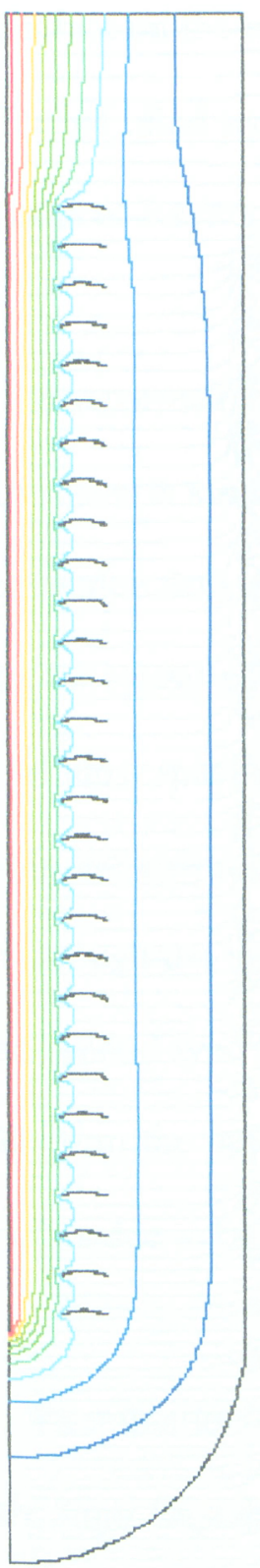

(a)

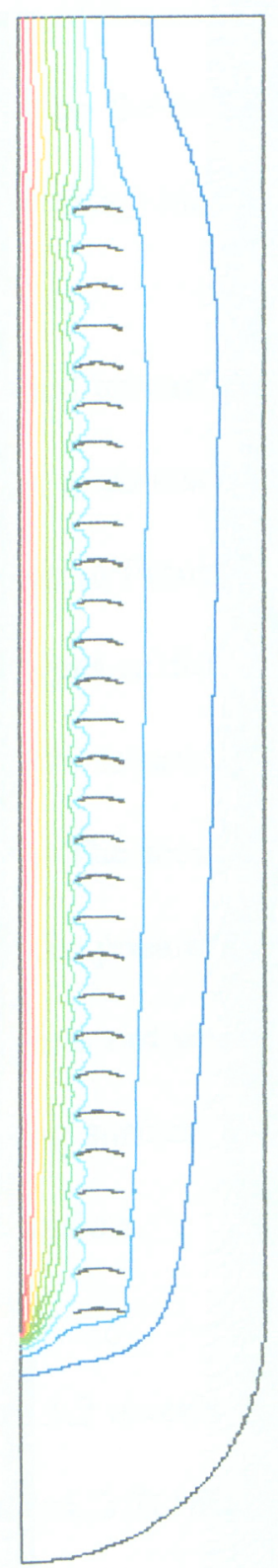

(b)

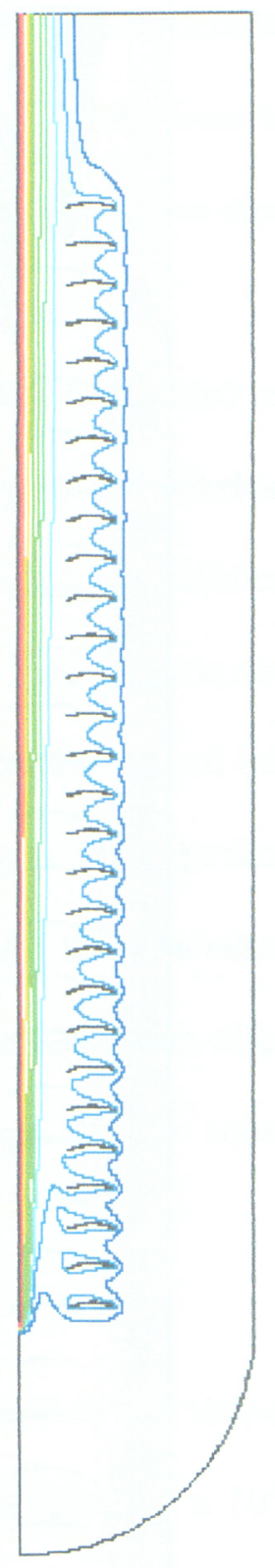

(c)

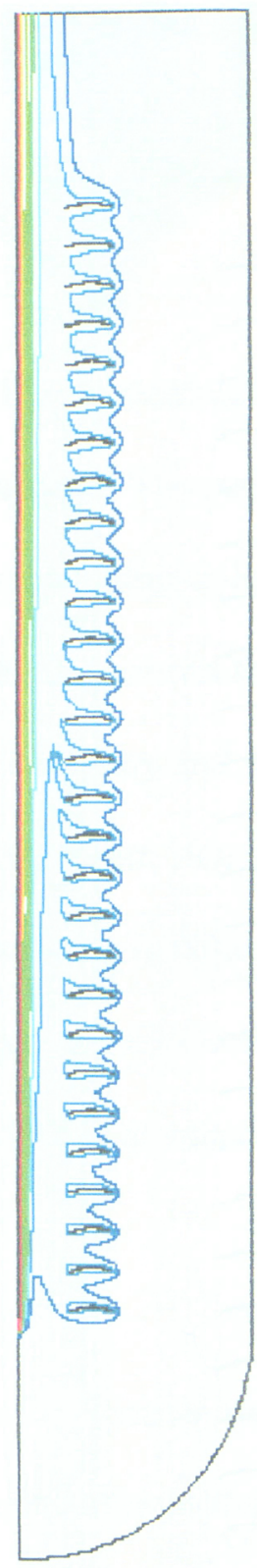

(d)

Figure 3.2 Effect of Rayleigh number on isotherms for $\phi=0^{\circ}$, blind tip-to-window spacing $d / L$ $=0.043$, dimensionless blind temperature $\mathrm{T}_{\mathrm{b}}{ }^{*}=0.3,(\mathrm{a}) \mathrm{Ra}_{\mathrm{L}}=10^{5},(\mathrm{~b}) \mathrm{Ra}_{\mathrm{L}}=10^{6},(\mathrm{c}) \mathrm{Ra}_{\mathrm{L}}=10^{8}$, (d) $\mathrm{Ra}_{\mathrm{L}}=5 \times 10^{8}$ (see Appendix-H for legend). 


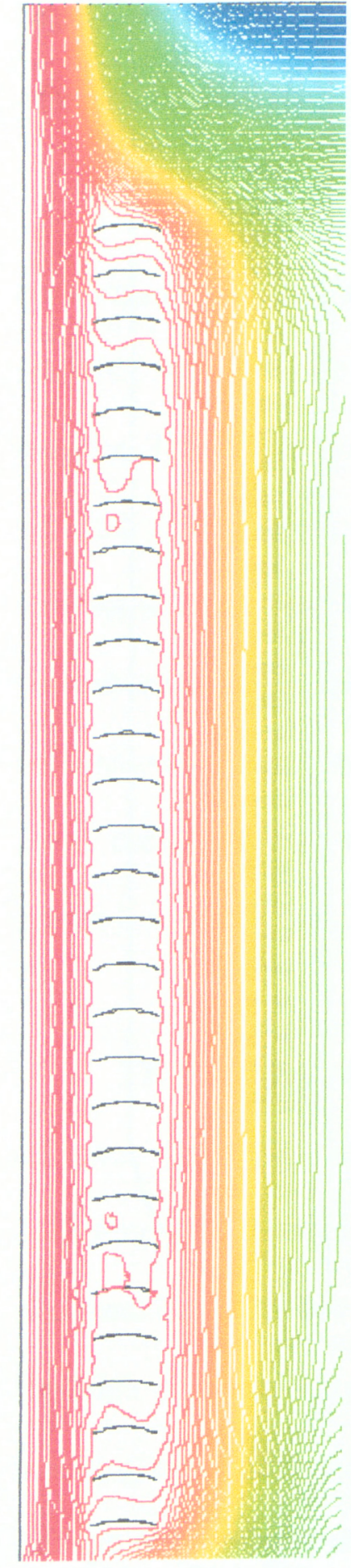

(a)

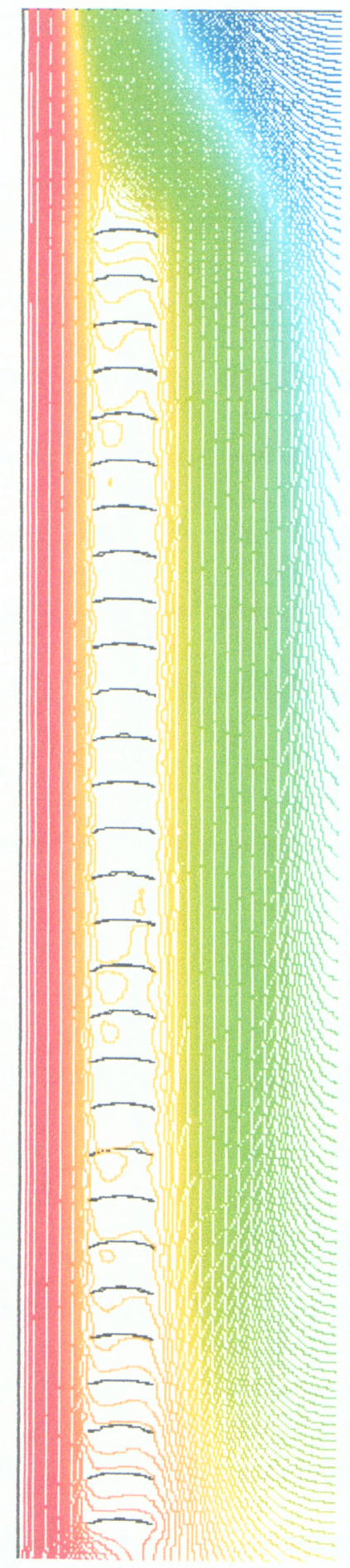

(b)

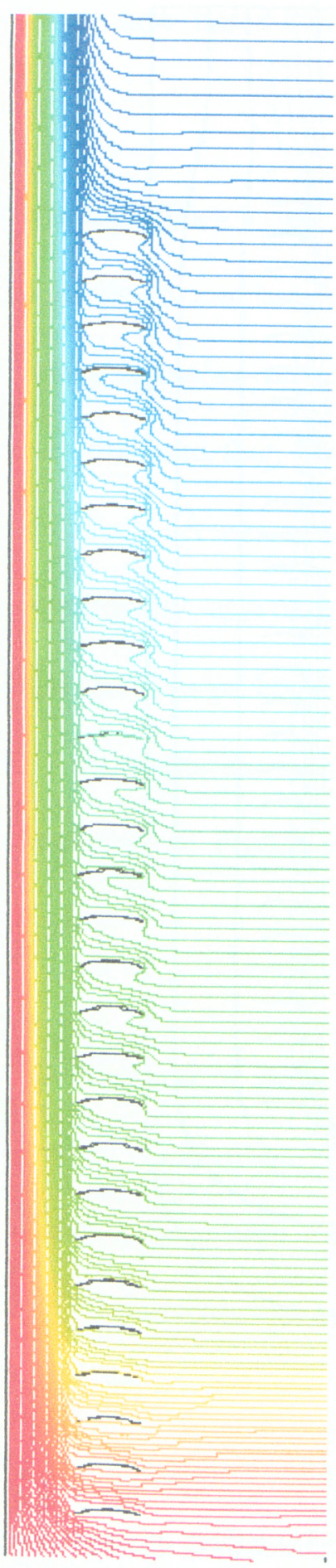

(c)

Figure 3.3 Effect of Rayleigh number on the flow field for $\phi=0^{\circ}$, blind tip-to-window spacing $\mathrm{d} / \mathrm{L}=0.043$, dimensionless blind temperature $\mathrm{T}_{\mathrm{b}}{ }^{*}=0.3$, (a) $\mathrm{Ra}_{\mathrm{L}}=10^{5}$, (b) $\mathrm{Ra}_{\mathrm{L}}=10^{6},(\mathrm{c}) \mathrm{Ra}_{\mathrm{L}}=5 \times 10^{8}$ (see Appendix-H for legend). 
strong effect on the magnitude of the window average Nusselt number. It should be noted that the effect of blind temperature on the convective heat transfer from the indoor glazing surface diminishes as Rayleigh number $\left(\mathrm{Ra}_{\mathrm{L}}\right)$ increases, i.e., as convection strengthens.

Now attention is directed toward the convection dominated regime. In this regime, the air movement is strong enough to convect heat away from the window surface. The strength of the convective flow can be seen in Figure 3.3(c). The velocity field corresponding to $R a_{L}=5 x$ $10^{8}$ can be classified as two types of flow. The first type of flow develops between the blind tip-to-window spacing. This flow is mainly drawn from the curved inlet boundary and the fluid moves in the upward direction. The second type of flow develops from the room side and it is drawn through the louvers. In the present case, the blind tip-to-window spacing is large enough and the second type of flow does not seem to have a significant effect on the convective heat transfer from the indoor glazing surface. It should be noted that convective heat transfer from the blind is due to both types of flow.

Examination of Figure 3.2 reveals that the locations and shapes of isotherms associated with the high Rayleigh numbers, 3.2(c) $\mathrm{Ra}_{\mathrm{L}}=10^{8}, 3.2(\mathrm{~d}) \mathrm{Ra}_{\mathrm{L}}=5 \times 10^{8}$, are different than those corresponding to low Rayleigh numbers. At high Rayleigh numbers, the isotherms are drawn closer to the window and thermal interaction between the indoor glazing surface and the blind is greatly reduced. In fact, the indoor glazing heat affected zone looks almost identical to the thermal boundary layer near an isothermal vertical flat plate. It has been observed that at high Rayleigh numbers, the presence of the blind has negligible effect on the temperature and flow 
field near the window surface. For this reason, the convective heat transfer from the window is independent of the blind temperature.

The second heat transfer quantity to be examined is the average convective transfer rates from the blind surface that are shown in Figure 3.4. In this figure, the effect of Rayleigh number on the average convective heat transfer from the blind is illustrated. Notice that the average blind Nusselt number corresponding to the low Rayleigh number, i.e., between $\mathrm{Ra}_{\mathrm{L}}=$ $10^{4}$ to $\mathrm{Ra}_{\mathrm{L}}=10^{6}$, shows weak dependence on the Rayleigh number. In this range of Rayleigh numbers, the flow is not strong enough to convect heat away from the blind and the blind is completely submerged in the window heat affected zone. The negative average convective heat

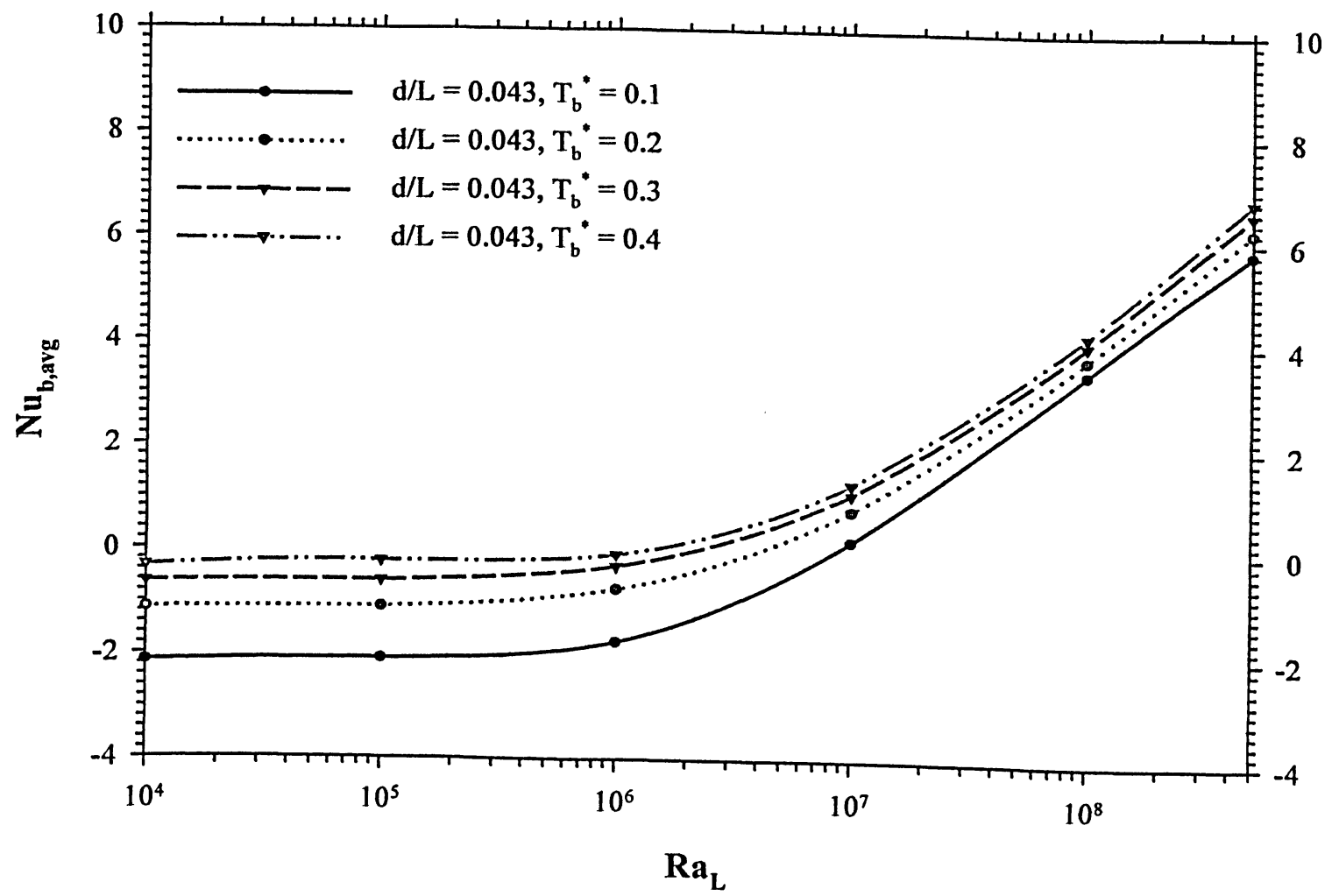

Figure 3.4 Variation of the average convective heat transfer rate from the blind with Rayleigh number, $\mathrm{d} / \mathrm{L}=0.043$, Louver angle $\phi=0^{\circ}$ 
transfer rates indicate that the blind is being heated through convection. As the Rayleigh number is increased beyond $\mathrm{Ra}_{\mathrm{L}}=10^{6}$, the strength of flow increases and the window heat affected zone sweeps closer to the window surface. Therefore, the blind begins to cool by convection and the average blind Nusselt number shows strong dependence on the Rayleigh number.

It should be noticed that the average blind Nusselt numbers show strong dependence on the dimensionless blind temperature for the entire range of Rayleigh numbers. In the conduction dominated regime, the maximum magnitude of the average blind Nusselt number corresponds to the lowest dimensionless blind temperature of $\mathrm{T}_{\mathrm{b}}{ }^{*}=0.2$ and the minimum magnitude corresponds to the highest dimensionless blind temperature of $T_{b}{ }^{*}=0.5$. It is interesting to note that in the convection dominated regime, i.e., beyond $\mathrm{Ra}_{\mathrm{L}} \approx 10^{7}$, the maximum magnitude of the average blind Nusselt number corresponds to the highest dimensionless blind temperature of $\mathrm{T}_{\mathrm{b}}{ }^{*}=0.5$, and the minimum magnitude corresponds to the lowest dimensionless blind temperature of $\mathrm{T}_{\mathrm{b}}{ }^{*}=0.2$. It should be noted that for both conduction and convection dominated regimes, the maximum heat transfer rates from/to the blind correspond to the maximum temperature difference between the blind and the surrounding air.

The third heat transfer quantity to be examined in this section is the local convective heat transfer coefficient distribution on the blind surface that is shown in Figure 3.5. In this figure, the dimensionless blind temperature has been fixed to $T_{b}{ }^{*}=0.3$. It can be seen that the blind Nusselt number corresponding to low Rayleigh numbers, i.e., $\operatorname{Ra}_{\mathrm{L}}=10^{4}$ and $\mathrm{Ra}_{\mathrm{L}}=10^{5}$, are almost constant. Furthermore, the convective heat transfer rates from all louvers except the 
$1^{\text {st }}$ and $29^{\text {th }}$ louvers fall on a single curve. This confirms that the heat is being transferred mainly through the conductive mode of heat transfer. An interesting observation can be made regarding the local convective coefficients on the $1^{\text {st }}$ and $29^{\text {th }}$ louver. Notice, the minimum magnitude of the local convective heat transfer is associated with the $1^{\text {st }}$ louver and the maximum magnitude corresponds to the $29^{\text {th }}$ louver. This is due to the fact that the $1^{\text {st }}$ louver resides in the cold air and the $29^{\text {th }}$ louver resides in the hot plume of lower blinds. Therefore, the convective heat transfer rates from the $1^{\text {st }}$ and $29^{\text {th }}$ louver are minimum and maximum, respectively.

This figure also shows that when the convective flow strengthens, i.e., beyond $\mathrm{Ra}_{\mathrm{L}}=$ $10^{7}$, the local convective heat transfer rate from the blind increases with the Rayleigh number.

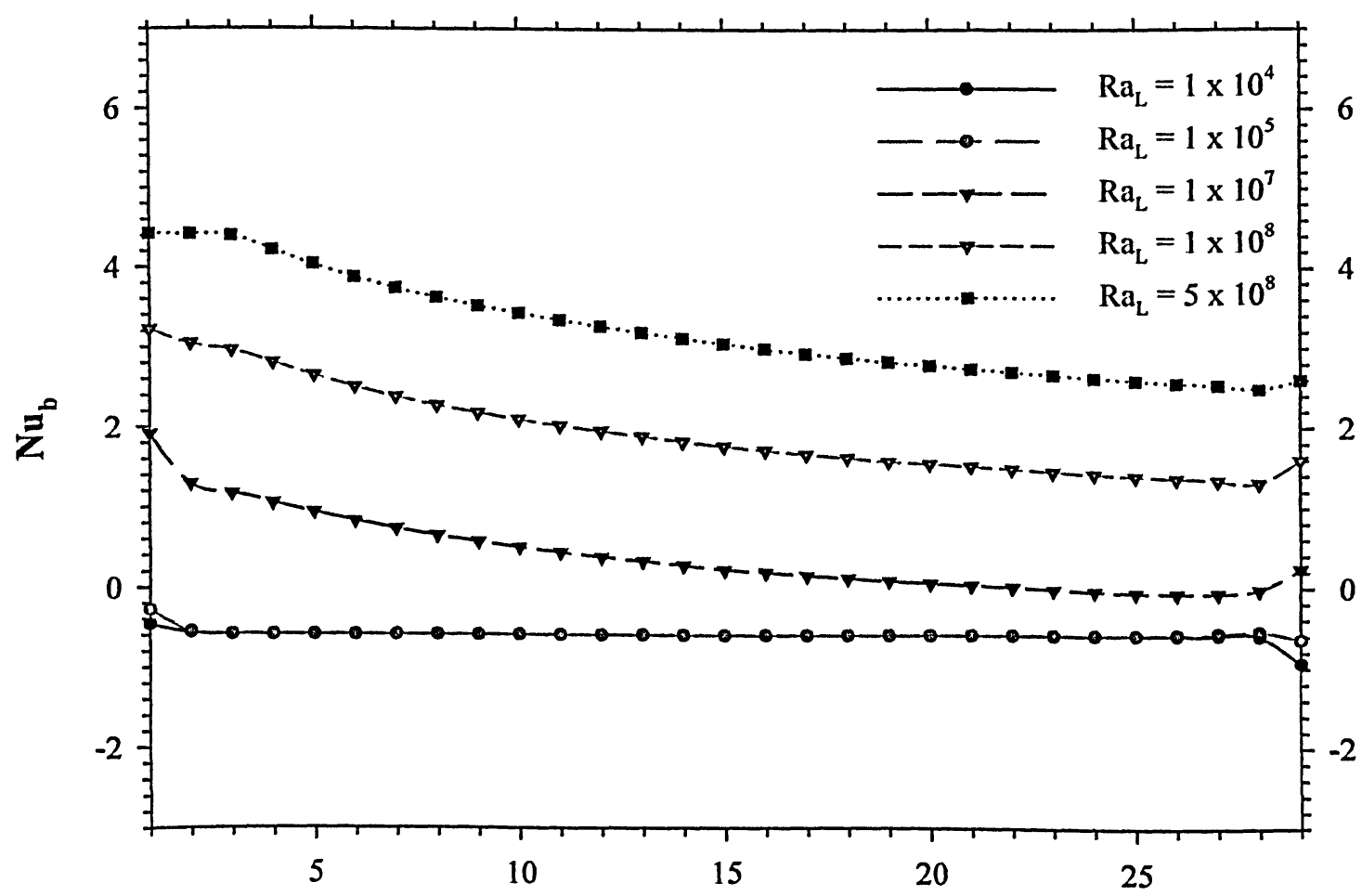

Louver Number

Figure 3.5 Variation of the local blind Nusselt number with Rayleigh number, $d / L=0.043$, dimensionless blind temperature $\mathrm{T}_{\mathrm{b}}{ }^{*}=0.3$, Louver angle $\phi=0^{\circ}$. 
At high Rayeigh numbers, the maximum Nusselt numbers correspond to the louvers that are placed near the leading edge of the window. The local convective heat transfer rates from the blind continue to decrease for louvers farther away from the leading edge of the window. It should be noticed that the convective heat transfer rate associated with the $29^{\text {th }}$ louver is greater than the $28^{\text {th }}$ louver. This is likely caused by the presence of the "end effect". The end effect induces additional flow of cold ambient air toward the top louver, resulting in additional cooling.

So far, the effect of Rayleigh number on the convective heat transfer has been examined for a blind tip-to-window spacing of $d / L=0.043$. It was observed that increasing the Rayleigh number decreased the interference of the blind with the indoor glazing heat affected zone. Now, attention will be directed towards the effect of Rayleigh number on the convective heat transfer when the blind is placed at a small blind tip-to-window spacing of $d / L=0.012$. An examination of this effect will help one to understand some differences in the key energy performance indices corresponding to a complete window and Venetian blind assembly for summer and winter weather conditions.

In Figure 3.6, the average convective Nusselt number on the indoor surface has been plotted as a function of the Rayleigh number. As previously discussed, the flat portion of the convective Nusselt number curves is associated with the conduction dominated regime. The average Nusslet number begins to show dependence on the Rayleigh number beyond $\mathrm{Ra}_{\mathrm{L}} \approx 10^{7}$ and it increases with the Rayleigh number. At high Rayleigh numbers, the comparison of the 
present solution with that of Ostrach [19] indicates that the blind is reducing the convective heat transfer from the indoor glazing surface by inhibiting the flow near the window.

The dependence of the average Nusselt number on the dimensionless blind temperature is an indication of the interference of the blind with the window heat affected zone. The interaction of the blind with the temperature and the velocity field can be seen in Figure 3.7. In this figure, the dimensionless blind temperature and the Rayleigh number is fixed to $T_{b}{ }^{*}=0.3$ and $\operatorname{Ra}_{\mathrm{L}}=5 \times 10^{8}$, respectively. Clearly, the blind louvers can be seen to disrupt the convective heat transfer from the indoor glazing surface. The blind disrupts the boundary layer flow that tends to increase the importance of conduction effects. The cellular flow that exists between many louvers is an indication of the interference between the louvers and the warm air rising from the indoor glazing surface.

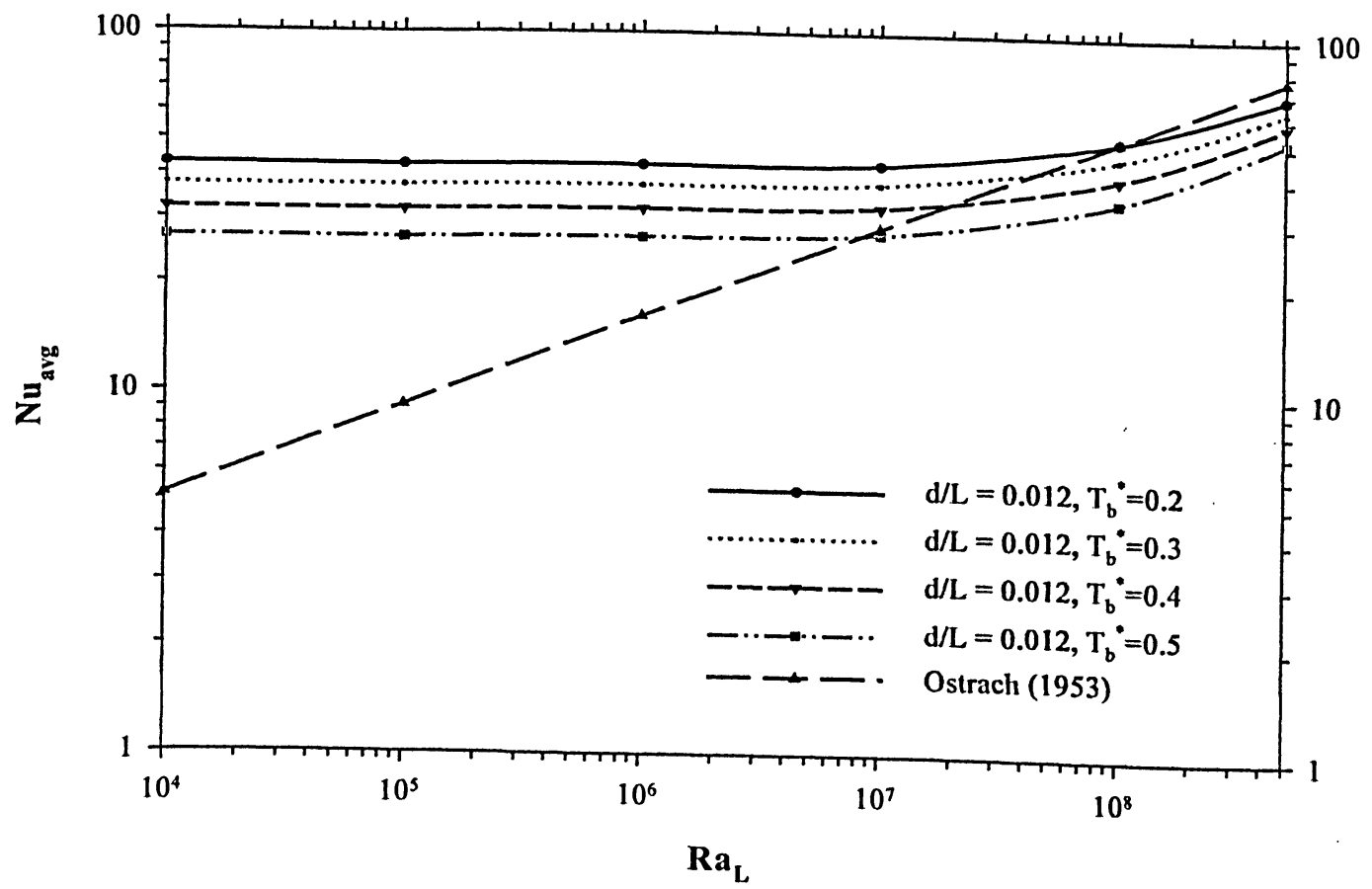

Figure 3.6 Variation of the average indoor glazing surface Nusselt number with Rayleigh number, $\mathrm{d} / \mathrm{L}=0.012$, Louver angle $\phi=0^{\circ}$. 


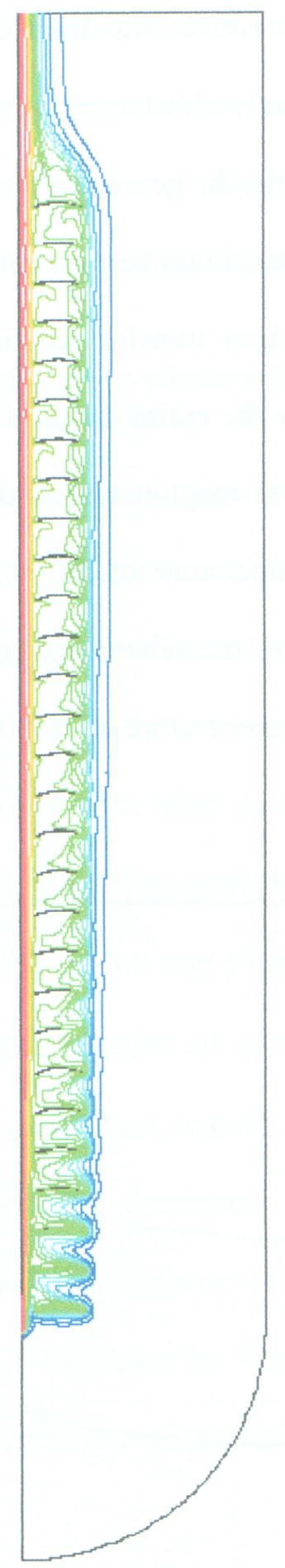

(a)

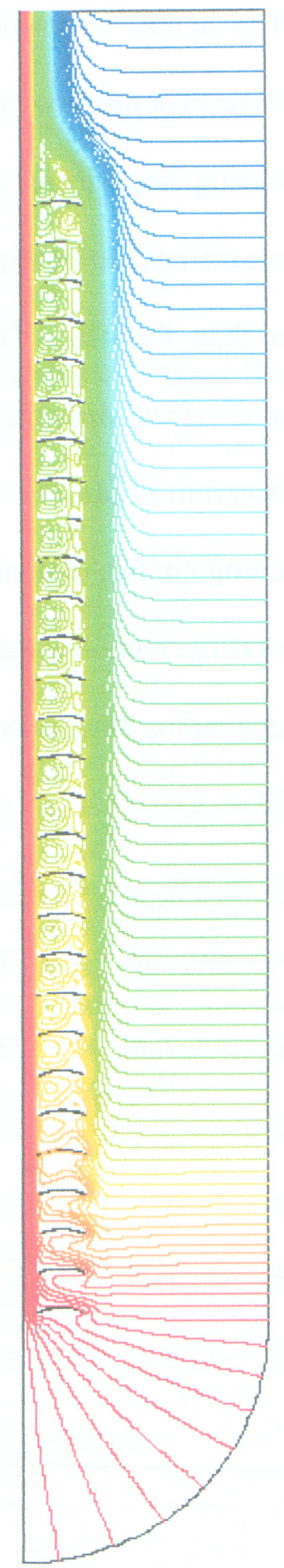

(b)

Figure 3.7 Interference of the blind with (a) the temperature and (b) the velocity fields for $\phi=0^{\circ}$, blind tip-to-window spacing $\mathrm{d} / \mathrm{L}=0.012$, dimensionless blind temperature $\mathrm{T}_{\mathrm{b}}{ }^{*}=0.3$, Rayleigh number $\mathrm{Ra}_{\mathrm{L}}=5 \times 10^{8}$, (see Appendix-H for legend). 
Figure 3.8 is a plot of the average blind convective heat transfer coefficients. The negative and positive magnitude of the average convective heat transfer coefficients indicate that the blind is being heated and cooled, respectively. In general, the average blind heat transfer coefficients are not highly sensitive to the Rayleigh number, except when the Rayleigh number is greater than $\mathrm{Ra}_{\mathrm{L}} \approx 10^{8}$. The average blind heat transfer coefficients show strong dependence on the dimensionless blind temperature for the entire range of Rayleigh numbers. An interesting observation can be made regarding the magnitudes of the average Nusselt number corresponding to the dimensionless blind temperature of $\mathrm{T}_{\mathrm{b}}{ }^{*}=0.2$ and $\mathrm{T}_{\mathrm{b}}{ }^{*}=0.3$ that appear to be decreasing with the Rayleigh number. On the other hand, the convective heat transfer rates corresponding to the dimensionless blind temperature of $T_{b}{ }^{*}=0.5$ appear to be

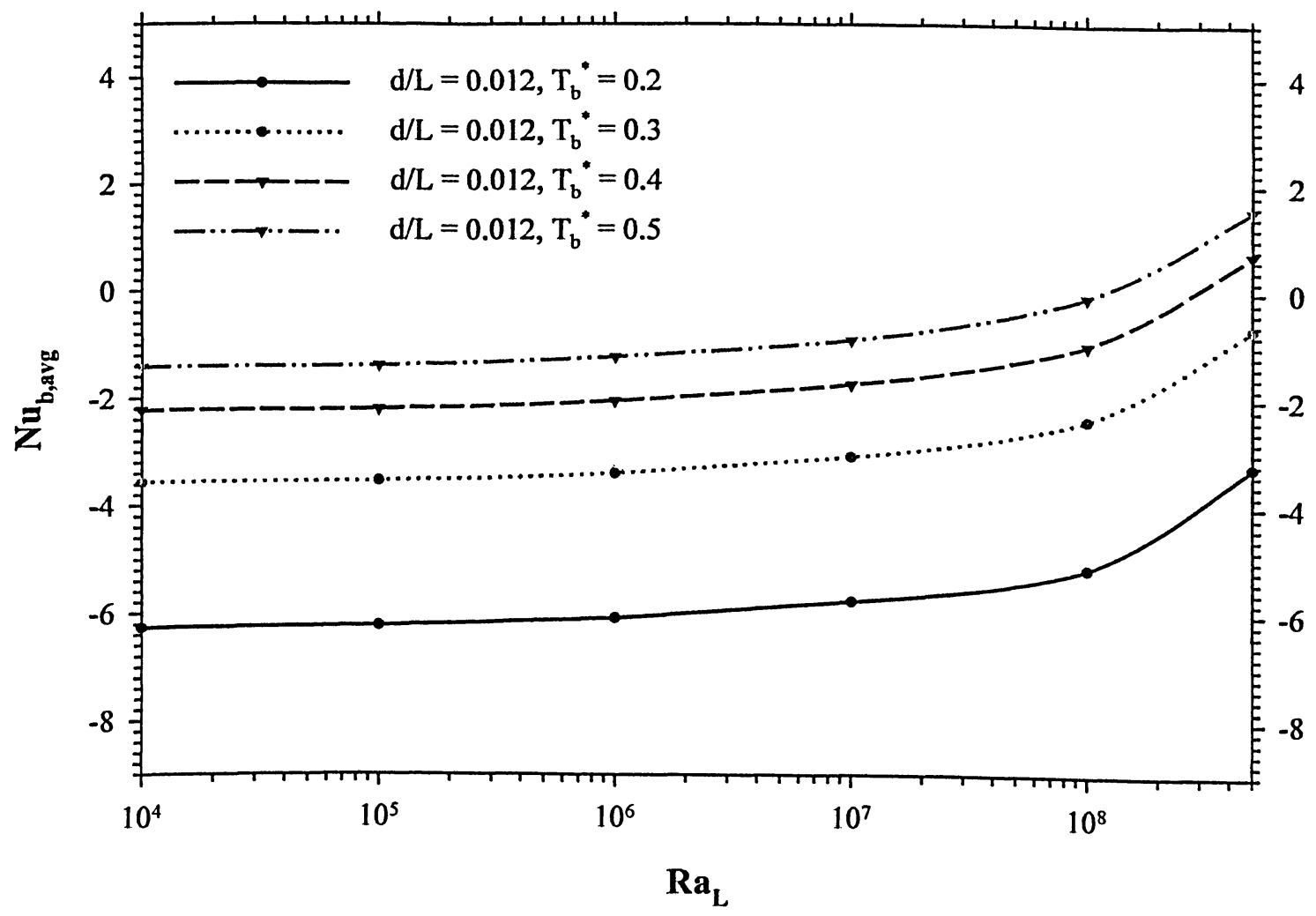

Figure 3.8 Variation of the average convective heat transfer rate from the blind with Rayleigh number, $\mathrm{d} / \mathrm{L}=0.012$, Louver angle $\phi=0^{\circ}$. 
increasing with the Rayleigh number. It should be noted that for all blind temperatures, increasing the Rayleigh number is increasing the average convective heat transfer rates in a negative to positive direction. Therefore, it can be concluded that increasing the Rayleigh number will increase the ability of the blind to be cooled by convection.

\subsubsection{Effect of Blind tip-to-window Spacing on the Convective Heat Transfer from the Indoor Glazing Surface}

In the previous section, the effect of Rayleigh number on the convective heat transfer was examined. Now, attention will be directed towards the effect of blind tip-to-window spacing on the convective heat transfer from the indoor glazing surface. The effect of blind tipto-window spacing will be demonstrated by comparing the average convective heat transfer rates from the window for the blind tip-to-window spacing of $d / L=0.012$ and $d / L=0.043$. In this section, the convective Nusslet number corresponding to the louver angles of $\phi=45^{\circ}$ and $\phi=$ $90^{\circ}$ are presented. Figure 3.9 and Figure 3.10 are the plots of the average window Nusselt

number for the louver angles of $\phi=45^{\circ}$ and $\phi=90^{\circ}$, respectively. Clearly, the strong sensitivity of the average heat transfer to the blind tip-to-window spacing can be seen from these figures. Notice that decreasing the blind tip-to-window spacing from $d / L=0.043$ to $\mathrm{d} / \mathrm{L}=0.012$ increases the dependence of the convective heat transfer on the dimensionless blind temperature. Also, it increases the importance of the conduction effects. This decreases the sensitivity of the average Nusselt numbers to the Rayleigh numbers. 


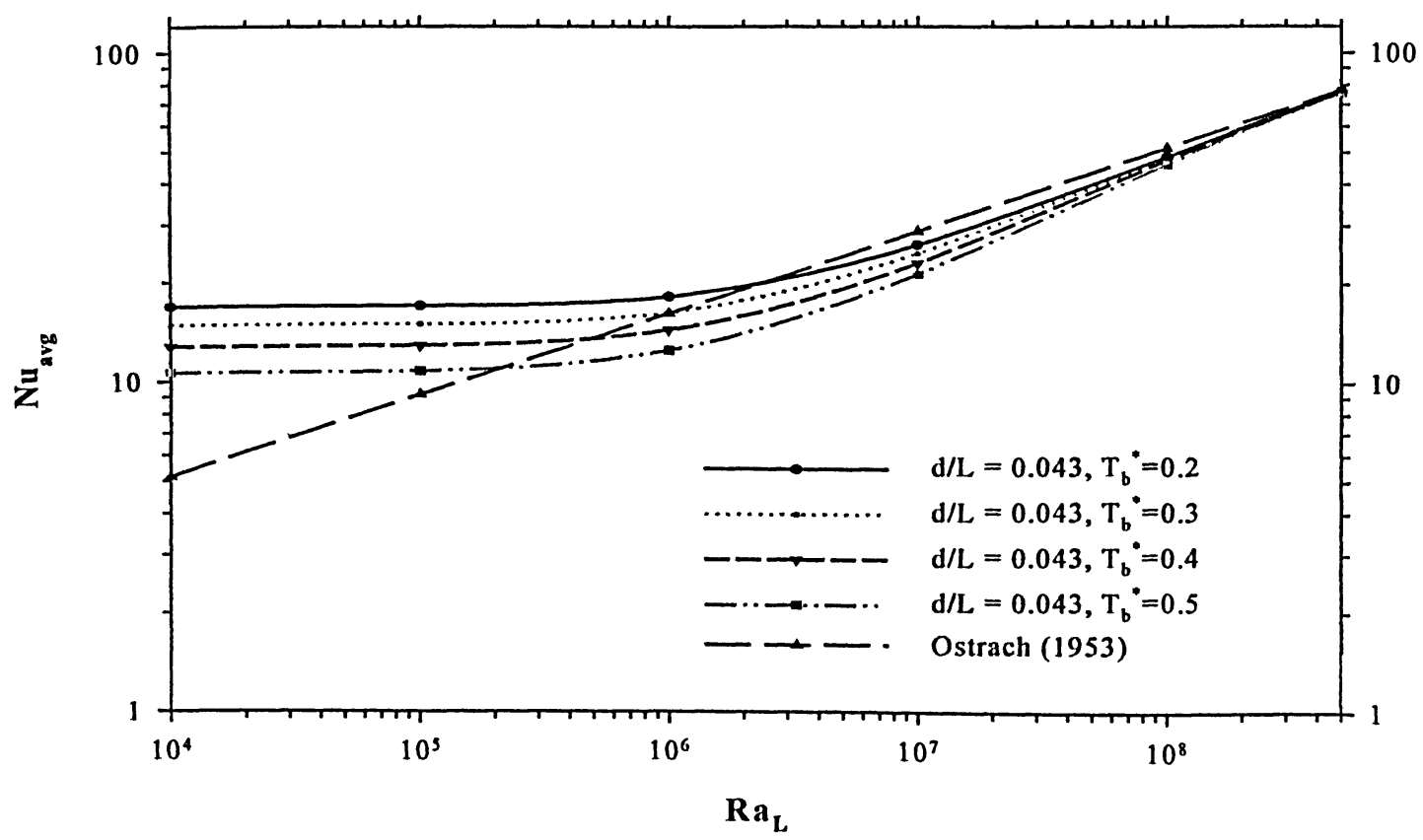

(a)

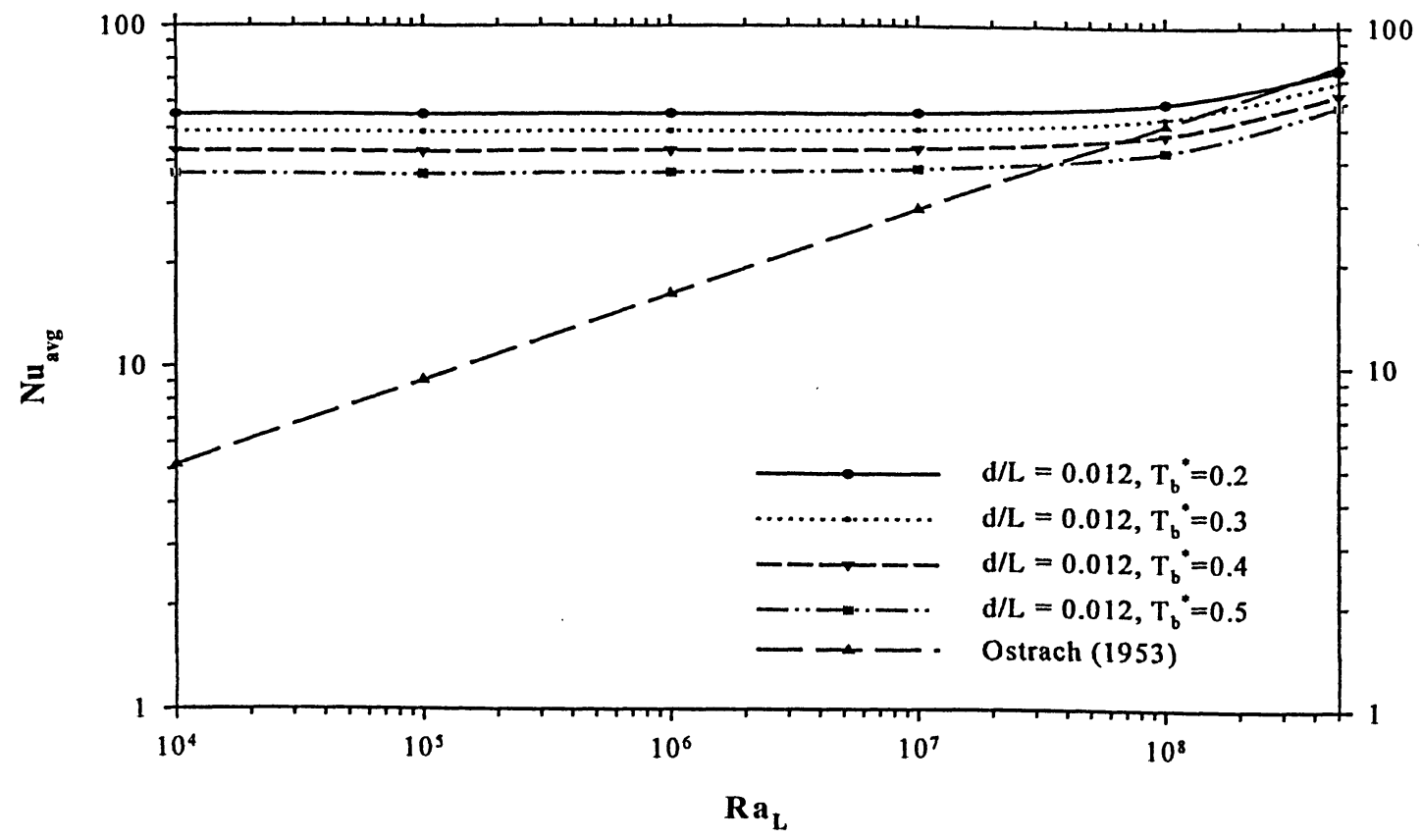

(b)

Figure 3.9 Variation of the average indoor glazing surface Nusselt number with Rayleigh number, (a) $d / L=0.043$, (b) $d / L=0.012$, Louver angle $\phi=45^{\circ}$. 


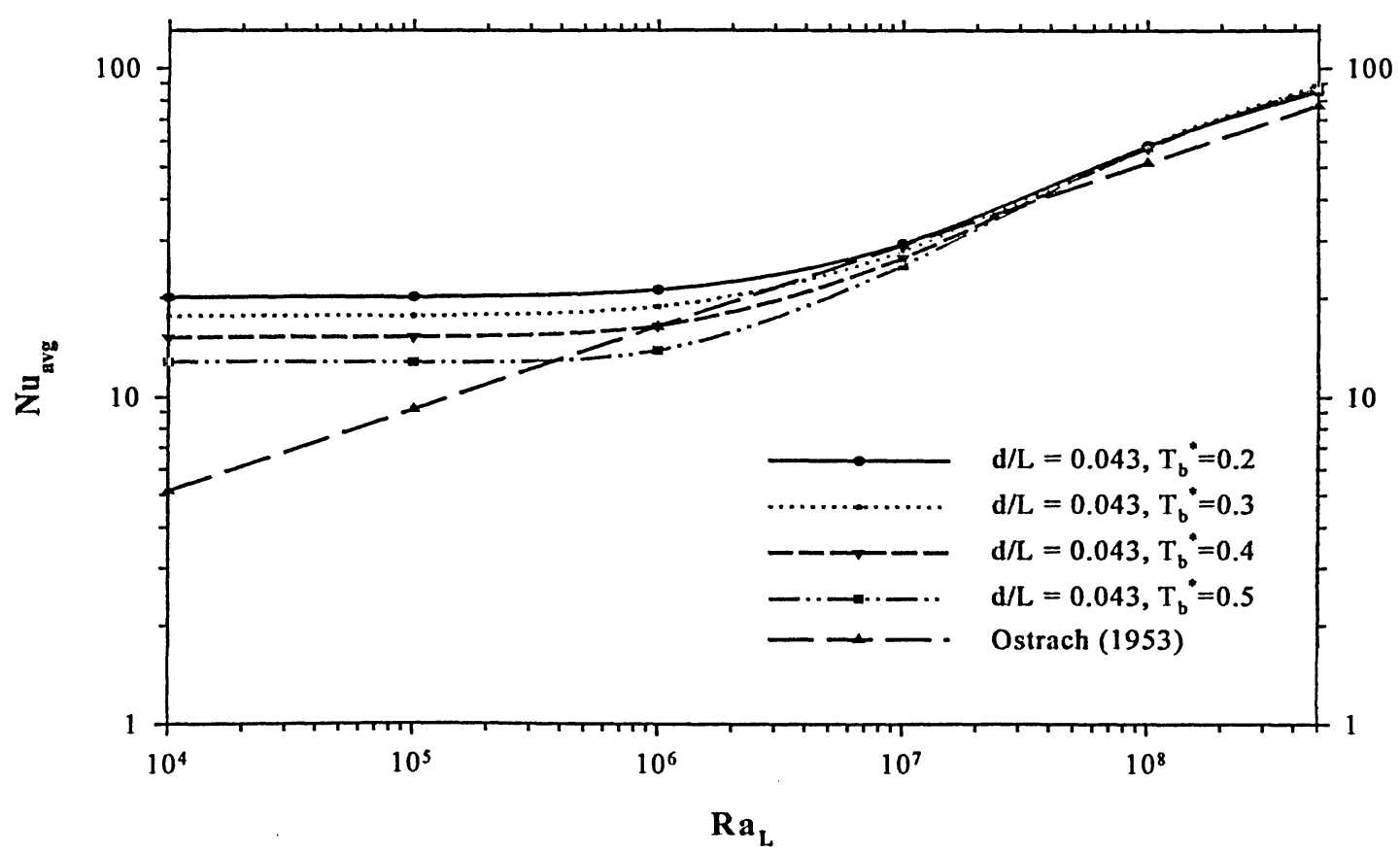

(a)

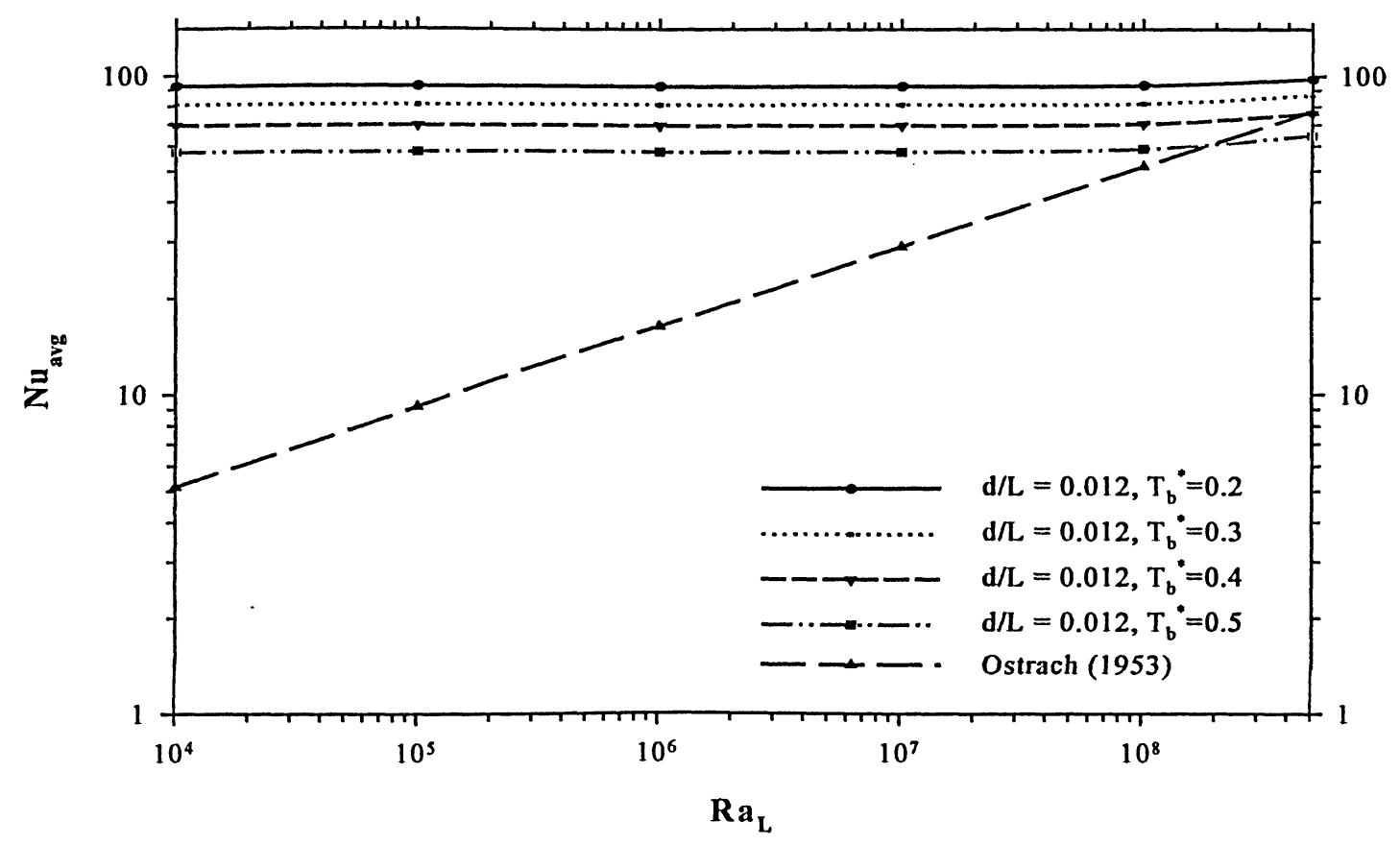

(b)

Figure 3.10 Variation of the average indoor glazing surface Nusselt number with Rayleigh number, (a) $\mathrm{d} / \mathrm{L}=0.043$, (b) $\mathrm{d} / \mathrm{L}=0.012$, Louver angle $\phi=90^{\circ}$. 
Referring to Figure 3.9 and Figure 3.10, a few observations must be made regarding the average convective heat transfer from the window over the range of Rayleigh numbers between $\mathrm{Ra}_{\mathrm{L}}=8 \times 10^{7}$ and $\mathrm{Ra}_{\mathrm{L}}=5 \times 10^{8}$. This range of Rayleigh numbers is of great importance to the present study because it is relevant to all results pertaining to the overall energy performance of a complete window/blind system. The first observation to be made is regarding Figure 3.9(a). Notice that the convective heat transfer corresponding to the louver angle of $\phi=45^{\circ}$ and the blind tip-to-window spacing of $\mathrm{d} / \mathrm{L}=0.043$ are within $\pm 2.3 \%$ of that for an unshaded window, i.e., the results of Ostrach [19]. It should be noted that the convective heat transfer rates are not sensitive to the dimensionless blind temperature. Examination of Figure 3.9(b) reveals that when the dimensionless blind temperature $T_{b}{ }^{*} \geq 0.4$, the convective heat transfer rates corresponding to the blind tip-to-window spacing of $d / L=0.012$ are lower than for a no blind case. This indicates that for dimensionless blind temperature $\mathrm{T}_{\mathrm{b}}{ }^{*} \geq 0.4$, the thermal performance of a window will improve due to the suppression of the convective heat transfer from the indoor glazing surface.

Referring to Figure 3.10(a), notice that the convective heat transfer rates corresponding to the louver angle of $\phi=90^{\circ}$ and the blind tip-to-window spacing of $d / L=0.043$ are higher than those of an unshaded window, i.e., Ostrach [19]. This is likely caused by the presence of the chimney effect that results in higher fluid velocities near the indoor glazing surface, compared to a no blind case. It should be noted that the convective heat transfer rates are not sensitive to the dimensionless blind temperature. Examination of Figure 3.10(b) reveals that the convective heat transfer rates corresponding to the blind tip-to-window spacing of $d / L=0.012$ are also greater than for a no blind case except when $T_{b}{ }^{*}=0.5$. It is interesting to 
note that the dimensionless blind temperature has a strong influence on the magnitude of the convective heat transfer rate from the window. Increasing the dimensionless blind temperature decreases the convective heat transfer from the window. Notice that when $\mathrm{T}_{\mathrm{b}}{ }^{*}=0.5$ and the Rayleigh number is greater than $2 \times 10^{8}$, the convective heat transfer rates from the window are lower than the no blind case. Recognizing this behaviour will assist in understanding the energy performance of a complete window/blind system for different weather conditions.

\subsubsection{Effect of Blind tip-to-window Spacing on the Blind Convective Heat Transfer Coefficients}

In the previous section of this chapter it was shown that the blind tip-to-window spacing had a significant effect on the convective heat transfer from the window. Now the influence of the blind tip-to-window spacing on the convective heat transfer rates from the blind will be examined. An understanding of this effect is very important because the blind tipto-window spacing will influence the blind temperature, which will affect both convective and radiative heat transfer from a window surface.

In Figure 3.11, the average blind convective heat transfer coefficients are plotted as a function of the Rayleigh number. In this figure, the louver angle has been fixed to $\phi=90^{\circ}$. It can be seen that, in the conduction dominated regime, the blind Nusselt numbers associated with $d / L=0.043$ are negative. This indicates that the window surface is heating the blind. As the Rayleigh number increases, the flow strengthens and there is less convective heat transfer from the window surface to the blind. This causes the magnitude of the convective heat transfer rates from the blind to change from negative to positive and the blind starts to cool through 


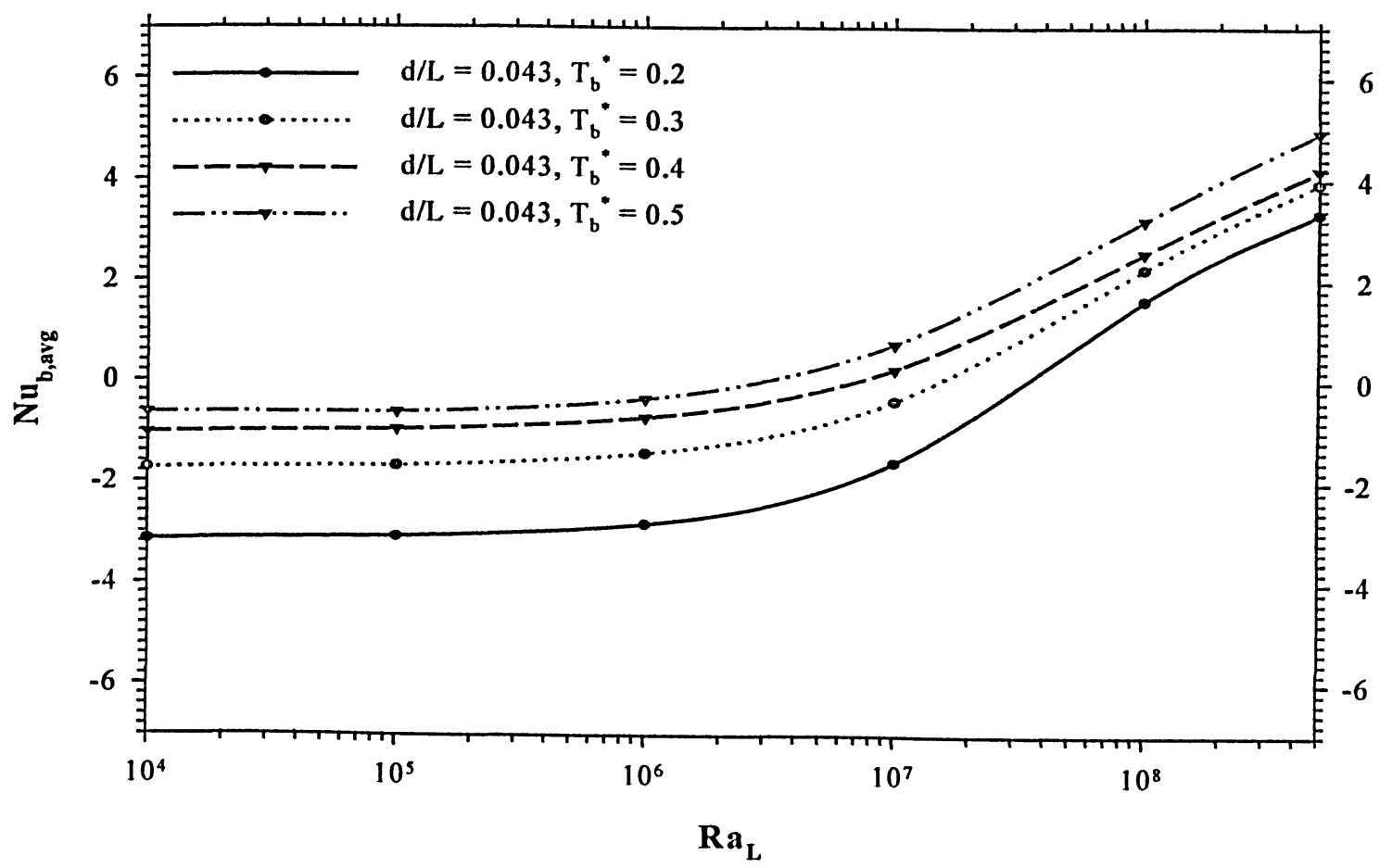

(a)

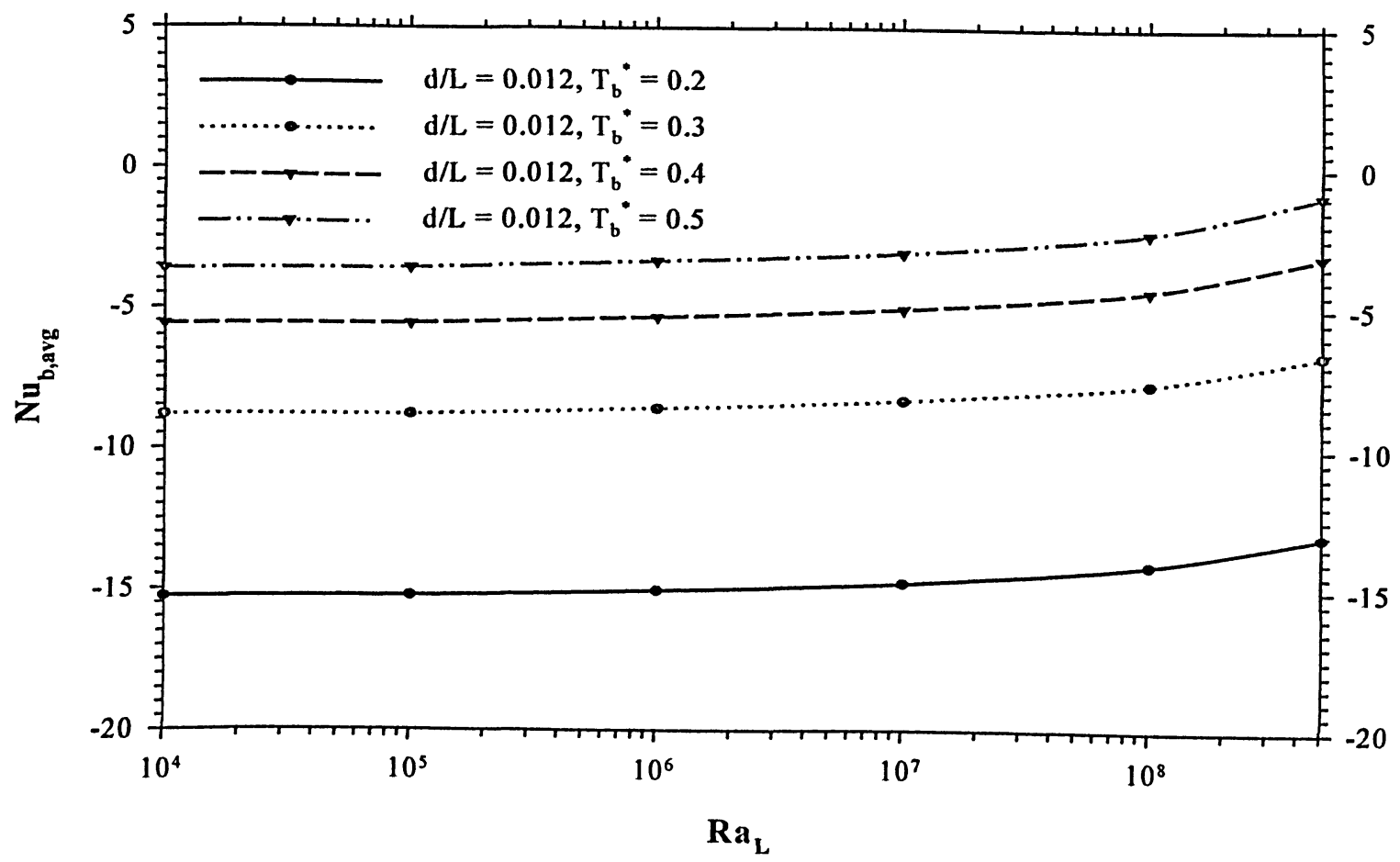

(b)

Figure 3.11 Variation of the average convective heat transfer rate from the blind with Rayleigh number, (a) $d / L=0.043$, (b) $d / L=0.012$, Louver angle $\phi=90^{\circ}$. 
Examination of the heat transfer rates associated with the blind tip-to-window spacing of $\mathrm{d} / \mathrm{L}=0.012$ reveals that the blind Nusselt number do not change from negative to positive. This indicates that for $\mathrm{d} / \mathrm{L}=0.012$, the blind is never cooled through convection. Based on these observations, it can be concluded that the blind temperature corresponding to the blind tip-towindow spacing of $d / L=0.043$ will be lower than that of $d / L=0.012$.

\subsubsection{Effect of Blind Angle on the Convective Heat Transfer}

It has been shown that the convective heat transfer from the indoor glazing surface and the blind is highly dependent upon the blind tip-to-window spacing. Now, the effect of louver angle on the convective heat transfer will be examined. Figure 3.12 is a plot of the variation of the average Nusselt number with Rayeligh number. In this figure, the convective heat transfer rates for three different louver angles are presented and the dimensionless blind temperature is fixed at $\mathrm{T}_{\mathrm{b}}{ }^{*}=0.3$. It is interesting to note that for both spacings, at a high Rayleigh number, $\mathrm{Ra}_{\mathrm{L}}=5 \times 10^{8}$, the convective heat transfer rates corresponding to $\phi=0^{\circ}$ and $\phi=45^{\circ}$ are almost equal in magnitude. It can be concluded that, at high Rayleigh numbers, the louver angle has a very weak effect on the convective heat transfer from the window, except when the louvers are almost fully closed.

It should be noticed that the average Nusselt numbers corresponding to the conduction dominated regime show strong dependence on the louver angle. In the conduction dominated regime, increasing the louver angle results in higher convective heat transfer rates from the window surface. Increasing the louver angle decreases the distance between the window and the blind. Also, it tends to increase the exposure of the cold louvers to the warm air between 
the window and the blind. For this reason, the heat transfer rates from the indoor glazing increase with the louver angle. Since the conduction effects for the blind tip-to-window spacing of $d / L=0.012$ are very important, therefore the convective Nusslet numbers are more sensitive to the louver angle for $d / L=0.012$ than those corresponding to $d / L=0.043$. Note that, for both blind tip-to-window spacings, the convective heat transfer rates corresponding to $\phi=90^{\circ}$ are greater than for the no blind case. At high Rayleigh number, the convective heat transfer rates associated with the blind tip-to-window spacing of $d / L=0.043$ increase due to the presence of the chimney effect. The Nusselt number associated with the blind tip-to-window spacing of $d / L=0.012$ increases because of the conduction effects. It should be noted that if the blind temperature is increased the window Nusselt number will decrease when $d / L=0.012$.

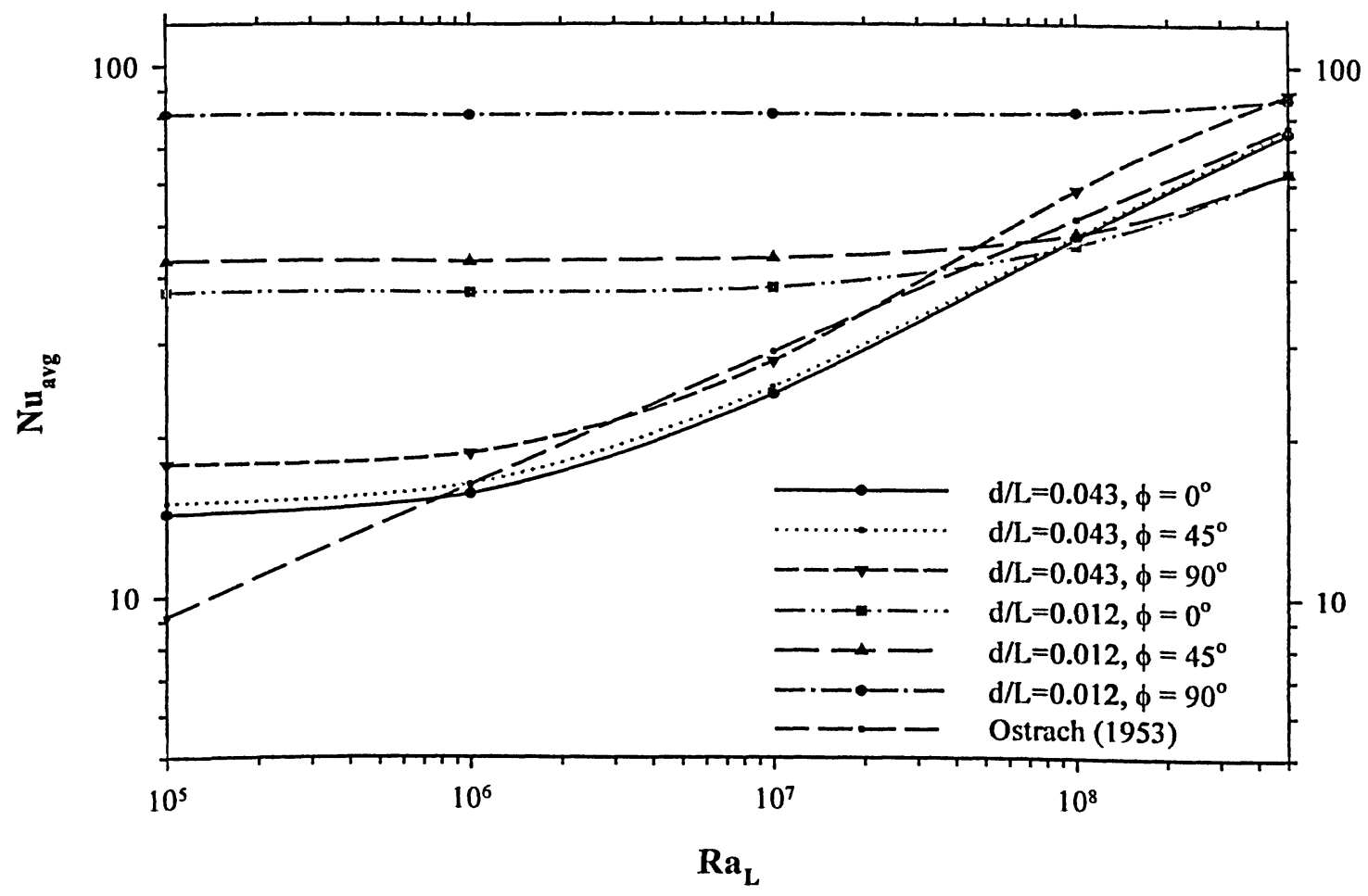

Figure 3.12 Variation of the dimensionless average indoor glazing surface Nusselt number with Rayleigh number, dimensionless blind temperature $\mathrm{T}_{\mathrm{b}}{ }^{*}=0.3$ 
The final heat transfer quantity to be examined is the influence of the louver angle on the convective heat transfer from the blind. Figure 3.13 illustrates how the convective heat transfer rates from the blind are influenced by the louver angle. Notice that the blind Nusselt numbers corresponding to $\phi=0^{\circ}$ and $\phi=45^{\circ}$ are almost exactly the same for $d / L=0.043$. For the blind tip-to-window spacing of $\mathrm{d} / \mathrm{L}=0.043$, increasing the louver angle from $\phi=45^{\circ}$ and $\phi=90^{\circ}$ decreases the convective heat transfer rate from the blind. This implies that when the blind is fully closed, the blind temperature will tend to increase. Notice that for the blind tip-to-window spacing of $\mathrm{d} / \mathrm{L}=0.012$, increasing the louver angle from $\phi=0^{\circ}$ and $\phi=90^{\circ}$ increases the magnitude of the convective heat transfer rates to the blind. This implies that blind will be heated more when the louver angle is increased, therefore increasing the louver angle will also increase the blind temperature.

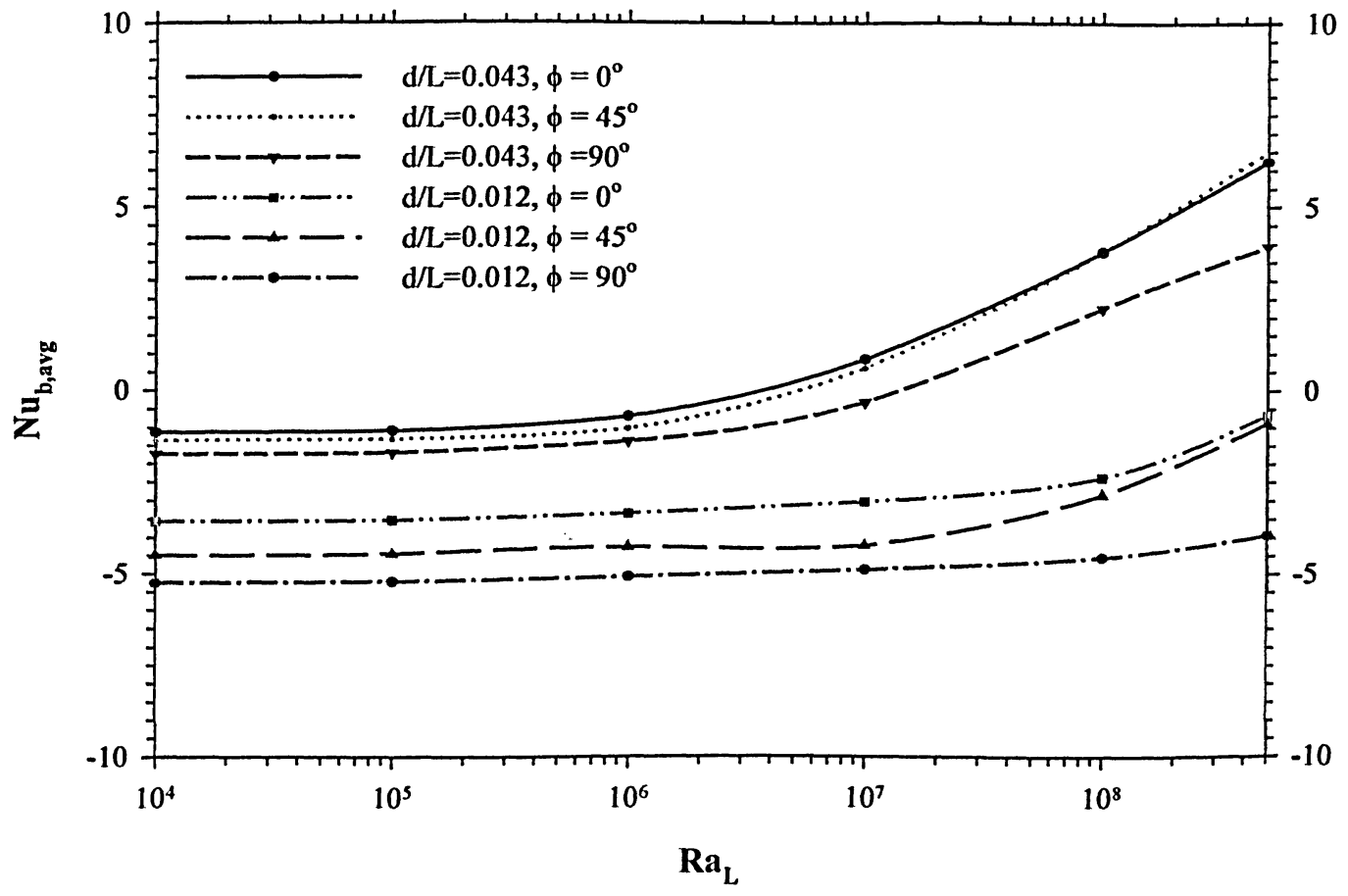

Figure 3.13 Variation of the average convective heat transfer rate from the blind with Rayleigh number, dimensionless blind temperature $\mathrm{T}_{\mathrm{b}}{ }^{*}=0.3$ 


\subsection{ENERGY PERFORMANCE ASSESSMENTS OF A WINDOW WITH A VENETIAN BLIND}

In the previous section of this chapter, the effect of the blind on the convective heat transfer from an indoor glazing surface was examined. Now, attention will be directed towards the effect of blinds on the overall thermal performance of a window. In this study, the CFD results obtained from the 2-D free convection model were used in the 1-D thermal resistance model of a window/blind system (given in Section 2.4). The key energy performance indicators were calculated for both single and double glazed windows. The specifications used for the window are given in Table 3.1, which are the "default" settings for the VISION [8] code. The emissivity of all the window glazings were set to $\varepsilon_{\mathrm{w}}=0.84$, which is the widely accepted value for untreated clear window glass. With these parameters fixed, the thermal performance of the window/blind system depends on:

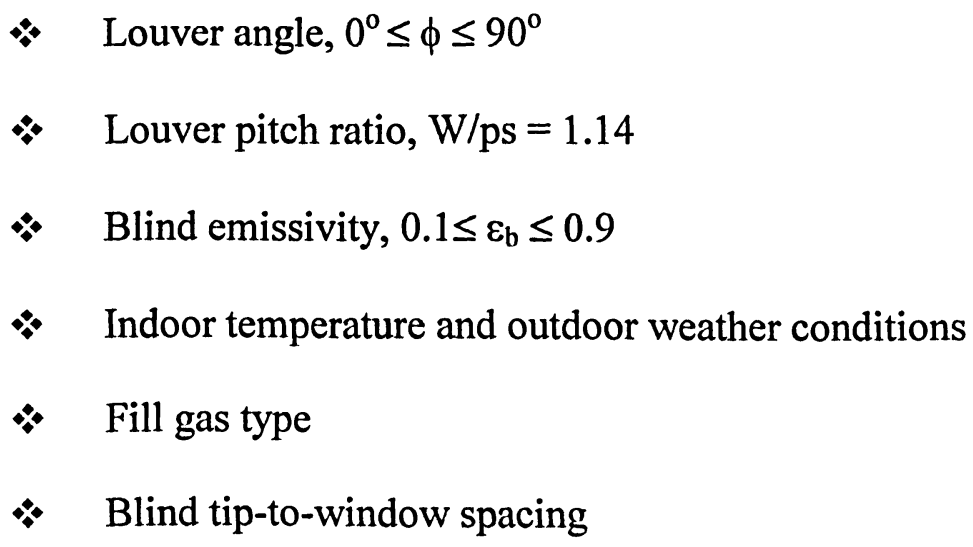

All of the results have been computed for a louver pitch ratio of $\mathrm{W} / \mathrm{P}=1.14$, which is a typical value for a commercial louvered blind. From a practical point of view, commercially available blinds are available in a wide range of surface treatments, each having a specific radiation emissivity associated with it. In this study, the full range of blind emissivity $\left(0.1 \leq \varepsilon_{b}\right.$ $\leq 0.9$ ) has been considered, although most commercial surface treatments (e.g., cloth, enamel paint) have an emissivity in the upper end of this range. So, for most calculations, the blind 
emissivity has been fixed at a typical value of $\varepsilon_{\mathrm{b}}=0.8$. Calculations were also performed for an energy efficient window with low-e coating and argon gas. The low-e coatings were assumed to apply at surface 3 (see Figure 2.2) and the surface emissivity ranged from $0.1-0.4$. All other window glazing surfaces were set to $\varepsilon_{\mathrm{W}}=0.84$.

Table 3.1: Window specifications used in the current study.

\begin{tabular}{|l|l|l|l|l|l|}
\hline $\begin{array}{l}\text { Fill Gas } \\
\text { Type }\end{array}$ & $\begin{array}{l}\text { Fill Gas } \\
\text { Layer } \\
\text { Thickness, } \mathrm{s}\end{array}$ & $\begin{array}{l}\text { Glazing } \\
\text { Thickness, } \mathrm{t}\end{array}$ & $\begin{array}{l}\text { Glazing } \\
\text { Conductivity, } \\
\mathrm{kgl}_{\mathrm{gl}}\end{array}$ & $\begin{array}{l}\text { Glazing } \\
\text { Emissivity, } \varepsilon_{\mathrm{w}}\end{array}$ & $\begin{array}{l}\text { Window } \\
\text { Height, } \mathrm{L}\end{array}$ \\
\hline Air* & $12.7 \mathrm{~mm}$ & $3 \mathrm{~mm}$ & $0.9 \mathrm{~W} / \mathrm{mK}$ & $\varepsilon_{1}=\varepsilon_{2}=\varepsilon_{3}=\varepsilon_{4}=0.84$ & $0.635 \mathrm{~m}$ \\
\hline Argon* & $12.7 \mathrm{~mm}$ & $3 \mathrm{~mm}$ & $0.9 \mathrm{~W} / \mathrm{mK}$ & $\begin{array}{l}\varepsilon_{1}=\varepsilon_{2}=\varepsilon_{4}=0.84 \\
\varepsilon_{3}=0.1-0.4\end{array}$ & $0.635 \mathrm{~m}$ \\
\hline
\end{tabular}

* Thermal properties were obtained from VISION [8]

\subsubsection{Baseline Data and Design Conditions}

To provide baseline data for comparison, calculations were initially made for an unshaded double and single glazed window. The calculations were performed for both summer and winter design weather conditions, as described in the Fenestration chapter of ASHRAE Handbook of Fundamentals [4]. Both design conditions were applied assuming zero incident solar heat flux. It was noticed that the flow on the indoor glazing surface did not remain laminar for the ASHRAE winter design conditions. To avoid transition to the turbulent flow regime, a decision was made to reduce the temperature difference between the indoor and the outdoors such that the flow on the indoor glazing surface remains laminar, i.e., $R a_{L} \leq 10^{9}$. The weather conditions corresponding to the present study are listed in Table 3.2. The results for the modified ASHRAE winter and summer design weather conditions are shown in Table 3.3. These results were obtained using VISION [8]. 
Table 3.2: ASHRAE Design Conditions for summer and winter [4].

\begin{tabular}{|l|c|c|c|c|}
\cline { 2 - 5 } \multicolumn{1}{c|}{} & $\begin{array}{c}\text { Indoors } \\
\text { Temp. } \\
\left({ }^{\circ} \mathrm{C}\right)\end{array}$ & $\begin{array}{c}\text { Outdoors } \\
\text { Temp. } \\
\left({ }^{\circ} \mathrm{C}\right)\end{array}$ & $\begin{array}{c}\text { Cloud Cover } \\
(\%)\end{array}$ & $\begin{array}{c}\text { Wind Speed } \mathrm{V}_{\mathbf{o}} \\
(\mathrm{m} / \mathrm{s})\end{array}$ \\
\hline Summer & 24 & 32 & 100 & 3.35 \\
\hline Winter & 21 & $6^{*}$ & 100 & 6.7 \\
\hline
\end{tabular}

* changed from $-18^{\circ} \mathrm{C}$ to avoid turbulent flow.

Table 3.3: $U$-value $\left(\mathrm{U}_{\mathrm{NB}}\right)$ and radiation heat flux to the indoor surroundings $\left(\mathrm{Q}_{\mathrm{R} 4, \mathrm{NB}}\right)$ for the unshaded window.

\begin{tabular}{|l|c|c|c|c|}
\hline Window Type & \multicolumn{2}{|l|}{ U-value, $\mathrm{U}_{\mathrm{NB}}\left(\mathrm{W} / \mathrm{m}^{2} \mathrm{~K}\right)$} & \multicolumn{2}{|c|}{$\begin{array}{r}\text { Radiation Heat Flux to the } \\
\text { indoor ambient, } \\
\mathrm{Q}_{\mathrm{R} 4 \mathrm{NB}}\left(\mathrm{W} / \mathrm{m}^{2}\right)\end{array}$} \\
& Summer & Winter & Summer & Winter \\
\hline Single Glazed Window & 5.71 & 6.07 & 29.8 & -52.8 \\
\hline Double Glazed Window & 2.97 & 2.87 & 16.3 & -27.1 \\
\hline
\end{tabular}

\subsubsection{Effects of Blind on the U- value of a Single/Double Glazed Window}

In order to compare the thermal performance, the overall heat transfer coefficient (Uvalue) of the centre-of-glass region is calculated and typical results are presented in terms of the ratio $\left(U / U_{N B}\right)$, where $U_{N B}$ is the overall heat transfer coefficient of the window with no blind. This ratio indicates the improvement in energy efficiency produced by the blind. Figure 3.14 and Figure 3.15 show the effects of the louver angle $(\phi)$ and the blind tip-to-window spacing $(d / L)$ on the $U$-value of a single and double glazed window, respectively. In these figures, the blind emissivity has been fixed at $\varepsilon_{\mathrm{b}}=0.8$. It can be seen that for all cases the blind significantly improves the $U$-value, mainly by reducing the thermal radiation from the window. Clearly, increasing the louver angle $(\phi)$ improves the energy performance of the window. Further improvements are realized when the blind tip-to-window spacing is decreased. 


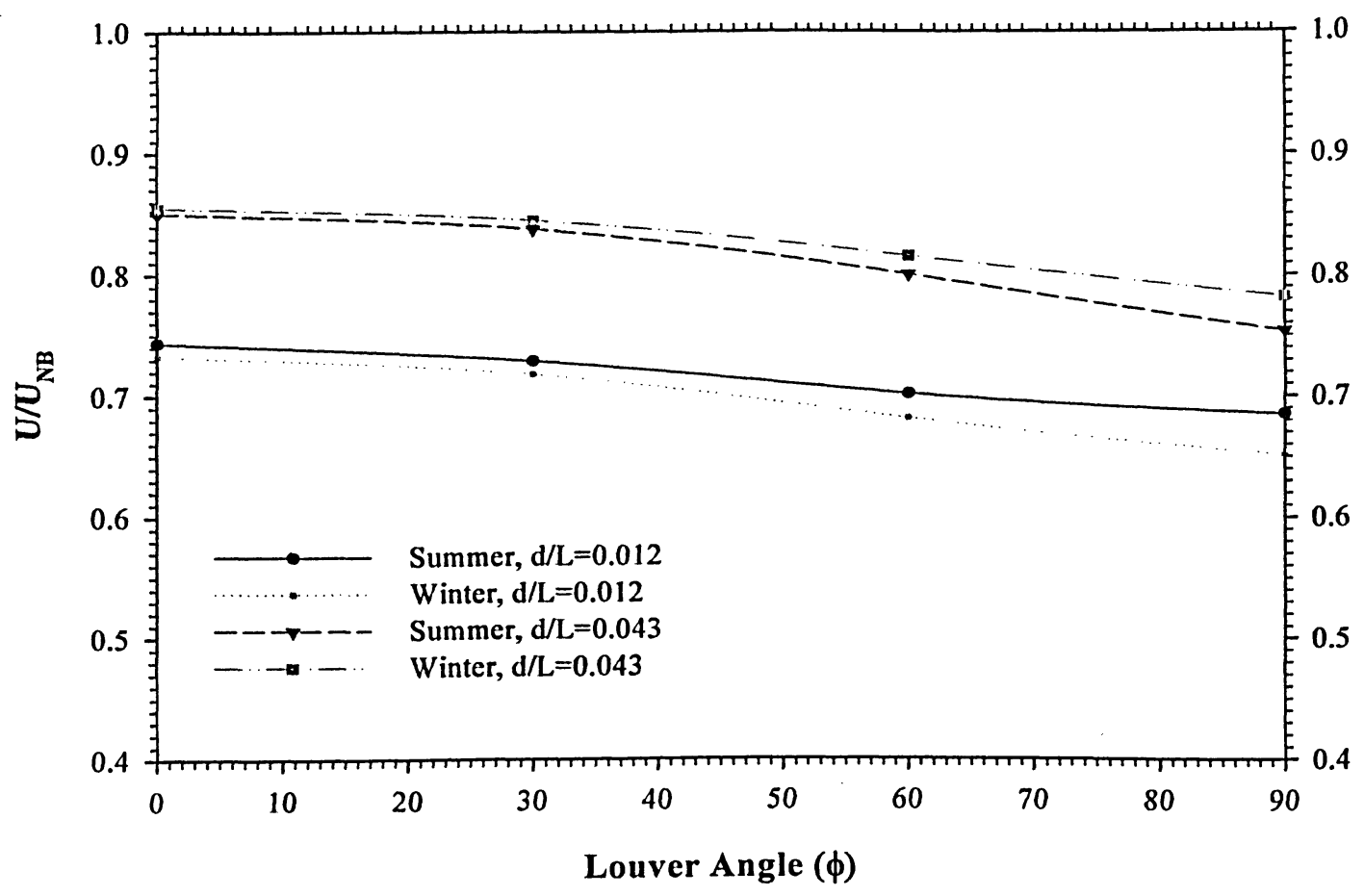

Figure 3.14 Variation of U-value ratio with louver angle and blind tip-to-window spacing for a single glazed window for summer and winter conditions $\left(\mathrm{W} / \mathrm{ps}=1.14, \varepsilon_{\mathrm{b}}=0.8\right)$.

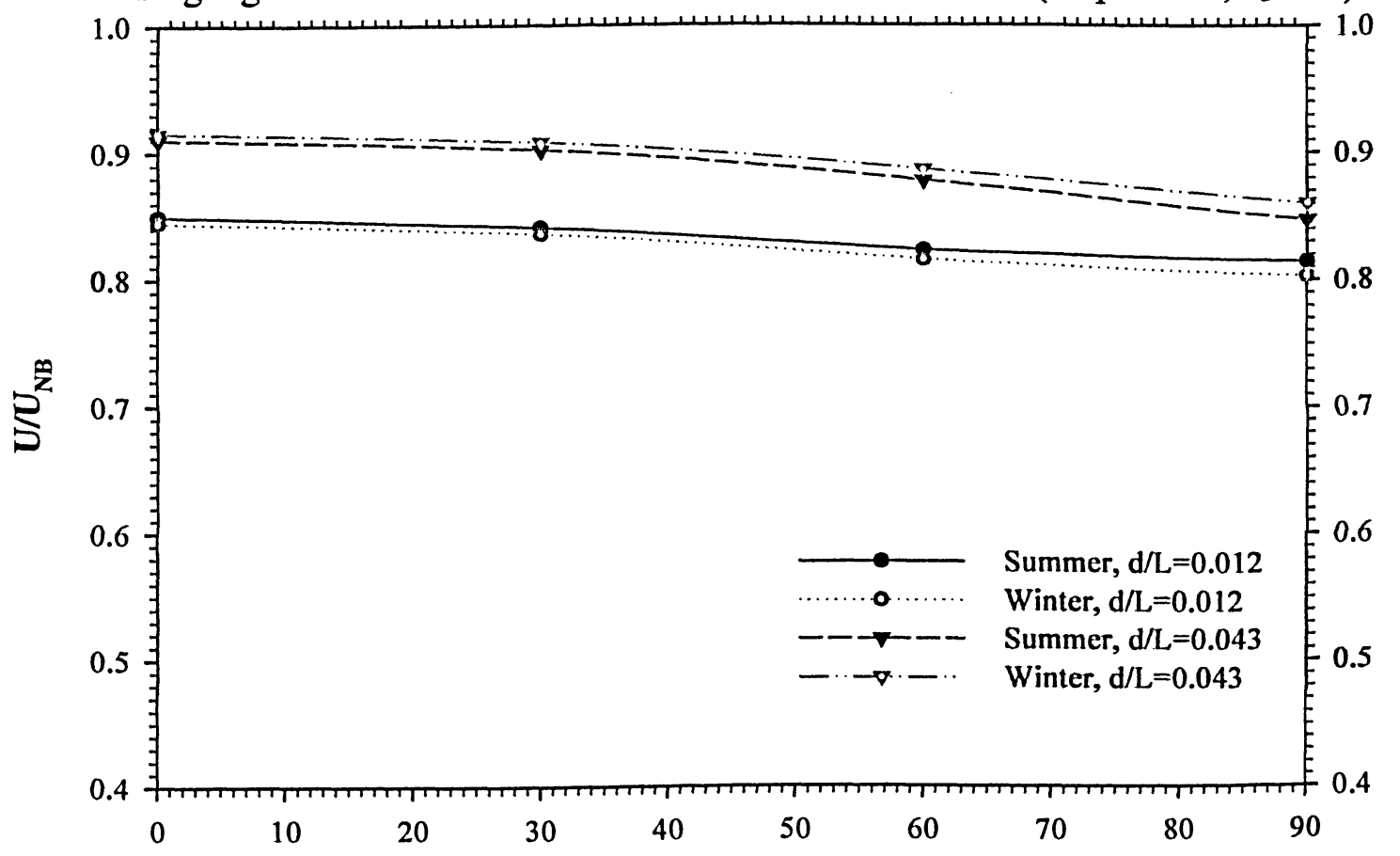

Louver Angle ( $\phi)$

Figure 3.15 Variation of $U$-value ratio with louver angle and blind tip-to-window spacing for a double glazed window for summer and winter conditions (W/ps $\left.=1.14, \varepsilon_{b}=0.8\right)$. 
The blind has the greatest impact on windows for the blind tip-to-window spacing of $\mathrm{d} / \mathrm{L}=0.012$ for winter weather conditions. The blind has reduced the $U$-values of the single glazed window by $27 \%$ when the blind is open $\left(\phi=0^{\circ}\right)$ and by $35 \%$ when the blind is fully closed. As expected, because of the higher overall thermal resistance of the window, the effect of the blind is much less for the double glazed window. For this case, the blind has reduced the U-value by $16 \%$ when the blind is open $\left(\phi=0^{\circ}\right)$ and by $20 \%$ when the blind is fully closed. The blind has the least effect on the heat transmission rate for a double glazed window for $d / L=0.043$ for summer conditions.

A number of interesting observations can be made regarding the combined effect of the weather conditions and the blind tip-to-window spacing on the U-value of single and double glazed window. Notice that when the blind tip-to-window spacing has been fixed to $d / L=0.043$, the blind provides more improvements in the U-value for summer conditions than for winter conditions. When the blind tip-to-window spacing is decreased to $\mathrm{d} / \mathrm{L}=0.012$, both single and double glazed windows perform better for winter conditions than for summer conditions. It should also be noticed that for both types of window, for the same blind tip-to-window spacing increasing the louver angle seems to also increase the effect of weather conditions on the Uvalue. To understand this phenomenon one must take into consideration all those factors that may influence the U-value under different weather conditions, since the blind can only influence the $U$-value of a window by affecting the radiative and the convective heat transmission from the indoor glazing surface. Therefore, examination of the radiative and the convective interplay between the window and the blind is an excellent way to understand the 
combined effect of the blind tip-to-window spacing and the weather conditions. This interplay will be discussed next.

Figure 3.16 and Figure 3.17 show the influence of the blind on the radiative heat transmission from the indoor glazing surface for the single and the double glazed window, respectively. Again, the blind emissivity has been fixed at $\varepsilon_{\mathrm{b}}=0.8$. It can be seen that a typical blind increases the thermal radiation resistance of the window. Even when the blind is open ( $\phi$ $=0^{\circ}$ ), depending on the weather conditions and the blind/window configuration, the net radiant heat flux to/from the indoor glazing is significantly reduced. When the blind is fully closed ( $\phi$ $=90^{\circ}$ ) this extra resistance is further increased, and ranges from $38 \%$ to $52 \%$ for a single glazed window and from $31 \%$ to $44 \%$ for a double glazed window. This extra thermal resistance is very beneficial to reduce unwanted heat losses during the winter, since the temperature difference between the indoor glazing and the room is much larger than in summer.

Referring to Figure 3.16 and Figure 3.17, it can be concluded that the presence of a blind reduces the U-value of a window by reducing the thermal radiation emission from the window. Clearly, the radiative heat transmission from the window is very sensitive to the blind tip-to-window spacing and weather conditions. Recall that the radiative view factors were assumed to be independent of the blind tip-to-window spacing. Therefore, the radiative heat transmission from the window can only be sensitive to the blind tip-to-window spacing if the blind temperature is different for different spacings. Decreasing the temperature difference between the blind and the window will reduce radiative heat transmission from the window. 


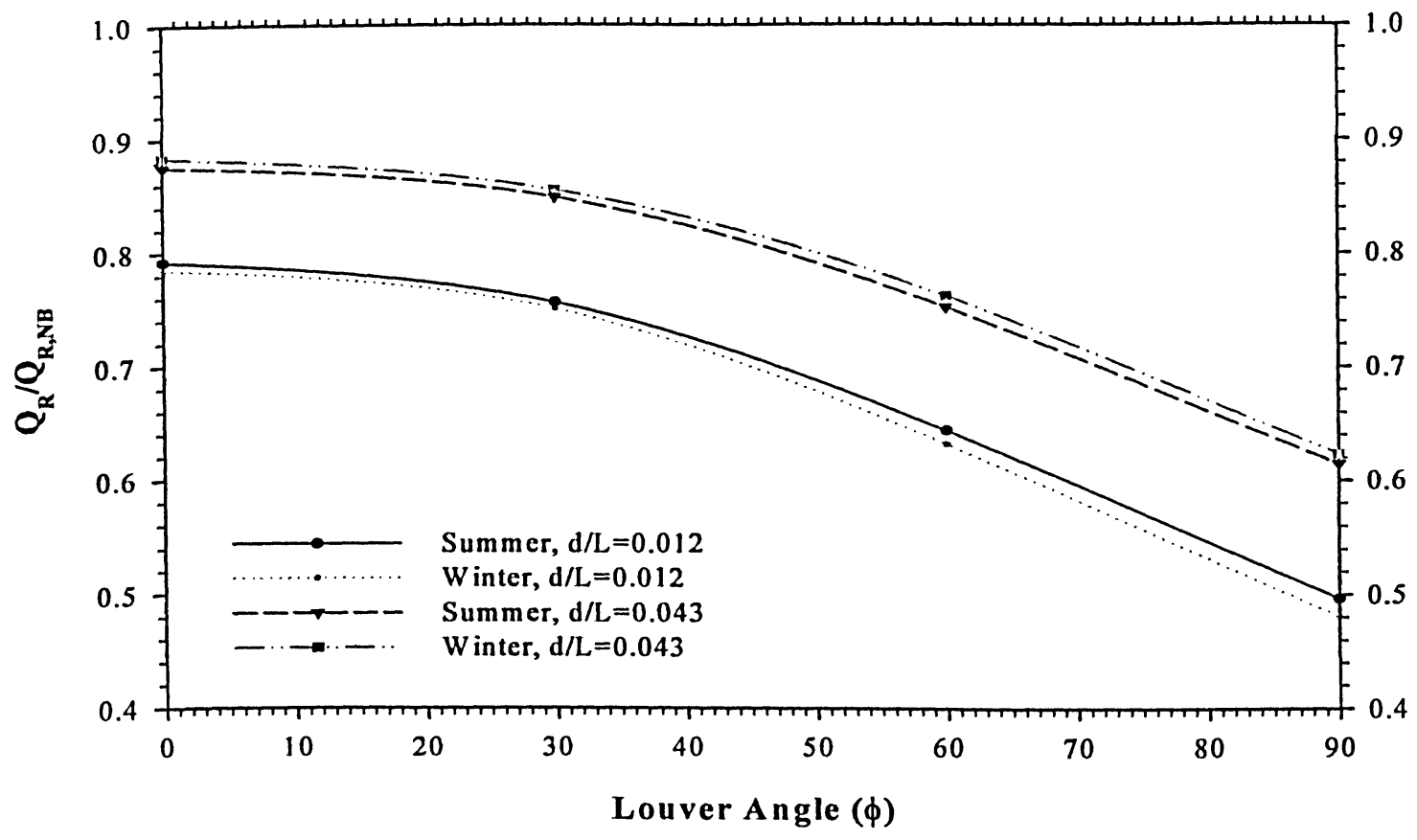

Figure 3.16 Effect of the presence of the blind on the radiative heat transmission from a single glazed window for summer and winter conditions (W/ps $=1.14, \varepsilon_{b}=0.8$ ).

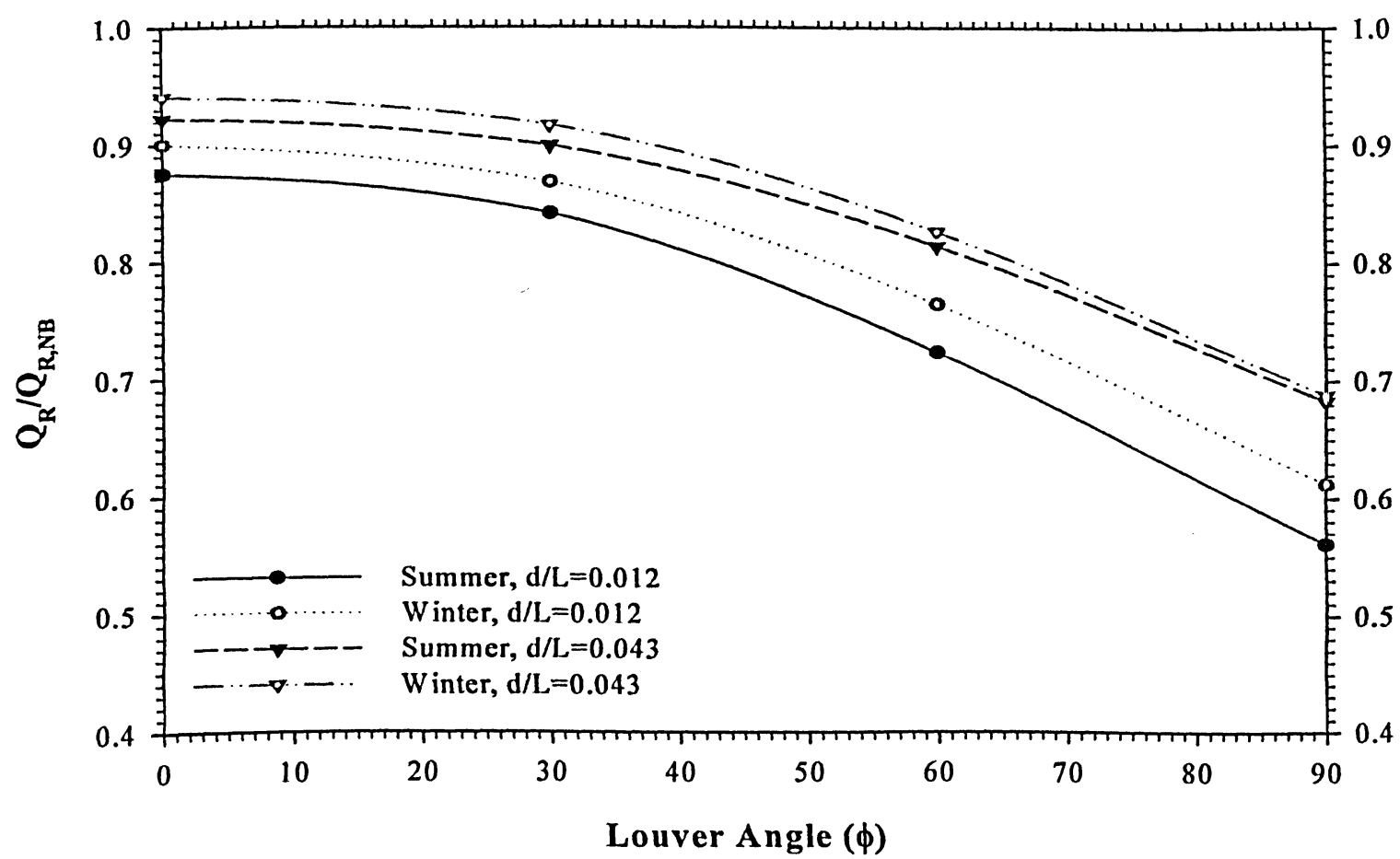

Figure 3.17 Effect of the presence of the blind on the radiative heat transmission from a double glazed window for summer and winter conditions $\left(\mathrm{W} / \mathrm{ps}=1.14, \varepsilon_{b}=0.8\right)$. 
It should be kept in mind that the blind temperature only depends on the balance between the convective and the radiative heat flux to/from the blind. When the blind is heated through radiation, then it is cooled by convection, and vice versa. For a given blind temperature and radiative heat flux on the blind, if the magnitude of the convective heat flux on the blind is higher than the net radiative heat flux to/from the blind, then the blind temperature will increase or decrease to reach the energy balance. When the blind tip-to-window spacing is fixed to $d / L=0.043$, the blind is cooled by convection. The convective heat transfer from the blind tends to increase the temperature difference between the blind and the window, i.e., decreases the blind temperature. On the other hand, when the blind tip-to-window spacing is fixed to $d / L=0.012$, the blind is convectively heated and it is cooled by radiation emission. Because of the hot window surface, the blind cannot become a net radiation emitter unless the temperature difference between the blind and the window is decreased, i.e., the blind temperature is increased. When the blind spacing is decreased from $d / L=0.043$ to $d / L=0.012$, the convective interactions between the blind and the window decrease the temperature difference between the window and the blind, i.e., blind temperature increases. For this reason, decreasing the blind tip-to-window spacing from $d / L=0.043$ to $d / L=0.012$ increases the blind temperature, which reduces the radiative heat transmission from the window.

In the previous sections of this chapter, it was observed that the magnitude and the direction (heating or cooling) of the convective heat transfer rates from the blind were dictated by the indoor flow Rayleigh number. Since the indoor flow Rayleigh number associated with the winter are higher than the summer, therefore the weather conditions also influence the radiative heat transfer from the window. 
It has been demonstrated that the U-value of single and double glazed window is reduced due to the thermal radiation shielding effect produced by the blind. Now, the focus will be directed towards the convective heat transfer rates from the window/blind system. The effect of the blind on the indoor glazing convective heat transfer is quantified as $\left(\mathrm{Q}_{c} / \mathrm{Q}_{\mathrm{c}, \mathrm{NB}}\right)$ where $\mathrm{Q}_{\mathrm{c}, \mathrm{NB}}$ is obtained from VISION [8], which is the convective heat flux corresponding to a no blind case. Figure 3.18 and Figure 3.19 show the influence of the blind on the convective heat transfer from the window for the single and the double glazed window, respectively. From these figures, it appears that the convective heat transfer from a double glazed window is more sensitive to the presence of a blind than a single glazed window. In reality, because of the large temperature difference between the window surface and the indoor ambient, the presence of the blind produces larger changes in the convective heat transmission from a single glazed window than a double glazed window. It is very important to mention that the ratio $\left(Q_{d} / Q_{c, N B}\right)$ only assists in understanding the impact of the convective heat transfer on the U-value. This ratio does not provide any information regarding the change in the magnitude of the convective heat transfer rates from the window associated with different blind/window and weather configurations.

Examination of Figure 3.18 and Figure 3.19 reveals that, for most louver angles, the blind suppresses the convective heat transmission from both windows except when the blind is almost fully closed. It should be noted that the suppression of the convective heat transmission from the window reduces the U-value. When the blind is fully closed, for all window/blind and weather configurations, the convective heat transmission from the window is higher than for a no blind case. Therefore, when the blind is closed, reductions in the U-value associated with 


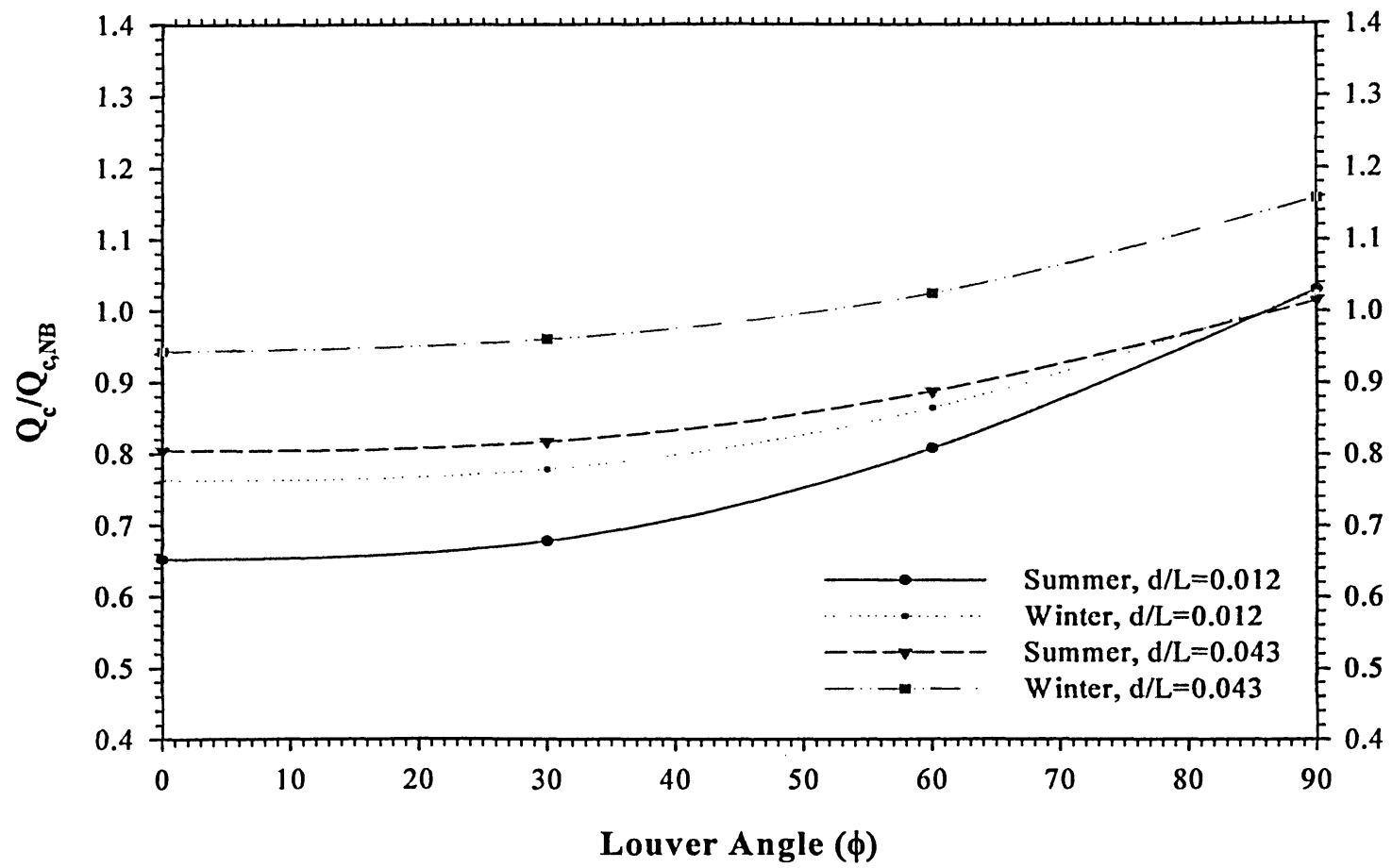

Figure 3.18 Effect of the blind on the convective heat transmission from a single glazed window for summer and winter conditions $\left(\mathrm{W} / \mathrm{ps}=1.14, \varepsilon_{\mathrm{b}}=0.8\right)$.

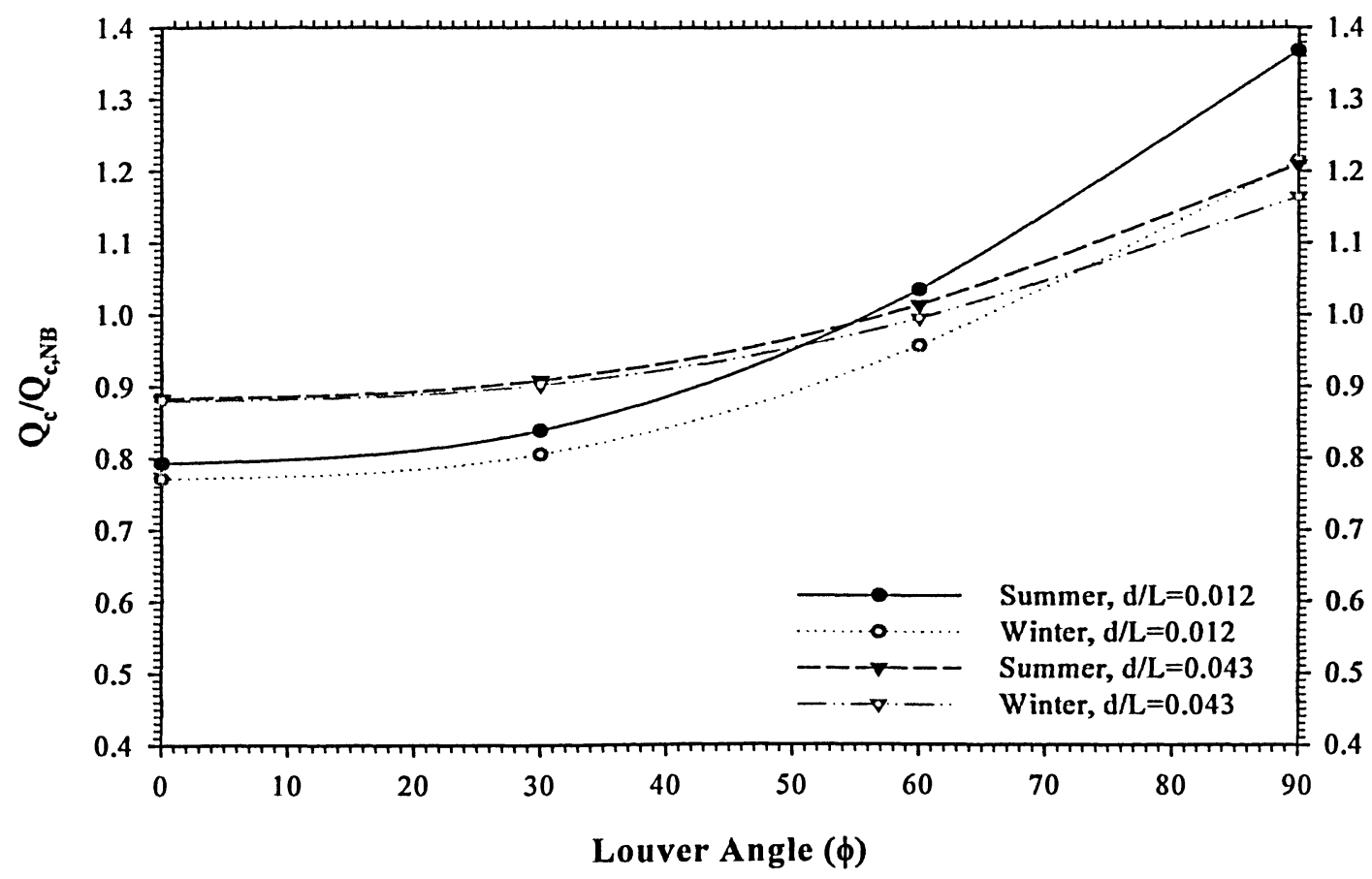

Figure 3.19 Effect of the blind on the convective heat transfer from a double glazed window for summer and winter conditions (W/ps $\left.=1.14, \varepsilon_{b}=0.8\right)$. 
the beneficial radiation shielding effect of the blind are partially offset by the increased convective heat transfer from the window.

\subsubsection{Effect of Blind Emissivity on the Centre of Glass U-value}

Figure 3.20 shows the effect of the blind emissivity on the U-value of a double glazed window under summer conditions. As can be expected, the U-value of the window/blind system decreases as the blind emissivity decreases. The maximum effect of the blind emissivity occurs when the blind is fully closed $\left(\phi=90^{\circ}\right)$. At this louver angle, as the emissivity decreases, the blind reflects more radiant heat back toward the window. In contrast, when the blind is open $\left(\phi=0^{\circ}\right)$, the U-value of the window/blind system shows weak dependence on the blind emissivity. One reason for the weak effect of $\varepsilon_{b}$ at $\phi=0^{\circ}$ is the significance of the direct window-to-ambient view through the louvers. For this reason, there is a significant amount of direct beam radiant heat exchange, which is unaffected by the blind emissivity $\varepsilon_{\mathrm{b}}$. Also, as the blind emissivity $\varepsilon_{\mathrm{b}}$ decreases, the reflectivity increases and a greater fraction of the radiation from the window is reflected to the room. In addition, the fraction of the radiant heat flux that is absorbed by the blind decreases, causing the blind temperature to decrease. As the blind temperature decreases, the net radiant heat exchange between the window and the blind tends to increase. At $\phi=0^{\circ}$, these effects almost completely negate the influence of blind emissivity on U-value. Even at $\phi=40^{\circ}$, a large reduction in the blind emissivity has only a slight beneficial effect on the U-value.

This result illustrates that the application of "low-e" coatings to the louvers would be an effective means of reducing the U-value only for the large louver angles. Notice that the robust 
low-e films that are currently available $\left(\varepsilon_{\mathrm{b}} \approx 0.3\right)$ would provide significant improvement in thermal performance, especially when the blind is almost fully closed.

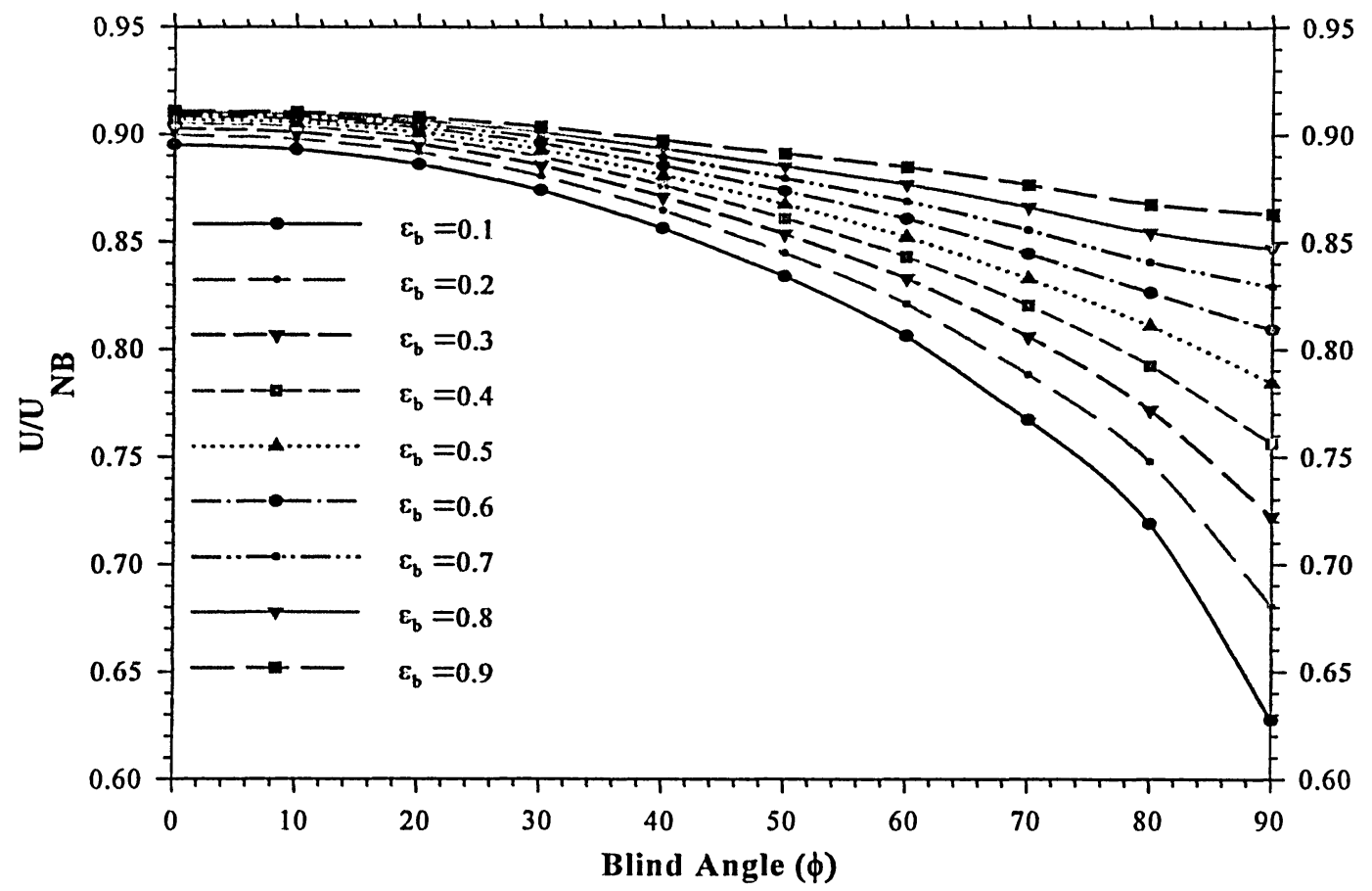

Figure 3.20 Variation of U-value ratio with louver angle for a double glazed window for summer conditions $\mathrm{d} / \mathrm{L}=0.043$.

\subsubsection{Effect of Blind on the Thermal Comfort of the Occupant}

It is well known that the presence of shading devices next to a fenestration provides thermal comfort for the occupants. Therefore, the improvement in the occupant comfort caused by the radiation shielding effect of a Venetian blind is also an important issue. For this reason, the ratio of the net radiant heat transfer rate to the indoor surroundings with the blind ( $\mathrm{Q}_{\mathrm{amb}}$ ) and without the blind $\left(\mathrm{Q}_{\mathrm{R}, \mathrm{NB}}\right)$ has been calculated. It should be noted that the net radiant heat transfer to the indoor surroundings $\left(\mathrm{Q}_{\mathrm{amb}}\right)$ includes the radiant heat transfer from the blind and the window. 
Figure 3.21 and Figure 3.22 show the influence of the blind on the net radiative heat transfer to the indoor surroundings for a single and a double glazed window, respectively. It can be seen that a typical blind with $\varepsilon_{b}=0.8$ decreases the net radiative heat transfer to the indoor surroundings. Even when the blind is open $\left(\phi=0^{\circ}\right)$, depending on the weather conditions and the blind/window configuration, the net radiant heat flux to the indoor surroundings has been reduced from $20 \%$ to $40 \%$ for a single glazed window and from $10 \%$ to $33 \%$ for a double glazed window. When the blind is fully closed $\left(\phi=90^{\circ}\right)$, the occupant comfort is further increased, and ranges from $49 \%$ to $69 \%$ for a single glazed window and from $39 \%$ to $61 \%$ for a double glazed window.

The dependence of the net radiant heat flux to the indoor surroundings on the louver angle can be explained as follows. The blind reduces the net radiant heat flux to the indoor surroundings by intercepting the radiation emitted from the window surface. The blind absorbs a portion of the intercepted radiation and reflects the rest towards the window and the indoor surroundings. The magnitude of the intercepted radiation is extremely sensitive to the windowto-blind view factor. When the blind is open the window-to-blind view is $38 \%$ and the window-to-ambient view is $62 \%$. Therefore, when the blind is open $\left(\phi=0^{\circ}\right)$, the blind can only intercept $38 \%$ of the window radiative heat flux. However, when the blind is fully closed $(\phi=$ $90^{\circ}$ ), due to increased window-to-blind view, the blind intercepts all radiation emitted from the window. Also, when the louver angle is increased from $\phi=0^{\circ}$ to $\phi=90^{\circ}$, the blind does not reflect radiative heat flux towards the indoor surroundings. For these reasons, the blind provides more thermal comfort when the blind is fully closed. 
Examination of Figure 3.21 and Figure 3.22 indicates that the net ambient radiative heat flux is also sensitive to the weather conditions. The net ambient radiative heat flux is sensitive to the weather conditions because of the increased temperature difference between the window and the indoor surroundings. It is also interesting to note that increasing the blind tip-towindow spacing decreases the net ambient radiative heat flux. To explain this phenomenon, attention is directed towards the single glazed window under summer conditions. When the blind tip-to-window spacing is fixed at $\mathrm{d} / \mathrm{L}=0.043$, the blind absorbs more radiant heat than it emits, i.e. the blind is radiatively heated. The blind loses the radiant heat through convection. Therefore, it does not affect the net ambient radiative heat flux. However, when the blind tipto-window spacing is decreased to $\mathrm{d} / \mathrm{L}=0.012$, the blind is convectively heated by the heat affected zone near the indoor glazing surface. The blind must lose the convective heat through radiation emission. Therefore, when the blind is placed at $d / L=0.012$, it increases the net ambient radiative heat flux. It is very important to mention that increasing the blind tip-towindow spacing from $d / L=0.012$ to $d / L=0.043$ increases the occupant comfort (from a radiation perspective) by more than $16 \%$. 


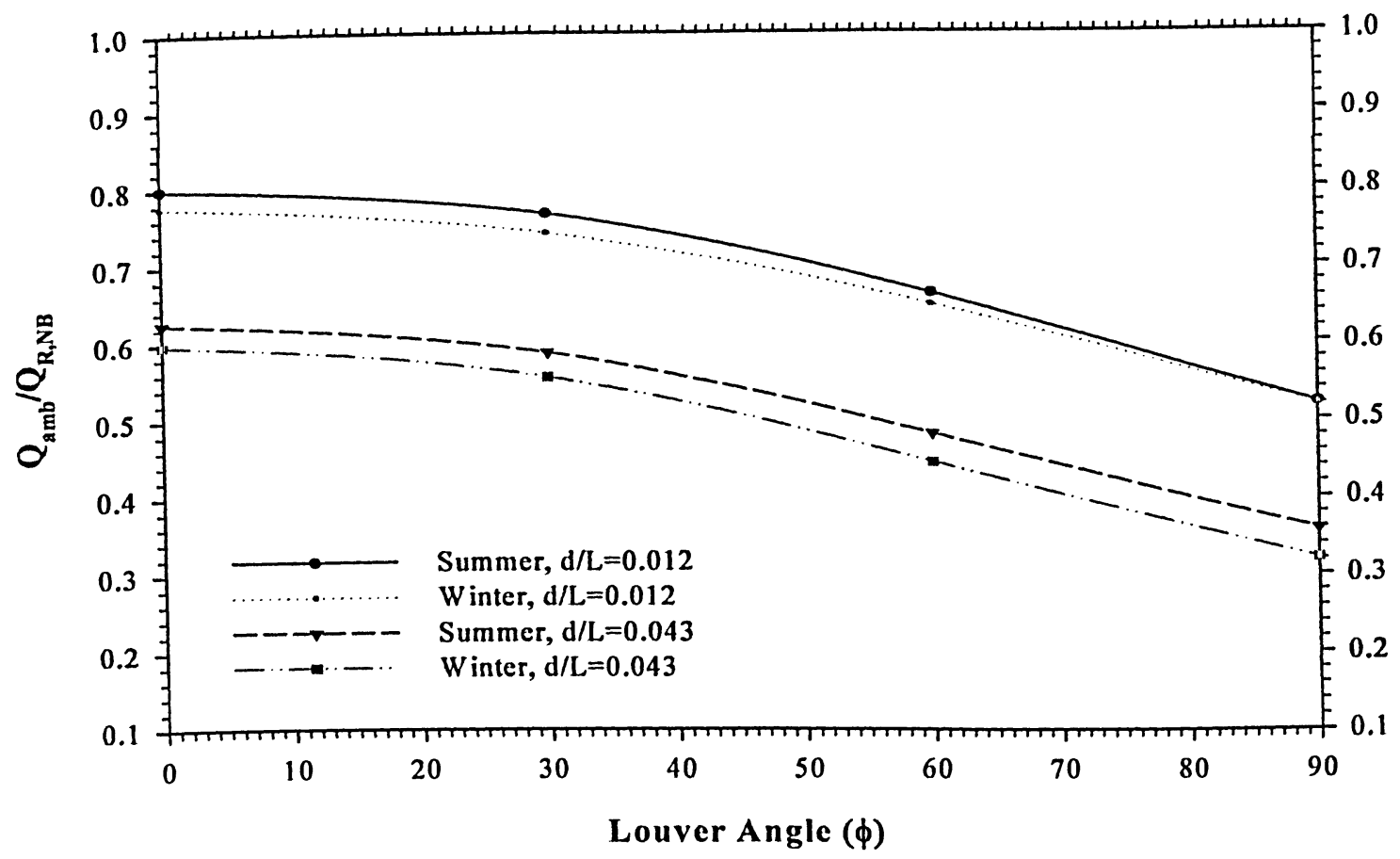

Figure 3.21 Effect of the blind on the ambient radiation heat flux ratio for a single glazed window $\left(\mathrm{W} / \mathrm{ps}=1.14, \varepsilon_{b}=0.8\right)$.

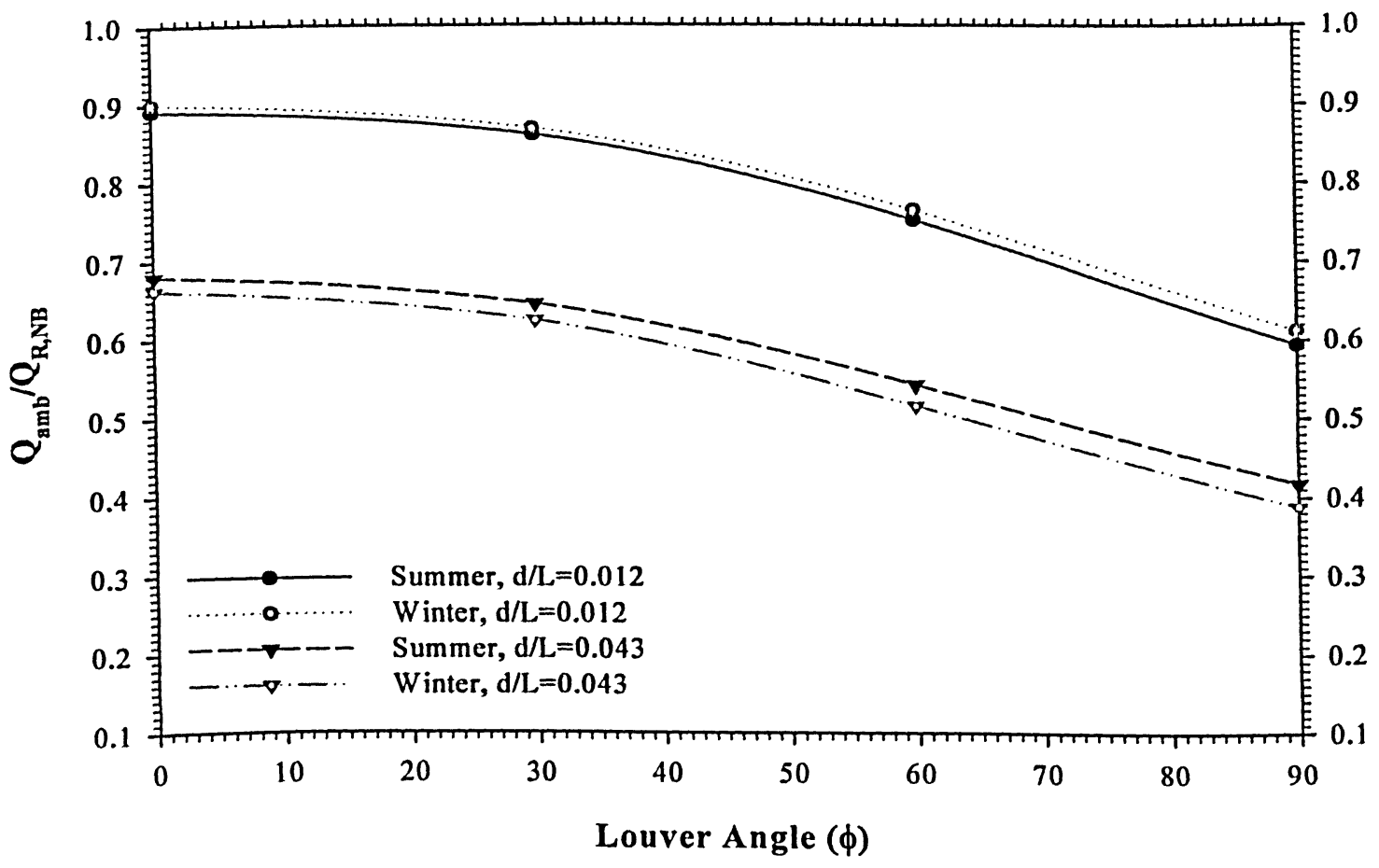

Figure 3.22 Effect of the blind on the indoor ambient radiation heat flux ratio for a double glazed window $\left(\mathrm{W} / \mathrm{ps}=1.14, \varepsilon_{\mathrm{b}}=0.8\right)$. 


\subsubsection{Effect of Blind Emissivity on Thermal Comfort of the Occupant}

The effect of the blind emissivity on radiant heat flux to the indoor surroundings for a double glazed window with summer conditions is shown in Figure 3.23. It should be noted that the net radiant heat transfer to the indoor surroundings $\left(\mathrm{Q}_{\mathrm{amb}}\right)$ includes the radiant heat transfer from the blind and the window. When the blind is fully closed $\left(\phi=90^{\circ}\right)$, the radiant heat flux almost approaches zero as the blind emissivity is reduced to $\varepsilon_{b}=0.1$. The radiation heat flux from the indoor glazing increases as $\varepsilon_{b}$ increases primarily because of the increased blind temperature. However, it can be seen in Figure 3.23 that, for $\phi=0^{\circ}$ and $30^{\circ}$, the emissivity of the blind has much less effect on the radiation heat flux from the window. This weak effect is primarily due the significance of the direct radiant heat exchange between the window and the ambient. Unfortunately, similar to the U-value, by reducing the blind emissivity, the radiative flux from the indoor glazing would not decrease significantly, except when the blind is almost fully closed.

It is interesting to note that, at $\phi=0^{\circ}$, decreasing the blind emissivity $\varepsilon_{b}$ increases the radiant heat transfer to the indoor surroundings. This phenomenon can be explained as follows. The blind reduces the net radiant heat flux to the indoor surroundings by intercepting the radiation emitted from the window surface. The blind absorbs a portion of the intercepted radiation and reflects the rest towards the window and the indoor surroundings. At $\phi=0^{\circ}$, the reflected components of radiation towards the window and the indoor surroundings are almost equal in magnitude. Since decreasing the blind emissivity $\varepsilon_{b}$ increases the reflected portion of the intercepted radiation, therefore, at $\phi=0^{\circ}$, the radiative heat transfer to the indoor 
surroundings increases because of the increased reflection of the radiant heat toward the indoor surroundings.

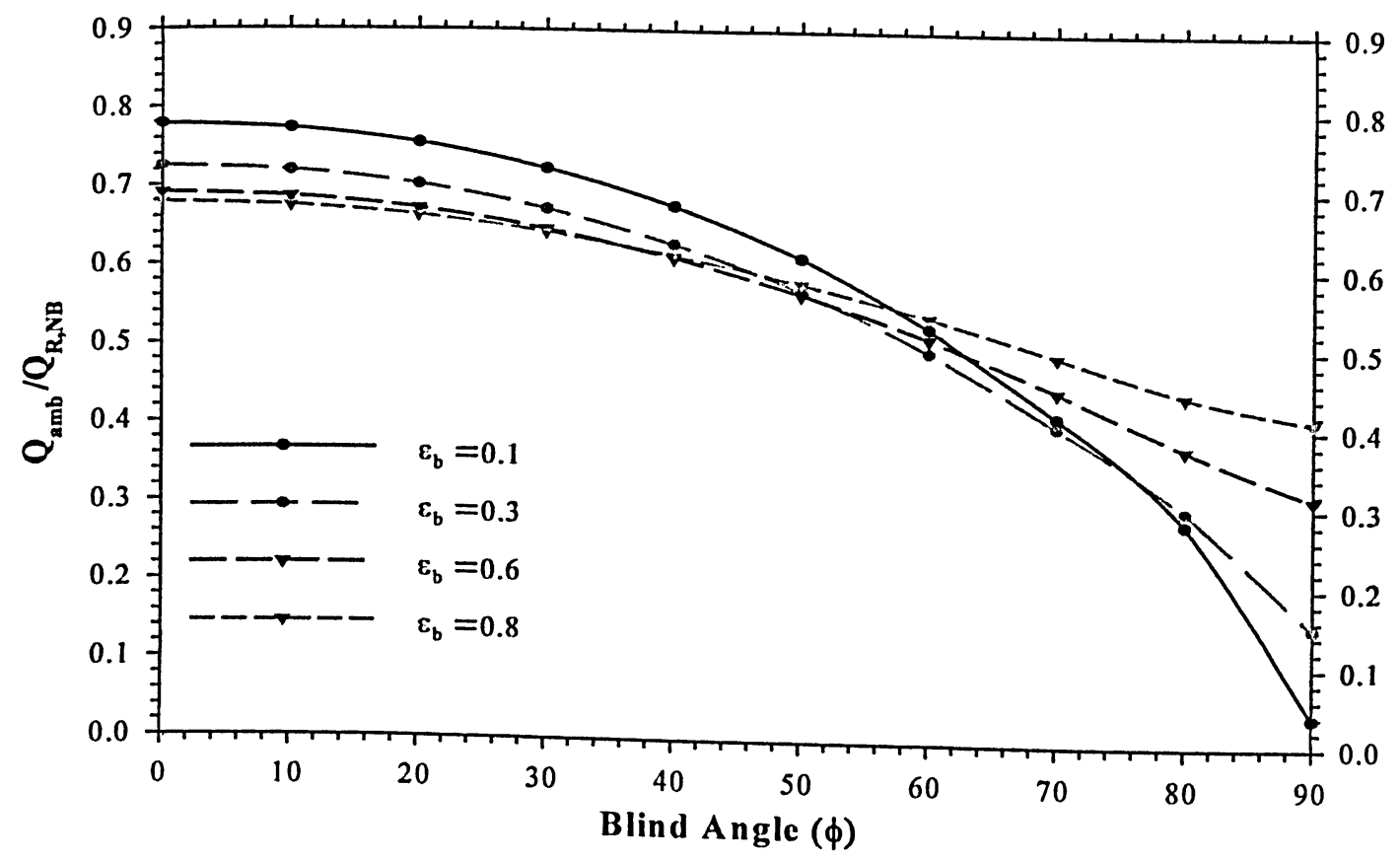

Figure 3.23 Variation of ambient radiation heat flux ratio for a double glazed window for summer conditions $\mathrm{d} / \mathrm{L}=0.043$.

\subsubsection{Effect of Blind on the Thermal Performance of an Energy Efficient Window with
low-e Coating}

A common situation involves energy efficient double glazed windows with low-e coatings. Figure 3.24 shows the effect of the louver angle $(\phi)$ on the U-value of a low-e double glazed window for summer conditions. For this window, the glazing gap cavity is filled with argon gas and low-e coating ranging from 0.1 to 0.4 , which is applied at surface (3). In this figure, the blind emissivity has been fixed at $\varepsilon_{b}=0.8$. It can be seen that, in all cases, the blind slightly improves the U-value. Depending on the low-e coating emissivity, the blind reduces the U-value about $8 \%$ when the blind is open $\left(\phi=0^{\circ}\right)$ and about $15 \%$ when the blind is fully closed $\left(\phi=90^{\circ}\right)$. As expected, decreasing the emissivity of the low-e coating decreases the 
effect of the blind. Decreasing the emissivity $\varepsilon_{3}$ decreases the indoor glazing surface temperature. For this reason, the magnitude of the radiative component of heat transfer becomes smaller and the influence of the blind on the U-value reduces.

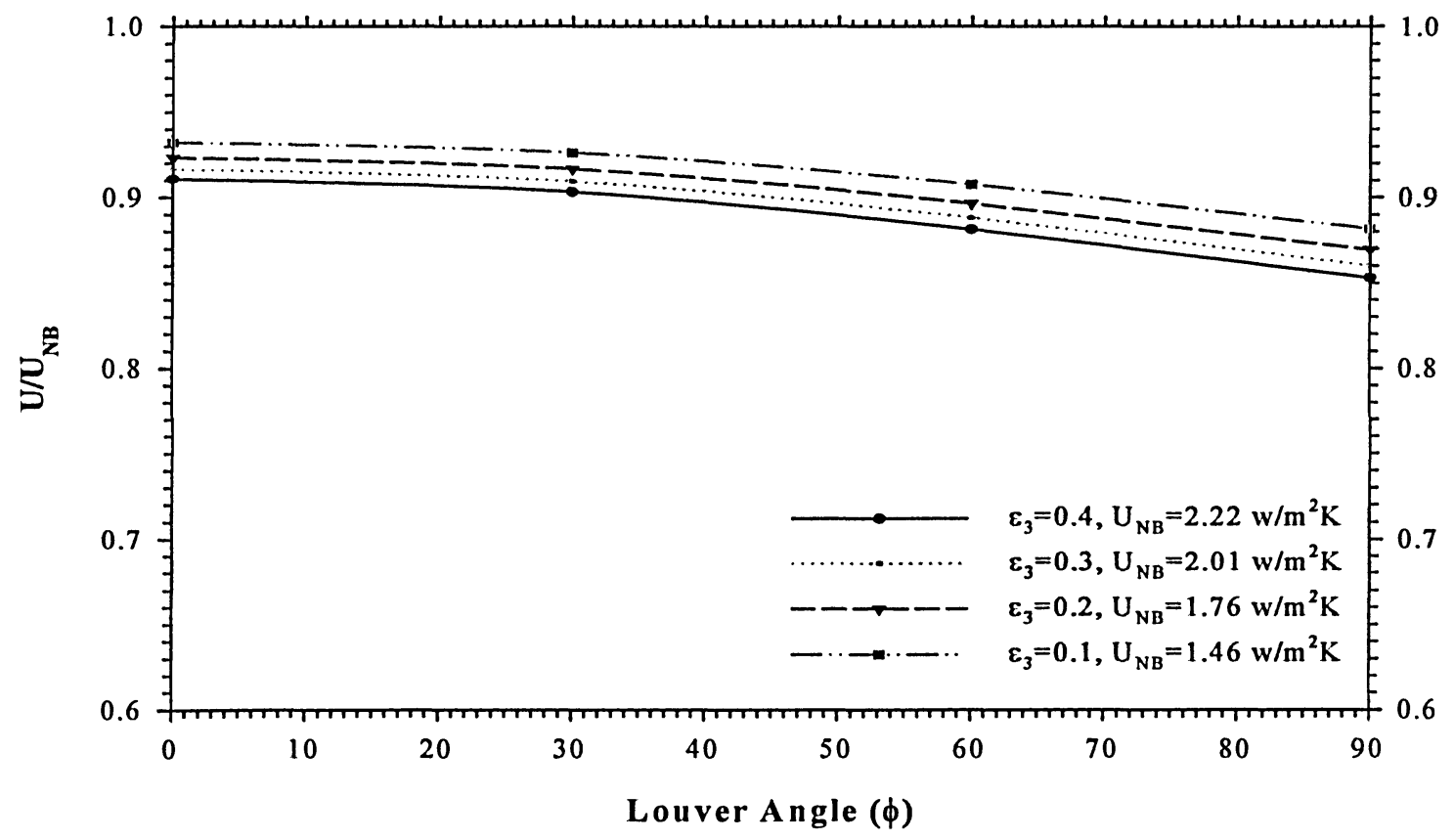

Figure 3.24 Variation of $U$-value ratio with louver angle for a low-e double glazed window for summer conditions $\left(\mathrm{d} / \mathrm{L}=0.043, \mathrm{~W} / \mathrm{ps}=1.14, \varepsilon_{\mathrm{b}}=0.8\right)$.

\subsubsection{On the "Optimum" Performance of the Window and Blind System}

It has been shown that the presence of a Venetian blind improves the thermal performance of a window. It has been observed that thermal performance of the window and blind system strongly depends on the blind tip-to-window spacing. It was shown that the Uvalue of the window was lower for the blind tip-to-window spacing of $d / L=0.012$ than $d / L=0.043$. Based on this observation, one may conclude that the energy performance of a window and blind system can be improved by reducing the blind tip-to-window spacing. It was also observed that the effect of the blind on the occupant thermal comfort was more beneficial for $d / L=0.043$ than $d / L=0.012$. Based on this observation, one may also conclude that thermal 
performance of a window and blind system can be improved by increasing the blind tip-towindow spacing.

In order to obtain the optimum benefits of the blinds, some trade-offs between the Uvalue and the occupant thermal comfort must be made. If energy performance is required, the blind should be placed very close to the window surface. If occupant thermal comfort is more important than energy performance, the blinds should be installed far away from the window. The author believes that the optimum performance of a window and blind system can be achieved by adjusting the blind tip-to-window spacing such that the magnitude of the convective heat transfer coefficient on the blind is equal to $h_{b}=0 \mathrm{~W} / \mathrm{m}^{2} \mathrm{~K}$. This blind tip-towindow spacing will provide the optimum performance due to the following:

* When the blind is placed at $d / L=0.043$, the $U$-value of the window is higher than $\mathrm{d} / \mathrm{L}=0.012$.

* For $\mathrm{d} / \mathrm{L}=0.043$, the blind is cooled by convection and adds to the cooling load of the building. This additional load on the HVAC equipment can also affect occupant thermal comfort.

When the blind is placed very close to the window, i.e., $\mathrm{d} / \mathrm{L}=0.012$, it is convectively heated or cooled and adds to the heating or the cooling load through net radiation emission.

Now, consider when the convective heat transfer coefficient on the blind is equal to $h_{b}=0 \mathrm{~W} / \mathrm{m}^{2} \mathrm{~K}$. The blind does not add to the heating or cooling load because the net 
radiative heat transfer from the blind is also equal to zero. For this reason, the blind tipto-window spacing corresponding to $h_{b}=0 \mathrm{~W} / \mathrm{m}^{2} \mathrm{~K}$ will be the "optimum" spacing.

Unfortunately, it is very difficult to predict the blind tip-to-window spacing corresponding to $h_{b}=0 \mathrm{~W} / \mathrm{m}^{2} \mathrm{~K}$ because it depends on the weather conditions, louver angle and the window geometry. Practically speaking, the optimum performance of a window and blind system cannot be achieved. However, an attempt should be made to maximize the benefits of the blind by manipulating the louver angle and the blind tip-to-window spacing. Under "nighttime" conditions, for an unoccupied conditioned space, the blind should be kept closed and the blind tip-to-window spacing should be decreased. In future, blind fixtures should be designed to manipulate the blind tip-to-window spacing for energy efficiency and thermal comfort.

\subsubsection{On the Accuracy of 1-D Thermal Resistance Model}

Examining the accuracy of present 1-D simplified thermal resistance model concludes this chapter. The numerical accuracy of the 1-D thermal resistance model is demonstrated by comparing the present predictions of $U$-value ratio $\left(\mathrm{U} / \mathrm{U}_{\mathrm{NB}}\right)$ with the finite volume solution [54]. In the finite volume study [54], the full conjugate (conduction/convection/radiation) heat transfer problem of a window and blind system was solved using a two-dimensional CFD model. The calculated $\mathrm{U}$-value ratio $\left(\mathrm{U} / \mathrm{U}_{\mathrm{NB}}\right)$ based on 1-D thermal resistance model and those obtained from the complete CFD model [54] are listed in Table 3.4. Comparisons are made for both single and double glazed window for summer conditions. The blind tip-to-window spacing has been fixed to $d / L=0.043$. It is evident that the present $1-D$ predictions agree well with the CFD solution [54]. The comparisons show very encouraging results, with all U-value 
results agreeing to within $3.2 \%$. This comparison clearly demonstrates that the current 1-D simplified thermal resistance model provides reasonably accurate estimates of the key energy performance indices associated with a window and blind system.

Table 3.4: Summer $U$-value ratio ( $U / U_{N B}$ ) Present 1-D model compared to CFD study [54]. $\mathrm{d} / \mathrm{L}=0.043, \varepsilon_{\mathrm{b}}=0.8, \mathrm{~W} / \mathrm{ps}=1.14$

\begin{tabular}{|c|c|c|c|}
\hline \multirow{2}{*}{ Window Type } & $\begin{array}{c}\text { Louver angle } \\
(\phi)\end{array}$ & $\begin{array}{c}1-\mathrm{D} \\
\left(\mathrm{U} / \mathrm{U}_{\mathrm{NB}}\right)\end{array}$ & $\begin{array}{c}\text { CFD [54] } \\
\left(\mathrm{U} / \mathrm{U}_{\mathrm{NB}}\right)\end{array}$ \\
\hline \multirow{3}{*}{ Single Glazed Window } & $0^{\circ}$ & 0.850 & 0.841 \\
\cline { 2 - 4 } & $30^{\circ}$ & 0.837 & 0.836 \\
\cline { 2 - 4 } & $60^{\circ}$ & 0.800 & 0.802 \\
\cline { 2 - 4 } & $90^{\circ}$ & 0.753 & 0.730 \\
\hline \multirow{3}{*}{ Double Glazed Window } & $0^{\circ}$ & 0.910 & 0.910 \\
\cline { 2 - 4 } & $30^{\circ}$ & 0.901 & 0.898 \\
\cline { 2 - 4 } & $60^{\circ}$ & 0.877 & 0.909 \\
\cline { 2 - 4 } & $90^{\circ}$ & 0.847 & 0.826 \\
\hline
\end{tabular}




\section{CHAPTER 4: CONCLUSIONS AND RECOMMENDATIONS}

\subsection{SUMMARY AND CONCLUSIONS}

A simplified numerical model for thermal analysis of a window and blind system has been developed. This model provides the heat exchange between a window and a Venetian blind for summer and winter conditions. The present solution applies to nighttime and daytime conditions with zero incident solar heat flux. The numerical modeling conducted in this study consisted of the following:

* Modeling of free convective heat exchange between an indoor glazing surface and a Venetian blind using finite element CFD analysis.

* Modeling of coupled conductive, convective and radiative heat transfer from a window and blind system using a 1-D thermal resistance approach.

In this study, the convective heat transfer coefficients on the indoor glazing surface and the blind were computed using a 2-D finite element model. These coefficients were then used in the 1-D thermal resistance model of a window and blind system. Calculations were performed to quantify the effect of the blind on the center-of-glass U-value of a window. In addition, the effect of the blind on the occupant thermal comfort was examined. The results have shown that: 
The presence of a blind has a significant effect on the convective and radiative heat transfer from a window.

* The convective heat transfer from the window and the blind depends strongly on the blind tip-to-window spacing $(\mathrm{d} / \mathrm{L})$. Decreasing the blind tip-to-window spacing $(\mathrm{d} / \mathrm{L})$ increases the interference of the blind with the flow and temperature fields near the window surface. In general, when this interference increases, conduction effects dominate over convection.

* In the conduction dominated regime, the convective heat transfer rates show strong dependence on the louver angle $(\phi)$ and dimensionless blind temperature $\left(\mathrm{T}_{\mathrm{b}}{ }^{*}\right)$ and weak dependence on the Rayleigh number $\left(\mathrm{Ra}_{\mathrm{L}}\right)$.

When the blind is placed far away from the window surface $(d / L=0.043)$, the convective heat transfer rates from the window are much less sensitive to the louver angle $(\phi)$ and the dimensionless blind temperature $\left(T_{b}{ }^{*}\right)$ than for $d / L=0.012$.

The blind improves the U-value of a window primarily by reducing thermal radiation heat transmission from the window.

The presence of a Venetian blind reduced the U-value of a single glazed window between $14 \%$ and $35 \%$. Increasing the louver angle $(\phi)$ improved the energy performance of the window.

The blind improved the U-value of a normal and Low-e (argon-filled) double glazed window between $9 \% \& 20 \%$ and $8 \% \& 15 \%$, respectively.

Blind tip-to-window spacing $(\mathrm{d} / \mathrm{L})$ has shown a strong effect on the $\mathrm{U}$-value. Decreasing the blind tip-to-window spacing from $d / L=0.043$ to $d / L=0.012$ improved the energy performance of both single and double glazed windows. 
On average, decreasing the blind tip-to-window spacing from $\mathrm{d} / \mathrm{L}=0.043$ to $\mathrm{d} / \mathrm{L}=0.012$ provided additional improvement in the U-value of a single and double glazed window by as much as $4 \%$ to $13 \%$.

The presence of the blind has been shown to increase the occupant thermal comfort by acting as a shield against the radiant heat transmission from the window.

The blind provided more thermal comfort when the blind was not convectively heated (in summer) i.e. when it was placed far away from the window surface $(d / L=0.043)$.

The presence of a Venetian blind increased the occupant thermal comfort by $20 \%$ to $69 \%$ and by $10 \%$ to $61 \%$ for a single and double glazed window, respectively.

The blind emissivity has a strong effect on the energy performance of a window. For $\phi=90^{\circ}$, decreasing the blind emissivity $\left(\varepsilon_{\mathrm{b}}\right)$ from 0.8 to 0.1 improved the U-value of a double glazed window by almost $22 \%$.

\subsection{RECOMMENDATIONS}

In order to obtain the benefits of blinds, some trade-offs between the U-value and the occupant thermal comfort must be made. If maximum energy performance is required, the blind should be placed very close to the window surface. If occupant thermal comfort is more important than energy performance, the blinds should be installed further away from the window. In future, blind fixtures should be designed to manipulate the blind tip-to-window spacing for energy efficiency and thermal comfort.

One limitation of the current model is that the convective heat transfer coefficients on the indoor glazing surface and the blind were computed assuming that the flow was laminar. 
Because of this assumption, restrictions had to be placed on the window size and the weather conditions. The laminar flow assumption had to be used because no experimental data pertaining to the turbulent flow regime is available to validate the numerical work. Practically speaking, more realistic estimates of the energy performance of a window and blind system can only be computed when the convective heat transfer coefficients associated with the turbulent flow regime are known. A study should be planned to obtain experimental data in the turbulent flow regime that may be used to validate future numerical work.

Another limitation of the current model is that it does not consider the frame effect on the convective heat transfer from a window and blind system. The frame effect should also be considered in the future. 
TITLE

BLIND TO WINDOW SPACING $\mathrm{d} / \mathrm{L}=0.043, \mathrm{~T} 0.2: \mathrm{RA}=1 . \mathrm{e}$

FIMESH(2-D,IMAX $=13, \mathrm{JMAX}=123, \mathrm{MXPOINT}=440$ )

EXPI

1017033049051069097

EXPJ

1029053061069077085093010101090117012501330141014901570165017301810189019702050213022102290237024502530 26102690277028502930301030903170325033303410349035703650373038103890397040504130421042904370445045304610 4690477048504930501050905170537

POINT

ANOI J KX Y

$\begin{array}{lllll}111 & 1 & 0 & -0.2\end{array}$

$21310-0.05$

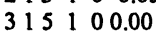

417100.017

519100.034

6111100.051

7113100.068

8115100.085

9117100.102

10119100.119

11121100.136

12123100.153

13125100.170

14127100.187

15129100.204

$\begin{array}{lllllll}16 & 131 & 0 & 0.221\end{array}$

17133100.238

18135100.255

19137100.272

20139100.289

21141100.306

22143100.323

23145100.340

24147100.357

25149100.374

26151100.391

27153100.408

28155100.425

29157100.442

30159100.459

31161100.476

32163100.493

33165100.510

34167100.527

35169100.544

36171100.561

37173100.578

38175100.595

39177100.612

40179100.629

41181100.646

42183100.663

43185100.680

44187100.697

45189100.714

46191100.731

47193100.748

48195100.765

49197100.782

50199100.799

511101100.816

521103100.833

531105100.850

541107100.867

551109100.884

561111100.901

571113100.918

581115100.935

591117100.952

4271119100.976
60112110100

611123101.15

$\begin{array}{lllll}6231 & 0.05 & -0.188\end{array}$

$\begin{array}{llll}6333 & 1 & 0.005-0.05\end{array}$

643510.0050 .00

$\begin{array}{llll}6537 & 1 & 0.0050 .017\end{array}$ $\begin{array}{llll}6639 & 1 & 0.0050 .034\end{array}$

6731110.0050 .051

6831310.0050 .068

6931510.0050 .085

7031710.0050 .102

7131910.0050 .119

7232110.0050 .136

7332310.0050 .153

7432510.0050 .170

7532710.0050 .187

7632910.0050 .204

7733110.0050 .221

7833310.0050 .238

7933510.0050 .255

8033710.0050 .272

8133910.0050 .289

8234110.0050 .306

8334310.0050 .323

8434510.0050 .340

8534710.0050 .357

8634910.0050 .374

8735110.0050 .391

8835310.0050 .408

8935510.0050 .425

9035710.0050 .442

9135910.0050 .459

9236110.0050 .476

9336310.0050 .493

9436510.0050 .510

9536710.0050 .527

9636910.0050 .544

9737110.0050 .561

9837310.0050 .578

9937510.0050 .595

10037710.0050 .612

10137910.0050 .629

10238110.0050 .646

10338310.0050 .663

10438510.0050 .680

10538710.0050 .697

10638910.0050 .714

10739110.0050 .731

10839310.0050 .748

10939510.0050 .765

11039710.0050 .782

11139910.0050 .799

112310110.0050 .816

113310310.0050 .833

114310510.0050 .850

115310710.0050 .867

116310910.0050 .884

117311110.0050 .901

118311310.0050 .918

119311510.0050 .935

120311710.0050 .952 
428311910.0050 .971

121312110.005 .995

122312310.0051 .15

$\begin{array}{lllll}12351 & 1 & 0.06 & -0.185\end{array}$ $1245310.038306-0.05$ 1255510.0383060 .00 $\begin{array}{llll}12657 & 0.0383060 .017\end{array}$ $\begin{array}{llll}12759 & 1 & 0.0383060 .034\end{array}$ $\begin{array}{lllll}1285111 & 0.0383060 .051\end{array}$ 12951310.0383060 .068 13051510.0383060 .085 $\begin{array}{llll}1315171 & 0.0383060 .102\end{array}$ 13251910.0383060 .119 13352110.0383060 .136 13452310.0383060 .153 13552510.0383060 .170 $\begin{array}{llll}136527 & 0.0383060 .187\end{array}$ $\begin{array}{lll}1375291 & 0.0383060 .204\end{array}$ $\begin{array}{llll}138531 & 0.038306 & 0.221\end{array}$ $\begin{array}{llll}139533 & 0.038306 & 0.238\end{array}$ $\begin{array}{lll}1405351 & 0.038306 & 0.255\end{array}$ $\begin{array}{lllll}1415371 & 0.038306 & 0.272\end{array}$ $\begin{array}{llll}142 & 53910.038306 & 0.289\end{array}$ $143541 \quad 10.0383060 .306$ $\begin{array}{llllll}144 & 5 & 43 & 1 & 0.038306 & 0.323\end{array}$ 14554510.0383060 .340 14654710.0383060 .357 $\begin{array}{lllllll}147 & 5 & 49 & 1 & 0.038306 & 0.374\end{array}$ 14855110.0383060 .391 14955310.0383060 .408 15055510.0383060 .425 15155710.0383060 .442 15255910.0383060 .459 15356110.0383060 .476 15456310.0383060 .493 15556510.0383060 .510 15656710.0383060 .527 15756910.0383060 .544 15857110.0383060 .561 15957310.0383060 .578 16057510.0383060 .595 16157710.0383060 .612 16257910.0383060 .629 16358110.0383060 .646 16458310.0383060 .663 16558510.0383060 .680 16658710.0383060 .697 16758910.0383060 .714 16859110.0383060 .731 16959310.0383060 .748 17059510.0383060 .765 17159710.0383060 .782 17259910.0383060 .799 173510110.0383060 .816 174510310.0383060 .833 175510510.0383060 .850

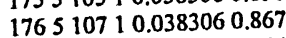
177510910.0383060 .884 178511110.0383060 .901 179511310.0383060 .918 180511510.0383060 .935 181511710.0383060 .952 429511910.0383060 .971 182512110.0383060 .99 183512310.0383061 .15

$\begin{array}{llll}18471 & 0.12 \quad-0.161\end{array}$ $\begin{array}{lllll}18573 & 1 & 0.0433077087 & -0.05\end{array}$ 1867510.04330770870 .00 $\begin{array}{llll}18777 & 0.0390261647 & 0.017\end{array}$ $\begin{array}{llll}18879 & 1 & 0.04330770870 .034\end{array}$ $\begin{array}{llllllll}189711 & 0.03902616470 .051\end{array}$ 19071310.04330770870 .068 $\begin{array}{lllll}1917 & 151 & 0.0390261647 & 0.085\end{array}$ 19271710.04330770870 .102 19371910.03902616470 .119 19472110.04330770870 .136
19572310.03902616470 .153 19672510.04330770870 .170 $19772710.0390261647 \quad 0.187$ 19872910.04330770870 .204 $\begin{array}{lllll}199731 & 0.0390261647 & 0.221\end{array}$ 20073310.04330770870 .238 $20173510.0390261647 \quad 0.255$ 20273710.04330770870 .272 20373910.03902616470 .289 20474110.04330770870 .306 $20574310.0390261647 \quad 0.323$ 20674510.04330770870 .340 20774710.03902616470 .357 20874910.04330770870 .374 20975110.03902616470 .391 21075310.04330770870 .408 $21175510.0390261647 \quad 0.425$ 21275710.04330770870 .442 21375910.03902616470 .459 21476110.04330770870 .476 21576310.03902616470 .493 21676510.04330770870 .510 21776710.03902616470 .527 21876910.04330770870 .544 21977110.03902616470 .561 22077310.04330770870 .578 22177510.03902616470 .595 22277710.04330770870 .612 22377910.03902616470 .629 22478110.04330770870 .646 22578310.03902616470 .663 22678510.04330770870 .680 22778710.03902616470 .697 22878910.04330770870 .714 22979110.03902616470 .731 23079310.04330770870 .748 23179510.03902616470 .765 23279710.04330770870 .782 23379910.03902616470 .799 234710110.04330770870 .816 235710310.03902616470 .833 236710510.04330770870 .850 237710710.03902616470 .867 238710910.04330770870 .884 239711110.03902616470 .901 240711310.04330770870 .918 241711510.03902616470 .935 242711710.04330770870 .952 $430711910.0390261647 \quad 0.971$ 243712110.0433077087 .99 244712310.04330770871 .15

$\begin{array}{llll}24591 & 1 & 0.122 & -0.1605\end{array}$ $2469310.0435587087-0.05$ 2479510.04355870870 .00 2489710.03927716470 .017 2499910.04355870870 .034 25091110.03927716470 .051 25191310.04355870870 .068 25291510.03927716470 .085 25391710.04355870870 .102 25491910.03927716470 .119 $\begin{array}{llll}255921 & 10.0435587087 & 0.136\end{array}$ 25692310.03927716470 .153 25792510.04355870870 .170 $\begin{array}{lllll}258927 & 0.0392771647 & 0.187\end{array}$ 25992910.04355870870 .204 $\begin{array}{lllll}260931 & 0.0392771647 & 0.221\end{array}$ 26193310.04355870870 .238 $26293510.0392771647 \quad 0.255$ $26393710.0435587087 \quad 0.272$ $26493910.0392771647 \quad 0.289$ $26594110.0435587087 \quad 0.306$ 26694310.03927716470 .323 $26794510.0435587087 \quad 0.340$ $26894710.0392771647 \quad 0.357$ $26994910.0435587087 \quad 0.374$ 27095110.03927716470 .391 27195310.04355870870 .408 27295510.03927716470 .425 
27395710.04355870870 .442 27495910.03927716470 .459 27596110.04355870870 .476 27696310.03927716470 .493 27796510.04355870870 .510 $\begin{array}{lllll}278967 & 0.0392771647 & 0.527\end{array}$ $\begin{array}{llllll}279969 & 0.0435587087 & 0.544\end{array}$ $\begin{array}{lllll}280971 & 1 & 0.0392771647 & 0.561\end{array}$ 28197310.04355870870 .578 28297510.03927716470 .595 $28397710.0435587087 \quad 0.612$ $28497910.0392771647 \quad 0.629$ 28598110.04355870870 .646 28698310.03927716470 .663 28798510.04355870870 .680 $\begin{array}{lllll}288987 & 0.0392771647 & 0.697\end{array}$ 28998910.04355870870 .714 29099110.03927716470 .731 $\begin{array}{lllll}291993 & 10.0435587087 & 0.748\end{array}$ 29299510.03927716470 .765 29399710.04355870870 .782 29499910.03927716470 .799 295910110.04355870870 .816 296910310.03927716470 .833 297910510.04355870870 .850 298910710.03927716470 .867 299910910.04355870870 .884 300911110.03927716470 .901 301911310.04355870870 .918 302911510.03927716470 .935 303911710.04355870870 .952 431911910.03927716470 .971 304912110.0435587087 .99 305912310.04355870871 .15

$30611110.18-0.1$

$\begin{array}{lllll}307 & 11 & 1 & 0.048092 & -0.05\end{array}$ 30811510.0480920 .00 $\begin{array}{llll}309117 & 1 & 0.0480920 .017\end{array}$ $\begin{array}{llll}310119 & 1 & 0.0480920 .034\end{array}$ $\begin{array}{llllll}311 & 11 & 111 & 0.0480920 .051\end{array}$ $\begin{array}{llllll}312 & 11 & 131 & 0.0480920 .068\end{array}$ $\begin{array}{lllll}313 & 11 & 151 & 0.048092 & 0.085\end{array}$ $\begin{array}{lllll}314 & 11 & 171 & 0.0480920 .102\end{array}$ 315111910.0480920 .119 316112110.0480920 .136 317112310.0480920 .153 $\begin{array}{llll}318 & 1125 & 1 & 0.0480920 .170\end{array}$ 319112710.0480920 .187 320112910.0480920 .204 321113110.0480920 .221 322113310.0480920 .238 323113510.0480920 .255 324113710.0480920 .272 325113910.0480920 .289 326114110.0480920 .306 327114310.0480920 .323 328114510.0480920 .340 329114710.0480920 .357 330114910.0480920 .374 $\begin{array}{llll}331 & 1151 & 0.048092 & 0.391\end{array}$ 332115310.0480920 .408 333115510.0480920 .425 334115710.0480920 .442 335115910.0480920 .459 336116110.0480920 .476 337116310.0480920 .493 338116510.0480920 .510 339116710.0480920 .527 340116910.0480920 .544 341117110.0480920 .561 342117310.0480920 .578 343117510.0480920 .595 344117710.0480920 .612 345117910.0480920 .629 346118110.0480920 .646 347118310.0480920 .663 348118510.0480920 .680 349118710.0480920 .697 350118910.0480920 .714 $\begin{array}{llll}351 & 119110.0480920 .731\end{array}$ 352119310.0480920 .748 353119510.0480920 .765 354119710.0480920 .782 355119910.0480920 .799 3561110110.0480920 .816 3571110310.0480920 .833 3581110510.0480920 .850 3591110710.0480920 .867 3601110910.0480920 .884 $\begin{array}{lllll}361 & 11 & 111 & 1 & 0.0480920 .901\end{array}$ 3621111310.0480920 .918 3631111510.0480920 .935 3641111710.0480920 .952 4321111910.0480920 .971 3651112110.048092 .99

3661112310.0480921 .15

$367133 \perp 0.18-0.1$ $\begin{array}{lllll}368 & 135 & 1 & 0.2 & 0.00\end{array}$ $\begin{array}{lllllllllllllll}369 & 137 & 0.2 & 0.017\end{array}$ 37013910.20 .034 371131110.20 .051 $\begin{array}{lllll}372 & 13131 & 0.20 .068\end{array}$ $\begin{array}{lllll}373 & 13151 & 0.20 .085\end{array}$ $\begin{array}{lllll}37413 & 1710.20 .102\end{array}$ 375131910.20 .119 376132110.20 .136 377132310.20 .153 378132510.20 .170 379132710.20 .187 380132910.20 .204 $\begin{array}{lllllll}381 & 1331 & 0.2 & 0.221\end{array}$

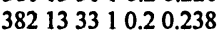
383133510.20 .255 $\begin{array}{llll}384 & 1337 & 0.2 & 0.272\end{array}$ 385133910.20 .289 386134110.20 .306 $\begin{array}{lllllll}387 & 1343 & 0.2 & 0.323\end{array}$ 388134510.20 .340 $3891347 \quad 0.20 .357$ 390134910.20 .374 391135110.20 .391 392135310.20 .408 393135510.20 .425 394135710.20 .442 395135910.20 .459 396136110.20 .476 397136310.20 .493 398136510.20 .510 399136710.20 .527 400136910.20 .544 401137110.20 .561 402137310.20 .578 403137510.20 .595 404137710.20 .612 405137910.20 .629 406138110.20 .646 407138310.20 .663 408138510.20 .680 409138710.20 .697 410138910.20 .714 411139110.20 .731 412139310.20 .748 413139510.20 .765 414139710.20 .782 415139910.20 .799 4161310110.20 .816 4171310310.20 .833 4181310510.20 .850 4191310710.20 .867 4201310910.20 .884 4211311110.20 .901 4221311310.20 .918 4231311510.20 .935 4241311710.20 .952 4331311910.20 .971 4251312110.2 .99 4261312310.21 .15 


$$
11
$$


174175

175176

176177

177178

178179

179180

180181

181429

429182

1821833.3

1841853.4

1851864.4

2452463.4

2462474.4

2432443.3

3043053.3

3063073.4

3073084.4

308309

309310

310311

311312

312313

313314

314315

315316

316317

317318

318319

319320

320321

321322

322323

323324

324325

325326

326327

327328

328329

329330

330331

331332

332333

333334

334335

335336

336337

337338

338339

339340

340341

341342

342343

343344

344345

345346 .

346347

355356

356357

357358

358359

359360

360361

361362

362363

363364

364432

432365

3653663.3

367368

368369

369370

370371

371372

372373

373374

374375

375376

376377

377378

378379

379380

380381

381382

382383

383384

384385

385386

386387

387388

388389

389390

390391

391392

392393

393394

394395

395396

396397

397398

398399

399400

400401

401402

402403

403404

404405

405406

406407

407408

408409

409410

410411

411412

412413

413414

414415

415416

416417

417418

418419

419420

420421

421422

422423

423424

424433 
433425

4254263.3

$73 \quad 1343.4$

$\begin{array}{ll}74 & 1353.4\end{array}$

751363.4

MORIZONTAL

$76 \quad 1373.4$

$\begin{array}{ll}77 & 1383.4\end{array}$

/pt pt ratio irat

781393.4

791403.4

801413.4

11623.3

2633.3

3643.3

4653.3

5663.3

6673.3

7683.3

8693.3

9703.3

10713.3

11723.3

12733.3

13743.3

14753.3

15763.3

16773.3

17783.3

18793.3

19803.3

20813.3

21823.3

22833.3

23843.3

24853.3

25863.3

26873.3

27883.3

28893.3

29903.3

30913.3

31923.3

32933.3

33943.3

34953.3

35963.3

36973.3

37983.3

38993.3

391003.3

401013.3

411023.3

421033.3

431043.3

441053.3

451063.3

461073.3

471083.3

481093.3

491103.3

501113.3

511123.3

521133.3

531143.3

541153.3

551163.3

561173.3

571183.3

581193.3

591203.3

601213.3

611223.3

631243.4

$\begin{array}{ll}64 & 1253.4\end{array}$

651263.4

661273.4

$\begin{array}{ll}67 & 1283.4\end{array}$

$\begin{array}{lll}68 & 1293.4\end{array}$

$\begin{array}{lll}69 & 1303.4\end{array}$

701313.4

711323.4

721333.4

811423.4

831443.4

841453.4

851463.4

$86 \quad 1473.4$

871483.4

$\begin{array}{ll}88 & 1493.4\end{array}$

891503.4

$90 \quad 1513.4$

$91 \quad 1523.4$

921533.4

931543.4

941553.4

951563.4

$96 \quad 1573.4$

$97 \quad 1583.4$

981593.4

991603.4

1001613.4

1011623.4

$\begin{array}{lll}102 & 1633.4\end{array}$

1031643.4

1041653.4

1051663.4

1061673.4

1071683.4

$108 \quad 1693.4$

1091703.4

1101713.4

1111723.4

1121733.4

$113 \quad 1743.4$

$114 \quad 1753.4$

1151763.4

1161773.4

1171783.4

$118 \quad 1793.4$

1191803.4

$120 \quad 1813.4$

$121 \quad 1823,4$

1221833.4

1241853.4

1251863.4

1261873.4

1271883.4

1281893.4

1291903.4

1301913.4

1311923.4

1321933.4

1331943.4

1341953.4

1351963.4

1361973.4

1371983.4

1381993.4

1392003.4

1402013.4

1412023.4

1422033.4

1432043.4

1442053.4

1452063.4

1462073.4

1472083.4

1482093.4

1492103.4

1502113.4 
1512123.4
1522133.4
1532143.4
1542153.4
1552163.4
1562173.4
1572183.4
1582193.4
1592203.4
1602213.4
1612223.4
1622233.4
1632243.4
1642253.4
1652263.4
1662273.4
1672283.4
1682293.4
1692303.4
1702313.4
1712323.4
1722333.4
1732343.4
1742353.4
1752363.4
1762373.4
1772383.4
1782393.4
1792403.4
1802413.4
1812423.4
1822433.4
1832443.4

185246

186247

244305

243304

242303

2463073.3

2473083.3

2483093.3

2493103.3

2503113.3

2513123.3

2523133.3

2533143.3

2543153.3

2553163.3

2563173.3

2573183.3

2583193.3

2593203.3

2603213.3

2613223.3

2623233.3

2633243.3

2643253.3

2653263.3

2663273.3

2673283.3

2683293.3

2693303.3

2703313.3

2713323.3

2723333.3

2733343.3

2743353.3

2753363.3

2763373.3

2773383.3

2783393.3

2793403.3

2803413.3

2813423.3

2823433.3

2833443.3
2843453.3

2853463.3

2863473.3

2873483.3

2883493.3

2893503.3

2903513.3

2913523.3

2923533.3

2933543.3

2943553.3

2953563.3

2963573.3

2973583.3

2983593.3

2993603.3

3003613.3

3013623.3

3023633.3

3033643.3

3043653.3

3053663.3

3073673.3

3083683.3

3093693.3

3103703.3

3113713.3

3123723.3

3133733.3

3143743.3

3153753.3

3163763.3

3173773.3

3183783.3

3193793.3

3203803.3

3213813.3

3223823.3

3233833.3

3243843.3

3253853.3

3263863.3

3273873.3

3283883.3

3293893.3

3303903.3

3313913.3

3323923.3

3333933.3

3343943.3

3353953.3

3363963.3

3373973.3

3383983.3

3393993.3

3404003.3

3414013.3

3424023.3

3434033.3

3444043.3

3454053.3

3464063.3

3474073.3

3484083.3

3494093.3

3504103.3

3514113.3

3524123.3

3534133.3

3544143.3

3554153.3

3564163.3

3574173.3

3584183.3

3594193.3

3604203.3

3614213.3

3624223.3

3634233.3 


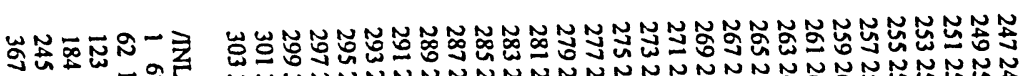

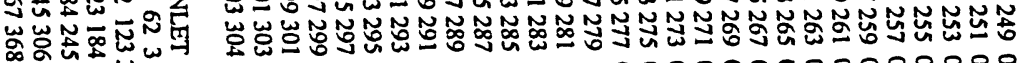
00000000000000000000000000000

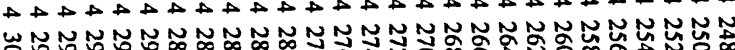

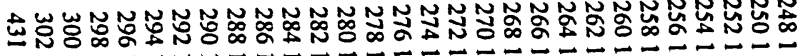

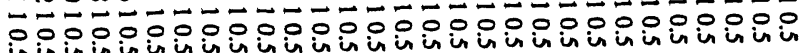

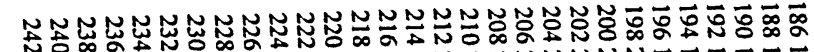
NN

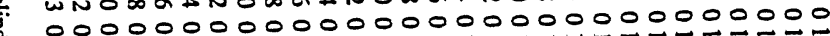
1. ANUTE

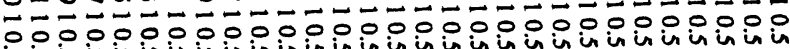

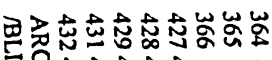

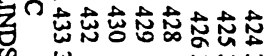

wim

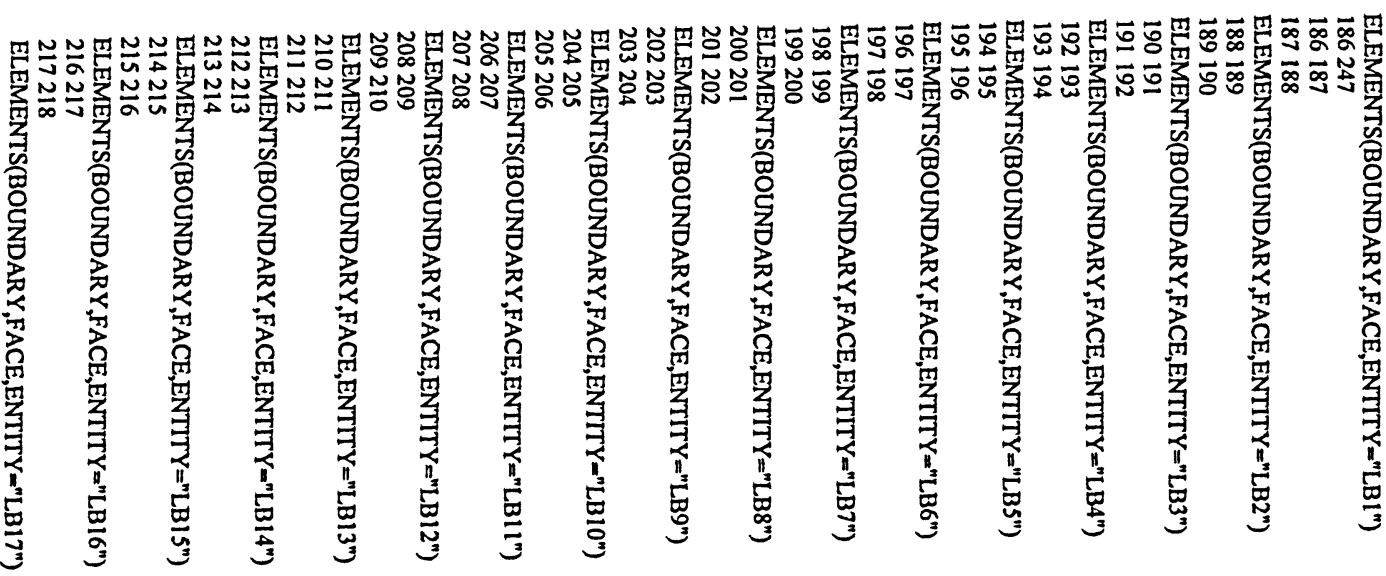

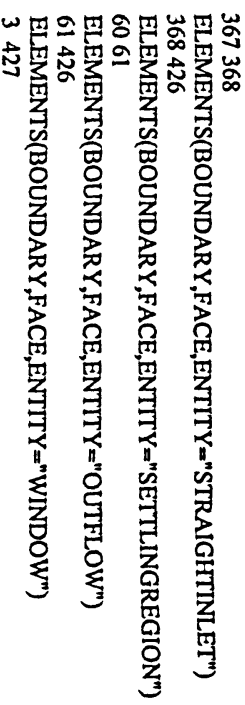

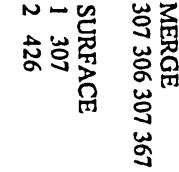

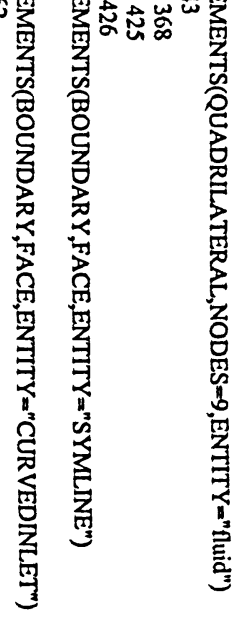




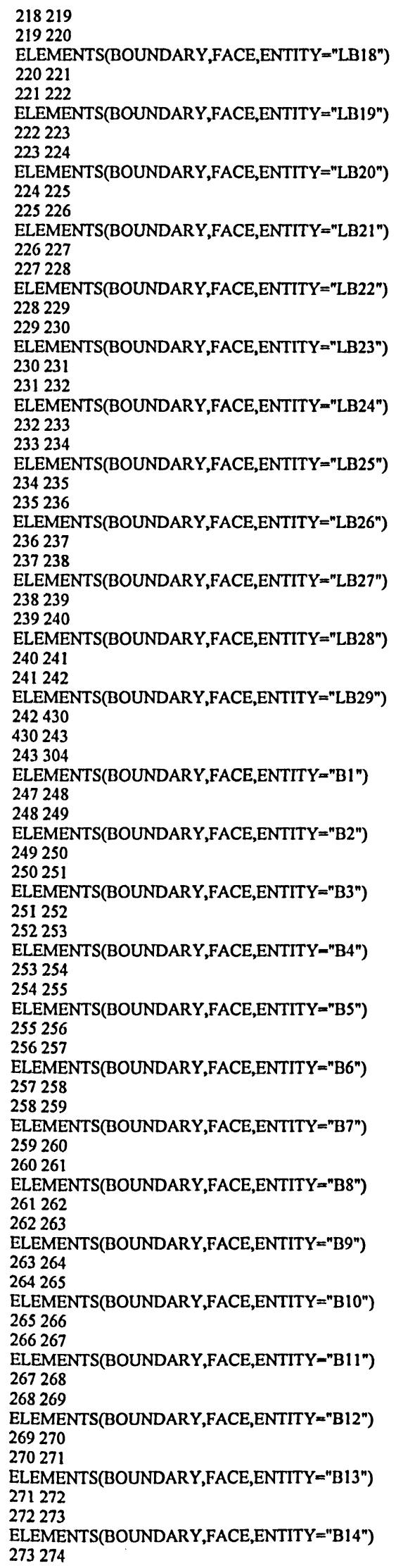

274275

ELEMENTS(BOUNDARY,FACE,ENTITY="B15")

275276

276277

ELEMENTS(BOUNDARY,FACE,ENTITY="B16")

277278

278279

ELEMENTS(BOUNDARY,FACE,ENTITY $=" B 17 ")$

279280

280281

ELEMENTS(BOUNDARY,FACE,ENTTTY $=" B 18$ ")

281282

282283

ELEMENTS(BOUNDARY,FACE,ENTITY="B19")

283284

284285

ELEMENTS(BOUNDARY,FACE,ENTITY="B20")

285286

286287

ELEMENTS(BOUNDARY,FACE,ENTITY="B21")

287288

288289

ELEMENTS(BOUNDARY,FACE,ENTITY="B22")

289290

290291

ELEMENTS(BOUNDARY,FACE,ENTITY="B23")

291292

292293

ELEMENTS(BOUNDARY,FACE,ENTITY="B24")

293294

294295

ELEMENTS(BOUNDARY,FACE,ENTITY $=$ "B25")

295296

296297

ELEMENTS(BOUNDARY,FACE,ENTITY="B26")

297298

298299

ELEMENTS(BOUNDARY,FACE,ENTITY="B27")

299300

300301

ELEMENTS(BOUNDARY,FACE,ENTITY="B28")

301302

302303

ELEMENTS(BOUNDARY,FACE,ENTITY="B29")

303431

431304

END

FIPREP

PROBLEM(NONLINEAR,BUOYANCY)

PRESSURE(PENALTY=1.E-8,DISCONTINUOUS)

$S P R=.71$

SPECIFICHEAT $($ CONSTANT $=$ \$PR)

VISCOSITY(CONSTANT $=1$.)

VOLUMEX(CONSTANT $=1$ )

GRAVITY(MAGNITUDE $=1$ )

The following four commands are replaced for restarts /EXECUTION(NEWJOB)

ISOLUTION(N.R. $=6$, VELCONV $=0.005$, RESCONV $=0.005$ )

ISTRATEGY(S.S. $=1)$

EXECUTION(RESTART)

SOLUTION $(\mathrm{S} . \mathrm{S} .=20, \mathrm{VELCONV}=.001, \mathrm{RESCONV}=.001, \mathrm{ACCF}=0.9)$

SRA $=1 . E+7$

DENSITY(CONSTANT $=$ SQRT(\$RA/SPR))

DATAPRINT(NORMAL,PAGE,NODES)

POSTPROCESS

ENTITY(FLUID,NAME="fluid")

ENTITY(PLOT,NAME="STRAIGHTINLET")

ENTITY(PLOT,NAME="SETTLINGREGION")

ENTITY(PLOT,NAME="OUTFLOW")

ENTITY(PLOT,NAME-"WINDOW")

ENTITY(SLIP,NAME $=$ "CURVEDINLET")

ENTITY(PLOT,NAME $=$ "SYMLINE")

ENTITY(PLOT,NAME="LB1")

ENTITY(PLOT,NAME="LB2")

ENTITY(PLOT,NAME="LB3") 


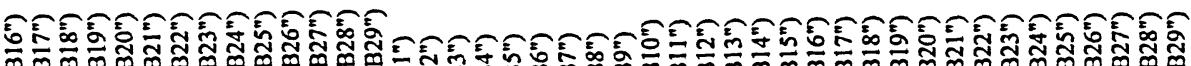

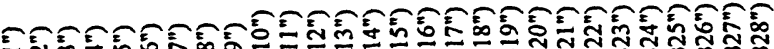

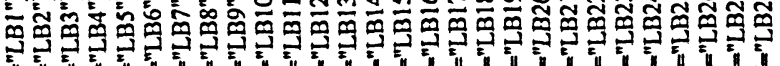
iI EE

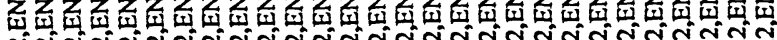
Oี

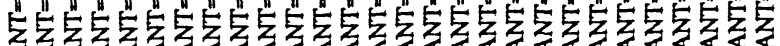
< $4<1$

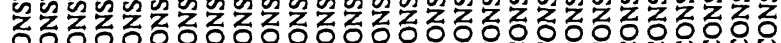
o o o o o o o o 0 0 0 0 0 0 0 0 0 0 0 w जी जी

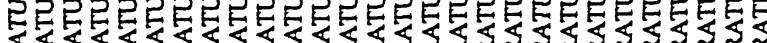
s

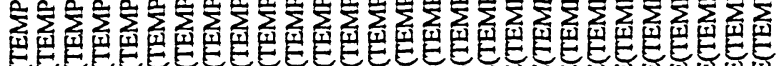

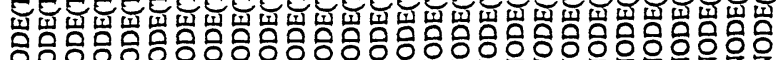

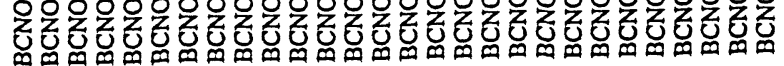

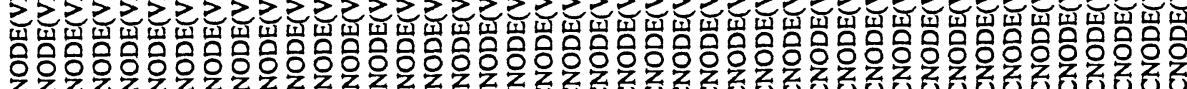

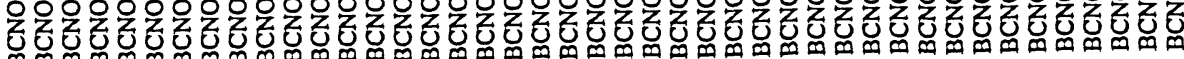

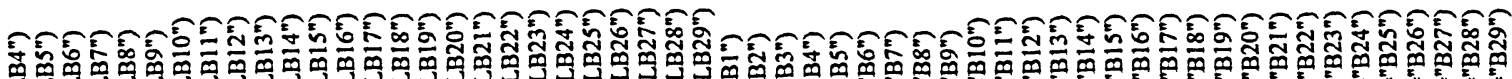

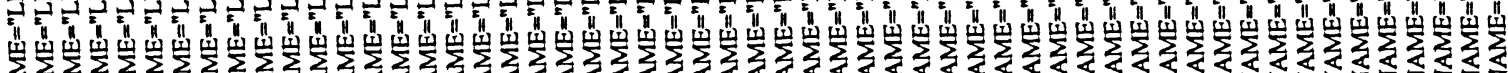

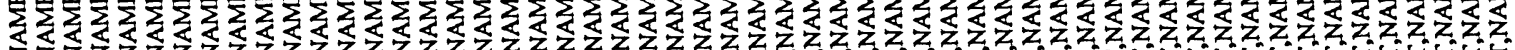
ó

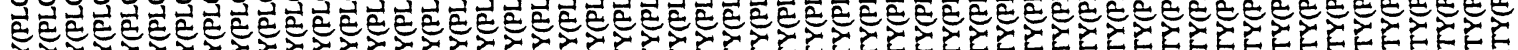

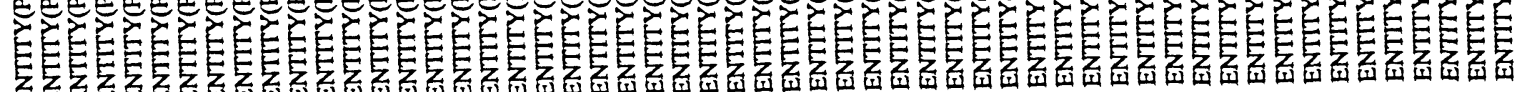

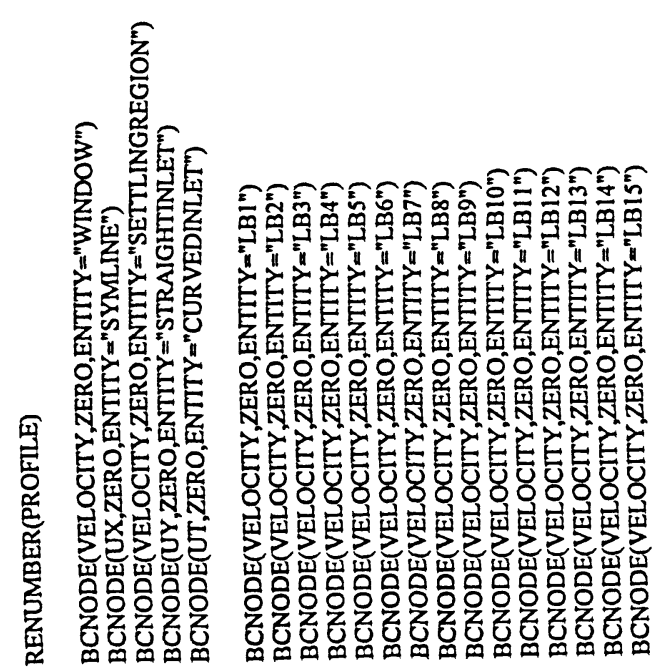




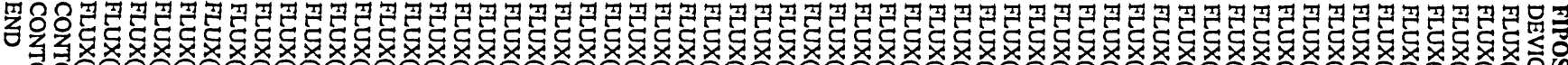

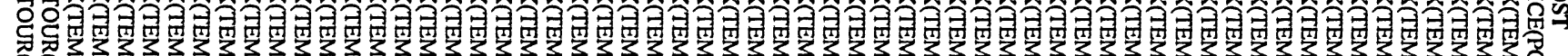

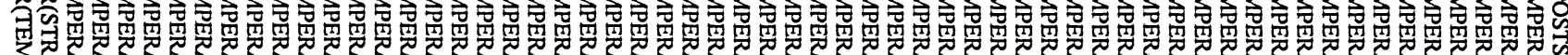

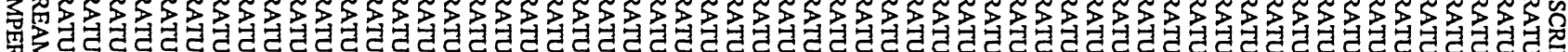

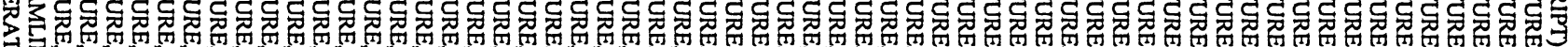
鱼讨

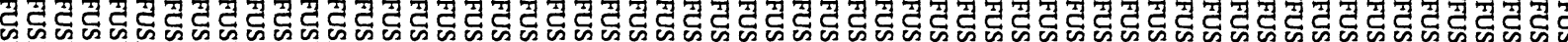

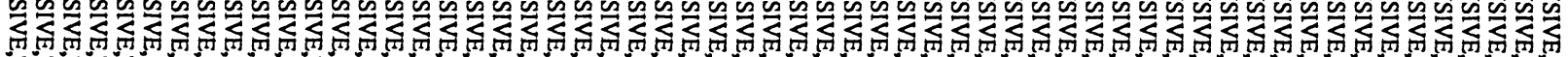

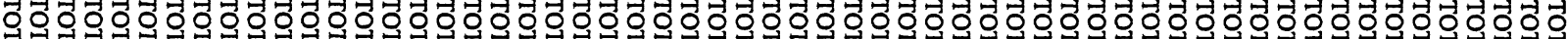
43

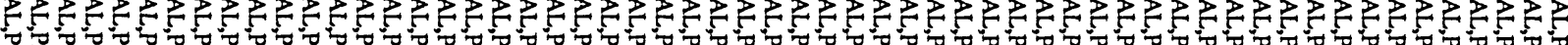

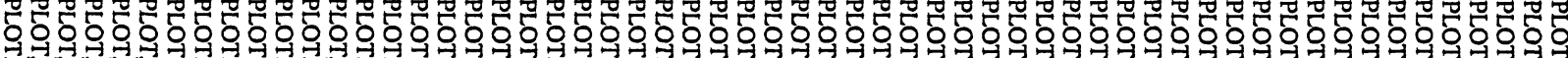

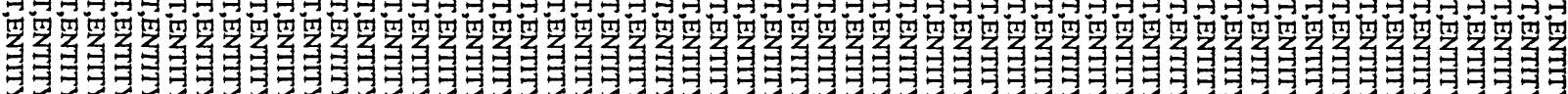

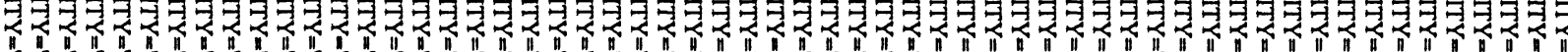

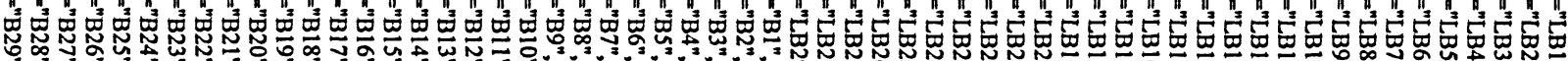

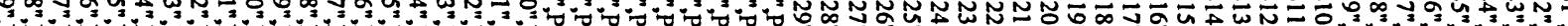

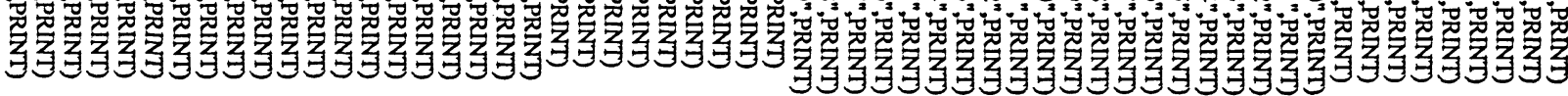

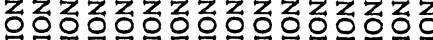

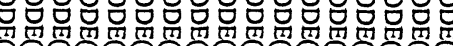

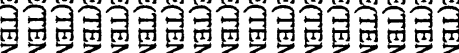

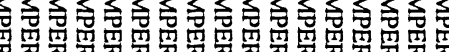

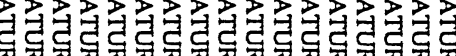

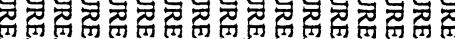
28083808808088080

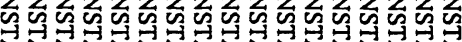

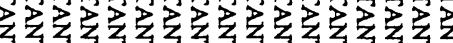

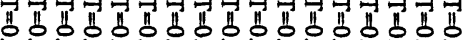

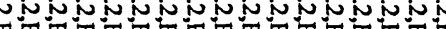

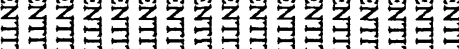

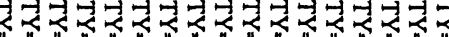

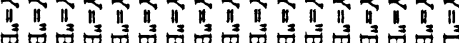

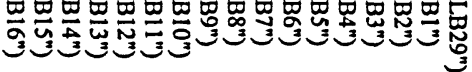


The data provided below is an example of the local heat flux ( $\left.q_{i, a v g}\right)$. Note complete output for each run is printed on more than 366 pages.

LIST OF DEFINING GROUPS:

1516

1ELEMENT SIDE

INTEGRATION POINT FLUXES/QUANTITIES INTEGRATED HEAT FLOW

561

4

DIFFUSIVE NORMAL $-0.2641342 E+03-0.6759773 E+03$

$\mathrm{X} \quad 0.2641342 \mathrm{E}+03 \quad 0.6759773 \mathrm{E}+03$

Y $\quad 0.0000000 \mathrm{E}+00 \quad 0.0000000 \mathrm{E}+00$

$-0.1997737 \mathrm{E}+01$

$0.1997737 \mathrm{E}+01$

$0.0000000 \mathrm{E}+00$

CONVECTIVE NORMAL $\quad 0.0000000 \mathrm{E}+00 \quad 0.0000000 \mathrm{E}+00$

$\begin{array}{lll}\mathrm{X} & 0.0000000 \mathrm{E}+00 \quad 0.0000000 \mathrm{E}+00\end{array}$

$0.0000000 \mathrm{E}+00$

Y $\quad 0.0000000 \mathrm{E}+00 \quad 0.0000000 \mathrm{E}+00$

$0.0000000 \mathrm{E}+00$

$0.0000000 \mathrm{E}+00$

TOTAL NORMAL $-0.2641342 E+03-0.6759773 E+03$

$\begin{array}{lll}X & 0.2641342 \mathrm{E}+03 & 0.6759773 \mathrm{E}+03\end{array}$

$\mathrm{Y} \quad 0.0000000 \mathrm{E}+00 \quad 0.0000000 \mathrm{E}+00$

$-0.1997737 \mathrm{E}+01$

$0.1997737 \mathrm{E}+01$

$0.0000000 \mathrm{E}+00$

COORDINATE ARC LN $0.3351869 \mathrm{E}-02 \quad 0.8981307 \mathrm{E}-03$

$\begin{array}{lll}\mathrm{X} & 0.0000000 \mathrm{E}+00 \quad 0.0000000 \mathrm{E}+00\end{array}$

$0.4250000 \mathrm{E}-02$

$\mathrm{Y} \quad 0.3351869 \mathrm{E}-02 \quad 0.8981307 \mathrm{E}-03$

$\begin{array}{llll}\text { NORMAL VEC } & X-0.1000000 \mathrm{E}+01 & -0.1000000 \mathrm{E}+01 \\ \mathrm{Y} & 0.0000000 \mathrm{E}+00 & 0.0000000 \mathrm{E}+00\end{array}$

$581 \quad 4$

DIFFUSIVE NORMAL $-0.2534075 \mathrm{E}+03-0.3148363 \mathrm{E}+03$

$\begin{array}{lll}\mathrm{X} & 0.2534075 \mathrm{E}+03 \quad 0.3148363 \mathrm{E}+03\end{array}$

$\begin{array}{lll}\mathrm{Y} & 0.1136868 \mathrm{E}-12 & 0.0000000 \mathrm{E}+00\end{array}$

$-0.1207518 \mathrm{E}+01$

$0.1207518 \mathrm{E}+01$

$0.2415845 \mathrm{E}-15$

CONVECTIVE NORMAL $\quad 0.0000000 \mathrm{E}+00 \quad 0.0000000 \mathrm{E}+00$

$\begin{array}{lll}\mathrm{X} & 0.0000000 \mathrm{E}+00 & 0.0000000 \mathrm{E}+00\end{array}$

$0.0000000 \mathrm{E}+00$

$\begin{array}{lll}\mathrm{Y} & 0.0000000 \mathrm{E}+00 \quad 0.0000000 \mathrm{E}+00\end{array}$

$0.0000000 \mathrm{E}+00$

$0.0000000 \mathrm{E}+00$ 
In this study, the average convective heat transfer coefficients on the indoor glazing surface and the blind were calculated using linear interpolation between the Rayleigh number $\left(\mathrm{Ra}_{\mathrm{L}}\right)$, louver angle $(\phi)$ and the blind temperature $\left(\mathrm{T}_{\mathrm{b}}{ }^{*}\right)$. The data provided below are examples of the average dimensionless convective heat transfer rates from the indoor glazing surface.

Table C-1: Average Nusselt number data for the indoor window surface, $\phi=0^{\circ}$.

\begin{tabular}{|c|c|c|c|c|c|c|c|c|}
\hline \multirow[b]{2}{*}{$\mathbf{R} \mathbf{a}_{I_{1}}$} & \multicolumn{4}{|c|}{$\begin{array}{c}N u_{\text {avg }} \\
d / L=0.012\end{array}$} & \multicolumn{4}{|c|}{$\begin{array}{c}N u_{\text {avg }} \\
d / L=0.043\end{array}$} \\
\hline & $T_{b}{ }^{*}=0.2$ & $T_{b}{ }^{*}=0.3$ & $T_{b}{ }^{*}=0.4$ & $T_{b}{ }^{*}=0.5$ & $T_{b}{ }^{*}=0.2$ & $T_{b}{ }^{*}=0.3$ & $T_{b}{ }^{*}=0.4$ & $T_{b}{ }^{*}=0.5$ \\
\hline $1.00 \mathrm{E}+04$ & 42.64 & 37.34 & 32.05 & 26.75 & 16.13 & 14.15 & 12.18 & 10.20 \\
\hline $1.00 \mathrm{E}+05$ & 42.68 & 37.39 & 32.10 & 26.81 & 16.26 & 14.30 & 12.38 & 10.40 \\
\hline $1.00 \mathrm{E}+06$ & 42.82 & 37.53 & 32.26 & 26.99 & 17.55 & 15.69 & 13.84 & 11.95 \\
\hline $1.00 \mathrm{E}+07$ & 43.41 & 38.26 & 33.09 & 27.89 & 25.83 & 24.14 & 22.37 & 20.44 \\
\hline $1.00 \mathrm{E}+08$ & 51.62 & 46.04 & 40.48 & 34.94 & 48.00 & 47.37 & 46.19 & 44.62 \\
\hline $5.00 \mathrm{E}+08$ & 68.84 & 63.25 & 57.84 & 52.19 & 74.82 & 75.09 & 74.05 & 73.22 \\
\hline
\end{tabular}

Table C-2: Average Nusselt number data for the indoor window surface, $\phi=45^{\circ}$.

\begin{tabular}{|c|c|c|c|c|c|c|c|c|}
\hline \multirow[b]{2}{*}{$\mathrm{Ra}_{\mathrm{l}}$} & \multicolumn{4}{|c|}{$\begin{array}{c}\mathrm{Nu}_{\text {avg }} \\
\mathrm{d} / \mathrm{L}=\mathbf{0 . 0 1 2}\end{array}$} & \multicolumn{4}{|c|}{$\begin{array}{c}\mathrm{Nu}_{\mathrm{avg}} \\
\mathrm{d} / \mathrm{L}=\mathbf{0 . 0 4 3}\end{array}$} \\
\hline & $\mathrm{T}_{\mathrm{b}}{ }^{*}=0.2$ & $\mathrm{~T}_{\mathrm{b}}^{*}=0.3$ & $\mathrm{~T}_{\mathrm{b}}^{*}=0.4$ & $\mathrm{~T}_{\mathrm{b}}{ }^{*}=0.5$ & $\mathrm{~T}_{\mathrm{b}}^{*}=0.2$ & $\mathrm{~T}_{\mathrm{b}}{ }^{*}=0.3$ & $\mathrm{~T}_{\mathrm{b}}{ }^{*}=0.4$ & $\mathrm{~T}_{\mathrm{b}}{ }^{*}=0.5$ \\
\hline $1.00 \mathrm{E}+04$ & 55.00 & 48.91 & 42.82 & 36.81 & 16.92 & 14.83 & 12.76 & 10.68 \\
\hline $1.00 \mathrm{E}+05$ & 55.02 & 48.94 & 42.84 & 36.89 & 17.06 & 15.00 & 12.91 & 10.82 \\
\hline $1.00 \mathrm{E}+06$ & 55.10 & 49.01 & 42.96 & 37.06 & 18.31 & 16.36 & 14.49 & 12.59 \\
\hline $1.00 \mathrm{E}+07$ & 55.49 & 49.57 & 43.51 & 38.00 & 26.37 & 24.86 & 23.23 & 21.57 \\
\hline $1.00 \mathrm{E}+08$ & 59.80 & 54.00 & 48.23 & 42.99 & 48.51 & 47.98 & 47.28 & 46.10 \\
\hline $5.00 \mathrm{E}+08$ & 74.51 & 69.09 & 63.10 & 58.42 & 76.63 & 76.26 & 75.61 & 75.69 \\
\hline
\end{tabular}

Table C-3: Average Nusselt number data for the indoor window surface, $\phi=90^{\circ}$.

\begin{tabular}{|c|c|c|c|c|c|c|c|c|}
\hline \multirow[b]{2}{*}{$\mathbf{R a}_{\mathbf{L}}$} & \multicolumn{4}{|c|}{$\begin{array}{c}\mathrm{Nu}_{\text {2vg }} \\
\mathrm{d} / \mathrm{L}=\mathbf{0 . 0 1 2}\end{array}$} & \multicolumn{4}{|c|}{$\begin{array}{c}\mathrm{Nu}_{\text {avg }} \\
\mathrm{d} / \mathrm{L}=\mathbf{0 . 0 4 3}\end{array}$} \\
\hline & $\mathrm{T}_{\mathrm{b}}{ }^{*}=0.2$ & $\mathrm{~T}_{\mathrm{b}}{ }^{*}=0.3$ & $T_{b}{ }^{*}=0.4$ & $T_{b}{ }^{*}=0.5$ & $\mathrm{~T}_{\mathrm{b}}{ }^{*}=0.2$ & $T_{b}{ }^{*}=0.3$ & $T_{b}^{*}=0.4$ & $T_{b}{ }^{*}=0.5$ \\
\hline $1.00 E+04$ & 92.45 & 80.91 & 69.37 & 57.22 & 20.14 & 17.65 & 15.16 & 12.81 \\
\hline $1.00 \mathrm{E}+05$ & 92.50 & 80.96 & 69.42 & 57.28 & 20.24 & 17.74 & 15.29 & 12.81 \\
\hline $1.00 \mathrm{E}+06$ & 92.58 & 81.04 & 69.51 & 57.37 & 21.08 & 18.71 & 16.36 & 13.76 \\
\hline $1.00 \mathrm{E}+07$ & 92.74 & 81.20 & 69.66 & 57.52 & 29.27 & 27.85 & 26.52 & 25.21 \\
\hline $1.00 \mathrm{E}+08$ & 93.47 & 81.85 & 70.56 & 58.68 & 58.20 & 58.47 & 57.40 & 57.61 \\
\hline $5.00 \mathrm{E}+08$ & 97.73 & 86.81 & 76.06 & 64.75 & 84.98 & 88.95 & 87.57 & 87.55 \\
\hline
\end{tabular}


The data provided below are examples of the average heat flux $\left(\mathrm{q}_{\mathrm{i}, \mathrm{avg}}\right)$ for the individual blind louver. Due to the large quantity of solutions not every solution could be presented in this appendix. The convective heat transfer coefficient for each louver is calculated using equation (2.65) given below:

$$
N u_{b, i}=\frac{-q_{i, a v g}(2 W)}{\left(T_{b}-T_{\infty}\right)}, h_{b, i}=\frac{N u_{b, i} k_{F}}{2 W}=\frac{-q_{i, a v g}\left(T_{w}-T_{\infty}\right) k_{F}}{L\left(T_{b}-T_{\infty}\right)}
$$

Note when the louver angle $\phi=90^{\circ}$, each louver is divided into two-sections. The average heat transfer coefficient for the blind is calculated using equation (2.66):

$$
N u_{b, \text { avg }}=\frac{\sum_{i=1}^{n} N u_{b, i}}{n}, \quad h_{b, \text { avg }}=\frac{\sum_{i=1}^{n} h_{b, i}}{n}
$$

Table C-4: Average heat flux ( $\mathrm{q}_{\mathrm{i}, \text { avg }}$ ) data for the individual blind louver, $\phi=0^{\circ}, \mathrm{T}_{\mathrm{b}}{ }^{*}=0.1$,

\begin{tabular}{|c|c|c|c|c|c|c|c|c|}
\hline & & & & & $\mathbf{R a}_{\mathbf{l}}$ & & & \\
\hline & $1.00 \mathrm{E}+04$ & $1.00 \mathrm{E}+05$ & $1.00 \mathrm{E}+06$ & $1.00 \mathrm{E}+07$ & $1.00 \mathrm{E}+08$ & $5.00 \mathrm{E}+08$ & $7.00 \mathrm{E}+08$ & $1.00 \mathrm{E}+09$ \\
\hline 1 & $7.116 \mathrm{E}+00$ & $6.502 \mathrm{E}+00$ & $1.155 \mathrm{E}+00$ & $-3.923 E+00$ & $-6.672 E+00$ & $-9.174 E+00$ & $-9.755 \mathrm{E}+00$ & $-1.039 \mathrm{E}+01$ \\
\hline 2 & $6.357 \mathrm{E}+00$ & $6.395 \mathrm{E}+00$ & $4.209 \mathrm{E}+00$ & $-2.127 \mathrm{E}+00$ & $-6.181 \mathrm{E}+00$ & $-9.266 \mathrm{E}+00$ & $-9.984 \mathrm{E}+00$ & $-1.070 \mathrm{E}+01$ \\
\hline 3 & $6.379 \mathrm{E}+00$ & $6.454 \mathrm{E}+00$ & $5.231 \mathrm{E}+00$ & $-1.614 \mathrm{E}+00$ & $-6.107 \mathrm{E}+00$ & $-9.012 \mathrm{E}+00$ & $-9.722 \mathrm{E}+00$ & $-1.042 \mathrm{E}+01$ \\
\hline 4 & $6.371 \mathrm{E}+00$ & $6.428 \mathrm{E}+00$ & $5.653 \mathrm{E}+00$ & $-1.141 \mathrm{E}+00$ & $-5.841 \mathrm{E}+00$ & $-8.626 \mathrm{E}+00$ & $-9.314 \mathrm{E}+00$ & $-1.000 \mathrm{E}+01$ \\
\hline 5 & $6.365 \mathrm{E}+00$ & $6.402 E+00$ & $5.872 \mathrm{E}+00$ & $-6.880 \mathrm{E}-01$ & $-5.536 \mathrm{E}+00$ & $-8.257 \mathrm{E}+00$ & $-8.925 \mathrm{E}+00$ & $-9.610 \mathrm{E}+00$ \\
\hline 6 & $6.360 \mathrm{E}+00$ & $6.384 E+00$ & $6.007 \mathrm{E}+00$ & $-2.591 \mathrm{E}-01$ & $-5.246 \mathrm{E}+00$ & $-7.940 \mathrm{E}+00$ & $-8.590 \mathrm{E}+00$ & $-9.274 \mathrm{E}+00$ \\
\hline 7 & 6.358 & +00 & $6.099 \mathrm{E}+00$ & $1.408 \mathrm{E}-01$ & $-4.985 \mathrm{E}+00$ & $-7.671 E+00$ & $-8.305 E+00$ & $-8.988 E+00$ \\
\hline 8 & $6.357 \mathrm{E}+00$ & $6.365 E+00$ & $6.167 E+00$ & $5.109 \mathrm{E}-01$ & $-4.751 E+00$ & $-7.441 E+00$ & $-8.058 \mathrm{E}+00$ & $-8.740 \mathrm{E}+00$ \\
\hline 9 & $6.356 \mathrm{E}+00$ & $6.361 \mathrm{E}+00$ & $6.215 E+00$ & $8.521 \mathrm{E}-01$ & $-4.542 \mathrm{E}+00$ & $-7.237 \mathrm{E}+00$ & $-7.839 \mathrm{E}+00$ & $-8.519 E+00$ \\
\hline 10 & $6.355 \mathrm{E}+00$ & $E+00$ & $6.250 \mathrm{E}+00$ & $1.166 \mathrm{E}+00$ & $-4.351 \mathrm{E}+00$ & $-7.055 \mathrm{E}+00$ & $-7.641 \mathrm{E}+00$ & $-8.319 \mathrm{E}+00$ \\
\hline 11 & $6.355 E+00$ & $6.357 \mathrm{E}+00$ & $6.276 \mathrm{E}+00$ & $1.456 \mathrm{E}+00$ & $-4.175 \mathrm{E}+00$ & $-6.890 \mathrm{E}+00$ & $-7.462 E+00$ & $-8.136 \mathrm{E}+00$ \\
\hline 12 & $6.355 \mathrm{E}+00$ & $6.356 \mathrm{E}+00$ & $6.294 \mathrm{E}+00$ & $1.724 \mathrm{E}+00$ & $-4.011 \mathrm{E}+00$ & $-6.739 \mathrm{E}+00$ & $-7.298 \mathrm{E}+00$ & $-7.968 \mathrm{E}+00$ \\
\hline 13 & $6.355 \mathrm{E}+00$ & $\Xi+00$ & $6.308 \mathrm{E}+00$ & $1.972 \mathrm{E}+00$ & $-3.858 \mathrm{E}+00$ & $-6.600 \mathrm{E}+00$ & $-7.147 \mathrm{E}+00$ & $-7.812 \mathrm{E}+00$ \\
\hline 14 & $6.355 \mathrm{E}+00$ & $6.355 \mathrm{E}+00$ & $6.318 \mathrm{E}+00$ & $2.202 \mathrm{E}+00$ & $-3.713 E+00$ & $-6.472 E+00$ & $-7.008 \mathrm{E}+00$ & $-7.669 \mathrm{E}+00$ \\
\hline 15 & $6.355 \mathrm{E}+00$ & $6.355 E+00$ & $6.325 \mathrm{E}+00$ & $2.417 \mathrm{E}+00$ & $-3.575 \mathrm{E}+00$ & $-6.354 \mathrm{E}+00$ & $-6.880 \mathrm{E}+00$ & $-7.535 \mathrm{E}+00$ \\
\hline 16 & $6.355 \mathrm{E}+00$ & $6.355 \mathrm{E}+00$ & $6.331 E+00$ & $2.617 \mathrm{E}+00$ & $-3.443 \mathrm{E}+00$ & $-6.243 E+00$ & $-6.760 \mathrm{E}+00$ & $-7.410 \mathrm{E}+00$ \\
\hline 17 & $6.355 \mathrm{E}+00$ & $6.354 \mathrm{E}+00$ & $6.334 \mathrm{E}+00$ & $2.804 \mathrm{E}+00$ & $-3.317 \mathrm{E}+00$ & $-6.139 \mathrm{E}+00$ & $-6.648 \mathrm{E}+00$ & $-7.292 \mathrm{E}+00$ \\
\hline 18 & $6.355 \mathrm{E}+00$ & $6.354 \mathrm{E}+00$ & $6.337 \mathrm{E}+00$ & $2.979 \mathrm{E}+00$ & $-3.196 \mathrm{E}+00$ & $-6.041 E+00$ & $-6.543 E+00$ & $-7.182 E+00$ \\
\hline 19 & $6.355 \mathrm{E}+00$ & $6.354 \mathrm{E}+00$ & $6.339 \mathrm{E}+00$ & $3.144 \mathrm{E}+00$ & $-3.079 \mathrm{E}+00$ & $-5.999 \mathrm{E}+00$ & $-6.444 \mathrm{E}+00$ & $-7.079 \mathrm{E}+00$ \\
\hline 20 & $6.355 \mathrm{E}+00$ & $6.353 \mathrm{E}+00$ & $6.339 E+00$ & $3.299 \mathrm{E}+00$ & $-2.966 \mathrm{E}+00$ & $-5.862 \mathrm{E}+00$ & $-5.189 \mathrm{E}-01$ & $-5.704 \mathrm{E}-01$ \\
\hline 21 & $6.354 \mathrm{E}+00$ & $6.352 \mathrm{E}+00$ & $6.338 \mathrm{E}+00$ & $3.444 \mathrm{E}+00$ & $-2.857 \mathrm{E}+00$ & $-5.779 \mathrm{E}+00$ & $-6.264 \mathrm{E}+00$ & $-6.889 \mathrm{E}+00$ \\
\hline 22 & $6.354 \mathrm{E}+00$ & $6.349 \mathrm{E}+00$ & $6.322 \mathrm{E}+00$ & $3.582 \mathrm{E}+00$ & $-2.750 \mathrm{E}+00$ & $-5.700 \mathrm{E}+00$ & $-5.050 \mathrm{E}-01$ & $-5.557 \mathrm{E}-01$ \\
\hline
\end{tabular}
$\mathrm{d} / \mathrm{L}=0.043$ 


\begin{tabular}{lllllllll}
23 & $6.354 \mathrm{E}+00$ & $6.343 \mathrm{E}+00$ & $6.322 \mathrm{E}+00$ & $3.709 \mathrm{E}+00$ & $-2.646 \mathrm{E}+00$ & $-5.624 \mathrm{E}+00$ & $-6.101 \mathrm{E}+00$ & $-6.718 \mathrm{E}+00$ \\
24 & $6.354 \mathrm{E}+00$ & $6.333 \mathrm{E}+00$ & $6.300 \mathrm{E}+00$ & $3.826 \mathrm{E}+00$ & $-2.543 \mathrm{E}+00$ & $-5.552 \mathrm{E}+00$ & $-6.026 \mathrm{E}+00$ & $-6.638 \mathrm{E}+00$ \\
25 & $6.354 \mathrm{E}+00$ & $6.313 \mathrm{E}+00$ & $6.256 \mathrm{E}+00$ & $3.932 \mathrm{E}+00$ & $-2.441 \mathrm{E}+00$ & $-5.484 \mathrm{E}+00$ & $-5.954 \mathrm{E}+00$ & $-6.563 \mathrm{E}+00$ \\
26 & $6.361 \mathrm{E}+00$ & $6.278 \mathrm{E}+00$ & $6.171 \mathrm{E}+00$ & $4.014 \mathrm{E}+00$ & $-2.340 \mathrm{E}+00$ & $-5.419 \mathrm{E}+00$ & $-5.885 \mathrm{E}+00$ & $-6.490 \mathrm{E}+00$ \\
27 & $6.400 \mathrm{E}+00$ & $6.224 \mathrm{E}+00$ & $6.011 \mathrm{E}+00$ & $4.059 \mathrm{E}+00$ & $-2.252 \mathrm{E}+00$ & $-5.354 \mathrm{E}+00$ & $-4.754 \mathrm{E}-01$ & $-5.247 \mathrm{E}-01$ \\
28 & $6.400 \mathrm{E}+00$ & $6.218 \mathrm{E}+00$ & $5.734 \mathrm{E}+00$ & $3.942 \mathrm{E}+00$ & $-2.237 \mathrm{E}+00$ & $-5.290 \mathrm{E}+00$ & $-5.766 \mathrm{E}+00$ & $-6.363 \mathrm{E}+00$ \\
29 & $1.083 \mathrm{E}+01$ & $8.488 \mathrm{E}+00$ & $6.248 \mathrm{E}+00$ & $3.026 \mathrm{E}+00$ & $-3.103 \mathrm{E}+00$ & $-5.690 \mathrm{E}+00$ & $-6.128 \mathrm{E}+00$ & $-6.656 \mathrm{E}+00$ \\
\hline
\end{tabular}

Table C-5: Average heat flux ( $\mathrm{q}_{\mathrm{i}, \text { avg }}$ ) data for the individual blind louver, $\phi=0^{\circ}, \mathrm{T}_{\mathrm{b}}{ }^{*}=0.2$, $\mathrm{d} / \mathrm{L}=0.043$

\begin{tabular}{|c|c|c|c|c|c|c|c|c|}
\hline $\begin{array}{c}\text { Louver } \\
\text { number (i) }\end{array}$ & & & & & $\mathbf{R} \mathbf{a}_{\mathbf{L}}$ & & & \\
\hline & $1.00 \mathrm{E}+04$ & $1.00 \mathrm{E}+05$ & $1.00 \mathrm{E}+06$ & $1.00 \mathrm{E}+07$ & $1.00 \mathrm{E}+08$ & $5.00 \mathrm{E}+08$ & $7.00 E+08$ & $1.00 \mathrm{E}+09$ \\
\hline 1 & $5.257 E+00$ & $4.316 \mathrm{E}+00$ & $-2.642 \mathrm{E}+00$ & $-8.762 \mathrm{E}+00$ & $-1.469 \mathrm{E}+01$ & $-2.016 \mathrm{E}+01$ & $-2.160 \mathrm{E}+01$ & $-2.302 \mathrm{E}+01$ \\
\hline 2 & $5.235 \mathrm{E}+00$ & $5.229 \mathrm{E}+00$ & $1.871 \mathrm{E}+00$ & $-5.548 \mathrm{E}+00$ & $-1.380 \mathrm{E}+01$ & $-2.059 \mathrm{E}+01$ & $-2.213 E+01$ & $-2.366 \mathrm{E}+01$ \\
\hline 3 & $5.313 E+00$ & $5.377 \mathrm{E}+00$ & $3.136 \mathrm{E}+00$ & $-4.874 \mathrm{E}+00$ & $-1.349 \mathrm{E}+01$ & $-2.005 \mathrm{E}+01$ & $-2.160 \mathrm{E}+01$ & $-2.311 \mathrm{E}+01$ \\
\hline 4 & $5.320 \mathrm{E}+00$ & $5.374 \mathrm{E}+00$ & $3.733 E+00$ & $-4.231 E+00$ & $-1.284 \mathrm{E}+01$ & $-1.921 \mathrm{E}+01$ & $-2.072 E+01$ & $-2.221 E+01$ \\
\hline 5 & $5.318 \mathrm{E}+00$ & $5.354 \mathrm{E}+00$ & $4.098 \mathrm{E}+00$ & $-3.613 E+00$ & $-1.214 \mathrm{E}+01$ & $-1.838 \mathrm{E}+01$ & $-1.986 \mathrm{E}+01$ & $-2.133 E+01$ \\
\hline 6 & $5.315 \mathrm{E}+00$ & $5.339 \mathrm{E}+00$ & $4.355 \mathrm{E}+00$ & $-3.033 E+00$ & $-1.150 \mathrm{E}+01$ & $-1.766 \mathrm{E}+01$ & $-1.912 \mathrm{E}+01$ & $-2.058 \mathrm{E}+01$ \\
\hline 7 & $5.314 \mathrm{E}+00$ & $5.328 \mathrm{E}+00$ & $4.547 \mathrm{E}+00$ & $-2.499 \mathrm{E}+00$ & $-1.093 E+01$ & $-1.705 \mathrm{E}+01$ & $-1.848 \mathrm{E}+01$ & $-1.995 \mathrm{E}+01$ \\
\hline 8 & $5.313 \mathrm{E}+00$ & $5.321 \mathrm{E}+00$ & $4.694 \mathrm{E}+00$ & $-2.010 \mathrm{E}+00$ & $-1.043 \mathrm{E}+01$ & $-1.651 \mathrm{E}+01$ & $-1.793 E+01$ & $-1.941 E+01$ \\
\hline 9 & $5.312 \mathrm{E}+00$ & $5.317 \mathrm{E}+00$ & $4.808 \mathrm{E}+00$ & $-1.566 \mathrm{E}+00$ & $-9.996 \mathrm{E}+00$ & $-1.604 \mathrm{E}+01$ & $-1.744 \mathrm{E}+01$ & $-1.892 \mathrm{E}+01$ \\
\hline 10 & $5.311 \mathrm{E}+00$ & $5.314 \mathrm{E}+00$ & $4.896 \mathrm{E}+00$ & $-1.161 \mathrm{E}+00$ & $-9.607 \mathrm{E}+00$ & $-1.561 \mathrm{E}+01$ & $-1.700 \mathrm{E}+01$ & $-1.848 \mathrm{E}+01$ \\
\hline 11 & $5.311 \mathrm{E}+00$ & $5.313 E+00$ & $4.964 \mathrm{E}+00$ & $-7.922 \mathrm{E}-01$ & $-9.255 \mathrm{E}+00$ & $-1.522 \mathrm{E}+01$ & $-1.659 \mathrm{E}+01$ & $-1.808 \mathrm{E}+01$ \\
\hline 12 & $5.311 \mathrm{E}+00$ & $5.311 \mathrm{E}+00$ & $5.018 \mathrm{E}+00$ & $-4.550 \mathrm{E}-01$ & $-8.935 E+00$ & $-1.487 \mathrm{E}+01$ & $-1.622 \mathrm{E}+01$ & $-1.770 \mathrm{E}+01$ \\
\hline 13 & $5.311 \mathrm{E}+00$ & $5.311 \mathrm{E}+00$ & $5.059 \mathrm{E}+00$ & $-1.461 \mathrm{E}-01$ & $-8.639 \mathrm{E}+00$ & $-1.454 \mathrm{E}+01$ & $-1.587 \mathrm{E}+01$ & $-1.736 \mathrm{E}+01$ \\
\hline 14 & $5.311 \mathrm{E}+00$ & $5.311 \mathrm{E}+00$ & $5.093 \mathrm{E}+00$ & $1.382 \mathrm{E}-01$ & $-8.365 \mathrm{E}+00$ & $-1.424 \mathrm{E}+01$ & $-1.556 \mathrm{E}+01$ & $-1.704 \mathrm{E}+01$ \\
\hline 15 & $5.311 \mathrm{E}+00$ & $5.311 \mathrm{E}+00$ & $5.119 \mathrm{E}+00$ & $4.006 \mathrm{E}-01$ & $-8.109 \mathrm{E}+00$ & $-1.396 \mathrm{E}+01$ & $-1.526 \mathrm{E}+01$ & $-1.674 \mathrm{E}+01$ \\
\hline 16 & $5.311 \mathrm{E}+00$ & $5.310 \mathrm{E}+00$ & $5.139 E+00$ & $6.436 \mathrm{E}-01$ & $-7.869 \mathrm{E}+00$ & $-1.371 E+01$ & $-1.498 \mathrm{E}+01$ & $-1.645 \mathrm{E}+01$ \\
\hline 17 & $5.311 \mathrm{E}+00$ & $5.310 \mathrm{E}+00$ & $5.157 \mathrm{E}+00$ & $8.920 \mathrm{E}-01$ & $-7.643 \mathrm{E}+00$ & $-1.346 \mathrm{E}+01$ & $-1.472 \mathrm{E}+01$ & $-1.619 E+01$ \\
\hline 18 & $5.311 \mathrm{E}+00$ & $5.309 \mathrm{E}+00$ & $5.169 \mathrm{E}+00$ & $1.079 \mathrm{E}+00$ & $-7.428 \mathrm{E}+00$ & $-1.324 \mathrm{E}+01$ & $-1.447 \mathrm{E}+01$ & $-1.593 E+01$ \\
\hline 19 & $5.311 \mathrm{E}+00$ & $5.309 \mathrm{E}+00$ & $5.179 \mathrm{E}+00$ & $1.276 \mathrm{E}+00$ & $-7.224 \mathrm{E}+00$ & $-1.303 E+01$ & $-1.424 \mathrm{E}+01$ & $-1.569 \mathrm{E}+01$ \\
\hline 20 & $5.311 \mathrm{E}+00$ & $5.308 \mathrm{E}+00$ & $5.185 \mathrm{E}+00$ & $1.459 \mathrm{E}+00$ & $-7.030 \mathrm{E}+00$ & $-1.282 \mathrm{E}+01$ & $-1.146 \mathrm{E}+00$ & $-1.264 \mathrm{E}+00$ \\
\hline 21 & $5.310 \mathrm{E}+00$ & $5.307 \mathrm{E}+00$ & $5.185 \mathrm{E}+00$ & $1.632 \mathrm{E}+00$ & $-6.844 \mathrm{E}+00$ & $-1.263 \mathrm{E}+01$ & $-1.382 \mathrm{E}+01$ & $-1.525 E+01$ \\
\hline 22 & $5.309 \mathrm{E}+00$ & $5.304 \mathrm{E}+00$ & $5.179 \mathrm{E}+00$ & $1.793 \mathrm{E}+00$ & $-6.666 \mathrm{E}+00$ & $-1.245 \mathrm{E}+01$ & $-1.113 E+00$ & $-1.229 \mathrm{E}+00$ \\
\hline 23 & $5.309 \mathrm{E}+00$ & $5.299 \mathrm{E}+00$ & $5.162 \mathrm{E}+00$ & $1.943 \mathrm{E}+00$ & $-6.493 E+00$ & $-1.228 \mathrm{E}+01$ & $-1.343 \mathrm{E}+01$ & $-1.485 E+01$ \\
\hline 24 & $5.309 \mathrm{E}+00$ & $5.287 \mathrm{E}+00$ & $5.127 \mathrm{E}+00$ & $2.081 \mathrm{E}+00$ & $-6.324 \mathrm{E}+00$ & $-1.212 \mathrm{E}+01$ & $-1.326 \mathrm{E}+01$ & $-1.466 \mathrm{E}+01$ \\
\hline 25 & $5.306 \mathrm{E}+00$ & $5.264 \mathrm{E}+00$ & $5.061 \mathrm{E}+00$ & $2.199 \mathrm{E}+00$ & $-6.156 \mathrm{E}+00$ & $-1.197 \mathrm{E}+01$ & $-1.309 \mathrm{E}+01$ & $-1.448 \mathrm{E}+01$ \\
\hline 26 & $5.303 \mathrm{E}+00$ & $5.220 \mathrm{E}+00$ & $4.946 \mathrm{E}+00$ & $2.283 \mathrm{E}+00$ & $-5.993 E+00$ & $-1.182 \mathrm{E}+01$ & $-1.292 \mathrm{E}+01$ & $-1.431 E+01$ \\
\hline 27 & $5.319 \mathrm{E}+00$ & $5.143 E+00$ & $4.752 \mathrm{E}+00$ & $2.287 \mathrm{E}+00$ & $-5.857 \mathrm{E}+00$ & $-1.168 \mathrm{E}+01$ & $-1.044 \mathrm{E}+00$ & $-1.155 \mathrm{E}+00$ \\
\hline 28 & $5.487 \mathrm{E}+00$ & $5.062 E+00$ & $4.458 \mathrm{E}+00$ & $2.022 \mathrm{E}+00$ & $-5.906 \mathrm{E}+00$ & $-1.152 \mathrm{E}+01$ & $-1.265 \mathrm{E}+01$ & $-1.400 \mathrm{E}+01$ \\
\hline 29 & $8.808 \mathrm{E}+00$ & $6.523 \mathrm{E}+00$ & $4.766 \mathrm{E}+00$ & $5.755 \mathrm{E}-01$ & $-7.615 \mathrm{E}+00$ & $-1.233 \mathrm{E}+01$ & $-1.340 \mathrm{E}+01$ & $-1.470 \mathrm{E}+01$ \\
\hline
\end{tabular}


Table C-6: Average heat flux ( $\left.\mathrm{q}_{\mathrm{i}, \mathrm{avg}}\right)$ data for the individual blind louver, $\phi=0^{\circ}, \mathrm{T}_{\mathrm{b}}{ }^{*}=0.3$, $\mathrm{d} / \mathrm{L}=0.043$

\begin{tabular}{|c|c|c|c|c|c|c|c|c|}
\hline $\begin{array}{l}\text { Louver } \\
\text { Imber (i) }\end{array}$ & & & & & $\mathbf{R a}_{\mathbf{l}}$ & & & \\
\hline & $1.00 \mathrm{E}+04$ & $1.00 \mathrm{E}+05$ & $1.00 \mathrm{E}+06$ & $1.00 \mathrm{E}+07$ & $1.00 \mathrm{E}+08$ & $5.00 \mathrm{E}+08$ & $7.00 \mathrm{E}+08$ & $1.00 \mathrm{E}+09$ \\
\hline 1 & $3.381 E+00$ & $2.033 \mathrm{E}+00$ & $-6.109 \mathrm{E}+00$ & $-1.405 E+01$ & $-2.359 \mathrm{E}+01$ & $-3.244 E+01$ & $-3.445 \mathrm{E}+01$ & $-3.675 E+01$ \\
\hline 2 & $4.108 \mathrm{E}+00$ & $4.018 \mathrm{E}+00$ & $-5.919 E+00$ & $-9.474 \mathrm{E}+00$ & $-2.232 \mathrm{E}+01$ & $-3.239 E+01$ & $-3.521 \mathrm{E}+01$ & $-3.765 E+01$ \\
\hline 3 & $4.245 E+00$ & $4.269 \mathrm{E}+00$ & $1.430 \mathrm{E}+00$ & $-8.594 E+00$ & $-2.174 \mathrm{E}+01$ & $-3.228 \mathrm{E}+01$ & $-3.446 \mathrm{E}+01$ & $-3.689 E+01$ \\
\hline 4 & $4.267 \mathrm{E}+00$ & $4.297 \mathrm{E}+00$ & $2.143 E+00$ & $-7.736 \mathrm{E}+00$ & $-2.063 E+01$ & $-3.098 \mathrm{E}+01$ & $-3.312 \mathrm{E}+01$ & $-3.549 E+01$ \\
\hline 5 & $4.270 \mathrm{E}+00$ & $4.291 \mathrm{E}+00$ & $2.587 \mathrm{E}+00$ & $-6.897 \mathrm{E}+00$ & $-1.948 E+01$ & $-2.966 \mathrm{E}+01$ & $-3.178 \mathrm{E}+01$ & $-3.411 \mathrm{E}+01$ \\
\hline 6 & $4.270 \mathrm{E}+00$ & $4.283 \mathrm{E}+00$ & $2.904 \mathrm{E}+00$ & $-6.117 \mathrm{E}+00$ & $-1.843 E+01$ & $-2.849 E+01$ & $-3.062 E+01$ & $-3.294 \mathrm{E}+01$ \\
\hline 7 & $4.269 \mathrm{E}+00$ & $4.276 \mathrm{E}+00$ & $3.144 \mathrm{E}+00$ & $-5.411 \mathrm{E}+00$ & $-1.751 \mathrm{E}+01$ & $-2.748 \mathrm{E}+01$ & $-2.963 \mathrm{E}+01$ & $-3.196 \mathrm{E}+01$ \\
\hline 8 & $4.268 \mathrm{E}+00$ & $4.272 \mathrm{E}+00$ & $3.381 \mathrm{E}+00$ & $-4.779 \mathrm{E}+00$ & $-1.671 E+01$ & $-2.661 \mathrm{E}+01$ & $-2.878 \mathrm{E}+01$ & $-3.112 \mathrm{E}+01$ \\
\hline 9 & $4.267 \mathrm{E}+00$ & $4.269 E+00$ & $3.476 \mathrm{E}+00$ & $-4.214 \mathrm{E}+00$ & $-1.601 \mathrm{E}+01$ & $-2.584 \mathrm{E}+01$ & $-2.802 \mathrm{E}+01$ & $-3.037 E+01$ \\
\hline 10 & $4.267 E+00$ & $4.268 \mathrm{E}+00$ & $3.591 \mathrm{E}+00$ & $-3.707 \mathrm{E}+00$ & $-1.539 \mathrm{E}+01$ & $-2.515 \mathrm{E}+01$ & $-2.733 \mathrm{E}+01$ & $-2.970 \mathrm{E}+01$ \\
\hline 11 & $4.267 \mathrm{E}+00$ & $4.267 \mathrm{E}+00$ & $3.682 \mathrm{E}+00$ & $-3.250 \mathrm{E}+00$ & $-1.484 \mathrm{E}+01$ & $-2.452 \mathrm{E}+01$ & $-2.670 \mathrm{E}+01$ & $-2.908 \mathrm{E}+01$ \\
\hline 12 & $4.267 \mathrm{E}+00$ & $4.267 \mathrm{E}+00$ & $3.754 \mathrm{E}+00$ & $-2.836 \mathrm{E}+00$ & $-1.434 \mathrm{E}+01$ & $-2.395 \mathrm{E}+01$ & $-2.611 \mathrm{E}+01$ & $-2.851 \mathrm{E}+01$ \\
\hline 13 & $4.267 \mathrm{E}+00$ & $4.267 \mathrm{E}+00$ & $3.811 \mathrm{E}+00$ & $-2.459 \mathrm{E}+00$ & $-1.388 \mathrm{E}+01$ & $-2.342 \mathrm{E}+01$ & $-2.557 \mathrm{E}+01$ & $-2.798 E+01$ \\
\hline 14 & $4.267 \mathrm{E}+00$ & $4.267 \mathrm{E}+00$ & $3.854 \mathrm{E}+00$ & $-2.114 \mathrm{E}+00$ & $-1.346 \mathrm{E}+01$ & $-2.293 E+01$ & $-2.507 \mathrm{E}+01$ & $-2.749 E+01$ \\
\hline 15 & $4.267 \mathrm{E}+00$ & $4.266 \mathrm{E}+00$ & $3.896 \mathrm{E}+00$ & $-1.747 \mathrm{E}+00$ & $-1.307 \mathrm{E}+01$ & $-2.247 \mathrm{E}+01$ & $-2.460 \mathrm{E}+01$ & $-2.702 E+01$ \\
\hline 16 & $4.267 \mathrm{E}+00$ & $4.266 \mathrm{E}+00$ & $3.927 \mathrm{E}+00$ & $-1.504 \mathrm{E}+00$ & $-1.272 \mathrm{E}+01$ & $-2.204 \mathrm{E}+01$ & $-2.415 \mathrm{E}+01$ & $-2.658 \mathrm{E}+01$ \\
\hline 17 & $4.267 \mathrm{E}+00$ & $4.266 \mathrm{E}+00$ & $3.953 \mathrm{E}+00$ & $-1.234 \mathrm{E}+00$ & $-1.238 \mathrm{E}+01$ & $-2.163 E+01$ & $-2.373 E+01$ & $-2.616 \mathrm{E}+01$ \\
\hline 18 & $4.267 \mathrm{E}+00$ & $4.265 \mathrm{E}+00$ & $3.974 \mathrm{E}+00$ & $-9.824 \mathrm{E}-01$ & $-1.207 \mathrm{E}+01$ & $-2.125 \mathrm{E}+01$ & $-2.333 \mathrm{E}+01$ & $-2.576 E+01$ \\
\hline 19 & $4.267 \mathrm{E}+00$ & $4.265 E+00$ & $3.989 \mathrm{E}+00$ & $-7.485 \mathrm{E}-01$ & $-1.172 E+01$ & $-2.089 \mathrm{E}+01$ & $-2.295 \mathrm{E}+01$ & $-2.538 \mathrm{E}+01$ \\
\hline 20 & $4.266 \mathrm{E}+00$ & $4.264 \mathrm{E}+00$ & $3.999 \mathrm{E}+00$ & $-5.302 \mathrm{E}-01$ & $-1.150 \mathrm{E}+01$ & $-2.055 \mathrm{E}+01$ & $-1.846 \mathrm{E}+00$ & $-2.043 E+00$ \\
\hline 21 & $4.266 \mathrm{E}+00$ & $4.262 E+00$ & $4.003 E+00$ & $-3.263 \mathrm{E}-01$ & $-1.123 \mathrm{E}+01$ & $-2.022 \mathrm{E}+01$ & $-2.225 \mathrm{E}+01$ & $-2.465 \mathrm{E}+01$ \\
\hline 22 & $4.265 \mathrm{E}+00$ & $4.259 \mathrm{E}+00$ & $3.996 \mathrm{E}+00$ & $-1.358 \mathrm{E}-01$ & $-1.099 \mathrm{E}+01$ & $-1.992 \mathrm{E}+01$ & $-1.791 \mathrm{E}+00$ & $-1.986 \mathrm{E}+00$ \\
\hline 23 & $4.264 \mathrm{E}+00$ & $4.254 \mathrm{E}+00$ & $3.974 \mathrm{E}+00$ & $4.106 \mathrm{E}-02$ & $-1.075 E+01$ & $-1.963 \mathrm{E}+01$ & $-2.161 \mathrm{E}+01$ & $-2.398 \mathrm{E}+01$ \\
\hline 24 & $4.259 \mathrm{E}+00$ & $4.243 E+00$ & $3.929 \mathrm{E}+00$ & $2.018 \mathrm{E}-01$ & $-1.054 \mathrm{E}+01$ & $-1.935 \mathrm{E}+01$ & $-2.131 E+01$ & $-2.367 \mathrm{E}+01$ \\
\hline 25 & $4.253 \mathrm{E}+00$ & $4.219 \mathrm{E}+00$ & $3.845 \mathrm{E}+00$ & $3.380 \mathrm{E}-01$ & $-1.033 E+01$ & $-1.909 E+01$ & $-2.103 E+01$ & $-2.337 \mathrm{E}+01$ \\
\hline 26 & $4.244 \mathrm{E}+00$ & $4.170 \mathrm{E}+00$ & $3.699 \mathrm{E}+00$ & $4.282 \mathrm{E}-01$ & $-1.013 \mathrm{E}+01$ & $-1.885 E+01$ & $-2.076 \mathrm{E}+01$ & $-2.307 \mathrm{E}+01$ \\
\hline 27 & $4.241 \mathrm{E}+00$ & $4.078 \mathrm{E}+00$ & $3.463 \mathrm{E}+00$ & $4.166 \mathrm{E}-01$ & $-9.914 \mathrm{E}+00$ & $-1.862 \mathrm{E}+01$ & $-1.675 E+00$ & $-1.863 E+00$ \\
\hline 28 & $4.338 \mathrm{E}+00$ & $3.937 \mathrm{E}+00$ & $3.127 \mathrm{E}+00$ & 8.291E-02 & $-9.683 E+00$ & $-1.828 \mathrm{E}+01$ & $-2.029 \mathrm{E}+01$ & $-2.256 \mathrm{E}+01$ \\
\hline 29 & $6.804 \mathrm{E}+00$ & $4.653 \mathrm{E}+00$ & $3.263 \mathrm{E}+00$ & $-1.778 \mathrm{E}+00$ & $-1.176 \mathrm{E}+01$ & $-1.907 \mathrm{E}+01$ & $-2.159 \mathrm{E}+01$ & $-2.372 E+01$ \\
\hline
\end{tabular}

Table C-7: Average heat flux $\left(\mathrm{q}_{\mathrm{i}, \mathrm{avg}}\right)$ data for the individual blind louver, $\phi=0^{\circ}, \mathrm{T}_{\mathrm{b}}{ }^{*}=0.4$, $\mathrm{d} / \mathrm{L}=0.043$

\begin{tabular}{ccccccccc}
\hline $\begin{array}{c}\text { Louver } \\
\text { number }(\mathrm{i})\end{array}$ & $\mathbf{1 . 0 0 \mathrm { E } + 0 4}$ & $\mathbf{1 . 0 0 \mathrm { E } + 0 5}$ & $\mathbf{1 . 0 0 \mathrm { E } + 0 6}$ & $\mathbf{1 . 0 0 \mathrm { E } + 0 7}$ & $\mathbf{1 . 0 0 \mathrm { E } + 0 8}$ & $\mathbf{5 . 0 0 \mathrm { E } + 0 8}$ & $\mathbf{7 . 0 0 \mathrm { E } + 0 8}$ & $\mathbf{1 . 0 0 \mathrm { E } + 0 9}$ \\
\hline 1 & $1.486 \mathrm{E}+00$ & $-7.863 \mathrm{E}-01$ & $-9.696 \mathrm{E}+00$ & $-1.968 \mathrm{E}+01$ & $-3.335 \mathrm{E}+01$ & $-4.525 \mathrm{E}+01$ & $-4.804 \mathrm{E}+01$ & $-5.127 \mathrm{E}+01$ \\
2 & $2.976 \mathrm{E}+00$ & $2.627 \mathrm{E}+00$ & $-2.118 \mathrm{E}+00$ & $-1.371 \mathrm{E}+01$ & $-3.204 \mathrm{E}+01$ & $-4.597 \mathrm{E}+01$ & $-4.896 \mathrm{E}+01$ & $-5.235 \mathrm{E}+01$ \\
3 & $3.174 \mathrm{E}+00$ & $3.044 \mathrm{E}+00$ & $-4.150 \mathrm{E}-01$ & $-1.260 \mathrm{E}+01$ & $-3.114 \mathrm{E}+01$ & $-4.506 \mathrm{E}+01$ & $-4.805 \mathrm{E}+01$ & $-5.142 \mathrm{E}+01$ \\
4 & $3.213 \mathrm{E}+00$ & $3.126 \mathrm{E}+00$ & $4.179 \mathrm{E}-01$ & $-1.149 \mathrm{E}+01$ & $-2.948 \mathrm{E}+01$ & $-4.333 \mathrm{E}+01$ & $-4.625 \mathrm{E}+01$ & $-4.954 \mathrm{E}+01$ \\
5 & $3.222 \mathrm{E}+00$ & $3.150 \mathrm{E}+00$ & $9.489 \mathrm{E}-01$ & $-1.041 \mathrm{E}+01$ & $-2.778 \mathrm{E}+01$ & $-4.153 \mathrm{E}+01$ & $-4.443 \mathrm{E}+01$ & $-4.765 \mathrm{E}+01$ \\
6 & $3.224 \mathrm{E}+00$ & $3.162 \mathrm{E}+00$ & $1.334 \mathrm{E}+00$ & $-9.413 \mathrm{E}+00$ & $-2.626 \mathrm{E}+01$ & $-3.993 \mathrm{E}+01$ & $-4.285 \mathrm{E}+01$ & $-4.605 \mathrm{E}+01$ \\
7 & $3.224 \mathrm{E}+00$ & $3.171 \mathrm{E}+00$ & $1.628 \mathrm{E}+00$ & $-8.520 \mathrm{E}+00$ & $-2.494 \mathrm{E}+01$ & $-3.855 \mathrm{E}+01$ & $-4.151 \mathrm{E}+01$ & $-4.473 \mathrm{E}+01$ \\
8 & $3.223 \mathrm{E}+00$ & $3.179 \mathrm{E}+00$ & $1.859 \mathrm{E}+00$ & $-7.729 \mathrm{E}+00$ & $-2.380 \mathrm{E}+01$ & $-3.736 \mathrm{E}+01$ & $-4.036 \mathrm{E}+01$ & $-4.360 \mathrm{E}+01$ \\
9 & $3.223 \mathrm{E}+00$ & $3.186 \mathrm{E}+00$ & $2.042 \mathrm{E}+00$ & $-7.029 \mathrm{E}+00$ & $-2.280 \mathrm{E}+01$ & $-3.631 \mathrm{E}+01$ & $-3.934 \mathrm{E}+01$ & $-4.261 \mathrm{E}+01$
\end{tabular}




\begin{tabular}{|c|c|c|c|c|c|c|c|c|}
\hline 10 & $3.223 E+00$ & $3.193 \mathrm{E}+00$ & $2.189 \mathrm{E}+00$ & $-6.405 E+00$ & $-2.191 E+01$ & $-3.538 \mathrm{E}+01$ & $-3.841 \mathrm{E}+01$ & $-4.172 \mathrm{E}+01$ \\
\hline 11 & $3.223 E+00$ & $3.198 \mathrm{E}+00$ & $2.308 \mathrm{E}+00$ & $-5.846 \mathrm{E}+00$ & $-2.112 \mathrm{E}+01$ & $-3.453 E+01$ & $-3.756 \mathrm{E}+01$ & $-4.090 \mathrm{E}+01$ \\
\hline 12 & $3.223 E+00$ & $3.203 \mathrm{E}+00$ & $2.405 \mathrm{E}+00$ & $-5.342 \mathrm{E}+00$ & $-2.041 \mathrm{E}+01$ & $-3.374 E+01$ & $-3.677 \mathrm{E}+01$ & $-4.014 \mathrm{E}+01$ \\
\hline 13 & $3.223 E+00$ & $3.206 \mathrm{E}+00$ & $2.485 E+00$ & $-4.885 E+00$ & $-1.976 \mathrm{E}+01$ & $-3.302 \mathrm{E}+01$ & $-3.604 \mathrm{E}+01$ & $-3.943 E+01$ \\
\hline 14 & $3.223 E+00$ & $3.209 E+00$ & $2.551 \mathrm{E}+00$ & $-4.469 E+00$ & $-1.917 \mathrm{E}+01$ & $-3.234 E+01$ & $-3.536 \mathrm{E}+01$ & $-3.877 E+01$ \\
\hline 15 & $3.222 \mathrm{E}+00$ & $3.212 \mathrm{E}+00$ & $2.606 \mathrm{E}+00$ & $-4.089 \mathrm{E}+00$ & $-1.862 \mathrm{E}+01$ & $-3.171 E+01$ & $-3.471 E+01$ & $-3.815 E+01$ \\
\hline 16 & $3.222 \mathrm{E}+00$ & $3.213 E+00$ & $2.653 \mathrm{E}+00$ & $-3.739 \mathrm{E}+00$ & $-1.812 \mathrm{E}+01$ & $-3.111 \mathrm{E}+01$ & $-3.410 \mathrm{E}+01$ & $-3.755 E+01$ \\
\hline 17 & $3.222 \mathrm{E}+00$ & $3.214 \mathrm{E}+00$ & $2.692 \mathrm{E}+00$ & $-3.416 \mathrm{E}+00$ & $-1.766 \mathrm{E}+01$ & $-3.055 \mathrm{E}+01$ & $-3.352 \mathrm{E}+01$ & $-3.699 \mathrm{E}+01$ \\
\hline 18 & $3.222 \mathrm{E}+00$ & $3.215 \mathrm{E}+00$ & $2.724 \mathrm{E}+00$ & $-3.117 \mathrm{E}+00$ & $-1.722 \mathrm{E}+01$ & $-3.002 E+01$ & $-3.296 \mathrm{E}+01$ & $-3.645 E+01$ \\
\hline 19 & $3.222 \mathrm{E}+00$ & $3.215 \mathrm{E}+00$ & $2.750 \mathrm{E}+00$ & $-2.840 \mathrm{E}+00$ & $-1.682 E+01$ & $-2.951 E+01$ & $-3.243 E+01$ & $-3.592 \mathrm{E}+01$ \\
\hline 20 & $3.222 \mathrm{E}+00$ & $3.213 E+00$ & $2.764 \mathrm{E}+00$ & $-2.590 \mathrm{E}+00$ & $-1.645 \mathrm{E}+01$ & $-2.904 \mathrm{E}+01$ & $-3.192 \mathrm{E}+01$ & $-3.541 \mathrm{E}+01$ \\
\hline 21 & $3.222 \mathrm{E}+00$ & $3.211 \mathrm{E}+00$ & $2.779 \mathrm{E}+00$ & $-2.341 \mathrm{E}+00$ & $-1.608 \mathrm{E}+01$ & $-2.857 E+01$ & $-3.142 \mathrm{E}+01$ & $-3.491 E+01$ \\
\hline 22 & $3.220 \mathrm{E}+00$ & $3.204 \mathrm{E}+00$ & $2.769 \mathrm{E}+00$ & $-2.126 \mathrm{E}+00$ & $-1.575 \mathrm{E}+01$ & $-2.815 \mathrm{E}+01$ & $-3.096 \mathrm{E}+01$ & $-3.442 E+01$ \\
\hline 23 & $3.219 \mathrm{E}+00$ & $3.198 \mathrm{E}+00$ & $2.759 E+00$ & $-1.911 \mathrm{E}+00$ & $-1.542 \mathrm{E}+01$ & $-2.773 E+01$ & $-3.050 \mathrm{E}+01$ & $-3.394 \mathrm{E}+01$ \\
\hline 24 & $3.214 \mathrm{E}+00$ & $3.183 E+00$ & $2.712 \mathrm{E}+00$ & $-1.726 \mathrm{E}+00$ & $-1.512 E+01$ & $-2.735 E+01$ & $-3.007 \mathrm{E}+01$ & $-3.348 E+01$ \\
\hline 25 & $3.204 \mathrm{E}+00$ & $3.156 \mathrm{E}+00$ & $2.619 \mathrm{E}+00$ & $-1.575 \mathrm{E}+00$ & $-1.483 E+01$ & $-2.699 \mathrm{E}+01$ & $-2.967 \mathrm{E}+01$ & $-3.304 E+01$ \\
\hline 26 & $3.187 \mathrm{E}+00$ & $3.108 \mathrm{E}+00$ & $2.453 \mathrm{E}+00$ & $-1.491 \mathrm{E}+00$ & $-1.456 \mathrm{E}+01$ & $-2.665 \mathrm{E}+01$ & $-2.927 \mathrm{E}+01$ & $-3.262 \mathrm{E}+01$ \\
\hline 27 & $3.190 \mathrm{E}+00$ & $2.984 \mathrm{E}+00$ & $2.100 \mathrm{E}+00$ & $-1.777 \mathrm{E}+00$ & $-1.444 \mathrm{E}+01$ & $-2.622 \mathrm{E}+01$ & $-2.891 \mathrm{E}+01$ & $-3.223 E+01$ \\
\hline 28 & $3.192 \mathrm{E}+00$ & $2.861 \mathrm{E}+00$ & $1.747 \mathrm{E}+00$ & $-2.062 \mathrm{E}+00$ & $-1.432 \mathrm{E}+01$ & $-2.578 E+01$ & $-2.855 \mathrm{E}+01$ & $-3.185 E+01$ \\
\hline 29 & $4.813 \mathrm{E}+00$ & $2.961 \mathrm{E}+00$ & $1.544 \mathrm{E}+00$ & $-4.270 \mathrm{E}+00$ & $-1.750 \mathrm{E}+01$ & $-2.667 E+01$ & $-3.037 \mathrm{E}+01$ & $-3.351 E+01$ \\
\hline
\end{tabular}

Table C-8: Average heat flux $\left(\mathrm{q}_{\mathrm{i}, \text { avg }}\right)$ data for the individual blind louver, $\phi=45^{\circ}, \mathrm{T}_{\mathrm{b}}{ }^{*}=0.2$, $\mathrm{d} / \mathrm{L}=0.043$

\begin{tabular}{|c|c|c|c|c|c|c|c|}
\hline $\begin{array}{c}\text { Louver } \\
\text { number (i) }\end{array}$ & & & & $\mathbf{R a}_{L}$ & & & \\
\hline & $1.00 \mathrm{E}+04$ & $1.00 \mathrm{E}+05$ & $1.00 \mathrm{E}+06$ & $1.00 \mathrm{E}+07$ & $1.00 \mathrm{E}+08$ & $5.00 \mathrm{E}+08$ & $7.00 \mathrm{E}+08$ \\
\hline 1 & $5.151 \mathrm{E}+00$ & $3.628 \mathrm{E}+00$ & $-3.498 \mathrm{E}+00$ & $-8.866 \mathrm{E}+00$ & $-1.399 \mathrm{E}+01$ & $-1.877 \mathrm{E}+01$ & $-1.904 \mathrm{E}+01$ \\
\hline 2 & $6.094 \mathrm{E}+00$ & $5.947 \mathrm{E}+00$ & $2.439 \mathrm{E}+00$ & $-4.777 \mathrm{E}+00$ & $-1.177 \mathrm{E}+01$ & $-1.824 \mathrm{E}+01$ & $-1.863 \mathrm{E}+01$ \\
\hline 3 & $6.254 \mathrm{E}+00$ & $6.287 \mathrm{E}+00$ & $4.258 \mathrm{E}+00$ & $-3.872 \mathrm{E}+00$ & $-1.205 \mathrm{E}+01$ & $-1.847 \mathrm{E}+01$ & $-1.885 E+01$ \\
\hline 4 & $6.269 \mathrm{E}+00$ & $6.323 E+00$ & $4.987 \mathrm{E}+00$ & $-3.243 E+00$ & $-1.207 \mathrm{E}+01$ & $-1.840 \mathrm{E}+01$ & $-1.877 \mathrm{E}+01$ \\
\hline 5 & $6.268 \mathrm{E}+00$ & $6.314 \mathrm{E}+00$ & $5.332 \mathrm{E}+00$ & $-2.690 E+00$ & $-1.185 \mathrm{E}+01$ & $-1.815 \mathrm{E}+01$ & $-1.852 \mathrm{E}+01$ \\
\hline 6 & $6.265 E+00$ & $6.301 \mathrm{E}+00$ & $5.528 \mathrm{E}+00$ & $-2.166 \mathrm{E}+00$ & $-1.150 \mathrm{E}+01$ & $-1.782 \mathrm{E}+01$ & $-1.819 \mathrm{E}+01$ \\
\hline 7 & $6.263 E+00$ & $6.290 \mathrm{E}+00$ & $5.657 \mathrm{E}+00$ & $-1.668 \mathrm{E}+00$ & $-1.111 \mathrm{E}+01$ & $-1.746 \mathrm{E}+01$ & $-1.784 \mathrm{E}+01$ \\
\hline 8 & $6.261 E+00$ & $6.281 \mathrm{E}+00$ & $5.752 \mathrm{E}+00$ & $-1.201 E+00$ & $-1.071 \mathrm{E}+01$ & $-1.709 \mathrm{E}+01$ & $-1.749 \mathrm{E}+01$ \\
\hline 9 & $6.259 \mathrm{E}+00$ & $6.275 \mathrm{E}+00$ & $5.825 \mathrm{E}+00$ & $-7.673 \mathrm{E}-01$ & $-1.032 E+01$ & $-1.675 E+01$ & $-1.715 E+01$ \\
\hline 10 & $6.258 \mathrm{E}+00$ & $6.270 \mathrm{E}+00$ & $5.883 \mathrm{E}+00$ & $-3.530 \mathrm{E}-01$ & $-9.949 \mathrm{E}+00$ & $-1.642 \mathrm{E}+01$ & $-1.683 \mathrm{E}+01$ \\
\hline 11 & $6.258 \mathrm{E}+00$ & $6.266 \mathrm{E}+00$ & $5.930 \mathrm{E}+00$ & $6.348 \mathrm{E}-03$ & $-9.597 \mathrm{E}+00$ & $-1.611 \mathrm{E}+01$ & $-1.653 \mathrm{E}+01$ \\
\hline 12 & $6.257 \mathrm{E}+00$ & $6.263 \mathrm{E}+00$ & $5.968 \mathrm{E}+00$ & $3.499 \mathrm{E}-01$ & $-9.266 \mathrm{E}+00$ & $-1.582 \mathrm{E}+01$ & $-1.624 \mathrm{E}+01$ \\
\hline 13 & $6.257 \mathrm{E}+00$ & $6.261 E+00$ & $5.999 \mathrm{E}+00$ & $6.679 \mathrm{E}-01$ & $-8.954 \mathrm{E}+00$ & $-1.554 \mathrm{E}+01$ & $-1.597 \mathrm{E}+01$ \\
\hline 14 & $6.256 \mathrm{E}+00$ & $6.260 \mathrm{E}+00$ & $6.024 \mathrm{E}+00$ & $9.627 \mathrm{E}-01$ & $-8.660 \mathrm{E}+00$ & $-1.528 \mathrm{E}+01$ & $-1.571 \mathrm{E}+01$ \\
\hline 15 & $6.256 \mathrm{E}+00$ & $6.258 \mathrm{E}+00$ & $6.044 \mathrm{E}+00$ & $1.236 \mathrm{E}+00$ & $-8.383 E+00$ & $-1.503 \mathrm{E}+01$ & $-1.547 \mathrm{E}+01$ \\
\hline 16 & $6.256 \mathrm{E}+00$ & $6.257 \mathrm{E}+00$ & $6.060 \mathrm{E}+00$ & $1.491 \mathrm{E}+00$ & $-8.120 \mathrm{E}+00$ & $-1.479 \mathrm{E}+01$ & $-1.523 \mathrm{E}+01$ \\
\hline 17 & $6.256 \mathrm{E}+00$ & $6.256 \mathrm{E}+00$ & $6.072 \mathrm{E}+00$ & $1.728 \mathrm{E}+00$ & $-7.872 E+00$ & $-1.457 \mathrm{E}+01$ & $-1.501 \mathrm{E}+01$ \\
\hline 18 & $6.256 \mathrm{E}+00$ & $6.255 \mathrm{E}+00$ & $6.081 \mathrm{E}+00$ & $1.950 \mathrm{E}+00$ & $-7.635 E+00$ & $-1.435 \mathrm{E}+01$ & $-1.480 \mathrm{E}+01$ \\
\hline 19 & $6.255 \mathrm{E}+00$ & $6.253 E+00$ & $6.085 \mathrm{E}+00$ & $2.158 \mathrm{E}+00$ & $-7.409 \mathrm{E}+00$ & $-1.414 \mathrm{E}+01$ & $-1.459 \mathrm{E}+01$ \\
\hline 20 & $6.255 \mathrm{E}+00$ & $6.251 \mathrm{E}+00$ & $6.084 \mathrm{E}+00$ & $2.354 \mathrm{E}+00$ & $-7.195 \mathrm{E}+00$ & $-1.395 \mathrm{E}+01$ & $-1.440 \mathrm{E}+01$ \\
\hline 21 & $6.254 \mathrm{E}+00$ & $6.249 \mathrm{E}+00$ & $6.076 \mathrm{E}+00$ & $2.538 \mathrm{E}+00$ & $-6.989 E+00$ & $-1.376 \mathrm{E}+01$ & $-1.421 \mathrm{E}+01$ \\
\hline
\end{tabular}




\begin{tabular}{llllllll}
22 & $6.253 \mathrm{E}+00$ & $6.245 \mathrm{E}+00$ & $6.061 \mathrm{E}+00$ & $2.714 \mathrm{E}+00$ & $-6.791 \mathrm{E}+00$ & $-1.357 \mathrm{E}+01$ & $-1.403 \mathrm{E}+01$ \\
23 & $6.249 \mathrm{E}+00$ & $6.240 \mathrm{E}+00$ & $6.034 \mathrm{E}+00$ & $2.881 \mathrm{E}+00$ & $-6.601 \mathrm{E}+00$ & $-1.339 \mathrm{E}+01$ & $-1.385 \mathrm{E}+01$ \\
24 & $6.307 \mathrm{E}+00$ & $6.229 \mathrm{E}+00$ & $5.990 \mathrm{E}+00$ & $3.038 \mathrm{E}+00$ & $-6.419 \mathrm{E}+00$ & $-1.322 \mathrm{E}+01$ & $-1.368 \mathrm{E}+01$ \\
25 & $6.278 \mathrm{E}+00$ & $6.206 \mathrm{E}+00$ & $5.910 \mathrm{E}+00$ & $3.131 \mathrm{E}+00$ & $-6.211 \mathrm{E}+00$ & $-1.307 \mathrm{E}+01$ & $-1.357 \mathrm{E}+01$ \\
26 & $6.248 \mathrm{E}+00$ & $6.183 \mathrm{E}+00$ & $5.829 \mathrm{E}+00$ & $3.224 \mathrm{E}+00$ & $-6.003 \mathrm{E}+00$ & $-1.291 \mathrm{E}+01$ & $-1.334 \mathrm{E}+01$ \\
27 & $6.303 \mathrm{E}+00$ & $6.169 \mathrm{E}+00$ & $5.745 \mathrm{E}+00$ & $3.132 \mathrm{E}+00$ & $-5.794 \mathrm{E}+00$ & $-1.287 \mathrm{E}+01$ & $-1.329 \mathrm{E}+01$ \\
28 & $6.535 \mathrm{E}+00$ & $6.202 \mathrm{E}+00$ & $5.704 \mathrm{E}+00$ & $2.559 \mathrm{E}+00$ & $-5.857 \mathrm{E}+00$ & $-1.259 \mathrm{E}+01$ & $-1.316 \mathrm{E}+01$ \\
29 & $1.126 \mathrm{E}+01$ & $9.326 \mathrm{E}+00$ & $8.221 \mathrm{E}+00$ & $2.327 \mathrm{E}+00$ & $-7.243 \mathrm{E}+00$ & $-1.205 \mathrm{E}+01$ & $-1.272 \mathrm{E}+01$ \\
\hline
\end{tabular}

Table C-9: Average heat flux ( $\mathrm{q}_{\mathrm{i}, \text { avg }}$ ) data for the individual blind louver, $\phi=45^{\circ}, \mathrm{T}_{\mathrm{b}}{ }^{*}=0.3$, $\mathrm{d} / \mathrm{L}=0.043$

\begin{tabular}{|c|c|c|c|c|c|c|c|}
\hline $\begin{array}{c}\text { Louver } \\
\text { number (i) }\end{array}$ & & & & $\mathbf{R} \mathbf{a}_{l}$ & & & \\
\hline & $1.00 \mathrm{E}+04$ & $1.00 \mathrm{E}+05$ & $1.00 \mathrm{E}+06$ & $1.00 \mathrm{E}+07$ & $1.00 \mathrm{E}+08$ & $5.00 \mathrm{E}+08$ & $7.00 \mathrm{E}+08$ \\
\hline 1 & $3.256 \mathrm{E}+00$ & $1.092 \mathrm{E}+00$ & $-7.355 \mathrm{E}+00$ & $-1.422 \mathrm{E}+01$ & $-2.275 E+01$ & $-2.977 \mathrm{E}+01$ & $-3.144 \mathrm{E}+01$ \\
\hline 2 & $4.292 \mathrm{E}+00$ & $4.600 \mathrm{E}+00$ & $3.588 \mathrm{E}+00$ & $-8.314 \mathrm{E}+00$ & $-1.917 \mathrm{E}+01$ & $-2.902 E+01$ & $-3.072 E+01$ \\
\hline 3 & $5.104 \mathrm{E}+00$ & $5.063 E+00$ & $2.539 \mathrm{E}+00$ & $-7.223 \mathrm{E}+00$ & $-1.907 \mathrm{E}+01$ & $-2.923 E+01$ & $-3.102 E+01$ \\
\hline 4 & $5.134 \mathrm{E}+00$ & $5.136 \mathrm{E}+00$ & $3.433 E+00$ & $-6.490 \mathrm{E}+00$ & $-1.890 \mathrm{E}+01$ & $-2.903 E+01$ & $-3.087 E+01$ \\
\hline 5 & $5.138 \mathrm{E}+00$ & $5.145 \mathrm{E}+00$ & $3.859 \mathrm{E}+00$ & $-5.839 \mathrm{E}+00$ & $-1.858 \mathrm{E}+01$ & $-2.869 \mathrm{E}+01$ & $-3.059 \mathrm{E}+01$ \\
\hline 6 & $5.137 \mathrm{E}+00$ & $5.141 \mathrm{E}+00$ & $4.099 \mathrm{E}+00$ & $-5.209 \mathrm{E}+00$ & $-1.812 \mathrm{E}+01$ & $-2.826 \mathrm{E}+01$ & $-3.023 E+01$ \\
\hline 7 & $5.135 \mathrm{E}+00$ & $5.137 \mathrm{E}+00$ & $4.258 \mathrm{E}+00$ & $-4.606 \mathrm{E}+00$ & $-1.758 \mathrm{E}+01$ & $-2.779 E+01$ & $-2.983 E+01$ \\
\hline 8 & $5.133 \mathrm{E}+00$ & $5.133 \mathrm{E}+00$ & $4.373 \mathrm{E}+00$ & $-3.514 \mathrm{E}+00$ & $-1.702 \mathrm{E}+01$ & $-2.730 \mathrm{E}+01$ & $-2.940 \mathrm{E}+01$ \\
\hline 9 & $5.131 E+00$ & $5.130 \mathrm{E}+00$ & $4.462 \mathrm{E}+00$ & $-3.028 \mathrm{E}+00$ & $-1.646 \mathrm{E}+01$ & $-2.681 \mathrm{E}+01$ & $-2.897 \mathrm{E}+01$ \\
\hline 10 & $5.129 E+00$ & $5.127 \mathrm{E}+00$ & $4.533 \mathrm{E}+00$ & $-2.580 \mathrm{E}+00$ & $-1.592 \mathrm{E}+01$ & $-2.634 \mathrm{E}+01$ & $-2.854 \mathrm{E}+01$ \\
\hline 11 & $5.129 \mathrm{E}+00$ & $5.126 \mathrm{E}+00$ & $4.591 \mathrm{E}+00$ & $-2.167 \mathrm{E}+00$ & $-1.541 \mathrm{E}+01$ & $-2.589 \mathrm{E}+01$ & $-2.814 \mathrm{E}+01$ \\
\hline 12 & $5.129 E+00$ & $5.126 \mathrm{E}+00$ & $4.638 \mathrm{E}+00$ & $-1.786 \mathrm{E}+00$ & $-1.493 E+01$ & $-2.546 \mathrm{E}+01$ & $-2.775 \mathrm{E}+01$ \\
\hline 13 & $5.128 \mathrm{E}+00$ & $5.125 \mathrm{E}+00$ & $4.677 \mathrm{E}+00$ & $-1.786 \mathrm{E}+00$ & $-1.447 \mathrm{E}+01$ & $-2.505 \mathrm{E}+01$ & $-2.739 E+01$ \\
\hline 14 & $5.128 \mathrm{E}+00$ & $5.125 \mathrm{E}+00$ & $4.710 \mathrm{E}+00$ & $-1.434 \mathrm{E}+00$ & $-1.404 \mathrm{E}+01$ & $-2.466 \mathrm{E}+01$ & $-2.704 \mathrm{E}+01$ \\
\hline 15 & $5.128 \mathrm{E}+00$ & $5.124 \mathrm{E}+00$ & $4.737 \mathrm{E}+00$ & $-1.108 \mathrm{E}+00$ & $-1.364 \mathrm{E}+01$ & $-2.429 \mathrm{E}+01$ & $-2.671 E+01$ \\
\hline 16 & $5.127 \mathrm{E}+00$ & $5.124 \mathrm{E}+00$ & $4.759 \mathrm{E}+00$ & $-8.060 \mathrm{E}-01$ & $-1.326 \mathrm{E}+01$ & $-2.394 \mathrm{E}+01$ & $-2.639 \mathrm{E}+01$ \\
\hline 17 & $5.127 \mathrm{E}+00$ & $5.123 E+00$ & $4.776 \mathrm{E}+00$ & $-5.255 \mathrm{E}-01$ & $-1.291 \mathrm{E}+01$ & $-2.360 \mathrm{E}+01$ & $-2.609 \mathrm{E}+01$ \\
\hline 18 & $5.127 \mathrm{E}+00$ & $5.123 \mathrm{E}+00$ & $4.789 \mathrm{E}+00$ & $-2.641 \mathrm{E}-01$ & $-1.257 \mathrm{E}+01$ & $-2.328 \mathrm{E}+01$ & $-2.580 \mathrm{E}+01$ \\
\hline 19 & $5.127 \mathrm{E}+00$ & $5.121 \mathrm{E}+00$ & $4.797 \mathrm{E}+00$ & $-2.020 \mathrm{E}-02$ & $-1.226 \mathrm{E}+01$ & $-2.297 \mathrm{E}+01$ & $-2.552 \mathrm{E}+01$ \\
\hline 20 & $5.127 \mathrm{E}+00$ & $5.119 \mathrm{E}+00$ & $4.798 \mathrm{E}+00$ & $2.085 \mathrm{E}-01$ & $-1.196 \mathrm{E}+01$ & $-2.267 \mathrm{E}+01$ & $-2.525 \mathrm{E}+01$ \\
\hline 21 & $5.126 \mathrm{E}+00$ & $5.117 \mathrm{E}+00$ & $4.792 \mathrm{E}+00$ & $4.239 \mathrm{E}-01$ & $-1.167 \mathrm{E}+01$ & $-2.239 \mathrm{E}+01$ & $-2.499 \mathrm{E}+01$ \\
\hline 22 & $5.125 \mathrm{E}+00$ & $5.114 \mathrm{E}+00$ & $4.778 \mathrm{E}+00$ & $6.280 \mathrm{E}-01$ & $-1.141 \mathrm{E}+01$ & $-2.212 \mathrm{E}+01$ & $-2.474 \mathrm{E}+01$ \\
\hline 23 & $5.124 \mathrm{E}+00$ & $5.109 \mathrm{E}+00$ & $4.746 \mathrm{E}+00$ & $8.218 \mathrm{E}-01$ & $-1.116 \mathrm{E}+01$ & $-2.186 \mathrm{E}+01$ & $-2.449 \mathrm{E}+01$ \\
\hline 24 & $5.118 \mathrm{E}+00$ & $5.098 \mathrm{E}+00$ & $4.698 \mathrm{E}+00$ & $1.005 \mathrm{E}+00$ & $-1.093 \mathrm{E}+01$ & $-2.161 \mathrm{E}+01$ & $-2.425 \mathrm{E}+01$ \\
\hline 25 & $5.113 \mathrm{E}+00$ & $5.076 \mathrm{E}+00$ & $4.610 \mathrm{E}+00$ & $1.130 \mathrm{E}+00$ & $-1.067 \mathrm{E}+01$ & $-2.131 \mathrm{E}+01$ & $-2.411 \mathrm{E}+01$ \\
\hline 26 & $5.107 \mathrm{E}+00$ & $5.054 \mathrm{E}+00$ & $4.521 \mathrm{E}+00$ & $1.255 \mathrm{E}+00$ & $-1.040 \mathrm{E}+01$ & $-2.100 \mathrm{E}+01$ & $-2.378 \mathrm{E}+01$ \\
\hline 27 & $5.139 \mathrm{E}+00$ & $5.034 \mathrm{E}+00$ & $4.427 \mathrm{E}+00$ & $1.202 \mathrm{E}+00$ & $-9.998 \mathrm{E}+00$ & $-2.074 \mathrm{E}+01$ & $-2.365 E+01$ \\
\hline 28 & $5.303 \mathrm{E}+00$ & $5.032 \mathrm{E}+00$ & $4.389 \mathrm{E}+00$ & $6.234 \mathrm{E}-01$ & $-9.507 \mathrm{E}+00$ & $-2.084 \mathrm{E}+01$ & $-2.339 E+01$ \\
\hline 29 & $9.104 \mathrm{E}+00$ & $7.425 \mathrm{E}+00$ & $6.726 \mathrm{E}+00$ & $-4.103 \mathrm{E}-02$ & $-1.101 \mathrm{E}+01$ & $-2.079 \mathrm{E}+01$ & $-2.346 \mathrm{E}+01$ \\
\hline
\end{tabular}


Table C-10: Average heat flux ( $\mathrm{q}_{\mathrm{i}, \text { avg }}$ ) data for the individual blind louver, $\phi=45^{\circ}, \mathrm{T}_{\mathrm{b}}{ }^{*}=0.4$, $\mathrm{d} / \mathrm{L}=0.043$

\begin{tabular}{|c|c|c|c|c|c|c|c|}
\hline $\begin{array}{c}\text { Louver } \\
\text { number (i) }\end{array}$ & & & & $\mathbf{R a}_{\mathbf{l}}$ & & & \\
\hline & $1.00 \mathrm{E}+04$ & $1.00 \mathrm{E}+05$ & $1.00 \mathrm{E}+06$ & $1.00 \mathrm{E}+07$ & $1.00 \mathrm{E}+08$ & $5.00 \mathrm{E}+08$ & $7.00 \mathrm{E}+08$ \\
\hline 1 & $1.340 \mathrm{E}+00$ & $-1.043 E+00$ & $-1.139 \mathrm{E}+01$ & $-1.995 \mathrm{E}+01$ & $-3.177 \mathrm{E}+01$ & $-4.169 \mathrm{E}+01$ & $-4.498 \mathrm{E}+01$ \\
\hline 2 & $3.886 \mathrm{E}+00$ & $3.348 \mathrm{E}+00$ & $-1.955 \mathrm{E}+01$ & $-1.198 \mathrm{E}+01$ & $-2.772 \mathrm{E}+01$ & $-4.019 \mathrm{E}+01$ & $-4.348 \mathrm{E}+01$ \\
\hline 3 & $3.950 \mathrm{E}+00$ & $3.878 \mathrm{E}+00$ & $5.541 \mathrm{E}-01$ & $-1.066 \mathrm{E}+01$ & $-2.745 \mathrm{E}+01$ & $-4.033 E+01$ & $-4.362 \mathrm{E}+01$ \\
\hline 4 & $3.997 \mathrm{E}+00$ & $3.979 \mathrm{E}+00$ & $1.619 \mathrm{E}+00$ & $-9.822 \mathrm{E}+00$ & $-2.718 \mathrm{E}+01$ & $-4.017 \mathrm{E}+01$ & $-4.346 \mathrm{E}+01$ \\
\hline 5 & $4.007 \mathrm{E}+00$ & $4.082 \mathrm{E}+00$ & $2.153 \mathrm{E}+00$ & $-9.085 E+00$ & $-2.669 \mathrm{E}+01$ & $-3.988 \mathrm{E}+01$ & $-4.317 \mathrm{E}+01$ \\
\hline 6 & $4.008 \mathrm{E}+00$ & $4.007 \mathrm{E}+00$ & $2.468 \mathrm{E}+00$ & $-8.360 \mathrm{E}+00$ & $-2.603 \mathrm{E}+01$ & $-3.946 \mathrm{E}+01$ & $-4.275 E+01$ \\
\hline 7 & $4.004 \mathrm{E}+00$ & $4.007 \mathrm{E}+00$ & $2.681 \mathrm{E}+00$ & $-7.657 \mathrm{E}+00$ & $-2.527 \mathrm{E}+01$ & $-3.895 \mathrm{E}+01$ & $-4.224 \mathrm{E}+01$ \\
\hline 8 & $4.003 \mathrm{E}+00$ & $4.006 \mathrm{E}+00$ & $2.839 \mathrm{E}+00$ & $-6.989 \mathrm{E}+00$ & $-2.449 \mathrm{E}+01$ & $-3.839 \mathrm{E}+01$ & $-4.168 \mathrm{E}+01$ \\
\hline 9 & $4.001 \mathrm{E}+00$ & $4.085 \mathrm{E}+00$ & $2.962 \mathrm{E}+00$ & $-6.367 \mathrm{E}+00$ & $-2.372 \mathrm{E}+01$ & $-3.781 \mathrm{E}+01$ & $-4.110 \mathrm{E}+01$ \\
\hline 10 & $4.000 \mathrm{E}+00$ & $4.003 \mathrm{E}+00$ & $3.062 \mathrm{E}+00$ & $-5.792 \mathrm{E}+00$ & $-2.297 \mathrm{E}+01$ & $-3.723 \mathrm{E}+01$ & $-4.052 \mathrm{E}+01$ \\
\hline 11 & $3.999 \mathrm{E}+00$ & $4.002 \mathrm{E}+00$ & $3.143 \mathrm{E}+00$ & $-5.261 \mathrm{E}+00$ & $-2.260 \mathrm{E}+01$ & $-3.667 \mathrm{E}+01$ & $-3.996 \mathrm{E}+01$ \\
\hline 12 & $3.999 \mathrm{E}+00$ & $4.001 \mathrm{E}+00$ & $3.211 \mathrm{E}+00$ & $-4.771 \mathrm{E}+00$ & $-2.159 \mathrm{E}+01$ & $-3.613 E+01$ & $-3.942 \mathrm{E}+01$ \\
\hline 13 & $3.999 \mathrm{E}+00$ & $4.000 \mathrm{E}+00$ & $3.268 \mathrm{E}+00$ & $-4.321 \mathrm{E}+00$ & $-2.096 \mathrm{E}+01$ & $-3.560 \mathrm{E}+01$ & $-3.889 E+01$ \\
\hline 14 & $3.999 \mathrm{E}+00$ & $3.999 \mathrm{E}+00$ & $3.316 \mathrm{E}+00$ & $-3.905 E+00$ & $-2.037 \mathrm{E}+01$ & $-3.510 \mathrm{E}+01$ & $-3.839 \mathrm{E}+01$ \\
\hline 15 & $3.999 \mathrm{E}+00$ & $3.999 \mathrm{E}+00$ & $3.357 \mathrm{E}+00$ & $-3.521 \mathrm{E}+00$ & $-1.981 E+01$ & $-3.462 \mathrm{E}+01$ & $-3.791 \mathrm{E}+01$ \\
\hline 16 & $3.999 \mathrm{E}+00$ & $3.999 \mathrm{E}+00$ & $3.391 \mathrm{E}+00$ & $-3.166 \mathrm{E}+00$ & $-1.928 \mathrm{E}+01$ & $-3.416 \mathrm{E}+01$ & $-3.745 \mathrm{E}+01$ \\
\hline 17 & $3.999 \mathrm{E}+00$ & $3.997 \mathrm{E}+00$ & $3.439 \mathrm{E}+00$ & $-2.836 \mathrm{E}+00$ & $-1.879 E+01$ & $-3.372 \mathrm{E}+01$ & $-3.701 E+01$ \\
\hline 18 & $3.999 \mathrm{E}+00$ & $3.997 \mathrm{E}+00$ & $3.454 \mathrm{E}+00$ & $-2.529 \mathrm{E}+00$ & $-1.832 E+01$ & $-3.330 \mathrm{E}+01$ & $-3.659 E+01$ \\
\hline 19 & $3.999 \mathrm{E}+00$ & $3.996 \mathrm{E}+00$ & $3.461 \mathrm{E}+00$ & $-2.243 E+00$ & $-1.788 \mathrm{E}+01$ & $-3.289 \mathrm{E}+01$ & $-3.618 E+01$ \\
\hline 20 & $3.998 \mathrm{E}+00$ & $3.995 \mathrm{E}+00$ & $3.461 E+00$ & $-1.976 \mathrm{E}+00$ & $-1.706 \mathrm{E}+01$ & $-3.250 \mathrm{E}+01$ & $-3.579 \mathrm{E}+01$ \\
\hline 21 & $3.998 \mathrm{E}+00$ & $3.993 \mathrm{E}+00$ & $3.458 \mathrm{E}+00$ & $-1.723 E+00$ & $-1.706 \mathrm{E}+01$ & $-3.212 E+01$ & $-3.541 \mathrm{E}+01$ \\
\hline 22 & $3.998 \mathrm{E}+00$ & $3.991 \mathrm{E}+00$ & $3.443 \mathrm{E}+00$ & $-1.485 \mathrm{E}+00$ & $-1.668 \mathrm{E}+01$ & $-3.175 E+01$ & $-3.504 \mathrm{E}+01$ \\
\hline 23 & $3.995 \mathrm{E}+00$ & $3.988 \mathrm{E}+00$ & $3.411 \mathrm{E}+00$ & $-1.258 \mathrm{E}+00$ & $-1.632 E+01$ & $-3.139 \mathrm{E}+01$ & $-3.468 \mathrm{E}+01$ \\
\hline 24 & $3.995 \mathrm{E}+00$ & $3.980 \mathrm{E}+00$ & $3.355 \mathrm{E}+00$ & $-1.044 \mathrm{E}+00$ & $-1.600 \mathrm{E}+01$ & $-3.104 E+01$ & $-3.433 E+01$ \\
\hline 25 & $3.995 \mathrm{E}+00$ & $3.959 \mathrm{E}+00$ & $3.250 \mathrm{E}+00$ & $-8.978 \mathrm{E}-01$ & $-1.568 \mathrm{E}+01$ & $-3.070 E+01$ & $-3.398 \mathrm{E}+01$ \\
\hline 26 & $3.995 \mathrm{E}+00$ & $3.938 \mathrm{E}+00$ & $3.145 \mathrm{E}+00$ & $-7.515 \mathrm{E}-01$ & $-1.536 \mathrm{E}+01$ & $-3.035 E+01$ & $-3.364 \mathrm{E}+01$ \\
\hline 27 & $3.995 \mathrm{E}+00$ & $3.902 \mathrm{E}+00$ & $3.016 \mathrm{E}+00$ & $-8.179 \mathrm{E}-01$ & $-1.510 \mathrm{E}+01$ & $-3.025 E+01$ & $-3.354 \mathrm{E}+01$ \\
\hline 28 & $3.995 \mathrm{E}+00$ & $3.852 \mathrm{E}+00$ & $2.939 \mathrm{E}+00$ & $-1.512 \mathrm{E}+00$ & $-1.479 \mathrm{E}+01$ & $-2.992 \mathrm{E}+01$ & $-3.321 E+01$ \\
\hline 29 & $6.968 \mathrm{E}+00$ & $5.519 \mathrm{E}+00$ & $4.951 \mathrm{E}+00$ & $-2.641 E+00$ & $-1.579 \mathrm{E}+01$ & $-2.932 \mathrm{E}+01$ & $-3.261 \mathrm{E}+01$ \\
\hline
\end{tabular}

Table C-11: Average heat flux ( $\mathrm{q}_{\mathrm{i}, \text { avg }}$ ) data for the individual blind louver, $\phi=90^{\circ}, \mathrm{T}_{\mathrm{b}}{ }^{*}=0.2$, $\mathrm{d} / \mathrm{L}=0.043$

\begin{tabular}{ccccccccc}
\hline $\begin{array}{c}\text { Louver } \\
\text { number (i) }\end{array}$ & \multicolumn{7}{c}{$\mathbf{R a}_{\mathrm{L}}$} \\
\hline & $\mathbf{1 . 0 0 \mathrm { E } + 0 4}$ & $\mathbf{1 . 0 0 \mathrm { E } + 0 5}$ & $\mathbf{1 . 0 0 \mathrm { E } + 0 6}$ & $\mathbf{1 . 0 0 \mathrm { E } + 0 7}$ & $\mathbf{1 . 0 0 \mathrm { E } + 0 8}$ & $\mathbf{5 . 0 0 \mathrm { E } + 0 8}$ & $\mathbf{7 . 0 0 \mathrm { E } + 0 8}$ & $\mathbf{1 . 0 0 \mathrm { E } + 0 9}$ \\
\hline 1 & $1.862 \mathrm{E}+01$ & $1.700 \mathrm{E}+01$ & $3.425 \mathrm{E}+00$ & $-1.773 \mathrm{E}+01$ & $-2.216 \mathrm{E}+01$ & $-1.558 \mathrm{E}+01$ & $-1.309 \mathrm{E}+01$ & $-1.172 \mathrm{E}+01$ \\
2 & $1.895 \mathrm{E}+01$ & $1.881 \mathrm{E}+01$ & $1.547 \mathrm{E}+01$ & $-8.707 \mathrm{E}+00$ & $-1.589 \mathrm{E}+01$ & $-1.925 \mathrm{E}+01$ & $-1.760 \mathrm{E}+01$ & $-1.650 \mathrm{E}+01$ \\
3 & $1.912 \mathrm{E}+01$ & $1.911 \mathrm{E}+01$ & $1.824 \mathrm{E}+01$ & $-4.355 \mathrm{E}+00$ & $-1.449 \mathrm{E}+01$ & $-1.973 \mathrm{E}+01$ & $-2.200 \mathrm{E}+01$ & $-2.391 \mathrm{E}+01$ \\
4 & $1.914 \mathrm{E}+01$ & $1.914 \mathrm{E}+01$ & $1.892 \mathrm{E}+01$ & $1.888 \mathrm{E}-01$ & $-1.303 \mathrm{E}+01$ & $-1.774 \mathrm{E}+01$ & $-1.971 \mathrm{E}+01$ & $-2.201 \mathrm{E}+01$ \\
5 & $1.914 \mathrm{E}+01$ & $1.914 \mathrm{E}+01$ & $1.909 \mathrm{E}+01$ & $4.130 \mathrm{E}+00$ & $-1.182 \mathrm{E}+01$ & $-1.609 \mathrm{E}+01$ & $-1.772 \mathrm{E}+01$ & $-1.946 \mathrm{E}+01$ \\
6 & $1.914 \mathrm{E}+01$ & $1.914 \mathrm{E}+01$ & $1.913 \mathrm{E}+01$ & $7.336 \mathrm{E}+00$ & $-1.077 \mathrm{E}+01$ & $-1.482 \mathrm{E}+01$ & $-1.622 \mathrm{E}+01$ & $-1.764 \mathrm{E}+01$
\end{tabular}


$1.914 \mathrm{E}+01 \quad 1.914 \mathrm{E}+01 \quad 1.914 \mathrm{E}+01 \quad 9.884 \mathrm{E}+00-9.754 \mathrm{E}+00-1.380 \mathrm{E}+01-1.507 \mathrm{E}+01-1.630 \mathrm{E}+01$

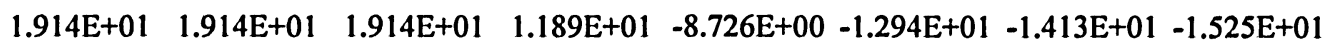
$\begin{array}{llllllll}1.914 \mathrm{E}+01 & 1.914 \mathrm{E}+01 & 1.914 \mathrm{E}+01 & 1.346 \mathrm{E}+01 & -7.673 \mathrm{E}+00 & -1.218 \mathrm{E}+01 & -1.333 \mathrm{E}+01 & -1.438 \mathrm{E}+01\end{array}$ $1.914 \mathrm{E}+01 \quad 1.914 \mathrm{E}+01 \quad 1.914 \mathrm{E}+01 \quad 1.469 \mathrm{E}+01 \quad-6.599 \mathrm{E}+00-1.149 \mathrm{E}+01-1.262 \mathrm{E}+01-1.362 \mathrm{E}+01$ $1.914 \mathrm{E}+01 \quad 1.914 \mathrm{E}+01 \quad 1.914 \mathrm{E}+01 \quad 1.566 \mathrm{E}+01 \quad-5.513 \mathrm{E}+00-1.084 \mathrm{E}+01-1.198 \mathrm{E}+01-1.295 \mathrm{E}+01$ $1.914 \mathrm{E}+01 \quad 1.914 \mathrm{E}+01 \quad 1.914 \mathrm{E}+01 \quad 1.641 \mathrm{E}+01-4.428 \mathrm{E}+00-1.023 \mathrm{E}+01-1.138 \mathrm{E}+01-1.233 \mathrm{E}+01$ $1.914 \mathrm{E}+01 \quad 1.914 \mathrm{E}+01 \quad 1.914 \mathrm{E}+01 \quad 1.700 \mathrm{E}+01 \quad-3.352 \mathrm{E}+00-9.634 \mathrm{E}+00-1.081 \mathrm{E}+01-1.177 \mathrm{E}+01$

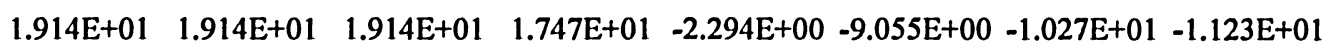

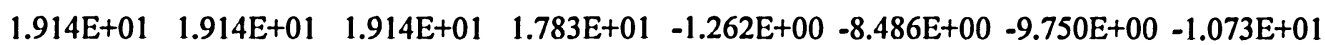

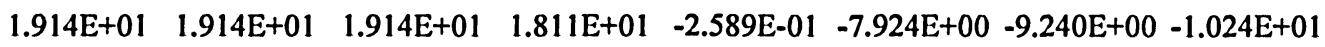

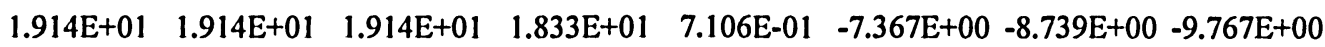

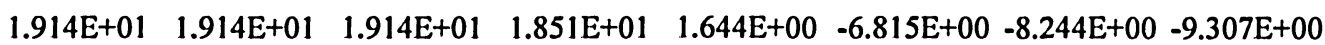
$\begin{array}{llllllll}1.914 \mathrm{E}+01 & 1.914 \mathrm{E}+01 & 1.914 \mathrm{E}+01 & 1.865 \mathrm{E}+01 & 2.541 \mathrm{E}+00 & -6.266 \mathrm{E}+00 & -7.756 \mathrm{E}+00 & -8.856 \mathrm{E}+00\end{array}$

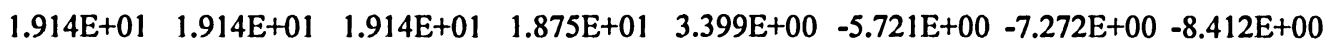

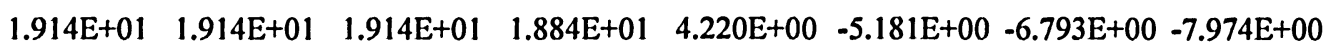
$\begin{array}{llllllll}1.914 \mathrm{E}+01 & 1.914 \mathrm{E}+01 & 1.914 \mathrm{E}+01 & 1.890 \mathrm{E}+01 & 5.003 \mathrm{E}+00 & -4.646 \mathrm{E}+00 & -6.318 \mathrm{E}+00 & -7.542 \mathrm{E}+00\end{array}$ $\begin{array}{llllllll}1.914 \mathrm{E}+01 & 1.914 \mathrm{E}+01 & 1.914 \mathrm{E}+01 & 1.895 \mathrm{E}+01 & 5.748 \mathrm{E}+00 & -4.115 \mathrm{E}+00 & -5.846 \mathrm{E}+00 & -7.115 \mathrm{E}+00\end{array}$

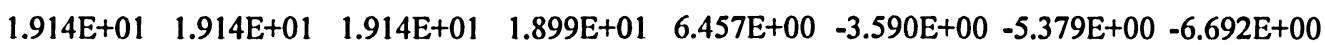
$\begin{array}{llllllll}1.914 \mathrm{E}+01 & 1.914 \mathrm{E}+01 & 1.914 \mathrm{E}+01 & 1.903 \mathrm{E}+01 & 7.131 \mathrm{E}+00 & -3.072 \mathrm{E}+00 & -4.916 \mathrm{E}+00 & -6.274 \mathrm{E}+00\end{array}$ $\begin{array}{llllllll}1.914 \mathrm{E}+01 & 1.914 \mathrm{E}+01 & 1.914 \mathrm{E}+01 & 1.905 \mathrm{E}+01 & 7.771 \mathrm{E}+00 & -2.560 \mathrm{E}+00 & -4.458 \mathrm{E}+00 & -5.859 \mathrm{E}+00\end{array}$ $\begin{array}{llllllll}1.915 \mathrm{E}+01 & 1.914 \mathrm{E}+01 & 1.914 \mathrm{E}+01 & 1.907 \mathrm{E}+01 & 8.382 \mathrm{E}+00 & -2.055 \mathrm{E}+00 & -4.005 \mathrm{E}+00 & -5.449 \mathrm{E}+00\end{array}$ $\begin{array}{llllllll}1.931 \mathrm{E}+01 & 1.927 \mathrm{E}+01 & 1.923 \mathrm{E}+01 & 1.918 \mathrm{E}+01 & 8.994 \mathrm{E}+00 & -1.559 \mathrm{E}+00 & -3.563 \mathrm{E}+00 & -5.053 \mathrm{E}+00\end{array}$ $\begin{array}{llllllll}2.401 \mathrm{E}+01 & 2.256 \mathrm{E}+01 & 2.150 \mathrm{E}+01 & 2.042 \mathrm{E}+01 & 9.778 \mathrm{E}+00 & -1.156 \mathrm{E}+00 & -3.271 \mathrm{E}+00 & -4.850 \mathrm{E}+00\end{array}$

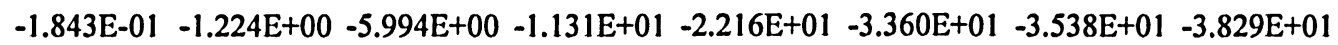

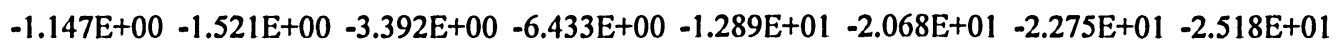
$-1.193 \mathrm{E}+00-1.440 \mathrm{E}+00-2.878 \mathrm{E}+00-5.478 \mathrm{E}+00-1.065 \mathrm{E}+01-1.573 \mathrm{E}+01-1.723 \mathrm{E}+01-1.892 \mathrm{E}+01$ $-1.201 \mathrm{E}+00-1.384 \mathrm{E}+00-2.623 \mathrm{E}+00-4.980 \mathrm{E}+00-9.416 \mathrm{E}+00-1.352 \mathrm{E}+01-1.480 \mathrm{E}+01-1.614 \mathrm{E}+01$ $-1.203 \mathrm{E}+00-1.347 \mathrm{E}+00-2.462 \mathrm{E}+00-4.650 \mathrm{E}+00-8.593 \mathrm{E}+00-1.220 \mathrm{E}+01-1.337 \mathrm{E}+01-1.454 \mathrm{E}+01$ $-1.204 \mathrm{E}+00-1.321 \mathrm{E}+00-2.346 \mathrm{E}+00-4.402 \mathrm{E}+00-7.991 \mathrm{E}+00-1.132 \mathrm{E}+01-1.242 \mathrm{E}+01-1.348 \mathrm{E}+01$ $-1.205 \mathrm{E}+00-1.302 \mathrm{E}+00-2.255 \mathrm{E}+00-4.204 \mathrm{E}+00-7.533 \mathrm{E}+00-1.068 \mathrm{E}+01-1.172 \mathrm{E}+01-1.270 \mathrm{E}+01$ $-1.206 \mathrm{E}+00-1.287 \mathrm{E}+00-2.180 \mathrm{E}+00-4.039 \mathrm{E}+00-7.176 \mathrm{E}+00-1.020 \mathrm{E}+01-1.118 \mathrm{E}+01-1.210 \mathrm{E}+01$

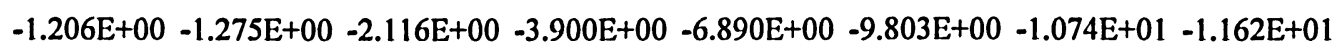
$-1.206 \mathrm{E}+00-1.265 \mathrm{E}+00-2.060 \mathrm{E}+00-3.780 \mathrm{E}+00-6.655 \mathrm{E}+00-9.476 \mathrm{E}+00-1.037 \mathrm{E}+01-1.122 \mathrm{E}+01$ $-1.207 \mathrm{E}+00-1.257 \mathrm{E}+00-2.011 \mathrm{E}+00-3.675 \mathrm{E}+00-6.458 \mathrm{E}+00-9.198 \mathrm{E}+00-1.006 \mathrm{E}+01-1.088 \mathrm{E}+01$ $-1.207 \mathrm{E}+00-1.250 \mathrm{E}+00-1.968 \mathrm{E}+00-3.583 \mathrm{E}+00-6.289 \mathrm{E}+00-8.958 \mathrm{E}+00-9.791 \mathrm{E}+00-1.058 \mathrm{E}+01$ $-1.207 \mathrm{E}+00-1.244 \mathrm{E}+00-1.929 \mathrm{E}+00-3.501 \mathrm{E}+00-6.142 \mathrm{E}+00-8.746 \mathrm{E}+00-9.556 \mathrm{E}+00-1.033 \mathrm{E}+01$ $-1.207 \mathrm{E}+00-1.238 \mathrm{E}+00-1.894 \mathrm{E}+00-3.427 \mathrm{E}+00-6.012 \mathrm{E}+00-8.558 \mathrm{E}+00-9.348 \mathrm{E}+00-1.010 \mathrm{E}+01$

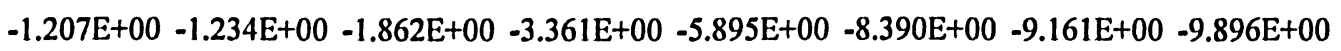

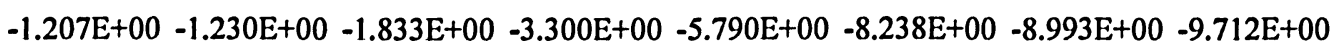
$-1.207 \mathrm{E}+00-1.227 \mathrm{E}+00-1.806 \mathrm{E}+00-3.245 \mathrm{E}+00-5.693 \mathrm{E}+00-8.099 \mathrm{E}+00-8.840 \mathrm{E}+00-9.546 \mathrm{E}+00$ $-1.206 \mathrm{E}+00-1.224 \mathrm{E}+00-1.782 \mathrm{E}+00-3.194 \mathrm{E}+00-5.604 \mathrm{E}+00-7.971 \mathrm{E}+00-8.699 \mathrm{E}+00-9.393 \mathrm{E}+00$

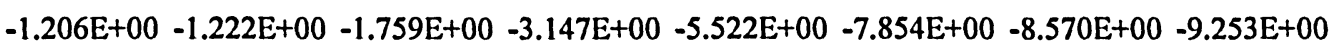
$-1.206 \mathrm{E}+00-1.220 \mathrm{E}+00-1.739 \mathrm{E}+00-3.103 \mathrm{E}+00-5.446 \mathrm{E}+00-7.745 \mathrm{E}+00-8.450 \mathrm{E}+00-9.124 \mathrm{E}+00$

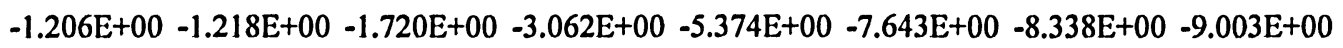

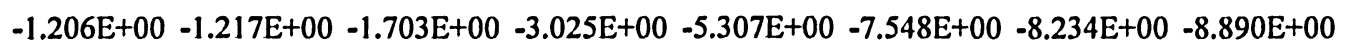
$-1.205 \mathrm{E}+00-1.218 \mathrm{E}+00-1.689 \mathrm{E}+00-2.990 \mathrm{E}+00-5.244 \mathrm{E}+00-7.459 \mathrm{E}+00-8.136 \mathrm{E}+00-8.785 \mathrm{E}+00$ $-1.201 \mathrm{E}+00-1.220 \mathrm{E}+00-1.677 \mathrm{E}+00-2.959 \mathrm{E}+00-5.185 \mathrm{E}+00-7.375 \mathrm{E}+00-8.044 \mathrm{E}+00-8.686 \mathrm{E}+00$

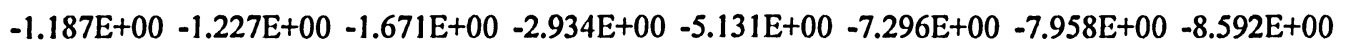


$56-1.032 \mathrm{E}+00-1.266 \mathrm{E}+00-1.687 \mathrm{E}+00-2.919 \mathrm{E}+00-5.054 \mathrm{E}+00-7.169 \mathrm{E}+00-7.810 \mathrm{E}+00-8.429 \mathrm{E}+00$

$57-6.575 \mathrm{E}-01-1.265 \mathrm{E}+00-1.727 \mathrm{E}+00-2.954 \mathrm{E}+00-5.070 \mathrm{E}+00-7.159 \mathrm{E}+00-7.781 \mathrm{E}+00-8.386 \mathrm{E}+00$

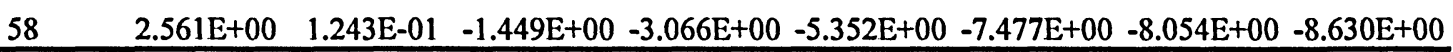

Table C-12: Average heat flux $\left(\mathrm{q}_{\mathrm{i}, \mathrm{avg}}\right)$ data for the individual blind louver, $\phi=90^{\circ}, \mathrm{T}_{\mathrm{b}}{ }^{*}=0.3$, $\mathrm{d} / \mathrm{L}=0.043$

\begin{tabular}{|c|c|c|c|c|c|c|c|c|}
\hline $\begin{array}{c}\text { Louver } \\
\text { number (i) }\end{array}$ & & & & $\mathbf{R a}_{\mathbf{l}}$ & & & & \\
\hline & $1.00 \mathrm{E}+04$ & $1.00 \mathrm{E}+05$ & $1.00 \mathrm{E}+06$ & $1.00 \mathrm{E}+07$ & $1.00 \mathrm{E}+08$ & $5.00 \mathrm{E}+08$ & $7.00 \mathrm{E}+08$ & $1.00 \mathrm{E}+09$ \\
\hline 1 & $1.534 \mathrm{E}+01$ & $1.365 \mathrm{E}+01$ & $-2.859 \mathrm{E}+00$ & $-2.770 \mathrm{E}+01$ & $-3.416 \mathrm{E}+01$ & $-2.177 \mathrm{E}+01$ & $-1.910 \mathrm{E}+01$ & $-1.751 E+01$ \\
\hline 2 & $1.655 \mathrm{E}+01$ & $1.643 \mathrm{E}+01$ & $1.227 \mathrm{E}+01$ & $-1.438 \mathrm{E}+01$ & $-2.489 \mathrm{E}+01$ & $-2.939 E+01$ & $-2.951 E+01$ & $-1.880 \mathrm{E}+01$ \\
\hline 3 & $1.673 \mathrm{E}+01$ & $1.672 \mathrm{E}+01$ & $1.558 \mathrm{E}+01$ & $-9.655 E+00$ & $-2.276 \mathrm{E}+01$ & $-3.138 E+01$ & $-3.674 \mathrm{E}+01$ & $-3.543 \mathrm{E}+01$ \\
\hline 4 & $1.675 E+01$ & $1.674 \mathrm{E}+01$ & $1.644 \mathrm{E}+01$ & $-4.823 E+00$ & $-2.051 E+01$ & $-2.838 \mathrm{E}+01$ & $-3.235 \mathrm{E}+01$ & $-4.048 E+01$ \\
\hline 5 & $1.675 \mathrm{E}+01$ & $1.675 \mathrm{E}+01$ & $1.667 \mathrm{E}+01$ & $-5.921 \mathrm{E}-01$ & $-1.870 \mathrm{E}+01$ & $-2.580 \mathrm{E}+01$ & $-2.887 \mathrm{E}+01$ & $-3.448 E+01$ \\
\hline 6 & $1.675 \mathrm{E}+01$ & $1.675 \mathrm{E}+01$ & $1.673 \mathrm{E}+01$ & $2.897 \mathrm{E}+00$ & $-1.720 \mathrm{E}+01$ & $-2.386 \mathrm{E}+01$ & $-2.639 \mathrm{E}+01$ & $-3.050 E+01$ \\
\hline 7 & $1.675 \mathrm{E}+01$ & $1.675 \mathrm{E}+01$ & $1.674 \mathrm{E}+01$ & $5.712 \mathrm{E}+00$ & $-1.586 \mathrm{E}+01$ & $-2.234 \mathrm{E}+01$ & $-2.453 \mathrm{E}+01$ & $-2.787 E+01$ \\
\hline 8 & $1.675 \mathrm{E}+01$ & $1.675 \mathrm{E}+01$ & $1.675 E+01$ & $7.964 \mathrm{E}+00$ & $-1.458 \mathrm{E}+01$ & $-2.108 \mathrm{E}+01$ & $-2.304 \mathrm{E}+01$ & $-2.596 \mathrm{E}+01$ \\
\hline 9 & $1.675 \mathrm{E}+01$ & $1.675 \mathrm{E}+01$ & $1.675 \mathrm{E}+01$ & $9.758 \mathrm{E}+00$ & $-1.333 \mathrm{E}+01$ & $-2.001 E+01$ & $-2.180 \mathrm{E}+01$ & $-2.444 \mathrm{E}+01$ \\
\hline 10 & $1.675 \mathrm{E}+01$ & $1.675 \mathrm{E}+01$ & $1.675 \mathrm{E}+01$ & $1.119 \mathrm{E}+01$ & $-1.209 \mathrm{E}+01$ & $-1.906 \mathrm{E}+01$ & $-2.072 \mathrm{E}+01$ & $-2.318 \mathrm{E}+01$ \\
\hline 11 & $1.675 \mathrm{E}+01$ & $1.675 \mathrm{E}+01$ & $1.675 \mathrm{E}+01$ & $1.232 \mathrm{E}+01$ & $-1.087 \mathrm{E}+01$ & $-1.820 \mathrm{E}+01$ & $-1.977 \mathrm{E}+01$ & $-2.208 \mathrm{E}+01$ \\
\hline 12 & $1.675 \mathrm{E}+01$ & $1.675 \mathrm{E}+01$ & $1.675 \mathrm{E}+01$ & $1.323 \mathrm{E}+01$ & $-9.667 \mathrm{E}+00$ & $-1.740 \mathrm{E}+01$ & $-1.891 E+01$ & $-2.112 \mathrm{E}+01$ \\
\hline 13 & $1.675 \mathrm{E}+01$ & $1.675 \mathrm{E}+01$ & $1.675 \mathrm{E}+01$ & $1.394 \mathrm{E}+01$ & $-8.486 \mathrm{E}+00$ & $-1.666 \mathrm{E}+01$ & $-1.811 \mathrm{E}+01$ & $-2.025 \mathrm{E}+01$ \\
\hline 14 & $1.675 \mathrm{E}+01$ & $1.675 \mathrm{E}+01$ & $1.675 \mathrm{E}+01$ & $1.452 \mathrm{E}+01$ & $-7.333 \mathrm{E}+00$ & $-1.594 \mathrm{E}+01$ & $-1.737 \mathrm{E}+01$ & $-1.946 \mathrm{E}+01$ \\
\hline 15 & $1.675 \mathrm{E}+01$ & $1.675 \mathrm{E}+01$ & $1.675 \mathrm{E}+01$ & $1.497 \mathrm{E}+01$ & $-6.212 \mathrm{E}+00$ & $-1.526 \mathrm{E}+01$ & $-1.667 E+01$ & $-1.873 \mathrm{E}+01$ \\
\hline 16 & $1.675 \mathrm{E}+01$ & $1.675 \mathrm{E}+01$ & $1.675 \mathrm{E}+01$ & $1.533 \mathrm{E}+01$ & $-5.127 \mathrm{E}+00$ & $-1.459 \mathrm{E}+01$ & $-1.601 E+01$ & $-1.804 \mathrm{E}+01$ \\
\hline 17 & $1.675 \mathrm{E}+01$ & $1.675 \mathrm{E}+01$ & $1.675 \mathrm{E}+01$ & $1.562 \mathrm{E}+01$ & $-4.080 \mathrm{E}+00$ & $-1.394 \mathrm{E}+01$ & $-1.537 \mathrm{E}+01$ & $-1.739 E+01$ \\
\hline 18 & $1.675 \mathrm{E}+01$ & $1.675 \mathrm{E}+01$ & $1.675 \mathrm{E}+01$ & $1.585 \mathrm{E}+01$ & $-3.072 \mathrm{E}+00$ & $-1.331 \mathrm{E}+01$ & $-1.475 E+01$ & $-1.676 \mathrm{E}+01$ \\
\hline 19 & $1.675 \mathrm{E}+01$ & $1.675 \mathrm{E}+01$ & $1.675 \mathrm{E}+01$ & $1.603 \mathrm{E}+01$ & $-2.104 \mathrm{E}+00$ & $-1.268 \mathrm{E}+01$ & $-1.415 \mathrm{E}+01$ & $-1.616 \mathrm{E}+01$ \\
\hline 20 & $1.675 \mathrm{E}+01$ & $1.675 \mathrm{E}+01$ & $1.675 \mathrm{E}+01$ & $1.618 \mathrm{E}+01$ & $-1.176 \mathrm{E}+00$ & $-1.207 \mathrm{E}+01$ & $-1.356 \mathrm{E}+01$ & $-1.558 \mathrm{E}+01$ \\
\hline 21 & $1.675 E+01$ & $1.675 \mathrm{E}+01$ & $1.675 \mathrm{E}+01$ & $1.630 \mathrm{E}+01$ & $-2.886 \mathrm{E}-01$ & $-1.147 \mathrm{E}+01$ & $-1.299 \mathrm{E}+01$ & $-1.502 \mathrm{E}+01$ \\
\hline 22 & $1.675 \mathrm{E}+01$ & $1.675 \mathrm{E}+01$ & $1.675 \mathrm{E}+01$ & $1.639 E+01$ & $5.595 \mathrm{E}-01$ & $-1.087 \mathrm{E}+01$ & $-1.243 E+01$ & $-1.447 \mathrm{E}+01$ \\
\hline 23 & $1.675 \mathrm{E}+01$ & $1.675 \mathrm{E}+01$ & $1.675 \mathrm{E}+01$ & $1.646 \mathrm{E}+01$ & $1.369 \mathrm{E}+00$ & $-1.028 \mathrm{E}+01$ & $-1.188 \mathrm{E}+01$ & $-1.394 \mathrm{E}+01$ \\
\hline 24 & $1.675 \mathrm{E}+01$ & $1.675 \mathrm{E}+01$ & $1.675 \mathrm{E}+01$ & $1.652 \mathrm{E}+01$ & $2.141 E+00$ & $-9.707 \mathrm{E}+00$ & $-1.134 E+01$ & $-1.341 \mathrm{E}+01$ \\
\hline 25 & $1.675 \mathrm{E}+01$ & $1.675 \mathrm{E}+01$ & $1.675 \mathrm{E}+01$ & $1.657 \mathrm{E}+01$ & $2.876 \mathrm{E}+00$ & $-9.138 \mathrm{E}+00$ & $-1.080 \mathrm{E}+01$ & $-1.289 E+01$ \\
\hline 26 & $1.675 \mathrm{E}+01$ & $1.675 \mathrm{E}+01$ & $1.675 \mathrm{E}+01$ & $1.660 \mathrm{E}+01$ & $3.576 \mathrm{E}+00$ & $-8.579 \mathrm{E}+00$ & $-1.028 E+01$ & $-1.239 E+01$ \\
\hline 27 & $1.675 \mathrm{E}+01$ & $1.675 \mathrm{E}+01$ & $1.675 \mathrm{E}+01$ & $1.664 \mathrm{E}+01$ & $4.244 \mathrm{E}+00$ & $-8.030 \mathrm{E}+00$ & $-9.771 E+00$ & $-1.189 E+01$ \\
\hline 28 & $1.689 \mathrm{E}+01$ & $1.686 \mathrm{E}+01$ & $1.683 \mathrm{E}+01$ & $1.675 \mathrm{E}+01$ & $4.902 \mathrm{E}+00$ & $-7.509 \mathrm{E}+00$ & $-9.290 \mathrm{E}+00$ & $-1.144 \mathrm{E}+01$ \\
\hline 29 & $2.073 E+01$ & $1.952 \mathrm{E}+01$ & $1.877 \mathrm{E}+01$ & $1.781 \mathrm{E}+01$ & $5.621 \mathrm{E}+00$ & $-7.281 E+00$ & $-9.154 \mathrm{E}+00$ & $-1.138 E+01$ \\
\hline 30 & $-1.769 \mathrm{E}+00$ & $-3.245 E+00$ & $-9.947 \mathrm{E}+00$ & $-1.827 \mathrm{E}+01$ & $-3.521 \mathrm{E}+01$ & $-4.950 \mathrm{E}+01$ & $-5.240 \mathrm{E}+01$ & $-5.721 E+01$ \\
\hline 31 & $-1.978 \mathrm{E}+00$ & $-2.618 \mathrm{E}+00$ & $-5.601 E+00$ & $-1.052 \mathrm{E}+01$ & $-2.122 \mathrm{E}+01$ & $-3.529 \mathrm{E}+01$ & $-3.612 E+01$ & $-3.841 \mathrm{E}+01$ \\
\hline 32 & $-1.902 \mathrm{E}+00$ & $-2.355 E+00$ & $-4.771 E+00$ & $-8.996 E+00$ & $-1.737 \mathrm{E}+01$ & $-3.024 \mathrm{E}+01$ & $-3.089 \mathrm{E}+01$ & $-2.890 \mathrm{E}+01$ \\
\hline 33 & $-1.860 \mathrm{E}+00$ & $-2.209 E+00$ & $-4.355 \mathrm{E}+00$ & $-8.196 \mathrm{E}+00$ & $-1.541 \mathrm{E}+01$ & $-2.614 \mathrm{E}+01$ & $-2.646 \mathrm{E}+01$ & $-2.594 \mathrm{E}+01$ \\
\hline 34 & $-1.838 \mathrm{E}+00$ & $-2.116 \mathrm{E}+00$ & $-4.091 E+00$ & $-7.662 E+00$ & $-1.409 \mathrm{E}+01$ & $-2.284 \mathrm{E}+01$ & $-2.322 \mathrm{E}+01$ & $-2.394 E+01$ \\
\hline 35 & $-1.826 \mathrm{E}+00$ & $-2.053 E+00$ & $-3.898 E+00$ & $-7.259 E+00$ & $-1.313 \mathrm{E}+01$ & $-2.079 \mathrm{E}+01$ & $-2.126 \mathrm{E}+01$ & $-2.249 \mathrm{E}+01$ \\
\hline 36 & $-1.820 \mathrm{E}+00$ & $-2.006 \mathrm{E}+00$ & $-3.746 \mathrm{E}+00$ & $-6.936 \mathrm{E}+00$ & $-1.240 \mathrm{E}+01$ & $-1.937 \mathrm{E}+01$ & $-1.995 \mathrm{E}+01$ & $-2.136 E+01$ \\
\hline
\end{tabular}




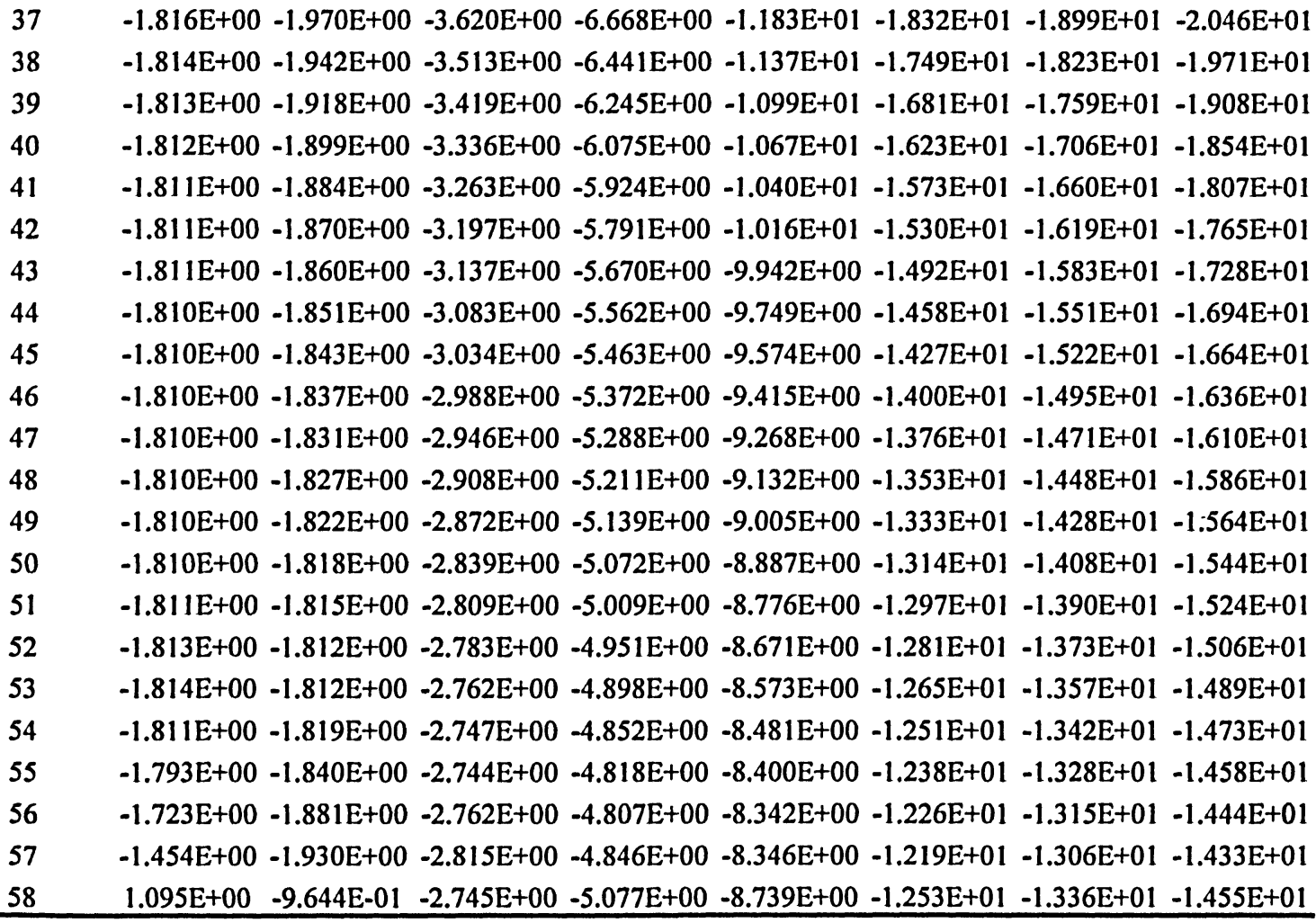

Table C-13: Average heat flux ( $\mathrm{q}_{\mathrm{i}, \text { avg }}$ ) data for the individual blind louver, $\phi=90^{\circ}, \mathrm{T}_{\mathrm{b}}{ }^{*}=0.4$, $\mathrm{d} / \mathrm{L}=0.043$

\begin{tabular}{|c|c|c|c|c|c|c|c|c|}
\hline $\begin{array}{c}\text { Louver } \\
\text { number (i) }\end{array}$ & & & & $\mathbf{R a}_{L}$ & & & & \\
\hline & $1.00 \mathrm{E}+04$ & $1.00 \mathrm{E}+05$ & $1.00 \mathrm{E}+06$ & $1.00 \mathrm{E}+07$ & $1.00 \mathrm{E}+08$ & $5.00 \mathrm{E}+08$ & $7.00 \mathrm{E}+08$ & $1.00 \mathrm{E}+09$ \\
\hline 1 & $1.203 \mathrm{E}+01$ & $9.289 \mathrm{E}+00$ & $-9.316 \mathrm{E}+00$ & $-3.578 E+01$ & $-4.770 \mathrm{E}+01$ & $-3.697 E+01$ & $-3.284 E+01$ & $-2.461 E+01$ \\
\hline 2 & $1.414 \mathrm{E}+01$ & $1.395 \mathrm{E}+01$ & $9.002 \mathrm{E}+00$ & $-2.010 \mathrm{E}+01$ & $-3.415 E+01$ & $-4.541 \mathrm{E}+01$ & $-4.404 \mathrm{E}+01$ & $-3.897 \mathrm{E}+01$ \\
\hline 3 & $1.434 \mathrm{E}+01$ & $1.432 \mathrm{E}+01$ & $1.287 \mathrm{E}+01$ & $-1.504 \mathrm{E}+01$ & $-3.106 \mathrm{E}+01$ & $-4.591 \mathrm{E}+01$ & $-4.809 \mathrm{E}+01$ & $-5.638 \mathrm{E}+01$ \\
\hline 4 & $1.435 \mathrm{E}+01$ & $1.435 \mathrm{E}+01$ & $1.394 \mathrm{E}+01$ & $-9.870 \mathrm{E}+00$ & $-2.794 \mathrm{E}+01$ & $-4.084 E+01$ & $-4.251 E+01$ & $-5.079 \mathrm{E}+01$ \\
\hline 5 & $1.435 \mathrm{E}+01$ & $1.435 \mathrm{E}+01$ & $1.424 \mathrm{E}+01$ & $-5.347 \mathrm{E}+00$ & $-2.550 \mathrm{E}+01$ & $-3.700 \mathrm{E}+01$ & $-3.837 \mathrm{E}+01$ & $-4.463 E+01$ \\
\hline 6 & $1.435 \mathrm{E}+01$ & $1.435 \mathrm{E}+01$ & $1.432 \mathrm{E}+01$ & $-1.590 \mathrm{E}+00$ & $-2.355 E+01$ & $-3.414 E+01$ & $-3.534 \mathrm{E}+01$ & $-4.048 \mathrm{E}+01$ \\
\hline 7 & $1.435 \mathrm{E}+01$ & $1.435 \mathrm{E}+01$ & $1.435 E+01$ & $1.477 \mathrm{E}+00$ & $-2.187 E+01$ & $-3.190 \mathrm{E}+01$ & $-3.302 E+01$ & $-3.755 E+01$ \\
\hline 8 & $1.435 \mathrm{E}+01$ & $1.435 \mathrm{E}+01$ & $1.435 \mathrm{E}+01$ & $3.964 E+00$ & $-2.035 \mathrm{E}+01$ & $-3.006 \mathrm{E}+01$ & $-3.113 E+01$ & $-3.529 \mathrm{E}+01$ \\
\hline 9 & $1.435 \mathrm{E}+01$ & $1.435 \mathrm{E}+01$ & $1.435 \mathrm{E}+01$ & $5.972 \mathrm{E}+00$ & $-1.890 \mathrm{E}+01$ & $-2.849 \mathrm{E}+01$ & $-2.953 E+01$ & $-3.343 \mathrm{E}+01$ \\
\hline 10 & $1.435 \mathrm{E}+01$ & $1.435 \mathrm{E}+01$ & $1.435 \mathrm{E}+01$ & $7.592 \mathrm{E}+00$ & $-1.750 \mathrm{E}+01$ & $-2.712 \mathrm{E}+01$ & $-2.815 \mathrm{E}+01$ & $-3.185 E+01$ \\
\hline 11 & $1.435 \mathrm{E}+01$ & $1.435 \mathrm{E}+01$ & $1.435 \mathrm{E}+01$ & $8.899 \mathrm{E}+00$ & $-1.614 E+01$ & $-2.590 \mathrm{E}+01$ & $-2.692 E+01$ & $-3.047 \mathrm{E}+01$ \\
\hline 12 & $1.435 \mathrm{E}+01$ & $1.435 \mathrm{E}+01$ & $1.435 \mathrm{E}+01$ & $9.952 \mathrm{E}+00$ & $-1.481 \mathrm{E}+01$ & $-2.479 \mathrm{E}+01$ & $-2.581 \mathrm{E}+01$ & $-2.924 \mathrm{E}+01$ \\
\hline 13 & $1.435 \mathrm{E}+01$ & $1.435 \mathrm{E}+01$ & $1.435 \mathrm{E}+01$ & $1.080 \mathrm{E}+01$ & $-1.352 E+01$ & $-2.377 \mathrm{E}+01$ & $-2.479 \mathrm{E}+01$ & $-2.813 E+01$ \\
\hline 14 & $1.435 \mathrm{E}+01$ & $1.435 \mathrm{E}+01$ & $1.435 \mathrm{E}+01$ & $1.149 \mathrm{E}+01$ & $-1.226 \mathrm{E}+01$ & $-2.282 \mathrm{E}+01$ & $-2.384 \mathrm{E}+01$ & $-2.712 E+01$ \\
\hline 15 & $1.435 \mathrm{E}+01$ & $1.435 \mathrm{E}+01$ & $1.435 \mathrm{E}+01$ & $1.204 \mathrm{E}+01$ & $-1.104 \mathrm{E}+01$ & $-2.193 E+01$ & $-2.296 \mathrm{E}+01$ & $-2.618 \mathrm{E}+01$ \\
\hline 16 & $1.435 \mathrm{E}+01$ & $1.435 \mathrm{E}+01$ & $1.435 \mathrm{E}+01$ & $1.249 \mathrm{E}+01$ & $-9.867 E+00$ & $-2.107 \mathrm{E}+01$ & $-2.211 E+01$ & $-2.530 \mathrm{E}+01$ \\
\hline 17 & $1.435 \mathrm{E}+01$ & $1.435 E+01$ & $1.435 \mathrm{E}+01$ & $1.285 \mathrm{E}+01$ & $-8.733 E+00$ & $-2.026 \mathrm{E}+01$ & $-2.131 E+01$ & $-2.448 \mathrm{E}+01$ \\
\hline 18 & $1.435 \mathrm{E}+01$ & $1.435 \mathrm{E}+01$ & $1.435 \mathrm{E}+01$ & $1.314 \mathrm{E}+01$ & $-7.642 \mathrm{E}+00$ & $-1.948 \mathrm{E}+01$ & $-2.054 \mathrm{E}+01$ & $-2.369 \mathrm{E}+01$ \\
\hline 19 & $1.435 \mathrm{E}+01$ & $1.435 \mathrm{E}+01$ & $1.435 \mathrm{E}+01$ & $1.337 \mathrm{E}+01$ & $-6.596 \mathrm{E}+00$ & $-1.872 \mathrm{E}+01$ & $-1.980 \mathrm{E}+01$ & $-2.295 \mathrm{E}+01$ \\
\hline
\end{tabular}


$1.435 \mathrm{E}+01 \quad 1.435 \mathrm{E}+01 \quad 1.435 \mathrm{E}+01 \quad 1.356 \mathrm{E}+01 \quad-5.592 \mathrm{E}+00-1.798 \mathrm{E}+01-1.908 \mathrm{E}+01-2.223 \mathrm{E}+01$

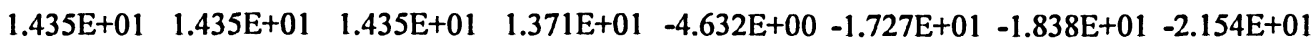

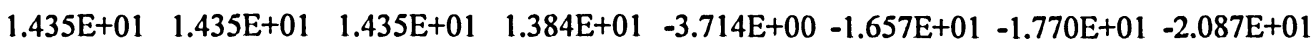
$\begin{array}{llllllll}1.435 \mathrm{E}+01 & 1.435 \mathrm{E}+01 & 1.435 \mathrm{E}+01 & 1.394 \mathrm{E}+01 & -2.837 \mathrm{E}+00 & -1.589 \mathrm{E}+01 & -1.703 \mathrm{E}+01 & -2.022 \mathrm{E}+01\end{array}$ $1.435 \mathrm{E}+01 \quad 1.435 \mathrm{E}+01 \quad 1.435 \mathrm{E}+01 \quad 1.402 \mathrm{E}+01 \quad-2.001 \mathrm{E}+00-1.522 \mathrm{E}+01-1.639 \mathrm{E}+01-1.959 \mathrm{E}+01$ $\begin{array}{llllllll}1.435 \mathrm{E}+01 & 1.435 \mathrm{E}+01 & 1.435 \mathrm{E}+01 & 1.408 \mathrm{E}+01 & -1.203 \mathrm{E}+00 & -1.457 \mathrm{E}+01 & -1.575 \mathrm{E}+01 & -1.897 \mathrm{E}+01\end{array}$ $\begin{array}{llllllll}1.435 \mathrm{E}+01 & 1.435 \mathrm{E}+01 & 1.435 \mathrm{E}+01 & 1.414 \mathrm{E}+01 & -4.420 \mathrm{E}-01 & -1.393 \mathrm{E}+01 & -1.513 \mathrm{E}+01 & -1.838 \mathrm{E}+01\end{array}$ $\begin{array}{llllllll}1.436 \mathrm{E}+01 & 1.436 \mathrm{E}+01 & 1.436 \mathrm{E}+01 & 1.418 \mathrm{E}+01 & 2.831 \mathrm{E}-01 & -1.332 \mathrm{E}+01 & -1.453 \mathrm{E}+01 & -1.780 \mathrm{E}+01\end{array}$ $\begin{array}{llllllll}1.447 \mathrm{E}+01 & 1.444 \mathrm{E}+01 & 1.443 \mathrm{E}+01 & 1.429 \mathrm{E}+01 & 9.805 \mathrm{E}-01 & -1.275 \mathrm{E}+01 & -1.399 \mathrm{E}+01 & -1.728 \mathrm{E}+01\end{array}$ $\begin{array}{llllllll}1.746 \mathrm{E}+01 & 1.636 \mathrm{E}+01 & 1.597 \mathrm{E}+01 & 1.509 \mathrm{E}+01 & 1.598 \mathrm{E}+00 & -1.270 \mathrm{E}+01 & -1.399 \mathrm{E}+01 & -1.742 \mathrm{E}+01\end{array}$

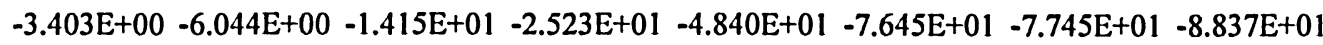

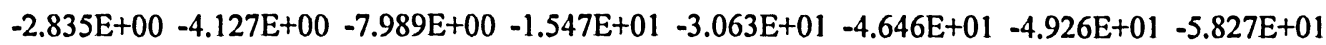

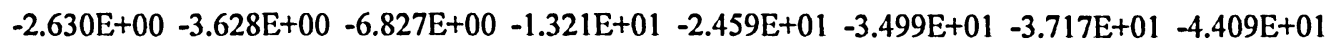

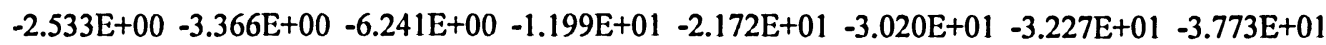

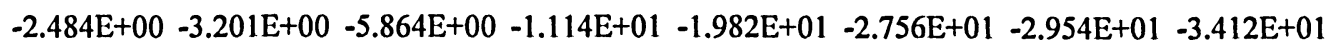
$-2.456 \mathrm{E}+00-3.085 \mathrm{E}+00-5.587 \mathrm{E}+00-1.050 \mathrm{E}+01-1.846 \mathrm{E}+01-2.590 \mathrm{E}+01-2.772 \mathrm{E}+01-3.169 \mathrm{E}+01$

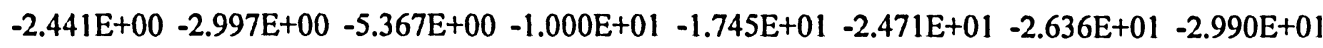

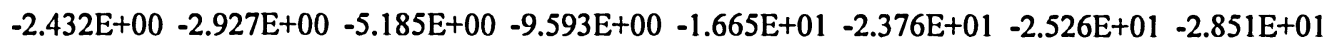

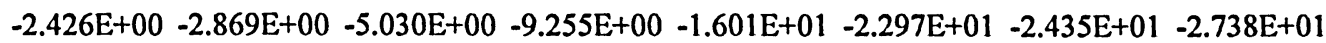

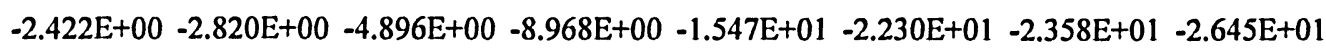

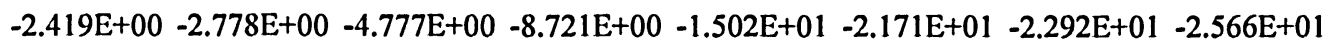

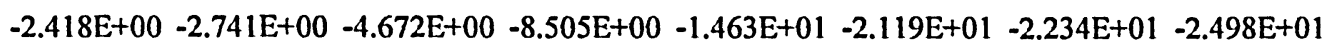

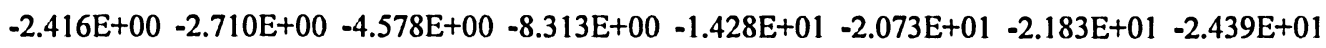

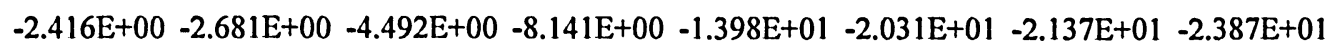

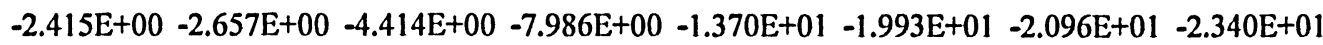
$-2.414 \mathrm{E}+00-2.635 \mathrm{E}+00-4.343 \mathrm{E}+00-7.844 \mathrm{E}+00-1.345 \mathrm{E}+01-1.958 \mathrm{E}+01-2.059 \mathrm{E}+01-2.298 \mathrm{E}+01$

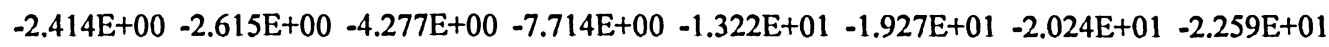
$-2.413 \mathrm{E}+00-2.597 \mathrm{E}+00-4.216 \mathrm{E}+00-7.595 \mathrm{E}+00-1.301 \mathrm{E}+01-1.897 \mathrm{E}+01-1.993 \mathrm{E}+01-2.224 \mathrm{E}+01$ $-2.413 \mathrm{E}+00-2.582 \mathrm{E}+00-4.160 \mathrm{E}+00-7.484 \mathrm{E}+00-1.282 \mathrm{E}+01-1.870 \mathrm{E}+01-1.964 \mathrm{E}+01-2.192 \mathrm{E}+01$

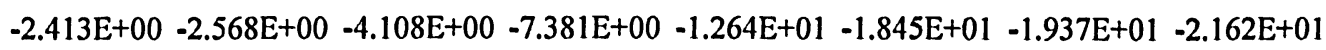
$-2.413 \mathrm{E}+00-2.556 \mathrm{E}+00-4.060 \mathrm{E}+00-7.284 \mathrm{E}+00-1.247 \mathrm{E}+01-1.821 \mathrm{E}+01-1.912 \mathrm{E}+01-2.134 \mathrm{E}+01$ $-2.415 \mathrm{E}+00-2.546 \mathrm{E}+00-4.015 \mathrm{E}+00-7.195 \mathrm{E}+00-1.232 \mathrm{E}+01-1.799 \mathrm{E}+01-1.888 \mathrm{E}+01-2.108 \mathrm{E}+01$

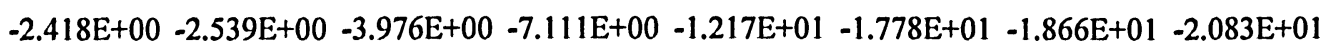

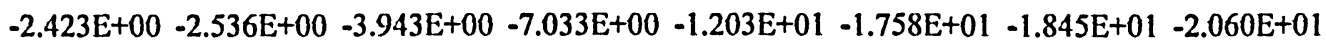
$-2.429 \mathrm{E}+00-2.539 \mathrm{E}+00-3.919 \mathrm{E}+00-6.965 \mathrm{E}+00-1.191 \mathrm{E}+01-1.739 \mathrm{E}+01-1.826 \mathrm{E}+01-2.038 \mathrm{E}+01$

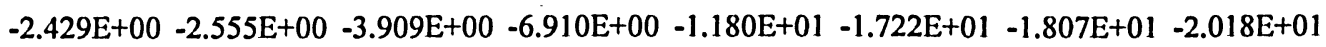
$-2.399 \mathrm{E}+00-2.592 \mathrm{E}+00-3.926 \mathrm{E}+00-6.886 \mathrm{E}+00-1.172 \mathrm{E}+01-1.707 \mathrm{E}+01-1.791 \mathrm{E}+01-1.999 \mathrm{E}+01$ $-2.228 \mathrm{E}+00-2.660 \mathrm{E}+00-3.988 \mathrm{E}+00-6.922 \mathrm{E}+00-1.173 \mathrm{E}+01-1.698 \mathrm{E}+01-1.780 \mathrm{E}+01-1.985 \mathrm{E}+01$ $-3.329 \mathrm{E}-01-2.211 \mathrm{E}+00-4.080 \mathrm{E}+00-7.245 \mathrm{E}+00-1.226 \mathrm{E}+01-1.746 \mathrm{E}+01-1.823 \mathrm{E}+01-2.017 \mathrm{E}+01$ 
Table C-14: Average heat flux $\left(\mathrm{q}_{\mathrm{i}, \text { avg }}\right)$ data for the individual blind louver, $\phi=90^{\circ}, \mathrm{T}_{\mathrm{b}}{ }^{*}=0.5$, $\mathrm{d} / \mathrm{L}=0.043$

\begin{tabular}{|c|c|c|c|c|c|c|c|c|}
\hline $\begin{array}{c}\text { Louver } \\
\text { number (i) }\end{array}$ & & & & $\mathbf{R a}_{\mathrm{L}}$ & & & & \\
\hline & $1.00 \mathrm{E}+04$ & $1.00 \mathrm{E}+05$ & $1.00 \mathrm{E}+06$ & $1.00 \mathrm{E}+07$ & $1.00 E+08$ & $5.00 \mathrm{E}+08$ & $7.00 \mathrm{E}+08$ & $1.00 \mathrm{E}+09$ \\
\hline 1 & $5.339 \mathrm{E}+00$ & $5.339 \mathrm{E}+00$ & $-1.316 \mathrm{E}+01$ & $-4.680 \mathrm{E}+01$ & $-6.054 \mathrm{E}+01$ & $-4.416 \mathrm{E}+01$ & $-3.018 \mathrm{E}+01$ & $-3.264 \mathrm{E}+01$ \\
\hline 2 & $1.151 \mathrm{E}+01$ & $1.151 \mathrm{E}+01$ & $7.218 \mathrm{E}+00$ & $-2.620 \mathrm{E}+01$ & $-4.381 \mathrm{E}+01$ & $-5.645 E+01$ & $-3.115 \mathrm{E}+01$ & $-4.698 \mathrm{E}+01$ \\
\hline 3 & $1.192 \mathrm{E}+01$ & $1.192 \mathrm{E}+01$ & $1.077 \mathrm{E}+01$ & $-2.066 \mathrm{E}+01$ & $-3.997 \mathrm{E}+01$ & $-5.674 \mathrm{E}+01$ & $-5.636 \mathrm{E}+01$ & $-5.749 \mathrm{E}+01$ \\
\hline 4 & $1.196 \mathrm{E}+01$ & $1.196 \mathrm{E}+01$ & $1.166 \mathrm{E}+01$ & $-1.519 \mathrm{E}+01$ & $-3.603 E+01$ & $-5.103 E+01$ & $-7.155 \mathrm{E}+01$ & $-6.359 E+01$ \\
\hline 5 & $1.196 \mathrm{E}+01$ & $1.196 \mathrm{E}+01$ & $1.188 \mathrm{E}+01$ & $-1.036 \mathrm{E}+01$ & $-3.294 E+01$ & $-4.648 E+01$ & $-6.120 \mathrm{E}+01$ & $-5.998 \mathrm{E}+01$ \\
\hline 6 & $1.196 \mathrm{E}+01$ & $1.196 \mathrm{E}+01$ & $1.194 \mathrm{E}+01$ & $-6.310 \mathrm{E}+00$ & $-3.050 E+01$ & $-4.306 \mathrm{E}+01$ & $-5.407 \mathrm{E}+01$ & $-5.439 E+01$ \\
\hline 7 & $1.196 \mathrm{E}+01$ & $1.196 \mathrm{E}+01$ & $1.196 \mathrm{E}+01$ & $-2.967 \mathrm{E}+00$ & $-2.845 E+01$ & $-4.038 \mathrm{E}+01$ & $-4.936 \mathrm{E}+01$ & $-5.011 \mathrm{E}+01$ \\
\hline 8 & $1.196 \mathrm{E}+01$ & $1.196 \mathrm{E}+01$ & $1.196 \mathrm{E}+01$ & $-2.278 \mathrm{E}-01$ & $-2.663 E+01$ & $-3.817 \mathrm{E}+01$ & $-4.599 \mathrm{E}+01$ & $-4.694 \mathrm{E}+01$ \\
\hline 9 & $1.196 \mathrm{E}+01$ & $1.196 \mathrm{E}+01$ & $1.196 \mathrm{E}+01$ & $2.010 \mathrm{E}+00$ & $-2.495 E+01$ & $-3.629 \mathrm{E}+01$ & $-4.332 \mathrm{E}+01$ & $-4.442 \mathrm{E}+01$ \\
\hline 10 & $1.196 \mathrm{E}+01$ & $1.196 \mathrm{E}+01$ & $1.196 \mathrm{E}+01$ & $3.837 \mathrm{E}+00$ & $-2.335 E+01$ & $-3.465 E+01$ & $-4.109 E+01$ & $-4.232 \mathrm{E}+01$ \\
\hline 11 & $1.196 \mathrm{E}+01$ & $1.196 \mathrm{E}+01$ & $1.196 \mathrm{E}+01$ & $5.327 \mathrm{E}+00$ & $-2.183 E+01$ & $-3.319 \mathrm{E}+01$ & $-3.916 \mathrm{E}+01$ & $-4.050 \mathrm{E}+01$ \\
\hline 12 & $1.196 \mathrm{E}+01$ & $1.196 \mathrm{E}+01$ & $1.196 \mathrm{E}+01$ & $6.544 \mathrm{E}+00$ & $-2.036 \mathrm{E}+01$ & $-3.187 \mathrm{E}+01$ & $-3.746 \mathrm{E}+01$ & $-3.891 E+01$ \\
\hline 13 & $1.196 \mathrm{E}+01$ & $1.196 \mathrm{E}+01$ & $1.196 \mathrm{E}+01$ & $7.537 \mathrm{E}+00$ & $-1.894 \mathrm{E}+01$ & $-3.065 E+01$ & $-3.594 \mathrm{E}+01$ & $-3.749 E+01$ \\
\hline 14 & $1.196 \mathrm{E}+01$ & $1.196 \mathrm{E}+01$ & $1.196 \mathrm{E}+01$ & $8.347 \mathrm{E}+00$ & $-1.756 \mathrm{E}+01$ & $-2.953 \mathrm{E}+01$ & $-3.455 E+01$ & $-3.619 \mathrm{E}+01$ \\
\hline 15 & $1.196 \mathrm{E}+01$ & $1.196 \mathrm{E}+01$ & $1.196 \mathrm{E}+01$ & $9.009 \mathrm{E}+00$ & $-1.624 \mathrm{E}+01$ & $-2.847 \mathrm{E}+01$ & $-3.329 \mathrm{E}+01$ & $-3.501 E+01$ \\
\hline 16 & $1.196 \mathrm{E}+01$ & $1.196 \mathrm{E}+01$ & $1.196 \mathrm{E}+01$ & $9.549 \mathrm{E}+00$ & $-1.497 \mathrm{E}+01$ & $-2.748 \mathrm{E}+01$ & $-3.211 \mathrm{E}+01$ & $-3.391 E+01$ \\
\hline 17 & $1.196 \mathrm{E}+01$ & $1.196 \mathrm{E}+01$ & $1.196 \mathrm{E}+01$ & $9.991 \mathrm{E}+00$ & $-1.374 \mathrm{E}+01$ & $-2.653 E+01$ & $-3.100 \mathrm{E}+01$ & $-3.288 \mathrm{E}+01$ \\
\hline 18 & $1.196 \mathrm{E}+01$ & $1.196 \mathrm{E}+01$ & $1.196 \mathrm{E}+01$ & $1.035 \mathrm{E}+01$ & $-1.257 \mathrm{E}+01$ & $-2.562 \mathrm{E}+01$ & $-2.996 \mathrm{E}+01$ & $-3.191 \mathrm{E}+01$ \\
\hline 19 & $1.196 \mathrm{E}+01$ & $1.196 \mathrm{E}+01$ & $1.196 \mathrm{E}+01$ & $1.065 \mathrm{E}+01$ & $-1.144 \mathrm{E}+01$ & +01 & & $-3.099 \mathrm{E}+01$ \\
\hline 20 & $1.196 \mathrm{E}+01$ & $1.196 \mathrm{E}+01$ & $1.196 \mathrm{E}+01$ & $1.089 \mathrm{E}+01$ & $-1.036 \mathrm{E}+01$ & $-2.391 \mathrm{E}+01$ & $-2.804 \mathrm{E}+01$ & $-3.011 \mathrm{E}+01$ \\
\hline 21 & $1.196 \mathrm{E}+01$ & $1.196 \mathrm{E}+01$ & $1.196 \mathrm{E}+01$ & $1.108 \mathrm{E}+01$ & $-9.320 \mathrm{E}+00$ & $-2.309 \mathrm{E}+01$ & $-2.713 E+01$ & $-2.926 \mathrm{E}+01$ \\
\hline 22 & $1.196 \mathrm{E}+01$ & $1.196 \mathrm{E}+01$ & $1.196 \mathrm{E}+01$ & $1.124 \mathrm{E}+01$ & $-8.330 \mathrm{E}+00$ & $-2.230 \mathrm{E}+01$ & $-2.627 \mathrm{E}+01$ & $-2.845 E+01$ \\
\hline 23 & $1.196 \mathrm{E}+01$ & $1.196 \mathrm{E}+01$ & $1.196 \mathrm{E}+01$ & $1.138 \mathrm{E}+01$ & $-7.382 E+00$ & $-2.153 E+01$ & $-2.543 \mathrm{E}+01$ & $-2.766 \mathrm{E}+01$ \\
\hline 24 & $1.196 \mathrm{E}+01$ & $1.196 \mathrm{E}+01$ & $1.196 \mathrm{E}+01$ & $1.148 \mathrm{E}+01$ & $-6.478 \mathrm{E}+00$ & & & $-2.690 \mathrm{E}+01$ \\
\hline 25 & $1.196 \mathrm{E}+01$ & $1.196 \mathrm{E}+01$ & $1.196 \mathrm{E}+01$ & $1.157 \mathrm{E}+01$ & $-5.614 \mathrm{E}+00$ & $-2.005 E+01$ & $-2.384 \mathrm{E}+01$ & $-2.616 \mathrm{E}+01$ \\
\hline 26 & $1.196 \mathrm{E}+01$ & $1.196 \mathrm{E}+01$ & $1.196 \mathrm{E}+01$ & $1.164 \mathrm{E}+01$ & $-4.789 \mathrm{E}+00$ & $-1.934 \mathrm{E}+01$ & $-2.308 \mathrm{E}+01$ & $-2.544 \mathrm{E}+01$ \\
\hline 27 & $1.196 \mathrm{E}+01$ & $1.196 \mathrm{E}+01$ & $1.196 \mathrm{E}+01$ & $1.171 \mathrm{E}+01$ & $-4.004 \mathrm{E}+00$ & $-1.866 \mathrm{E}+01$ & $-2.235 \mathrm{E}+01$ & $-2.475 \mathrm{E}+01$ \\
\hline 28 & $1.203 \mathrm{E}+01$ & $1.203 \mathrm{E}+01$ & $1.202 \mathrm{E}+01$ & $1.182 \mathrm{E}+01$ & $-3.270 \mathrm{E}+00$ & $-1.806 \mathrm{E}+01$ & $-2.172 \mathrm{E}+01$ & $-2.416 \mathrm{E}+01$ \\
\hline 29 & $1.333 \mathrm{E}+01$ & $1.333 \mathrm{E}+01$ & $1.325 \mathrm{E}+01$ & $1.248 \mathrm{E}+01$ & $-2.824 \mathrm{E}+00$ & -1.82 & +01 & $-2.454 \mathrm{E}+01$ \\
\hline 30 & $-8.641 \mathrm{E}+00$ & $-8.641 E+00$ & $-1.831 \mathrm{E}+01$ & $-3.293 E+01$ & $-6.269 \mathrm{E}+01$ & $-9.331 E+01$ & $-1.240 \mathrm{E}+02$ & $-1.085 \mathrm{E}+02$ \\
\hline 31 & $-5.562 \mathrm{E}+00$ & $-5.562 \mathrm{E}+00$ & $-1.042 \mathrm{E}+01$ & $-2.020 \mathrm{E}+01$ & $-4.019 \mathrm{E}+01$ & $-6.258 \mathrm{E}+01$ & $-7.472 \mathrm{E}+01$ & $-7.793 E+01$ \\
\hline 32 & $-4.842 \mathrm{E}+00$ & $-4.842 \mathrm{E}+00$ & $-8.899 \mathrm{E}+00$ & $-1.729 \mathrm{E}+01$ & $-3.224 \mathrm{E}+01$ & $-4.812 \mathrm{E}+01$ & $-5.277 \mathrm{E}+01$ & $-5.603 E+01$ \\
\hline 33 & $-4.470 \mathrm{E}+00$ & $-4.470 \mathrm{E}+00$ & $-8.119 \mathrm{E}+00$ & $-1.573 E+01$ & $-2.849 \mathrm{E}+01$ & $-4.168 \mathrm{E}+01$ & $-4.330 \mathrm{E}+01$ & $-5.004 \mathrm{E}+01$ \\
\hline 34 & $-4.235 \mathrm{E}+00$ & $-4.235 \mathrm{E}+00$ & $-7.615 \mathrm{E}+00$ & $-1.465 \mathrm{E}+01$ & $-2.602 \mathrm{E}+01$ & $-3.782 \mathrm{E}+01$ & $-3.839 \mathrm{E}+01$ & $-4.590 \mathrm{E}+01$ \\
\hline 35 & $-4.069 E+00$ & $-4.069 \mathrm{E}+00$ & $-7.249 \mathrm{E}+00$ & $-1.382 \mathrm{E}+01$ & $-2.426 \mathrm{E}+01$ & $-3.521 \mathrm{E}+01$ & $-3.549 \mathrm{E}+01$ & $-4.288 \mathrm{E}+01$ \\
\hline 36 & $-3.942 E+00$ & $-3.942 \mathrm{E}+00$ & $-6.962 \mathrm{E}+00$ & $-1.317 \mathrm{E}+01$ & $-2.294 \mathrm{E}+01$ & $-3.328 \mathrm{E}+01$ & $-3.377 E+01$ & $-4.052 \mathrm{E}+01$ \\
\hline 37 & $-3.840 \mathrm{E}+00$ & $-3.840 \mathrm{E}+00$ & $-6.725 \mathrm{E}+00$ & $-1.263 \mathrm{E}+01$ & $-2.191 \mathrm{E}+01$ & $-3.177 \mathrm{E}+01$ & $-3.273 E+01$ & $-3.864 \mathrm{E}+01$ \\
\hline 38 & $-3.755 \mathrm{E}+00$ & $-3.755 E+00$ & $-6.525 \mathrm{E}+00$ & $-1.219 \mathrm{E}+01$ & $-2.107 \mathrm{E}+01$ & $-3.054 \mathrm{E}+01$ & $-3.196 \mathrm{E}+01$ & $-3.713 E+01$ \\
\hline 39 & $-3.683 E+00$ & $-3.683 E+00$ & $-6.352 \mathrm{E}+00$ & $-1.181 \mathrm{E}+01$ & $-2.038 \mathrm{E}+01$ & $-2.952 \mathrm{E}+01$ & $-3.130 \mathrm{E}+01$ & $-3.588 \mathrm{E}+01$ \\
\hline 40 & $-3.621 \mathrm{E}+00$ & $-3.621 \mathrm{E}+00$ & $-6.200 \mathrm{E}+00$ & $-1.149 \mathrm{E}+01$ & $-1.978 \mathrm{E}+01$ & $-2.864 \mathrm{E}+01$ & $-3.068 \mathrm{E}+01$ & $-3.481 E+01$ \\
\hline 41 & $-3.567 \mathrm{E}+00$ & $-3.567 \mathrm{E}+00$ & $-6.064 \mathrm{E}+00$ & $-1.120 \mathrm{E}+01$ & $-1.927 \mathrm{E}+01$ & $-2.788 \mathrm{E}+01$ & $-3.009 E+01$ & $-3.389 E+01$ \\
\hline 42 & $-3.519 \mathrm{E}+00$ & $-3.519 E+00$ & $-5.943 E+00$ & $-1.095 \mathrm{E}+01$ & $-1.882 \mathrm{E}+01$ & $-2.722 E+01$ & $-2.953 \mathrm{E}+01$ & $-3.308 \mathrm{E}+01$ \\
\hline 43 & $-3.476 \mathrm{E}+00$ & $-3.476 \mathrm{E}+00$ & $-5.833 \mathrm{E}+00$ & $-1.073 E+01$ & $-1.841 \mathrm{E}+01$ & $-2.663 \mathrm{E}+01$ & $-2.900 \mathrm{E}+01$ & $-3.236 \mathrm{E}+01$ \\
\hline
\end{tabular}




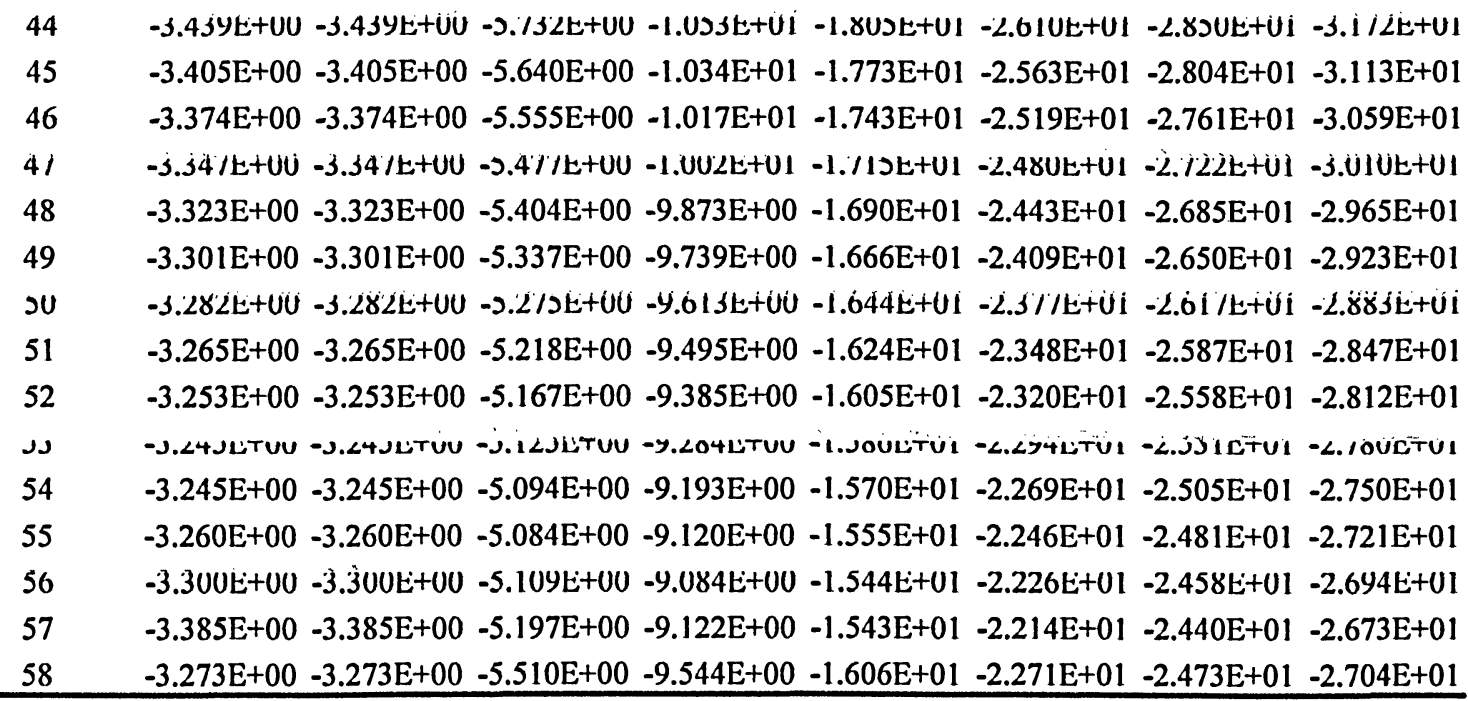

Table C-15: Average heat flux ( $\mathrm{q}_{\mathrm{i}, \mathrm{avg}}$ ) data for the individual blind louver, $\phi=0^{\circ}$, $\mathrm{T}_{\mathrm{b}}{ }^{*}=0.2, \mathrm{~d} / \mathrm{L}=0.012$

\begin{tabular}{ccccccc}
\hline $\begin{array}{c}\text { Louver } \\
\text { number (i) }\end{array}$ & & \multicolumn{5}{c}{$\mathbf{R a}_{\mathrm{L}}$} \\
\hline 1 & $1.00 \mathrm{E}+04$ & $1.00 \mathrm{E}+05$ & $1.00 \mathrm{E}+06$ & $1.00 \mathrm{E}+07$ & $1.00 \mathrm{E}+08$ & $5.00 \mathrm{E}+08$ \\
\hline 2 & $1.626 \mathrm{E}+01$ & $1.595 \mathrm{E}+01$ & $1.450 \mathrm{E}+01$ & $9.209 \mathrm{E}+00$ & $-8.923 \mathrm{E}+00$ & $-1.776 \mathrm{E}+01$ \\
3 & $1.571 \mathrm{E}+01$ & $1.568 \mathrm{E}+01$ & $1.537 \mathrm{E}+01$ & $1.470 \mathrm{E}+01$ & $-1.469 \mathrm{E}-01$ & $-1.308 \mathrm{E}+01$ \\
4 & $1.570 \mathrm{E}+01$ & $1.567 \mathrm{E}+01$ & $1.524 \mathrm{E}+01$ & $1.439 \mathrm{E}+01$ & $5.260 \mathrm{E}+00$ & $-8.916 \mathrm{E}+00$ \\
5 & $1.570 \mathrm{E}+01$ & $1.568 \mathrm{E}+01$ & $1.527 \mathrm{E}+01$ & $1.448 \mathrm{E}+01$ & $8.893 \mathrm{E}+00$ & $-5.118 \mathrm{E}+00$ \\
6 & $1.570 \mathrm{E}+01$ & $1.568 \mathrm{E}+01$ & $1.531 \mathrm{E}+01$ & $1.459 \mathrm{E}+01$ & $1.117 \mathrm{E}+01$ & $-1.917 \mathrm{E}+00$ \\
7 & $1.570 \mathrm{E}+01$ & $1.569 \mathrm{E}+01$ & $1.534 \mathrm{E}+01$ & $1.467 \mathrm{E}+01$ & $1.268 \mathrm{E}+01$ & $7.444 \mathrm{E}-01$ \\
8 & $1.570 \mathrm{E}+01$ & $1.569 \mathrm{E}+01$ & $1.536 \mathrm{E}+01$ & $1.473 \mathrm{E}+01$ & $1.368 \mathrm{E}+01$ & $2.964 \mathrm{E}+00$ \\
9 & $1.570 \mathrm{E}+01$ & $1.569 \mathrm{E}+01$ & $1.538 \mathrm{E}+01$ & $1.478 \mathrm{E}+01$ & $1.436 \mathrm{E}+01$ & $4.849 \mathrm{E}+00$ \\
10 & $1.570 \mathrm{E}+01$ & $1.569 \mathrm{E}+01$ & $1.540 \mathrm{E}+01$ & $1.482 \mathrm{E}+01$ & $1.482 \mathrm{E}+01$ & $6.466 \mathrm{E}+00$ \\
11 & $1.570 \mathrm{E}+01$ & $1.569 \mathrm{E}+01$ & $1.542 \mathrm{E}+01$ & $1.485 \mathrm{E}+01$ & $1.513 \mathrm{E}+01$ & $7.861 \mathrm{E}+00$ \\
12 & $1.570 \mathrm{E}+01$ & $1.570 \mathrm{E}+01$ & $1.543 \mathrm{E}+01$ & $1.488 \mathrm{E}+01$ & $1.535 \mathrm{E}+01$ & $9.070 \mathrm{E}+00$ \\
13 & $1.570 \mathrm{E}+01$ & $1.570 \mathrm{E}+01$ & $1.545 \mathrm{E}+01$ & $1.491 \mathrm{E}+01$ & $1.550 \mathrm{E}+01$ & $1.012 \mathrm{E}+01$ \\
14 & $1.570 \mathrm{E}+01$ & $1.570 \mathrm{E}+01$ & $1.546 \mathrm{E}+01$ & $1.493 \mathrm{E}+01$ & $1.561 \mathrm{E}+01$ & $1.104 \mathrm{E}+01$ \\
15 & $1.570 \mathrm{E}+01$ & $1.570 \mathrm{E}+01$ & $1.547 \mathrm{E}+01$ & $1.495 \mathrm{E}+01$ & $1.570 \mathrm{E}+01$ & $1.185 \mathrm{E}+01$ \\
16 & $1.570 \mathrm{E}+01$ & $1.570 \mathrm{E}+01$ & $1.548 \mathrm{E}+01$ & $1.497 \mathrm{E}+01$ & $1.576 \mathrm{E}+01$ & $1.255 \mathrm{E}+01$ \\
17 & $1.570 \mathrm{E}+01$ & $1.570 \mathrm{E}+01$ & $1.549 \mathrm{E}+01$ & $1.499 \mathrm{E}+01$ & $1.581 \mathrm{E}+01$ & $1.318 \mathrm{E}+01$ \\
18 & $1.570 \mathrm{E}+01$ & $1.570 \mathrm{E}+01$ & $1.550 \mathrm{E}+01$ & $1.500 \mathrm{E}+01$ & $1.585 \mathrm{E}+01$ & $1.373 \mathrm{E}+01$ \\
19 & $1.570 \mathrm{E}+01$ & $1.570 \mathrm{E}+01$ & $1.550 \mathrm{E}+01$ & $1.502 \mathrm{E}+01$ & $1.589 \mathrm{E}+01$ & $1.421 \mathrm{E}+01$ \\
20 & $1.570 \mathrm{E}+01$ & $1.570 \mathrm{E}+01$ & $1.551 \mathrm{E}+01$ & $1.503 \mathrm{E}+01$ & $1.592 \mathrm{E}+01$ & $1.464 \mathrm{E}+01$ \\
21 & $1.570 \mathrm{E}+01$ & $1.570 \mathrm{E}+01$ & $1.552 \mathrm{E}+01$ & $1.505 \mathrm{E}+01$ & $1.594 \mathrm{E}+01$ & $1.502 \mathrm{E}+01$ \\
22 & $1.570 \mathrm{E}+01$ & $1.570 \mathrm{E}+01$ & $1.552 \mathrm{E}+01$ & $1.506 \mathrm{E}+01$ & $1.597 \mathrm{E}+01$ & $1.536 \mathrm{E}+01$ \\
23 & $1.570 \mathrm{E}+01$ & $1.570 \mathrm{E}+01$ & $1.553 \mathrm{E}+01$ & $1.506 \mathrm{E}+01$ & $1.600 \mathrm{E}+01$ & $1.592 \mathrm{E}+01$ \\
24 & $1.570 \mathrm{E}+01$ & $1.570 \mathrm{E}+01$ & $1.553 \mathrm{E}+01$ & $1.505 \mathrm{E}+01$ & $1.601 \mathrm{E}+01$ & $1.615 \mathrm{E}+01$ \\
25 & $1.571 \mathrm{E}+01$ & $1.569 \mathrm{E}+01$ & $1.552 \mathrm{E}+01$ & $1.502 \mathrm{E}+01$ & $1.598 \mathrm{E}+01$ & $1.636 \mathrm{E}+01$ \\
& & & & & &
\end{tabular}




\begin{tabular}{lllllll}
26 & $1.572 \mathrm{E}+01$ & $1.568 \mathrm{E}+01$ & $1.550 \mathrm{E}+01$ & $1.493 \mathrm{E}+01$ & $1.585 \mathrm{E}+01$ & $1.651 \mathrm{E}+01$ \\
27 & $1.577 \mathrm{E}+01$ & $1.565 \mathrm{E}+01$ & $1.546 \mathrm{E}+01$ & $1.472 \mathrm{E}+01$ & $1.542 \mathrm{E}+01$ & $1.652 \mathrm{E}+01$ \\
28 & $1.597 \mathrm{E}+01$ & $1.561 \mathrm{E}+01$ & $1.530 \mathrm{E}+01$ & $1.419 \mathrm{E}+01$ & $1.385 \mathrm{E}+01$ & $1.512 \mathrm{E}+01$ \\
29 & $2.079 \mathrm{E}+01$ & $1.864 \mathrm{E}+01$ & $1.632 \mathrm{E}+01$ & $1.466 \mathrm{E}+01$ & $1.008 \mathrm{E}+01$ & $9.393 \mathrm{E}+00$ \\
\hline
\end{tabular}

Table C-16: Average heat flux $\left(\mathrm{q}_{\mathrm{i}, \mathrm{avg}}\right)$ data for the individual blind louver, $\phi=90^{\circ}$, $\mathrm{T}_{\mathrm{b}}{ }^{*}=0.3, \mathrm{~d} / \mathrm{L}=0.012$

\begin{tabular}{|c|c|c|c|c|c|c|}
\hline $\begin{array}{c}\text { Louver } \\
\text { number (i) }\end{array}$ & & & & $\mathbf{R a}_{\mathbf{L}}$ & & \\
\hline & $1.00 \mathrm{E}+04$ & $1.00 \mathrm{E}+05$ & $1.00 \mathrm{E}+06$ & $1.00 \mathrm{E}+07$ & $1.00 \mathrm{E}+08$ & $5.00 \mathrm{E}+08$ \\
\hline 1 & $1.323 \mathrm{E}+01$ & $1.260 \mathrm{E}+01$ & $1.064 \mathrm{E}+01$ & $3.454 \mathrm{E}+00$ & $-1.701 \mathrm{E}+01$ & $-2.891 \mathrm{E}+01$ \\
\hline 2 & $1.335 \mathrm{E}+01$ & $1.320 \mathrm{E}+01$ & $1.262 \mathrm{E}+01$ & $1.127 \mathrm{E}+01$ & $-5.925 \mathrm{E}+00$ & $-2.187 \mathrm{E}+01$ \\
\hline 3 & $1.339 \mathrm{E}+01$ & $1.327 \mathrm{E}+01$ & $1.261 \mathrm{E}+01$ & $1.115 \mathrm{E}+01$ & $2.631 \mathrm{E}-01$ & $-1.666 \mathrm{E}+01$ \\
\hline 4 & $1.341 \mathrm{E}+01$ & $1.332 \mathrm{E}+01$ & $1.268 \mathrm{E}+01$ & $1.136 \mathrm{E}+01$ & $4.330 \mathrm{E}+00$ & $-1.206 \mathrm{E}+01$ \\
\hline 5 & $1.342 \mathrm{E}+01$ & $1.335 \mathrm{E}+01$ & $1.274 \mathrm{E}+01$ & $1.155 \mathrm{E}+01$ & $6.893 \mathrm{E}+00$ & $-8.309 \mathrm{E}+00$ \\
\hline 6 & $1.343 \mathrm{E}+01$ & $1.337 \mathrm{E}+01$ & $1.279 \mathrm{E}+01$ & $1.169 \mathrm{E}+01$ & $8.585 E+00$ & $-5.351 \mathrm{E}+00$ \\
\hline 7 & $1.343 \mathrm{E}+01$ & $1.338 \mathrm{E}+01$ & $1.284 \mathrm{E}+01$ & $1.179 \mathrm{E}+01$ & $9.724 \mathrm{E}+00$ & $-2.928 \mathrm{E}+00$ \\
\hline 8 & $1.343 E+01$ & $1.339 \mathrm{E}+01$ & $1.287 \mathrm{E}+01$ & $1.187 \mathrm{E}+01$ & $1.050 \mathrm{E}+01$ & $-8.668 \mathrm{E}-01$ \\
\hline 9 & $1.343 E+01$ & $1.340 \mathrm{E}+01$ & $1.290 \mathrm{E}+01$ & $1.194 \mathrm{E}+01$ & $1.103 \mathrm{E}+01$ & $9.040 \mathrm{E}-01$ \\
\hline 10 & $1.343 \mathrm{E}+01$ & $1.341 \mathrm{E}+01$ & $1.293 \mathrm{E}+01$ & $1.199 \mathrm{E}+01$ & $1.140 \mathrm{E}+01$ & $2.435 \mathrm{E}+00$ \\
\hline 11 & $1.343 \mathrm{E}+01$ & $1.341 \mathrm{E}+01$ & $1.296 \mathrm{E}+01$ & $1.204 \mathrm{E}+01$ & $1.165 \mathrm{E}+01$ & $3.763 E+00$ \\
\hline 12 & $1.343 \mathrm{E}+01$ & $1.342 \mathrm{E}+01$ & $1.298 \mathrm{E}+01$ & $1.208 \mathrm{E}+01$ & $1.184 \mathrm{E}+01$ & $4.918 \mathrm{E}+00$ \\
\hline 13 & $1.343 \mathrm{E}+01$ & $1.342 \mathrm{E}+01$ & $1.300 \mathrm{E}+01$ & $1.212 \mathrm{E}+01$ & $1.198 \mathrm{E}+01$ & $5.927 \mathrm{E}+00$ \\
\hline 14 & $1.343 E+01$ & $1.342 \mathrm{E}+01$ & $1.302 \mathrm{E}+01$ & $1.216 \mathrm{E}+01$ & $1.209 \mathrm{E}+01$ & $6.810 \mathrm{E}+00$ \\
\hline 15 & $1.343 \mathrm{E}+01$ & $1.342 \mathrm{E}+01$ & $1.304 \mathrm{E}+01$ & $1.219 \mathrm{E}+01$ & $1.217 \mathrm{E}+01$ & $7.584 \mathrm{E}+00$ \\
\hline 16 & $1.343 \mathrm{E}+01$ & $1.343 \mathrm{E}+01$ & $1.305 \mathrm{E}+01$ & $1.222 \mathrm{E}+01$ & $1.224 \mathrm{E}+01$ & $8.265 E+00$ \\
\hline 17 & $1.343 E+01$ & $1.343 E+01$ & $1.307 \mathrm{E}+01$ & $1.224 \mathrm{E}+01$ & $1.230 \mathrm{E}+01$ & $8.866 \mathrm{E}+00$ \\
\hline 18 & $1.343 \mathrm{E}+01$ & $1.343 \mathrm{E}+01$ & $1.308 \mathrm{E}+01$ & $1.227 \mathrm{E}+01$ & $1.235 \mathrm{E}+01$ & $9.396 \mathrm{E}+00$ \\
\hline 19 & $1.343 \mathrm{E}+01$ & $1.343 \mathrm{E}+01$ & $1.309 \mathrm{E}+01$ & $1.229 \mathrm{E}+01$ & $1.239 \mathrm{E}+01$ & $9.864 \mathrm{E}+00$ \\
\hline 20 & $1.343 \mathrm{E}+01$ & $1.343 \mathrm{E}+01$ & $1.310 \mathrm{E}+01$ & $1.231 \mathrm{E}+01$ & $1.243 \mathrm{E}+01$ & $1.028 \mathrm{E}+01$ \\
\hline 21 & $1.343 E+01$ & $1.343 \mathrm{E}+01$ & $1.311 \mathrm{E}+01$ & $1.233 \mathrm{E}+01$ & $1.246 \mathrm{E}+01$ & $1.065 \mathrm{E}+01$ \\
\hline 22 & $1.343 \mathrm{E}+01$ & $1.343 \mathrm{E}+01$ & $1.312 \mathrm{E}+01$ & $1.234 \mathrm{E}+01$ & $1.249 \mathrm{E}+01$ & $1.098 \mathrm{E}+01$ \\
\hline 23 & $1.343 \mathrm{E}+01$ & $1.343 \mathrm{E}+01$ & $1.313 E+01$ & $1.235 \mathrm{E}+01$ & $1.252 \mathrm{E}+01$ & $1.127 \mathrm{E}+01$ \\
\hline 24 & $1.343 E+01$ & $1.343 \mathrm{E}+01$ & $1.313 \mathrm{E}+01$ & $1.234 \mathrm{E}+01$ & $1.253 \mathrm{E}+01$ & $1.152 \mathrm{E}+01$ \\
\hline 25 & $1.343 E+01$ & $1.343 E+01$ & $1.313 E+01$ & $1.229 \mathrm{E}+01$ & $1.251 \mathrm{E}+01$ & $1.175 \mathrm{E}+01$ \\
\hline 26 & $1.344 \mathrm{E}+01$ & $1.341 \mathrm{E}+01$ & $1.311 \mathrm{E}+01$ & $1.218 \mathrm{E}+01$ & $1.236 \mathrm{E}+01$ & $1.191 \mathrm{E}+01$ \\
\hline 27 & $1.347 \mathrm{E}+01$ & $1.338 \mathrm{E}+01$ & $1.306 \mathrm{E}+01$ & $1.188 \mathrm{E}+01$ & $1.182 \mathrm{E}+01$ & $1.194 \mathrm{E}+01$ \\
\hline 28 & $1.360 \mathrm{E}+01$ & $1.331 \mathrm{E}+01$ & $1.289 \mathrm{E}+01$ & $1.117 \mathrm{E}+01$ & $9.871 \mathrm{E}+00$ & $9.857 \mathrm{E}+00$ \\
\hline 29 & $1.755 \mathrm{E}+01$ & $1.559 \mathrm{E}+01$ & $1.346 \mathrm{E}+01$ & $1.207 \mathrm{E}+01$ & $5.164 \mathrm{E}+00$ & $2.222 \mathrm{E}+00$ \\
\hline
\end{tabular}


Table C-17: Average heat flux ( $\mathrm{q}_{\mathrm{i}, \text { avg }}$ ) data for the individual blind louver, $\phi=0^{\circ}$, $\mathrm{T}_{\mathrm{b}}{ }^{*}=0.4, \mathrm{~d} / \mathrm{L}=0.012$

\begin{tabular}{|c|c|c|c|c|c|c|}
\hline $\begin{array}{c}\text { Louver } \\
\text { number (i) }\end{array}$ & & & & $\mathbf{R a}_{\mathbf{l}}$ & & \\
\hline & $1.00 E+04$ & $1.00 E+05$ & $1.00 \mathrm{E}+06$ & $1.00 \mathrm{E}+07$ & $1.00 \mathrm{E}+08$ & $5.00 \mathrm{E}+08$ \\
\hline 1 & $1.027 \mathrm{E}+01$ & $9.248 \mathrm{E}+00$ & $6.595 \mathrm{E}+00$ & $-2.206 \mathrm{E}+00$ & $-2.572 \mathrm{E}+01$ & $-4.125 \mathrm{E}+01$ \\
\hline 2 & $1.106 \mathrm{E}+01$ & $1.076 \mathrm{E}+01$ & $9.859 \mathrm{E}+00$ & $7.754 \mathrm{E}+00$ & $-1.200 \mathrm{E}+01$ & $-3.155 E+01$ \\
\hline 3 & $1.116 \mathrm{E}+01$ & $1.091 \mathrm{E}+01$ & $9.938 \mathrm{E}+00$ & $7.871 \mathrm{E}+00$ & $-4.968 \mathrm{E}+00$ & $-2.509 \mathrm{E}+01$ \\
\hline 4 & $1.120 \mathrm{E}+01$ & $1.099 \mathrm{E}+01$ & $1.006 \mathrm{E}+01$ & $8.223 E+00$ & $-3.370 \mathrm{E}-01$ & $-1.940 \mathrm{E}+01$ \\
\hline 5 & $1.122 \mathrm{E}+01$ & $1.105 \mathrm{E}+01$ & $1.016 \mathrm{E}+01$ & $8.509 \mathrm{E}+00$ & $2.544 \mathrm{E}+00$ & $-1.502 \mathrm{E}+01$ \\
\hline 6 & $1.123 \mathrm{E}+01$ & $1.108 \mathrm{E}+01$ & $1.023 \mathrm{E}+01$ & $8.705 E+00$ & $4.442 \mathrm{E}+00$ & $-1.187 \mathrm{E}+01$ \\
\hline 7 & $1.123 E+01$ & $1.111 \mathrm{E}+01$ & $1.030 \mathrm{E}+01$ & $8.846 \mathrm{E}+00$ & $5.722 \mathrm{E}+00$ & $-9.333 E+00$ \\
\hline 8 & $1.124 \mathrm{E}+01$ & $1.113 \mathrm{E}+01$ & $1.035 \mathrm{E}+01$ & $8.957 \mathrm{E}+00$ & $6.595 \mathrm{E}+00$ & $-7.122 \mathrm{E}+00$ \\
\hline 9 & $1.124 \mathrm{E}+01$ & $1.115 \mathrm{E}+01$ & $1.040 \mathrm{E}+01$ & $9.048 \mathrm{E}+00$ & $7.197 \mathrm{E}+00$ & $-5.208 \mathrm{E}+00$ \\
\hline 10 & $1.124 \mathrm{E}+01$ & $1.116 \mathrm{E}+01$ & $1.044 \mathrm{E}+01$ & $9.127 \mathrm{E}+00$ & $7.618 \mathrm{E}+00$ & $-3.551 \mathrm{E}+00$ \\
\hline 11 & $1.124 \mathrm{E}+01$ & $1.117 \mathrm{E}+01$ & $1.048 \mathrm{E}+01$ & $9.195 \mathrm{E}+00$ & $7.918 \mathrm{E}+00$ & $-2.108 \mathrm{E}+00$ \\
\hline 12 & $1.124 \mathrm{E}+01$ & $1.118 \mathrm{E}+01$ & $1.051 \mathrm{E}+01$ & $9.256 \mathrm{E}+00$ & $8.138 \mathrm{E}+00$ & $-8.525 \mathrm{E}-01$ \\
\hline 13 & $1.124 \mathrm{E}+01$ & $1.119 \mathrm{E}+01$ & $1.054 \mathrm{E}+01$ & $9.311 \mathrm{E}+00$ & $8.306 \mathrm{E}+00$ & $2.451 \mathrm{E}-01$ \\
\hline 14 & $1.124 \mathrm{E}+01$ & $1.120 \mathrm{E}+01$ & $1.057 \mathrm{E}+01$ & $9.360 \mathrm{E}+00$ & $8.435 E+00$ & $1.207 \mathrm{E}+00$ \\
\hline 15 & $1.124 \mathrm{E}+01$ & $1.121 \mathrm{E}+01$ & $1.060 \mathrm{E}+01$ & $9.404 \mathrm{E}+00$ & $8.540 \mathrm{E}+00$ & $2.053 \mathrm{E}+00$ \\
\hline 16 & $1.124 \mathrm{E}+01$ & $1.121 \mathrm{E}+01$ & $1.062 \mathrm{E}+01$ & $9.447 \mathrm{E}+00$ & $8.626 \mathrm{E}+00$ & $2.799 \mathrm{E}+00$ \\
\hline 17 & $1.124 \mathrm{E}+01$ & $1.122 \mathrm{E}+01$ & $1.064 \mathrm{E}+01$ & $9.486 \mathrm{E}+00$ & $8.700 \mathrm{E}+00$ & $3.459 \mathrm{E}+00$ \\
\hline 18 & $1.124 \mathrm{E}+01$ & $1.122 \mathrm{E}+01$ & $1.066 \mathrm{E}+01$ & $9.521 \mathrm{E}+00$ & $8.764 E+00$ & $4.044 \mathrm{E}+00$ \\
\hline 19 & $1.124 \mathrm{E}+01$ & $1.122 \mathrm{E}+01$ & $1.068 \mathrm{E}+01$ & $9.555 \mathrm{E}+00$ & $8.821 E+00$ & $4.565 \mathrm{E}+00$ \\
\hline 20 & $1.124 \mathrm{E}+01$ & $1.123 \mathrm{E}+01$ & $1.070 \mathrm{E}+01$ & $9.584 \mathrm{E}+00$ & $8.871 E+00$ & $5.029 E+00$ \\
\hline 21 & $1.124 \mathrm{E}+01$ & $1.123 \mathrm{E}+01$ & $1.071 \mathrm{E}+01$ & $9.610 \mathrm{E}+00$ & $8.918 \mathrm{E}+00$ & $5.444 \mathrm{E}+00$ \\
\hline 22 & $1.124 \mathrm{E}+01$ & $1.123 \mathrm{E}+01$ & $1.072 \mathrm{E}+01$ & $9.631 \mathrm{E}+00$ & $8.960 \mathrm{E}+00$ & $5.815 \mathrm{E}+00$ \\
\hline 23 & $1.124 \mathrm{E}+01$ & $1.123 \mathrm{E}+01$ & $1.073 \mathrm{E}+01$ & $9.642 \mathrm{E}+00$ & $8.995 \mathrm{E}+00$ & $6.150 \mathrm{E}+00$ \\
\hline 24 & $1.124 \mathrm{E}+01$ & $1.123 \mathrm{E}+01$ & $1.074 \mathrm{E}+01$ & $9.633 \mathrm{E}+00$ & $9.016 \mathrm{E}+00$ & $6.450 \mathrm{E}+00$ \\
\hline 25 & $1.123 E+01$ & $1.123 \mathrm{E}+01$ & $1.074 \mathrm{E}+01$ & $9.588 \mathrm{E}+00$ & $8.995 \mathrm{E}+00$ & $6.713 \mathrm{E}+00$ \\
\hline 26 & $1.123 \mathrm{E}+01$ & $1.122 \mathrm{E}+01$ & $1.071 \mathrm{E}+01$ & $9.454 \mathrm{E}+00$ & $8.834 \mathrm{E}+00$ & $6.910 \mathrm{E}+00$ \\
\hline 27 & $1.133 E+01$ & $1.118 \mathrm{E}+01$ & $1.066 \mathrm{E}+01$ & $9.107 \mathrm{E}+00$ & $8.213 E+00$ & $6.941 E+00$ \\
\hline 28 & $1.131 \mathrm{E}+01$ & $1.108 \mathrm{E}+01$ & $1.048 \mathrm{E}+01$ & $8.212 \mathrm{E}+00$ & $5.950 \mathrm{E}+00$ & $4.487 \mathrm{E}+00$ \\
\hline 29 & $1.445 \mathrm{E}+01$ & $1.268 \mathrm{E}+01$ & $1.076 \mathrm{E}+01$ & $9.099 \mathrm{E}+00$ & $-1.141 \mathrm{E}-01$ & $-4.992 \mathrm{E}+00$ \\
\hline
\end{tabular}

Table C-18: Average heat flux ( $\mathrm{q}_{\mathrm{i}, \text { avg }}$ ) data for the individual blind louver, $\phi=0^{\circ}$, $\mathrm{T}_{\mathrm{b}}{ }^{*}=0.5, \mathrm{~d} / \mathrm{L}=0.012$

\begin{tabular}{ccccccc}
\hline $\begin{array}{c}\text { Louver } \\
\text { number (i) }\end{array}$ & \multicolumn{7}{c}{$\mathbf{R a}_{\mathbf{l}}$} \\
\hline 1 & $\mathbf{1 . 0 0 \mathrm { E } + 0 4}$ & $\mathbf{1 . 0 0 \mathrm { E } + 0 5}$ & $\mathbf{1 . 0 0 \mathrm { E } + 0 6}$ & $\mathbf{1 . 0 0 \mathrm { E } + 0 7}$ & $\mathbf{1 . 0 0 \mathrm { E } + 0 8}$ & $\mathbf{5 . 0 0 \mathrm { E } + 0 8}$ \\
\hline 1 & $7.196 \mathrm{E}+00$ & $5.787 \mathrm{E}+00$ & $2.445 \mathrm{E}+00$ & $-7.929 \mathrm{E}+00$ & $-3.471 \mathrm{E}+01$ & $-5.386 \mathrm{E}+01$ \\
3 & $8.673 \mathrm{E}+00$ & $8.206 \mathrm{E}+00$ & $6.988 \mathrm{E}+00$ & $4.097 \mathrm{E}+00$ & $-1.825 \mathrm{E}+01$ & $-4.154 \mathrm{E}+01$ \\
4 & $8.829 \mathrm{E}+00$ & $8.440 \mathrm{E}+00$ & $7.167 \mathrm{E}+00$ & $4.462 \mathrm{E}+00$ & $-1.032 \mathrm{E}+01$ & $-3.367 \mathrm{E}+01$ \\
5 & $8.893 \mathrm{E}+00$ & $8.564 \mathrm{E}+00$ & $7.335 \mathrm{E}+00$ & $4.967 \mathrm{E}+00$ & $-1.914 \mathrm{E}+00$ & $-2.681 \mathrm{E}+01$ \\
6 & $8.924 \mathrm{E}+00$ & $8.641 \mathrm{E}+00$ & $7.467 \mathrm{E}+00$ & $5.343 \mathrm{E}+00$ & $1.821 \mathrm{E}-01$ & $-2.169 \mathrm{E}+01$ \\
7 & $8.940 \mathrm{E}+00$ & $8.694 \mathrm{E}+00$ & $7.570 \mathrm{E}+00$ & $5.594 \mathrm{E}+00$ & $1.592 \mathrm{E}+00$ & $-1.840 \mathrm{E}+01$ \\
& $8.949 \mathrm{E}+00$ & $8.734 \mathrm{E}+00$ & $7.657 \mathrm{E}+00$ & $5.775 \mathrm{E}+00$ & $2.557 \mathrm{E}+00$ & $-1.571 \mathrm{E}+01$
\end{tabular}




\begin{tabular}{ccccccc}
8 & $8.954 \mathrm{E}+00$ & $8.765 \mathrm{E}+00$ & $7.729 \mathrm{E}+00$ & $5.918 \mathrm{E}+00$ & $3.224 \mathrm{E}+00$ & $-1.333 \mathrm{E}+01$ \\
9 & $8.957 \mathrm{E}+00$ & $8.792 \mathrm{E}+00$ & $7.793 \mathrm{E}+00$ & $6.036 \mathrm{E}+00$ & $3.695 \mathrm{E}+00$ & $-1.126 \mathrm{E}+01$ \\
10 & $8.958 \mathrm{E}+00$ & $8.814 \mathrm{E}+00$ & $7.849 \mathrm{E}+00$ & $6.138 \mathrm{E}+00$ & $4.033 \mathrm{E}+00$ & $-9.458 \mathrm{E}+00$ \\
11 & $8.960 \mathrm{E}+00$ & $8.833 \mathrm{E}+00$ & $7.899 \mathrm{E}+00$ & $6.228 \mathrm{E}+00$ & $4.285 \mathrm{E}+00$ & $-7.897 \mathrm{E}+00$ \\
12 & $8.961 \mathrm{E}+00$ & $8.850 \mathrm{E}+00$ & $7.945 \mathrm{E}+00$ & $6.307 \mathrm{E}+00$ & $4.477 \mathrm{E}+00$ & $-6.536 \mathrm{E}+00$ \\
13 & $8.961 \mathrm{E}+00$ & $8.864 \mathrm{E}+00$ & $7.986 \mathrm{E}+00$ & $6.378 \mathrm{E}+00$ & $4.628 \mathrm{E}+00$ & $-5.347 \mathrm{E}+00$ \\
14 & $8.961 \mathrm{E}+00$ & $8.876 \mathrm{E}+00$ & $8.022 \mathrm{E}+00$ & $6.442 \mathrm{E}+00$ & $4.753 \mathrm{E}+00$ & $-4.306 \mathrm{E}+00$ \\
15 & $8.962 \mathrm{E}+00$ & $8.887 \mathrm{E}+00$ & $8.056 \mathrm{E}+00$ & $6.501 \mathrm{E}+00$ & $4.856 \mathrm{E}+00$ & $-3.389 \mathrm{E}+00$ \\
16 & $8.962 \mathrm{E}+00$ & $8.897 \mathrm{E}+00$ & $8.088 \mathrm{E}+00$ & $6.556 \mathrm{E}+00$ & $4.946 \mathrm{E}+00$ & $-2.580 \mathrm{E}+00$ \\
17 & $8.962 \mathrm{E}+00$ & $8.905 \mathrm{E}+00$ & $8.115 \mathrm{E}+00$ & $6.606 \mathrm{E}+00$ & $5.024 \mathrm{E}+00$ & $-1.865 \mathrm{E}+00$ \\
18 & $8.962 \mathrm{E}+00$ & $8.912 \mathrm{E}+00$ & $8.143 \mathrm{E}+00$ & $6.653 \mathrm{E}+00$ & $5.094 \mathrm{E}+00$ & $-1.228 \mathrm{E}+00$ \\
19 & $8.962 \mathrm{E}+00$ & $8.919 \mathrm{E}+00$ & $8.167 \mathrm{E}+00$ & $6.696 \mathrm{E}+00$ & $5.158 \mathrm{E}+00$ & $-6.606 \mathrm{E}-01$ \\
20 & $8.962 \mathrm{E}+00$ & $8.924 \mathrm{E}+00$ & $8.189 \mathrm{E}+00$ & $6.735 \mathrm{E}+00$ & $5.217 \mathrm{E}+00$ & $-1.532 \mathrm{E}-01$ \\
21 & $8.962 \mathrm{E}+00$ & $8.929 \mathrm{E}+00$ & $8.210 \mathrm{E}+00$ & $6.771 \mathrm{E}+00$ & $5.270 \mathrm{E}+00$ & $3.019 \mathrm{E}-01$ \\
22 & $8.960 \mathrm{E}+00$ & $8.934 \mathrm{E}+00$ & $8.227 \mathrm{E}+00$ & $6.799 \mathrm{E}+00$ & $5.315 \mathrm{E}+00$ & $7.115 \mathrm{E}-01$ \\
23 & $8.957 \mathrm{E}+00$ & $8.936 \mathrm{E}+00$ & $8.240 \mathrm{E}+00$ & $6.818 \mathrm{E}+00$ & $5.347 \mathrm{E}+00$ & $1.081 \mathrm{E}+00$ \\
24 & $8.951 \mathrm{E}+00$ & $8.938 \mathrm{E}+00$ & $8.248 \mathrm{E}+00$ & $6.816 \mathrm{E}+00$ & $5.331 \mathrm{E}+00$ & $1.415 \mathrm{E}+00$ \\
25 & $8.942 \mathrm{E}+00$ & $8.934 \mathrm{E}+00$ & $8.245 \mathrm{E}+00$ & $6.770 \mathrm{E}+00$ & $5.164 \mathrm{E}+00$ & $1.711 \mathrm{E}+00$ \\
26 & $8.930 \mathrm{E}+00$ & $8.921 \mathrm{E}+00$ & $8.222 \mathrm{E}+00$ & $6.627 \mathrm{E}+00$ & $4.482 \mathrm{E}+00$ & $1.936 \mathrm{E}+00$ \\
27 & $8.919 \mathrm{E}+00$ & $8.886 \mathrm{E}+00$ & $8.155 \mathrm{E}+00$ & $6.247 \mathrm{E}+00$ & $1.947 \mathrm{E}+00$ & $2.010 \mathrm{E}+00$ \\
28 & $8.940 \mathrm{E}+00$ & $8.771 \mathrm{E}+00$ & $7.990 \mathrm{E}+00$ & $5.216 \mathrm{E}+00$ & $-1.108 \mathrm{E}+01$ & $-9.963 \mathrm{E}-01$ \\
29 & $1.122 \mathrm{E}+01$ & $9.724 \mathrm{E}+00$ & $7.917 \mathrm{E}+00$ & $5.835 \mathrm{E}+00$ & $-5.127 \mathrm{E}+00$ & $-1.264 \mathrm{E}+01$ \\
\hline
\end{tabular}

Table C-19: Average heat flux $\left(\mathrm{q}_{\mathrm{i}, \mathrm{avg}}\right)$ data for the individual blind louver, $\phi=90^{\circ}$, $\mathrm{T}_{\mathrm{b}}{ }^{*}=0.2, \mathrm{~d} / \mathrm{L}=0.012$

\begin{tabular}{ccccccc}
\hline $\begin{array}{c}\text { Louver } \\
\text { number }(\mathrm{i})\end{array}$ & & & & \multicolumn{5}{c}{$\mathbf{R a}_{\mathbf{L}}$} \\
\hline 1 & $1.00 \mathrm{E}+04$ & $1.00 \mathrm{E}+05$ & $1.00 \mathrm{E}+06$ & $1.00 \mathrm{E}+07$ & $1.00 \mathrm{E}+08$ & $5.00 \mathrm{E}+08$ \\
\hline 2 & $8.929 \mathrm{E}+01$ & $8.894 \mathrm{E}+01$ & $8.825 \mathrm{E}+01$ & $8.642 \mathrm{E}+01$ & $6.866 \mathrm{E}+01$ & $2.254 \mathrm{E}-01$ \\
3 & $8.907 \mathrm{E}+01$ & $8.907 \mathrm{E}+01$ & $8.907 \mathrm{E}+01$ & $8.907 \mathrm{E}+01$ & $8.905 \mathrm{E}+01$ & $7.589 \mathrm{E}+01$ \\
4 & $8.907 \mathrm{E}+01$ & $8.907 \mathrm{E}+01$ & $8.907 \mathrm{E}+01$ & $8.907 \mathrm{E}+01$ & $8.907 \mathrm{E}+01$ & $8.721 \mathrm{E}+01$ \\
5 & $8.907 \mathrm{E}+01$ & $8.907 \mathrm{E}+01$ & $8.907 \mathrm{E}+01$ & $8.907 \mathrm{E}+01$ & $8.907 \mathrm{E}+01$ & $8.885 \mathrm{E}+01$ \\
6 & $8.907 \mathrm{E}+01$ & $8.907 \mathrm{E}+01$ & $8.907 \mathrm{E}+01$ & $8.907 \mathrm{E}+01$ & $8.907 \mathrm{E}+01$ & $8.909 \mathrm{E}+01$ \\
7 & $8.907 \mathrm{E}+01$ & $8.907 \mathrm{E}+01$ & $8.907 \mathrm{E}+01$ & $8.907 \mathrm{E}+01$ & $8.907 \mathrm{E}+01$ & $8.912 \mathrm{E}+01$ \\
8 & $8.907 \mathrm{E}+01$ & $8.907 \mathrm{E}+01$ & $8.907 \mathrm{E}+01$ & $8.907 \mathrm{E}+01$ & $8.907 \mathrm{E}+01$ & $8.912 \mathrm{E}+01$ \\
9 & $8.907 \mathrm{E}+01$ & $8.907 \mathrm{E}+01$ & $8.907 \mathrm{E}+01$ & $8.907 \mathrm{E}+01$ & $8.907 \mathrm{E}+01$ & $8.913 \mathrm{E}+01$ \\
10 & $8.907 \mathrm{E}+01$ & $8.907 \mathrm{E}+01$ & $8.907 \mathrm{E}+01$ & $8.907 \mathrm{E}+01$ & $8.907 \mathrm{E}+01$ & $8.913 \mathrm{E}+01$ \\
11 & $8.907 \mathrm{E}+01$ & $8.907 \mathrm{E}+01$ & $8.907 \mathrm{E}+01$ & $8.907 \mathrm{E}+01$ & $8.907 \mathrm{E}+01$ & $8.913 \mathrm{E}+01$ \\
12 & $8.907 \mathrm{E}+01$ & $8.907 \mathrm{E}+01$ & $8.907 \mathrm{E}+01$ & $8.907 \mathrm{E}+01$ & $8.907 \mathrm{E}+01$ & $8.913 \mathrm{E}+01$ \\
13 & $8.907 \mathrm{E}+01$ & $8.907 \mathrm{E}+01$ & $8.907 \mathrm{E}+01$ & $8.907 \mathrm{E}+01$ & $8.907 \mathrm{E}+01$ & $8.913 \mathrm{E}+01$ \\
14 & $8.907 \mathrm{E}+01$ & $8.907 \mathrm{E}+01$ & $8.907 \mathrm{E}+01$ & $8.907 \mathrm{E}+01$ & $8.907 \mathrm{E}+01$ & $8.913 \mathrm{E}+01$ \\
15 & $8.907 \mathrm{E}+01$ & $8.907 \mathrm{E}+01$ & $8.907 \mathrm{E}+01$ & $8.907 \mathrm{E}+01$ & $8.907 \mathrm{E}+01$ & $8.913 \mathrm{E}+01$ \\
16 & $8.907 \mathrm{E}+01$ & $8.907 \mathrm{E}+01$ & $8.907 \mathrm{E}+01$ & $8.907 \mathrm{E}+01$ & $8.907 \mathrm{E}+01$ & $8.913 \mathrm{E}+01$ \\
17 & $8.907 \mathrm{E}+01$ & $8.907 \mathrm{E}+01$ & $8.907 \mathrm{E}+01$ & $8.907 \mathrm{E}+01$ & $8.907 \mathrm{E}+01$ & $8.913 \mathrm{E}+01$ \\
18 & $8.907 \mathrm{E}+01$ & $8.907 \mathrm{E}+01$ & $8.907 \mathrm{E}+01$ & $8.907 \mathrm{E}+01$ & $8.907 \mathrm{E}+01$ & $8.913 \mathrm{E}+01$
\end{tabular}




\begin{tabular}{|c|c|c|c|c|c|c|}
\hline 19 & $8.907 E+01$ & $8.907 \mathrm{E}+01$ & $8.907 \mathrm{E}+01$ & $8.907 \mathrm{E}+01$ & $8.907 \mathrm{E}+01$ & $8.913 E+01$ \\
\hline 20 & $8.907 \mathrm{E}+01$ & $8.907 \mathrm{E}+01$ & $8.907 \mathrm{E}+01$ & $8.907 \mathrm{E}+01$ & $8.907 E+01$ & $8.913 E+01$ \\
\hline 21 & $8.907 E+01$ & $8.907 \mathrm{E}+01$ & $8.907 \mathrm{E}+01$ & $8.907 \mathrm{E}+01$ & $8.907 E+01$ & $8.913 E+01$ \\
\hline 22 & $8.907 \mathrm{E}+01$ & $8.907 \mathrm{E}+01$ & $8.907 \mathrm{E}+01$ & $8.907 \mathrm{E}+01$ & $8.907 \mathrm{E}+01$ & $8.913 E+01$ \\
\hline 23 & $8.907 E+01$ & $8.907 \mathrm{E}+01$ & $8.907 \mathrm{E}+01$ & $8.907 \mathrm{E}+01$ & $8.907 \mathrm{E}+01$ & $8.913 E+01$ \\
\hline 24 & $8.907 E+01$ & $8.907 \mathrm{E}+01$ & $8.907 \mathrm{E}+01$ & $8.907 \mathrm{E}+01$ & $8.907 \mathrm{E}+01$ & $8.913 E+01$ \\
\hline 25 & $8.907 \mathrm{E}+01$ & $8.907 \mathrm{E}+01$ & $8.907 \mathrm{E}+01$ & $8.907 E+01$ & $8.907 E+01$ & $8.913 E+01$ \\
\hline 26 & $8.907 E+01$ & $8.907 E+01$ & $8.907 \mathrm{E}+01$ & $8.907 \mathrm{E}+01$ & $8.907 E+01$ & $8.913 E+01$ \\
\hline 27 & $8.907 \mathrm{E}+01$ & $8.907 \mathrm{E}+01$ & $8.907 \mathrm{E}+01$ & $8.907 \mathrm{E}+01$ & $8.907 \mathrm{E}+01$ & $8.913 E+01$ \\
\hline 28 & $8.926 \mathrm{E}+01$ & $8.926 \mathrm{E}+01$ & $8.926 \mathrm{E}+01$ & $8.926 \mathrm{E}+01$ & $8.924 \mathrm{E}+01$ & $8.927 \mathrm{E}+01$ \\
\hline 29 & $9.516 \mathrm{E}+01$ & $9.459 \mathrm{E}+01$ & $9.357 \mathrm{E}+01$ & $9.230 \mathrm{E}+01$ & $9.222 \mathrm{E}+01$ & $9.138 \mathrm{E}+01$ \\
\hline 30 & $6.980 \mathrm{E}-01$ & $-1.973 \mathrm{E}-01$ & $-2.108 \mathrm{E}+00$ & $-5.729 \mathrm{E}+00$ & $-1.560 \mathrm{E}+01$ & $-2.524 \mathrm{E}+01$ \\
\hline 31 & $-1.047 \mathrm{E}+00$ & $-1.518 \mathrm{E}+00$ & $-2.712 \mathrm{E}+00$ & $-5.030 \mathrm{E}+00$ & $-1.016 \mathrm{E}+01$ & $-1.543 \mathrm{E}+01$ \\
\hline 32 & $-1.063 \mathrm{E}+00$ & $-1.436 \mathrm{E}+00$ & $-2.494 \mathrm{E}+00$ & $-4.575 \mathrm{E}+00$ & $-8.909 \mathrm{E}+00$ & $-1.344 \mathrm{E}+01$ \\
\hline 33 & $-1.047 \mathrm{E}+00$ & $-1.363 \mathrm{E}+00$ & $-2.347 \mathrm{E}+00$ & $-4.288 \mathrm{E}+00$ & $-8.190 \mathrm{E}+00$ & $-1.232 \mathrm{E}+01$ \\
\hline 34 & $-1.034 \mathrm{E}+00$ & $-1.309 \mathrm{E}+00$ & $-2.240 \mathrm{E}+00$ & $-4.076 \mathrm{E}+00$ & $-7.700 \mathrm{E}+00$ & $-1.155 \mathrm{E}+01$ \\
\hline 35 & $-1.025 \mathrm{E}+00$ & $-1.269 \mathrm{E}+00$ & $-2.157 \mathrm{E}+00$ & $-3.908 E+00$ & $-7.334 \mathrm{E}+00$ & $-1.098 \mathrm{E}+01$ \\
\hline 36 & $-1.019 E+00$ & $-1.237 \mathrm{E}+00$ & $-2.089 \mathrm{E}+00$ & $-3.770 \mathrm{E}+00$ & $-7.043 E+00$ & $-1.052 E+01$ \\
\hline 37 & $-1.016 \mathrm{E}+00$ & $-1.211 \mathrm{E}+00$ & $-2.031 E+00$ & $-3.652 E+00$ & $-6.803 E+00$ & $-1.014 \mathrm{E}+01$ \\
\hline 38 & $-1.013 \mathrm{E}+00$ & $-1.190 \mathrm{E}+00$ & $-1.980 \mathrm{E}+00$ & $-3.549 \mathrm{E}+00$ & $-6.600 \mathrm{E}+00$ & $-9.827 \mathrm{E}+00$ \\
\hline 39 & $-1.012 \mathrm{E}+00$ & $-1.172 \mathrm{E}+00$ & $-1.936 \mathrm{E}+00$ & $-3.460 \mathrm{E}+00$ & $-6.423 E+00$ & $-9.552 \mathrm{E}+00$ \\
\hline 40 & $-1.011 \mathrm{E}+00$ & $-1.156 \mathrm{E}+00$ & $-1.895 \mathrm{E}+00$ & $-3.380 \mathrm{E}+00$ & $-6.268 \mathrm{E}+00$ & $-9.312 \mathrm{E}+00$ \\
\hline 41 & $-1.010 \mathrm{E}+00$ & $-1.142 \mathrm{E}+00$ & $-1.859 \mathrm{E}+00$ & $-3.309 \mathrm{E}+00$ & $-6.130 \mathrm{E}+00$ & $-9.099 \mathrm{E}+00$ \\
\hline 42 & $-1.009 \mathrm{E}+00$ & $-1.129 \mathrm{E}+00$ & $-1.826 \mathrm{E}+00$ & $-3.245 E+00$ & $-6.006 \mathrm{E}+00$ & $-8.909 \mathrm{E}+00$ \\
\hline 43 & $-1.009 \mathrm{E}+00$ & $-1.118 \mathrm{E}+00$ & $-1.795 E+00$ & $-3.187 E+00$ & $-5.893 \mathrm{E}+00$ & $-8.737 E+00$ \\
\hline 44 & $-1.009 E+00$ & $-1.109 \mathrm{E}+00$ & $-1.767 \mathrm{E}+00$ & $-3.134 \mathrm{E}+00$ & $-5.790 \mathrm{E}+00$ & $-8.581 E+00$ \\
\hline 45 & $-1.009 E+00$ & $-1.100 \mathrm{E}+00$ & $-1.741 \mathrm{E}+00$ & $-3.085 E+00$ & $-5.696 \mathrm{E}+00$ & $-8.437 \mathrm{E}+00$ \\
\hline 46 & $-1.009 \mathrm{E}+00$ & $-1.092 \mathrm{E}+00$ & $-1.717 \mathrm{E}+00$ & $-3.040 \mathrm{E}+00$ & $-5.608 E+00$ & $-8.305 E+00$ \\
\hline 47 & $-1.009 \mathrm{E}+00$ & $-1.085 E+00$ & $-1.695 \mathrm{E}+00$ & $-2.998 \mathrm{E}+00$ & $-5.527 \mathrm{E}+00$ & $-8.183 \mathrm{E}+00$ \\
\hline 48 & $-1.009 \mathrm{E}+00$ & $-1.079 \mathrm{E}+00$ & $-1.674 \mathrm{E}+00$ & $-2.958 \mathrm{E}+00$ & $-5.452 \mathrm{E}+00$ & $-8.070 \mathrm{E}+00$ \\
\hline 49 & $-1.009 E+00$ & $-1.074 \mathrm{E}+00$ & $-1.655 \mathrm{E}+00$ & $-2.922 \mathrm{E}+00$ & $-5.381 \mathrm{E}+00$ & $-7.964 \mathrm{E}+00$ \\
\hline 50 & $-1.009 \mathrm{E}+00$ & $-1.070 \mathrm{E}+00$ & $-1.637 \mathrm{E}+00$ & $-2.887 \mathrm{E}+00$ & $-5.315 \mathrm{E}+00$ & $-7.865 \mathrm{E}+00$ \\
\hline 51 & $-1.008 \mathrm{E}+00$ & $-1.066 \mathrm{E}+00$ & $-1.621 \mathrm{E}+00$ & $-2.855 \mathrm{E}+00$ & $-5.253 E+00$ & $-7.772 \mathrm{E}+00$ \\
\hline 52 & $-1.002 \mathrm{E}+00$ & $-1.065 \mathrm{E}+00$ & $-1.607 \mathrm{E}+00$ & $-2.826 \mathrm{E}+00$ & $-5.194 \mathrm{E}+00$ & $-7.684 E+00$ \\
\hline 53 & $-9.861 \mathrm{E}-01$ & $-1.066 \mathrm{E}+00$ & $-1.596 \mathrm{E}+00$ & $-2.800 \mathrm{E}+00$ & $-5.139 E+00$ & $-7.600 \mathrm{E}+00$ \\
\hline 54 & $-9.461 \mathrm{E}-01$ & $-1.070 \mathrm{E}+00$ & $-1.589 E+00$ & $-2.780 \mathrm{E}+00$ & $-5.088 \mathrm{E}+00$ & $-7.522 \mathrm{E}+00$ \\
\hline 55 & $-8.475 \mathrm{E}-01$ & $-1.078 \mathrm{E}+00$ & $-1.588 \mathrm{E}+00$ & $-2.769 \mathrm{E}+00$ & $-5.045 E+00$ & $-7.449 E+00$ \\
\hline 56 & $-5.911 \mathrm{E}-01$ & $-1.078 \mathrm{E}+00$ & $-1.599 \mathrm{E}+00$ & $-2.776 \mathrm{E}+00$ & $-5.019 E+00$ & $-7.389 E+00$ \\
\hline 57 & $2.002 \mathrm{E}-01$ & $-9.443 \mathrm{E}-01$ & $-1.627 \mathrm{E}+00$ & $-2.815 \mathrm{E}+00$ & $-5.038 \mathrm{E}+00$ & $-7.369 \mathrm{E}+00$ \\
\hline 58 & $7.589 \mathrm{E}+00$ & $3.879 \mathrm{E}+00$ & $2.457 \mathrm{E}-01$ & $-2.501 \mathrm{E}+00$ & $-5.226 \mathrm{E}+00$ & $-7.671 \mathrm{E}+00$ \\
\hline
\end{tabular}


Table C-20: Average heat flux ( $\mathrm{q}_{\mathrm{i}, \mathrm{avg}}$ ) data for the individual blind louver, $\phi=90^{\circ}$, $\mathrm{T}_{\mathrm{b}}{ }^{*}=0.4, \mathrm{~d} / \mathrm{L}=0.012$

\begin{tabular}{|c|c|c|c|c|c|c|}
\hline $\begin{array}{c}\text { Louver } \\
\text { number (i) }\end{array}$ & & & & $\mathbf{R}_{\mathbf{a}_{\mathbf{L}}}$ & & \\
\hline & $1.00 \mathrm{E}+04$ & $1.00 \mathrm{E}+05$ & $1.00 \mathrm{E}+06$ & $1.00 \mathrm{E}+07$ & $1.00 \mathrm{E}+08$ & $5.00 \mathrm{E}+08$ \\
\hline 1 & $6.593 \mathrm{E}+01$ & $6.515 \mathrm{E}+01$ & $6.381 E+01$ & $6.062 \mathrm{E}+01$ & $3.549 \mathrm{E}+01$ & $-1.130 \mathrm{E}+00$ \\
\hline 2 & $6.680 \mathrm{E}+01$ & $6.680 \mathrm{E}+01$ & $6.680 \mathrm{E}+01$ & $6.680 \mathrm{E}+01$ & $6.675 \mathrm{E}+01$ & $7.439 E+01$ \\
\hline 3 & $6.680 \mathrm{E}+01$ & $6.680 \mathrm{E}+01$ & $6.680 \mathrm{E}+01$ & $6.680 \mathrm{E}+01$ & $6.680 \mathrm{E}+01$ & $8.594 \mathrm{E}+01$ \\
\hline 4 & $6.680 \mathrm{E}+01$ & $6.680 \mathrm{E}+01$ & $6.680 \mathrm{E}+01$ & $6.680 \mathrm{E}+01$ & $6.680 \mathrm{E}+01$ & $8.764 \mathrm{E}+01$ \\
\hline 5 & $6.680 \mathrm{E}+01$ & $6.680 \mathrm{E}+01$ & $6.680 \mathrm{E}+01$ & $6.680 \mathrm{E}+01$ & $6.680 \mathrm{E}+01$ & $8.790 \mathrm{E}+01$ \\
\hline 6 & $6.680 \mathrm{E}+01$ & $6.680 \mathrm{E}+01$ & $6.680 \mathrm{E}+01$ & $6.680 \mathrm{E}+01$ & $6.680 \mathrm{E}+01$ & $8.793 E+01$ \\
\hline 7 & $6.680 \mathrm{E}+01$ & $6.680 \mathrm{E}+01$ & $6.680 \mathrm{E}+01$ & $6.680 \mathrm{E}+01$ & $6.680 \mathrm{E}+01$ & $8.794 \mathrm{E}+01$ \\
\hline 8 & $6.680 \mathrm{E}+01$ & $6.680 \mathrm{E}+01$ & $6.680 \mathrm{E}+01$ & $6.680 \mathrm{E}+01$ & $6.680 \mathrm{E}+01$ & $8.794 \mathrm{E}+01$ \\
\hline 9 & $6.680 \mathrm{E}+01$ & $6.680 \mathrm{E}+01$ & $6.680 \mathrm{E}+01$ & $6.680 \mathrm{E}+01$ & $6.680 \mathrm{E}+01$ & $8.794 \mathrm{E}+01$ \\
\hline 10 & $6.680 \mathrm{E}+01$ & $6.680 \mathrm{E}+01$ & $6.680 \mathrm{E}+01$ & $6.680 \mathrm{E}+01$ & $6.680 \mathrm{E}+01$ & $8.794 \mathrm{E}+01$ \\
\hline 11 & $6.680 \mathrm{E}+01$ & $6.680 \mathrm{E}+01$ & $6.680 \mathrm{E}+01$ & $6.680 \mathrm{E}+01$ & $6.680 \mathrm{E}+01$ & $8.794 \mathrm{E}+01$ \\
\hline 12 & $6.680 E+01$ & $6.680 \mathrm{E}+01$ & $6.680 \mathrm{E}+01$ & $6.680 \mathrm{E}+01$ & $6.680 \mathrm{E}+01$ & $8.794 E+01$ \\
\hline 13 & $6.680 \mathrm{E}+01$ & $6.680 \mathrm{E}+01$ & $6.680 \mathrm{E}+01$ & $6.680 \mathrm{E}+01$ & $6.680 \mathrm{E}+01$ & $8.794 \mathrm{E}+01$ \\
\hline 14 & $6.680 \mathrm{E}+01$ & $6.680 \mathrm{E}+01$ & $6.680 \mathrm{E}+01$ & $6.680 \mathrm{E}+01$ & $6.680 \mathrm{E}+01$ & $8.794 E+01$ \\
\hline 15 & $6.680 \mathrm{E}+01$ & $6.680 \mathrm{E}+01$ & $6.680 \mathrm{E}+01$ & $6.680 \mathrm{E}+01$ & $6.680 \mathrm{E}+01$ & $8.794 \mathrm{E}+01$ \\
\hline 16 & $6.680 \mathrm{E}+01$ & $6.680 \mathrm{E}+01$ & $6.680 \mathrm{E}+01$ & $6.680 \mathrm{E}+01$ & $6.680 \mathrm{E}+01$ & $8.794 \mathrm{E}+01$ \\
\hline 17 & $6.680 \mathrm{E}+01$ & $6.680 \mathrm{E}+01$ & $6.680 \mathrm{E}+01$ & $6.680 \mathrm{E}+01$ & $6.680 \mathrm{E}+01$ & $8.794 \mathrm{E}+01$ \\
\hline 18 & $6.680 \mathrm{E}+01$ & $6.680 \mathrm{E}+01$ & $6.680 \mathrm{E}+01$ & $6.680 \mathrm{E}+01$ & $6.680 \mathrm{E}+01$ & $8.794 \mathrm{E}+01$ \\
\hline 19 & $6.680 \mathrm{E}+01$ & $6.680 \mathrm{E}+01$ & $6.680 \mathrm{E}+01$ & $6.680 \mathrm{E}+01$ & $6.680 \mathrm{E}+01$ & $8.794 \mathrm{E}+01$ \\
\hline 20 & $6.680 \mathrm{E}+01$ & $6.680 \mathrm{E}+01$ & $6.680 \mathrm{E}+01$ & $6.680 \mathrm{E}+01$ & $6.680 \mathrm{E}+01$ & $8.794 E+01$ \\
\hline 21 & $6.680 \mathrm{E}+01$ & $6.680 \mathrm{E}+01$ & $6.680 \mathrm{E}+01$ & $6.680 \mathrm{E}+01$ & $6.680 \mathrm{E}+01$ & $8.794 \mathrm{E}+01$ \\
\hline 22 & $6.680 \mathrm{E}+01$ & $6.680 \mathrm{E}+01$ & $6.680 \mathrm{E}+01$ & $6.680 \mathrm{E}+01$ & $6.680 \mathrm{E}+01$ & $8.794 \mathrm{E}+01$ \\
\hline 23 & $6.680 \mathrm{E}+01$ & $6.680 \mathrm{E}+01$ & $6.680 \mathrm{E}+01$ & $6.680 \mathrm{E}+01$ & $6.680 \mathrm{E}+01$ & $8.794 E+01$ \\
\hline 24 & $6.680 \mathrm{E}+01$ & $6.680 \mathrm{E}+01$ & $6.680 \mathrm{E}+01$ & $6.680 \mathrm{E}+01$ & $6.680 \mathrm{E}+01$ & $8.794 \mathrm{E}+01$ \\
\hline 25 & $6.680 \mathrm{E}+01$ & $6.680 \mathrm{E}+01$ & $6.680 \mathrm{E}+01$ & $6.680 \mathrm{E}+01$ & $6.680 \mathrm{E}+01$ & $8.794 E+01$ \\
\hline 26 & $6.680 \mathrm{E}+01$ & $6.680 \mathrm{E}+01$ & $6.680 \mathrm{E}+01$ & $6.680 \mathrm{E}+01$ & $6.680 \mathrm{E}+01$ & $8.794 \mathrm{E}+01$ \\
\hline 27 & $6.680 \mathrm{E}+01$ & $6.680 \mathrm{E}+01$ & $6.680 \mathrm{E}+01$ & $6.680 \mathrm{E}+01$ & $6.680 \mathrm{E}+01$ & $8.794 \mathrm{E}+01$ \\
\hline 28 & $6.695 \mathrm{E}+01$ & $6.695 \mathrm{E}+01$ & $6.695 \mathrm{E}+01$ & $6.694 \mathrm{E}+01$ & $6.693 \mathrm{E}+01$ & $8.808 \mathrm{E}+01$ \\
\hline 29 & $7.122 \mathrm{E}+01$ & $7.070 \mathrm{E}+01$ & $6.979 \mathrm{E}+01$ & $6.909 \mathrm{E}+01$ & $6.952 \mathrm{E}+01$ & $9.037 \mathrm{E}+01$ \\
\hline 30 & $-2.788 \mathrm{E}+00$ & $-5.237 \mathrm{E}+00$ & $-9.726 \mathrm{E}+00$ & $-1.774 \mathrm{E}+01$ & $-3.738 E+01$ & $-2.524 \mathrm{E}+01$ \\
\hline 31 & $-2.703 \mathrm{E}+00$ & $-4.163 E+00$ & $-7.241 \mathrm{E}+00$ & $-1.286 \mathrm{E}+01$ & $-2.425 \mathrm{E}+01$ & $-1.583 \mathrm{E}+01$ \\
\hline 32 & $-2.427 \mathrm{E}+00$ & $-3.653 \mathrm{E}+00$ & $-6.438 \mathrm{E}+00$ & $-1.148 \mathrm{E}+01$ & $-2.120 \mathrm{E}+01$ & $-1.378 \mathrm{E}+01$ \\
\hline 33 & $-2.280 \mathrm{E}+00$ & $-3.368 \mathrm{E}+00$ & $-5.973 E+00$ & $-1.062 \mathrm{E}+01$ & $-1.947 \mathrm{E}+01$ & $-1.264 \mathrm{E}+01$ \\
\hline 34 & $-2.194 \mathrm{E}+00$ & $-3.181 \mathrm{E}+00$ & $-5.650 \mathrm{E}+00$ & $-1.002 E+01$ & $-1.830 \mathrm{E}+01$ & $-1.186 \mathrm{E}+01$ \\
\hline 35 & $-2.141 E+00$ & $-3.047 \mathrm{E}+00$ & $-5.404 \mathrm{E}+00$ & $-9.558 \mathrm{E}+00$ & $-1.742 \mathrm{E}+01$ & $-1.129 \mathrm{E}+01$ \\
\hline 36 & $-2.106 E+00$ & $-2.943 E+00$ & $-5.207 \mathrm{E}+00$ & $-9.191 \mathrm{E}+00$ & $-1.673 E+01$ & $-1.083 E+01$ \\
\hline 37 & $-2.083 \mathrm{E}+00$ & $-2.859 \mathrm{E}+00$ & $-5.042 E+00$ & $-8.889 \mathrm{E}+00$ & $-1.615 \mathrm{E}+01$ & $-1.046 \mathrm{E}+01$ \\
\hline 38 & $-2.067 E+00$ & $-2.788 \mathrm{E}+00$ & $-4.901 E+00$ & $-8.633 E+00$ & $-1.566 \mathrm{E}+01$ & $-1.014 \mathrm{E}+01$ \\
\hline 39 & $-2.055 \mathrm{E}+00$ & $-2.728 \mathrm{E}+00$ & $-4.778 \mathrm{E}+00$ & $-8.412 \mathrm{E}+00$ & $-1.524 \mathrm{E}+01$ & $-9.865 E+00$ \\
\hline 40 & $-2.046 \mathrm{E}+00$ & $-2.675 E+00$ & $-4.670 \mathrm{E}+00$ & $-8.218 E+00$ & $-1.487 \mathrm{E}+01$ & $-9.627 \mathrm{E}+00$ \\
\hline 41 & $-2.039 \mathrm{E}+00$ & $-2.628 \mathrm{E}+00$ & $-4.572 \mathrm{E}+00$ & $-8.045 E+00$ & $-1.454 \mathrm{E}+01$ & $-9.415 \mathrm{E}+00$ \\
\hline 42 & $-2.034 \mathrm{E}+00$ & $-2.586 \mathrm{E}+00$ & $-4.485 E+00$ & $-7.889 E+00$ & $-1.424 \mathrm{E}+01$ & $-9.226 \mathrm{E}+00$ \\
\hline 43 & $-2.030 \mathrm{E}+00$ & $-2.549 \mathrm{E}+00$ & $-4.405 \mathrm{E}+00$ & $-7.748 \mathrm{E}+00$ & $-1.397 \mathrm{E}+01$ & $-9.055 \mathrm{E}+00$ \\
\hline
\end{tabular}




\begin{tabular}{lllllll}
44 & $-2.027 \mathrm{E}+00$ & $-2.515 \mathrm{E}+00$ & $-4.332 \mathrm{E}+00$ & $-7.619 \mathrm{E}+00$ & $-1.373 \mathrm{E}+01$ & $-8.899 \mathrm{E}+00$ \\
45 & $-2.024 \mathrm{E}+00$ & $-2.484 \mathrm{E}+00$ & $-4.265 \mathrm{E}+00$ & $-7.500 \mathrm{E}+00$ & $-1.350 \mathrm{E}+01$ & $-8.756 \mathrm{E}+00$ \\
46 & $-2.022 \mathrm{E}+00$ & $-2.456 \mathrm{E}+00$ & $-4.204 \mathrm{E}+00$ & $-7.390 \mathrm{E}+00$ & $-1.329 \mathrm{E}+01$ & $-8.625 \mathrm{E}+00$ \\
47 & $-2.021 \mathrm{E}+00$ & $-2.431 \mathrm{E}+00$ & $-4.146 \mathrm{E}+00$ & $-7.287 \mathrm{E}+00$ & $-1.310 \mathrm{E}+01$ & $-8.503 \mathrm{E}+00$ \\
48 & $-2.021 \mathrm{E}+00$ & $-2.408 \mathrm{E}+00$ & $-4.093 \mathrm{E}+00$ & $-7.191 \mathrm{E}+00$ & $-1.292 \mathrm{E}+01$ & $-8.390 \mathrm{E}+00$ \\
49 & $-2.021 \mathrm{E}+00$ & $-2.387 \mathrm{E}+00$ & $-4.043 \mathrm{E}+00$ & $-7.102 \mathrm{E}+00$ & $-1.275 \mathrm{E}+01$ & $-8.284 \mathrm{E}+00$ \\
50 & $-2.022 \mathrm{E}+00$ & $-2.368 \mathrm{E}+00$ & $-3.997 \mathrm{E}+00$ & $-7.018 \mathrm{E}+00$ & $-1.260 \mathrm{E}+01$ & $-8.185 \mathrm{E}+00$ \\
51 & $-2.024 \mathrm{E}+00$ & $-2.351 \mathrm{E}+00$ & $-3.954 \mathrm{E}+00$ & $-6.939 \mathrm{E}+00$ & $-1.245 \mathrm{E}+01$ & $-8.092 \mathrm{E}+00$ \\
52 & $-2.026 \mathrm{E}+00$ & $-2.337 \mathrm{E}+00$ & $-3.916 \mathrm{E}+00$ & $-6.865 \mathrm{E}+00$ & $-1.231 \mathrm{E}+01$ & $-8.004 \mathrm{E}+00$ \\
53 & $-2.025 \mathrm{E}+00$ & $-2.327 \mathrm{E}+00$ & $-3.883 \mathrm{E}+00$ & $-6.798 \mathrm{E}+00$ & $-1.218 \mathrm{E}+01$ & $-7.921 \mathrm{E}+00$ \\
54 & $-2.014 \mathrm{E}+00$ & $-2.321 \mathrm{E}+00$ & $-3.856 \mathrm{E}+00$ & $-6.739 \mathrm{E}+00$ & $-1.205 \mathrm{E}+01$ & $-7.843 \mathrm{E}+00$ \\
55 & $-1.972 \mathrm{E}+00$ & $-2.323 \mathrm{E}+00$ & $-3.841 \mathrm{E}+00$ & $-6.695 \mathrm{E}+00$ & $-1.194 \mathrm{E}+01$ & $-7.770 \mathrm{E}+00$ \\
56 & $-1.831 \mathrm{E}+00$ & $-2.334 \mathrm{E}+00$ & $-3.843 \mathrm{E}+00$ & $-6.680 \mathrm{E}+00$ & $-1.186 \mathrm{E}+01$ & $-7.708 \mathrm{E}+00$ \\
57 & $-1.323 \mathrm{E}+00$ & $-2.314 \mathrm{E}+00$ & $-3.872 \mathrm{E}+00$ & $-6.722 \mathrm{E}+00$ & $-1.186 \mathrm{E}+01$ & $-7.681 \mathrm{E}+00$ \\
58 & $3.927 \mathrm{E}+00$ & $5.959 \mathrm{E}-01$ & $-3.055 \mathrm{E}+00$ & $-6.861 \mathrm{E}+00$ & $-1.233 \mathrm{E}+01$ & $-7.873 \mathrm{E}+00$ \\
\hline
\end{tabular}

Table C-21: Average heat flux ( $\left.\mathrm{q}_{\mathrm{i}, \mathrm{avg}}\right)$ data for the individual blind louver, $\phi=90^{\circ}$, $\mathrm{T}_{\mathrm{b}}{ }^{*}=0.5, \mathrm{~d} / \mathrm{L}=0.012$

\begin{tabular}{|c|c|c|c|c|c|c|}
\hline $\begin{array}{c}\text { Louver } \\
\text { number (i) }\end{array}$ & & & & $\mathbf{R a}_{\mathbf{l}}$ & & \\
\hline & $1.00 \mathrm{E}+04$ & $1.00 \mathrm{E}+05$ & $1.00 \mathrm{E}+06$ & $1.00 \mathrm{E}+07$ & $1.00 \mathrm{E}+08$ & $5.00 \mathrm{E}+08$ \\
\hline 1 & $8.929 \mathrm{E}+01$ & $8.899 \mathrm{E}+01$ & $8.825 \mathrm{E}+01$ & $7.977 \mathrm{E}+01$ & $7.130 \mathrm{E}+01$ & 2.019E-01 \\
\hline 2 & $8.907 \mathrm{E}+01$ & $8.907 \mathrm{E}+01$ & $8.907 \mathrm{E}+01$ & $8.906 \mathrm{E}+01$ & $8.906 \mathrm{E}+01$ & $7.587 \mathrm{E}+01$ \\
\hline 3 & $8.907 \mathrm{E}+01$ & $8.907 \mathrm{E}+01$ & $8.907 \mathrm{E}+01$ & $8.907 E+01$ & $8.907 \mathrm{E}+01$ & $8.720 \mathrm{E}+01$ \\
\hline 4 & $8.907 \mathrm{E}+01$ & $8.907 \mathrm{E}+01$ & $8.907 \mathrm{E}+01$ & $8.907 \mathrm{E}+01$ & $8.907 \mathrm{E}+01$ & $8.885 E+01$ \\
\hline 5 & $8.907 \mathrm{E}+01$ & $8.907 \mathrm{E}+01$ & $8.907 \mathrm{E}+01$ & $8.907 \mathrm{E}+01$ & $8.907 \mathrm{E}+01$ & $8.909 E+01$ \\
\hline 6 & $8.907 \mathrm{E}+01$ & $8.907 \mathrm{E}+01$ & $8.907 \mathrm{E}+01$ & $8.907 E+01$ & $8.907 \mathrm{E}+01$ & $8.912 \mathrm{E}+01$ \\
\hline 7 & $8.907 \mathrm{E}+01$ & $8.907 \mathrm{E}+01$ & $8.907 \mathrm{E}+01$ & $8.907 \mathrm{E}+01$ & $8.907 \mathrm{E}+01$ & $8.912 \mathrm{E}+01$ \\
\hline 8 & $8.907 \mathrm{E}+01$ & $8.907 \mathrm{E}+01$ & $8.907 \mathrm{E}+01$ & $8.907 \mathrm{E}+01$ & $8.907 \mathrm{E}+01$ & $8.913 \mathrm{E}+01$ \\
\hline 9 & $8.907 \mathrm{E}+01$ & $8.907 \mathrm{E}+01$ & $8.907 \mathrm{E}+01$ & $8.907 \mathrm{E}+01$ & $8.907 \mathrm{E}+01$ & $8.913 E+01$ \\
\hline 10 & $8.907 \mathrm{E}+01$ & $8.907 \mathrm{E}+01$ & $8.907 E+01$ & $8.907 \mathrm{E}+01$ & $8.907 \mathrm{E}+01$ & $8.913 E+01$ \\
\hline 11 & $8.907 E+01$ & $8.907 E+01$ & $8.907 \mathrm{E}+01$ & $8.907 \mathrm{E}+01$ & $8.907 E+01$ & $8.913 E+01$ \\
\hline 12 & $8.907 \mathrm{E}+01$ & $8.907 \mathrm{E}+01$ & $8.907 \mathrm{E}+01$ & $8.907 \mathrm{E}+01$ & $8.907 E+01$ & $8.913 E+01$ \\
\hline 13 & $8.907 \mathrm{E}+01$ & $8.907 \mathrm{E}+01$ & $8.907 \mathrm{E}+01$ & $8.907 \mathrm{E}+01$ & $8.907 E+01$ & $8.913 \mathrm{E}+01$ \\
\hline 14 & $8.907 \mathrm{E}+01$ & $8.907 \mathrm{E}+01$ & $8.907 E+01$ & $8.907 \mathrm{E}+01$ & $8.907 \mathrm{E}+01$ & $8.913 E+01$ \\
\hline 15 & $8.907 \mathrm{E}+01$ & $8.907 \mathrm{E}+01$ & $8.907 \mathrm{E}+01$ & $8.907 \mathrm{E}+01$ & $8.907 \mathrm{E}+01$ & $8.913 E+01$ \\
\hline 16 & $8.907 \mathrm{E}+01$ & $8.907 E+01$ & $8.907 E+01$ & $8.907 \mathrm{E}+01$ & $8.907 \mathrm{E}+01$ & $8.913 E+01$ \\
\hline 17 & $8.907 \mathrm{E}+01$ & $8.907 \mathrm{E}+01$ & $8.907 \mathrm{E}+01$ & $8.907 \mathrm{E}+01$ & $8.907 \mathrm{E}+01$ & $8.913 E+01$ \\
\hline 18 & $8.907 E+01$ & $8.907 E+01$ & $8.907 \mathrm{E}+01$ & $8.907 \mathrm{E}+01$ & $8.907 E+01$ & $8.913 E+01$ \\
\hline 19 & $8.907 \mathrm{E}+01$ & $8.907 \mathrm{E}+01$ & $8.907 E+01$ & $8.907 \mathrm{E}+01$ & $8.907 \mathrm{E}+01$ & $8.913 \mathrm{E}+01$ \\
\hline 20 & $8.907 \mathrm{E}+01$ & $8.907 \mathrm{E}+01$ & $8.907 \mathrm{E}+01$ & $8.907 \mathrm{E}+01$ & $8.907 \mathrm{E}+01$ & $8.913 E+01$ \\
\hline 21 & $8.907 \mathrm{E}+01$ & $8.907 E+01$ & $8.907 E+01$ & $8.907 \mathrm{E}+01$ & $8.907 \mathrm{E}+01$ & $8.913 E+01$ \\
\hline 22 & $8.907 \mathrm{E}+01$ & $8.907 E+01$ & $8.907 E+01$ & $8.907 \mathrm{E}+01$ & $8.907 \mathrm{E}+01$ & $8.913 E+01$ \\
\hline 23 & $8.907 \mathrm{E}+01$ & $8.907 \mathrm{E}+01$ & $8.907 E+01$ & $8.907 \mathrm{E}+01$ & $8.907 \mathrm{E}+01$ & $8.913 E+01$ \\
\hline 24 & $8.907 \mathrm{E}+01$ & $8.907 \mathrm{E}+01$ & $8.907 E+01$ & $8.907 \mathrm{E}+01$ & $8.907 \mathrm{E}+01$ & $8.913 \mathrm{E}+01$ \\
\hline 25 & $8.907 \mathrm{E}+01$ & $8.907 E+01$ & $8.907 E+01$ & $8.907 \mathrm{E}+01$ & $8.907 \mathrm{E}+01$ & $8.913 E+01$ \\
\hline
\end{tabular}




\begin{tabular}{|c|c|c|c|c|c|c|}
\hline 26 & $8.907 \mathrm{E}+01$ & $8.907 \mathrm{E}+01$ & $8.907 \mathrm{E}+01$ & $8.907 E+01$ & $8.907 \mathrm{E}+01$ & $8.913 E+01$ \\
\hline 27 & $8.907 \mathrm{E}+01$ & $8.907 \mathrm{E}+01$ & $8.907 \mathrm{E}+01$ & $8.907 \mathrm{E}+01$ & $8.907 \mathrm{E}+01$ & $8.913 E+01$ \\
\hline 28 & $8.926 \mathrm{E}+01$ & $8.926 \mathrm{E}+01$ & $8.926 \mathrm{E}+01$ & $8.925 \mathrm{E}+01$ & $8.924 \mathrm{E}+01$ & $8.927 \mathrm{E}+01$ \\
\hline 29 & $9.516 \mathrm{E}+01$ & $9.469 \mathrm{E}+01$ & $9.356 \mathrm{E}+01$ & $9.296 \mathrm{E}+01$ & $9.236 \mathrm{E}+01$ & $9.137 \mathrm{E}+01$ \\
\hline 30 & $6.980 \mathrm{E}-01$ & $-7.984 \mathrm{E}-02$ & $-2.106 \mathrm{E}+00$ & $-8.674 \mathrm{E}+00$ & $-1.524 \mathrm{E}+01$ & $-2.524 \mathrm{E}+01$ \\
\hline 31 & $-1.047 \mathrm{E}+00$ & $-1.441 \mathrm{E}+00$ & $-2.711 \mathrm{E}+00$ & $-6.309 E+00$ & $-9.907 E+00$ & $-1.543 \mathrm{E}+01$ \\
\hline 32 & $-1.063 E+00$ & $-1.365 \mathrm{E}+00$ & $-2.494 \mathrm{E}+00$ & $-5.568 \mathrm{E}+00$ & $-8.642 E+00$ & $-1.344 \mathrm{E}+01$ \\
\hline 33 & $-1.047 \mathrm{E}+00$ & $-1.296 \mathrm{E}+00$ & $-2.347 \mathrm{E}+00$ & $-5.135 E+00$ & $-7.924 \mathrm{E}+00$ & $-1.232 \mathrm{E}+01$ \\
\hline 34 & $-1.034 \mathrm{E}+00$ & $-1.244 \mathrm{E}+00$ & $-2.240 \mathrm{E}+00$ & $-4.840 \mathrm{E}+00$ & $-7.440 \mathrm{E}+00$ & $-1.155 \mathrm{E}+01$ \\
\hline 35 & $-1.025 \mathrm{E}+00$ & $-1.206 \mathrm{E}+00$ & $-2.157 \mathrm{E}+00$ & $-4.620 \mathrm{E}+00$ & $-7.083 E+00$ & $-1.098 \mathrm{E}+01$ \\
\hline 36 & $-1.019 E+00$ & $-1.176 \mathrm{E}+00$ & $-2.089 \mathrm{E}+00$ & $-4.445 \mathrm{E}+00$ & $-6.801 E+00$ & $-1.052 E+01$ \\
\hline 37 & $-1.016 \mathrm{E}+00$ & $-1.152 E+00$ & $-2.031 \mathrm{E}+00$ & $-4.301 E+00$ & $-6.570 \mathrm{E}+00$ & $-1.014 \mathrm{E}+01$ \\
\hline 38 & $-1.013 E+00$ & $-1.133 \mathrm{E}+00$ & $-1.980 \mathrm{E}+00$ & $-4.177 \mathrm{E}+00$ & $-6.375 E+00$ & $-9.827 \mathrm{E}+00$ \\
\hline 39 & $-1.012 \mathrm{E}+00$ & $-1.116 \mathrm{E}+00$ & $-1.936 \mathrm{E}+00$ & $-4.071 \mathrm{E}+00$ & $-6.205 E+00$ & $-9.552 \mathrm{E}+00$ \\
\hline 40 & $-1.011 \mathrm{E}+00$ & $-1.102 E+00$ & $-1.895 \mathrm{E}+00$ & $-3.976 \mathrm{E}+00$ & $-6.057 \mathrm{E}+00$ & $-9.312 E+00$ \\
\hline 41 & $-1.010 \mathrm{E}+00$ & $-1.090 \mathrm{E}+00$ & $-1.859 \mathrm{E}+00$ & $-3.892 \mathrm{E}+00$ & $-5.925 \mathrm{E}+00$ & $-9.099 E+00$ \\
\hline 42 & $-1.009 \mathrm{E}+00$ & $-1.079 E+00$ & $-1.825 \mathrm{E}+00$ & $-3.816 \mathrm{E}+00$ & $-5.806 \mathrm{E}+00$ & $-8.909 E+00$ \\
\hline 43 & $-1.009 E+00$ & $-1.070 \mathrm{E}+00$ & $-1.795 E+00$ & $-3.746 \mathrm{E}+00$ & $-5.698 \mathrm{E}+00$ & $-8.737 E+00$ \\
\hline 44 & $-1.009 E+00$ & $-1.062 E+00$ & $-1.767 \mathrm{E}+00$ & $-3.683 E+00$ & $-5.599 \mathrm{E}+00$ & $-8.581 E+00$ \\
\hline 45 & $-1.009 \mathrm{E}+00$ & $-1.054 \mathrm{E}+00$ & $-1.741 \mathrm{E}+00$ & $-3.625 \mathrm{E}+00$ & $-5.509 \mathrm{E}+00$ & $-8.438 E+00$ \\
\hline 46 & $-1.009 \mathrm{E}+00$ & $-1.048 \mathrm{E}+00$ & $-1.716 \mathrm{E}+00$ & $-3.571 \mathrm{E}+00$ & $-5.425 \mathrm{E}+00$ & $-8.306 \mathrm{E}+00$ \\
\hline 47 & $-1.009 \mathrm{E}+00$ & $-1.042 \mathrm{E}+00$ & $-1.694 \mathrm{E}+00$ & $-3.521 E+00$ & $-5.348 \mathrm{E}+00$ & $-8.184 \mathrm{E}+00$ \\
\hline 48 & $-1.009 \mathrm{E}+00$ & $-1.037 \mathrm{E}+00$ & $-1.673 \mathrm{E}+00$ & $-3.474 E+00$ & $-5.275 \mathrm{E}+00$ & $-8.071 \mathrm{E}+00$ \\
\hline 49 & $-1.009 \mathrm{E}+00$ & $-1.033 \mathrm{E}+00$ & $-1.654 \mathrm{E}+00$ & $-3.431 E+00$ & $-5.207 \mathrm{E}+00$ & $-7.965 E+00$ \\
\hline 50 & $-1.009 \mathrm{E}+00$ & $-1.029 \mathrm{E}+00$ & $-1.636 \mathrm{E}+00$ & $-3.390 \mathrm{E}+00$ & $-5.144 \mathrm{E}+00$ & $-7.866 \mathrm{E}+00$ \\
\hline 51 & $-1.008 \mathrm{E}+00$ & $-1.027 \mathrm{E}+00$ & $-1.620 \mathrm{E}+00$ & $-3.352 \mathrm{E}+00$ & $-5.084 \mathrm{E}+00$ & $-7.772 E+00$ \\
\hline 52 & $-1.002 \mathrm{E}+00$ & $-1.027 \mathrm{E}+00$ & $-1.606 \mathrm{E}+00$ & $-3.316 \mathrm{E}+00$ & $-5.027 \mathrm{E}+00$ & $-7.684 \mathrm{E}+00$ \\
\hline 53 & $-9.861 \mathrm{E}-01$ & $-1.030 \mathrm{E}+00$ & $-1.595 \mathrm{E}+00$ & $-3.284 \mathrm{E}+00$ & $-4.974 \mathrm{E}+00$ & $-7.601 E+00$ \\
\hline 54 & $-9.461 \mathrm{E}-01$ & $-1.037 \mathrm{E}+00$ & $-1.588 \mathrm{E}+00$ & $-3.257 \mathrm{E}+00$ & $-4.926 \mathrm{E}+00$ & $-7.523 E+00$ \\
\hline 55 & $-8.475 \mathrm{E}-01$ & $-1.044 \mathrm{E}+00$ & $-1.587 \mathrm{E}+00$ & $-3.237 \mathrm{E}+00$ & $-4.887 \mathrm{E}+00$ & $-7.450 \mathrm{E}+00$ \\
\hline 56 & $-5.911 \mathrm{E}-01$ & $-1.030 \mathrm{E}+00$ & $-1.599 \mathrm{E}+00$ & $-3.233 \mathrm{E}+00$ & $-4.867 \mathrm{E}+00$ & $-7.389 E+00$ \\
\hline 57 & $2.002 \mathrm{E}-01$ & $-8.273 \mathrm{E}-01$ & $-1.628 \mathrm{E}+00$ & $-3.261 \mathrm{E}+00$ & $-4.895 \mathrm{E}+00$ & $-7.369 \mathrm{E}+00$ \\
\hline 58 & $7.589 \mathrm{E}+00$ & $4.396 \mathrm{E}+00$ & $2.371 \mathrm{E}-01$ & $-2.422 \mathrm{E}+00$ & $-5.081 \mathrm{E}+00$ & $-7.670 \mathrm{E}+00$ \\
\hline
\end{tabular}




\section{APPENDIX-D: C-PROGRAM FOR A DOUBLE GLAZED WINDOW WITH A BLIND}

\#include<stdio.h $>$

\#include $<$ math.h $>$

\#define PI 3.14159265

\#define sigma 5.67e-8

\#define 129

\#define $\mathrm{n} 200$

$1 * j=$ no of box+1*/

\#define $\mathrm{m} 20 \quad / * \mathrm{~m}=$ no of surf in box starting CCW lower slat_surf=always EVEN\& $>=2 * 1$

I*NOTE: DO NOT EXCEED TOTAL SURFACE 899, window MAX=300,BLIND MAX=580,ambient=1 *

double window_2glazing(double velocity,double Tli,double To,double Tamb,double Tb, double Angle);

/*Solves the double glazed window heat flows*/

double window_Convection(double Tb,double Tambi,double TW, double Angle); $\quad{ }^{\star *}$ Calculates inside window convection

double gap_Convection(double TB,double Tamb);

/*Calculates window gap convection coeffcient*/

void main(void)

double

wly[301],wuy[301],box LX[30],box_LY[30],box_UX[30],box_UY[30],box_LXR[30],box_LYR[30],box_UXR[30],box UYR[30],b_LX[30][21],b_UX[30][21],

b_LY[30][21],b_UY[30][21];

double d,w,pitch,angle,length,step_w,step_box,step_bw,cross 1,cross2,uncross 1,uncross2,test 1,test2,test3,test4,ch I,ch2;

double F[900][900],A[900],q[900],em[900],J[900],T[900],sum[900],suml[900];

double Tw,T_blind,Tamb,ew,eb,q_balance,qw_rad,qb_rad,q_amb,relax,Told,TBi,Error;

double velocity, $\mathrm{T}_{-}$outside, $\mathrm{hB}, \mathrm{q}$ _total, $\mathrm{h}$ _inside, $\mathrm{q}$ _rad_glazing,U_value,Errorl,Angle;

int $i, j, k, c o u n t e r, c o u n t e r 2 ;$

int tes1,tes2,tes3,tes 4 ,bh1,bh2,temp;

FILE "fp=fopen("viewface.txt","w")

FILE *fip=fopen("Heat_Transfer.txt","w"); $/ *$ Write heat flows in this file*/

for $(e b=0.1 ; e b<=0.1 ; e b=e b+0.1)\{$

J

for (Angle $=00.0 ;$ Angle $c=90.0 ;$ Angle $=$ angle +10$)\{/$ Blind Slat Angle CCW*

/

$d=0 ; \quad \quad / *$ Use for Convection only $* /$

velocity $=3.35$

T_outside $=305.15$

Tamb $=297.15 ; \quad 1 *$ Indoor temperature*/

$\mathrm{Tw}=299.9 ; \quad / *$ Initial guess for window indoor glazing temperature */

Error1=10;

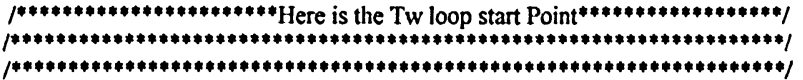

for $($ counter $2=1 ;$ counter $2<=1$ es; counter $2++)($

if(Error1 $>-10)\{\mathrm{Tw}-\mathrm{T} w+0.3 ;\} \quad 1 *$ To speed up convergence* $/$

if $($ Error $1>-3 \& \&$ Errorl $<=10)\{\mathrm{Tw}=\mathrm{Tw}+0.1 ;\}$

if Errorl $>=1)\{\mathrm{Tw}=\mathrm{T} w+0.05$;

if(Error $1<=1 \& \&$ Error $1>=0.1)\{\mathrm{Tw}=\mathrm{Tw}+0.002$; $\}$

if Error $1<0.1)\{\mathrm{Tw}=\mathrm{Tw}+0.0005 ;\}$

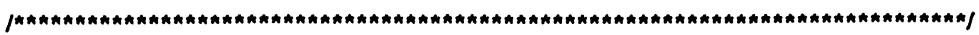

J

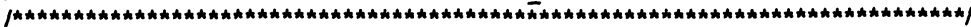

$T$ blind $=0.2 *(T w-T a m b)+T a m b ; \quad \quad I^{*}$ Initial guess for the blind temperature*/

$\mathrm{ew}=0.84 ; \quad / *$ Window Emissivity*/

$d=0 ; \quad \quad / *$ Blind Tip-Window Spacing*/

$w=25.0 \mathrm{e}-3 ; \quad / *$ Blind Slat width $*$ I

pitch=7.0/8.0; $\quad / *$ Blind Pitch $* /$

length $=0.635 ; \quad \quad \quad / *$ Window Height $* I$

angle $=$ Angle; 
angle $=$ angle*PI/180.0; $\quad 1 *$ Conversion from degree to radians $* /$

step box=pitch $*$; $\quad$ /*To Read blind cavity coordinates $* /$

step_w $=$ length $/ \mathrm{n} ; \quad$ /*To Read window sub-surface coordinates $*$

step_bw $=\left(2^{*} \mathrm{w} / \mathrm{m}\right) ; \quad \quad / *$ To Read blind slat sub-surface coordinates $* /$

box_LX[0]=0; box_UX[0]=0; box_LXR[0]=0;box_UXR[0]=0;box_LY[0]=0; box_UY[0]=0;

box_LYR $[0]=0 ; b o x \_U Y R[0]=0 ; w l y[0]=0 ; w u y[0]=0 ; b_{-} L X[0][0]=0 ; b \_L Y[0][0]=0$;

b_UX[0][0] $=0 ;$ b_UY $[0][0]=0$;

1 *sets all coordinates equal to zero C-CODE Requirement for correctness $*$

$1 *$ from this point tes 1 -no of window surface,tes $2=$ starting number of blind surf, $* /$

/*tes3=ending of blind surf, tes $4=$ ambinet $*$

tes $1=\mathrm{n}$;

tes $2=n+1$

$\operatorname{tes} 3=\operatorname{tes} 2+m * 1-1$

$\operatorname{tes} 4=\operatorname{tes} 3+1$

* sets Surface Areas, emissivity,Temperature*/

for $(i=1 ; i<=(e s+; i++)\}$

if(i<=tes1) $\{A[i]=$ step $w ; T[i]=T w ;$ em[i]=ew;

if $(i>=t e s 2 \& \& i<=t e s 3)\{A[i]=$ step_bw; $T[i]=T$ blind; em[i]=eb;

iff $(i=\operatorname{tes} 4)\{A[i]=$ length; $T[i]=T a m b ; e m[i]=1.0 ;\}$

for $(i=1 ; j<=1 ; j++)\{\quad / *$ Reads coordinates of upper-lower slat in the cavity*/

\}

temp $=\mathrm{i}-1$; box_LX[i]=d; box_UX[i]=d; box_LXR[i]=d+w*cos(angle);

box_UXR[i] $=\bar{d}+w^{*} \cos \left(\right.$ angle); box_LY[i]=temp*step_box;box_UY $[i]=b o x \_L Y[i]+$ step_box;

box LYR[i]=box LY[i]+w*sin(angle); box UYR[i]=box UY[i]+w*sin(angle);

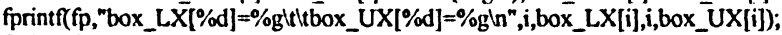

fprintfffp,"box_LY[\%d]=\%glttbox_UY[\%d]=\%glnln",i,box_LY[i],i,box_UY[i]); */

for $(j=1, j<=n \cdot j++)\{\quad 1 *$ Reads Window surface coordinates $* /$

tcmp $-\mathrm{j}-1$;

wly $[j]=$ wuy[temp];

wuy $[j]=$ wly[j]+step_w;

/*fprintf(fp," wly[\%d]=\%gltwuy[\%d] $=\% g \ln "$ j,wly[j] j,wuy[j]); */

\}

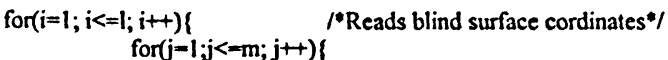

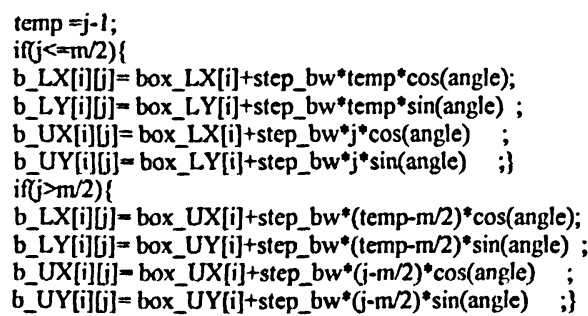

/*fprintf(fp,"b_LX[\%d][\%d] =\%glttb_LY[\%d][\%d] =\%gln",ij,b_LX[i][j],i,j,b_LY[i][j]);

fprintf(fp,"b_UX[\%d][\%d]=\%gltttb_UY[\%d][\%d]=\%gln",i,j,b_UX[i][j],i,j,b_UY[i][j]); */

3)

for $(i=1 ; i<=n ; i++)\{$ temp=n; $/ *$ sets to increase blind number by $n * /$

for $(j=1 ; j<=1 ; j++)\}$

for $(k=1 ; k<-m ; k++)\{$ if(b_LX[i] $[k]=0)\left\{b_{-} L X[j][k]=1 c-20 ;\right\}$

if(b_UX[i] $[k]-0)\left\{b_{-} U X[j][k]=1 e-20 ;\right\}$

testl $=\left(b_{-} L Y[j][k]-w l y[i]\right) / b \_L X[j][k] * d+w l y[i] ;$

/*Determination of View obstructions and Computation of UNCrossed String Length*/

ifftestl <=box_LY[j]) \{uncrossl = sqrt(pow(wly[i]-box_LY[j],2)+pow(d,2))+sqrt(pow(b_LY[j][k]-box_LY[j],2)+pow(b_LX[j][k]-d,2)); if(test l >-box_UY[j]) \{uncross 1 =sqrt(pow(wly[i]-box_UY[j],2)+pow(d,2))+sqrt(pow(b_LY[j][k]-box_UY[j],2)+pow(b_LX[j][k]-d,2));

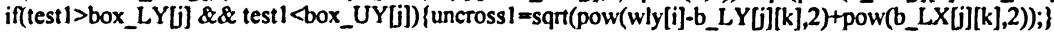

test2=(b_LY[i][k]-wuy[i])b LX[i][k]*d + wuy[i];

$/$ Determination of View obstructions and Computation of Crossed String Length*/

if(test2<=box_LY[j])\{crossl= sqri(pow(wuy[i]-box_LY[j],2)+pow(d,2))+sqrt(pow(b LY[j][k]-box LY[j],2)+pow(b LX[i] [k]-d,2));

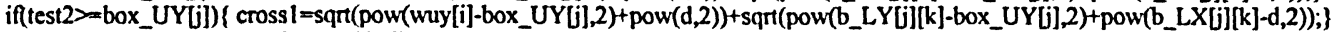

if(test2>box_LY $[j] \& \&$ test2<box_UY[j]) $\{$ cross $1=$ sqrt (pow(wuy[i]-b_LY[j] $[k], 2)+$ pow(b_LX[j] $[k], 2)) ;\}$

test3=(b_UY[j] [k]-wly[i])/b_UX[j][k]*d+wly[i];

/*Determination of View obstructions and Computation of Crossed String Length*/

if(test3<=box_LY[j])\{ cross2=sqrt(pow(wly[i]-box_LY[j],2)+pow(d,2))+sqrt(pow(b_UY[j][k]-box_LY[j],2)+pow(b_UX[j][k]-d,2));\} 
if(test4>box_LY[j] \&\& test4<box_UY[j]) \{ uncross2=sqrt(pow(wuy[i]-b_UY[j][k],2)+pow(b_UX[j][k],2)); \}

if $(\mathrm{k}>\mathrm{m} / 2)\left\{\quad I^{*}\right.$ Correct Crossing and Uncrossing for Upperr and Lower Blind Surface*/

chl $=$ cross 1 ; 2 2 $=$ uncross 1 ; uncross $1=\operatorname{chl} ;$ cross $1=\operatorname{ch} 2$;

$\operatorname{ch} 1=\operatorname{cross} 2 ; \operatorname{ch} 2=$ uncross $2 ;$ uncross $2=\operatorname{ch} 1 ; \operatorname{cross} 2=\operatorname{ch} 2 ;\}$

/"fprintf(fp,"ucl $=\% g|t c l=\% g l t u c 2=\% g| t c 2=\% g l n "$, uncross 1, cross 1 , uncross2, cross2); $*$

/"Calculates Window-Blind and Blind-Window View Factors*/

temp = temp+1;

$\mathrm{F}[\mathrm{i}][$ temp] $=($ cross $1+$ cross 2 -uncross 1 -uncross 2$)(2 *$ step_w $)$;

$\mathrm{F}[$ temp] $[i]=$ (cross $1+$ cross2-uncross 1 -uncross 2$)(2 *$ step_bw);

$33\}$

for $(i=1 ; i<=n ; i++)\{$

for $(j=1 ; j<=n ; j++)\{F[i][j]=0.0 ;\}\} \quad / *$ sets win-win view $=0 * /$

for $(i=t e s 2 ; i<=t e s 3 ; i++)$ (

for $(j=\operatorname{tes} 2 ; j<=\operatorname{tes} 3 ; j++)\{F[i][j]=0.0 ;\}\} \quad / *$ sets blind-blind view $=0 * /$

for $(i=1 ; i<=1 ; i++)\{$ bhl=tes $1+(i-1) * m$;

$1^{*}$ Calculates and sets blind-blind view for overall Computation*/

for $(j=1 ; j<-m ; j++)$ ( bh2=tesl $+(i-1)^{*} m$;

for $(k=1 ; k<=m ; k++)\{b h 2=b h 2+1$;

bhl $=$ bhl $1+1$;

uncross $1=$ sqrt(pow(b_LY[i][j]-b_LY[i][k],2)+pow(b_LX[i][j]-b_LX[i][k],2));

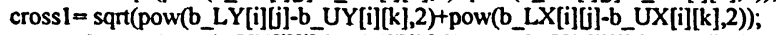

uncross $2=$ sqrt(pow(b UY[i][j]-b UY[i][k],2)+pow(b_UX[i][j]-b UX[i][k],2));

cross2= sqrt(pow(b_UYY[i][j]-b_LY $[i][k], 2)+$ pow(b_UX[i][j]-b_LX $[i][k], 2)$ );

$\mathrm{F}[\mathrm{bh} 1][\mathrm{bh} 2]=$ (cross $1+\mathrm{cross} 2$-uncross 1 -uncross 2$) /(2$ *step_bw);

if( $b h 1=b h 2)\{F[b h 1][b h 2]=0 ;\}$

/*fprintf(fp,"F[\%d][\%d] =\%gln",bhl,bh2,F[bhl][bh2]);

$*$

\}\})

$1 *$ Sets blind-window to ambinet view factors*/

for $(i=1 ; i<=\operatorname{tes} 3 ; i++)\{\operatorname{sum}[i]=0.0$;

for $(j=1 ; j<=$ tes $3 j++)\{\operatorname{sum}[i]=\operatorname{sum}[i]+F[i][j] ;\}$

F[tes 4$][$ tes 4$]=0$;

F[i][tes 4$]=1$-sum[i];

$F[$ tes 4$][i]=F[i][\text { tes } 4]^{*} A[i] / A[$ tes 4$]$;

$/ *$ All View Factors are Calculated, Checks sum $=1 ? * /$

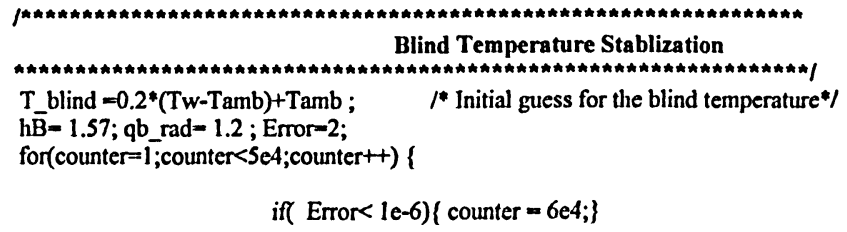

if Error $<1 e-6)\{$ counter $=6 e 4 ;\}$

for $(i=1 ; i<=\operatorname{tes} 4 ; \mathrm{i}++)\{\operatorname{sum}[i]=0.0$; for $(j=1, j<=\operatorname{tes} 4 ; j++)\{\operatorname{sum}[i]=\operatorname{sum}[i]+F[i][j]$

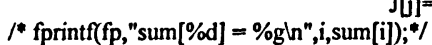

$I^{*}$ Heat Transfer b/w window-blind-ambient Computation Begins*

for $(k=1 ; k<100 ; k++)$;

for $(i=1 ; i<=t e s 4 ; i++)$ (sum $[i]=0.0$; suml $[i]=0.0$;

for $(j=1 ; j<=\operatorname{tes} 4 ; j++)\left\{\operatorname{sum}[i]=\operatorname{sum}[i]+J[j]^{*} F[i][j] ;\right.$

suml $[i]=$ suml $\left.[i]+J[j]^{*} F[i][j] * A[i] ;\right\}$

$\mathrm{J}[\mathrm{i}]=\mathrm{em}[\mathrm{i}]^{*} \operatorname{sigma}{ }^{*}$ pow $(\mathrm{T}[\mathrm{i}], 4)+(1-\mathrm{em}[\mathrm{i}])^{*} \operatorname{sum}[\mathrm{i}]$

$\mathrm{q}[\mathrm{i}]=\mathrm{J}[\mathrm{i}] * \mathrm{~A}[\mathrm{i}]-$ sum $1[\mathrm{i}]$;

if $(k=99)\{/ *$ fprintf(fp,"q[\%d] - \%gln",i,q[i]);*//\}

$\mathrm{qb} \mathrm{rad}=0.0 ; \mathrm{qw} \mathrm{rad}=0.0$;

for $(i=1 ; i<-t e s 4 ; i++)\left\{\right.$ if $(i<-n)\left\{q w_{-}\right.$rad $=q w_{-}$rad $\left.+q[i] ;\right\}$

if $\left(i>n \& \&\right.$ i<tes4) \{qb_rad $\left.=q b \_r a d+q[i] ;\right\}$

$q$ amb $=q[$ tes 4$]$;

$q$ balance $=q_{L} a m b+q w_{2}$ rad $+q b_{-} r a d ;$

\} 


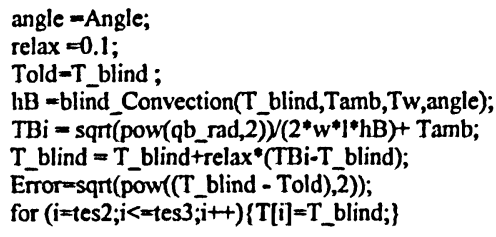

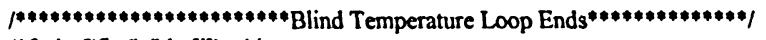

/*fprintf(fip,"n",i,q[i]); */

q_total = window_2glazing(velocity,Tw,T_outside,Tamb,T_blind,angle);

$h$ inside =window Convection( $T$ blind, Tamb, Tw, angle);

q_rad_glazing $=q$ _total $-h_{\text {_inside }}$ length* $(T w-T a m b)$;

$U_{\text {_value }}=q_{\text {_totaV }}$ (length ${ }^{*}\left(T_{-}\right.$outside-Tamb));

Errorl = sqrt(pow(q_rad_glazing-qw_rad,2));

printf("Current Error is= \%gltAngle= \%glt,Blind Emisivity = \%gln",Errorl,angle,eb);

if(Error $1<=5 e-3)\{$ counter $2=1 e 6 ;\}$

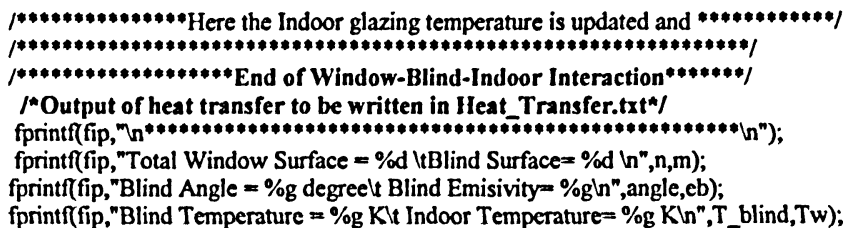

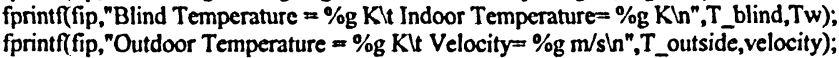

fprintff(fip,"Total Heat flow = \%g Wh Balance= \%g ln",q total,Error1);

fprintf(fip,"Radiative Heat from window $=\% \mathrm{~g}$ Wt Balance $=\% \mathrm{~g}$ (n",qw rad,q balance);

fprintf(fip,"Radiative Heat from blind $=\% \mathrm{~g}$ Wh Radiative Heat To Ambient=\%g Wh",qb_rad,q_amb);

fprintf(fip,"h Blind $=\% \mathrm{~g}$ Wh $\mathrm{h}$ window $\% \mathrm{~g} \mathrm{ln} n$, $\mathrm{hB}, \mathrm{h}$ inside);

fprintf(fip,"U_value = \%g W/C Sq.mlt window Length= \%g ln",U_value,length);

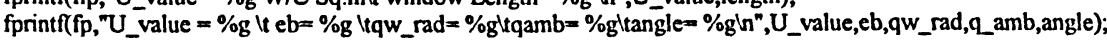

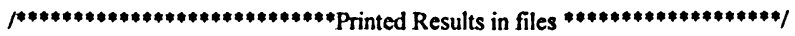

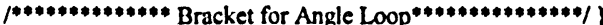

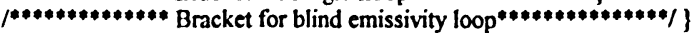

fclose(fp);

fclose(fip);

double window_2glazing(double velocity,double T1i,double To,double Tamb,double Tb, double Angle)

double T20,T2i,T10,T20_old,T2i_old,T10_old;

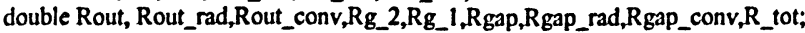

double q_tot,q_out,q_g2,q_gap,q_g1;

double $h_{\text {_out, }} \mathrm{h}_{\text {inside, }}$ _gap, $\mathrm{k}$ _glass, glass_thickness, $20, \mathrm{el}$ gap,e2_gap;

double Aw,errorl,error 2,error3,q_rad_window, theta, TBlind:

int counter 1 ;

/*FILE $* f p p=$ fopen("Result_2glaze.txt","w"); */

$\mathrm{T} 2 \mathrm{O}=\mathrm{To} ; \quad \quad / *$ initail guess for 2 nd galzing outside surface temp $* /$

$\mathrm{T} 2 \mathrm{i}=\mathrm{To} ; \quad \quad / *$ initail guess for 2 nd galzing inside gap surface temp $\%$

$\mathrm{TlO}=\mathrm{Tli}$; $\quad 1 *$ initail guess for lst galzing inside gap surface temp $\%$

T2o_old $=1.1 * \mathrm{~T} 20$;

T2i old $=1.1 * \mathrm{~T} 2 \mathrm{i}$

I*for iteration difference temps*/

T10_old = $1.1 *$ Tlo;

TBlind = Tb;

theta=Angle;

glass_thickness $=3 e-3$;

$k$ glass $=0.900$;

$\overrightarrow{\mathrm{Aw}}=0.635$;

e2o $=0.84 ; \quad \quad \quad$ *emissivity for outside surface 2 nd glazing $*$

e2_gap $=0.84$; $\quad / *$ emissivity for inside gap surface 2 nd glazing*/

el gap = 0.84; $\quad / \%$ emissivity for inside gap surface lst glazing $\%$

if (velocity $>2)$ (

h_out $=8.07 *$ pow $($ velocity,0.605):

- $/$ calculates convection coefficient for outside*/

if $($ velocity $<=2)$ (h_out $=12.27$;

counterl $=0$

while (counter $1<5000$ ) 
$h_{-}$inside $=$window_Convection(TBlind,Tamb,Tli,theta); $/ *$ calculates inside window convection coeffcient $*$

h_gap = gap_Convection(T2i,T10); I*requires modification gap convection coeffcient*/

etrorl $=\operatorname{sqrt}\left(\right.$ pow $\left(\mathrm{T} 10 \_\right.$old $\left.\left.-\mathrm{T} 10,2\right)\right)$

error2 $=$ sqrt(pow $($ T2i_old - T2i,2));

error3 = sqrt(pow $($ T20_old - T2o,2));

counter $1=$ counter $1+\bar{l}$;

$1 *$ condtions to set the stop iteration process $* /$

if (error $1>1$ e- 6 \&\& error $>>$ e- 6 \&\& error $3>1 e-6)$ (

Tlo_old = Tlo; $\quad / *$ update last iteration temps $* /$

T2i_old $=\mathrm{T} 2 \mathrm{i}$

T20_old = T20;

Rout_conv $=1 /($ Aw $*$ h_out $)$;

/*outside convection resistance*/

Rout_rad $=1 /\left(\mathrm{Aw}^{*}\right.$ sigma* $\left.\mathrm{e}^{*} \mathrm{o}^{*}(\mathrm{To}+\mathrm{T} 2 \mathrm{o}) *\left(\mathrm{To}^{*} \mathrm{To}+\mathrm{T} 2 \mathrm{o}^{*} \mathrm{~T} 2 \mathrm{o}\right)\right) ; /{ }^{*}$ outside radiation resistance*/

Rout $=$ Rout_conv*Rout_rad/(Rout_convt Rout_rad); $/ *$ outside total resistance*/

$\mathrm{Rg}_{2} 2=$ glass_thickness $/\left(\overline{\mathrm{k}} \_\right.$glass $\left.* \mathrm{Aw}\right) ;$

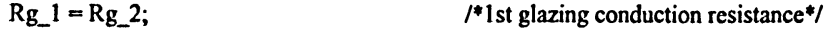

Rgap_rad $=\left(1 / \mathrm{e} 2 \_\right.$gap $\left.+1 / \mathrm{el}_{\text {_gap }}-1\right) /($ sigma * Aw*(T2i+Tlo)*(T2i*T2i $\left.+\mathrm{Tlo} * \mathrm{~T} 10)\right)$;

Rgap_conv $=1 /\left(\mathrm{Aw}^{*} \mathrm{~h}_{\text {ggap }}\right) ; \quad /$ glazing gap convection resistance $*$

Rgap $=$ Rgap_conv*Rgap_rad/(Rgap_conv+Rgap_rad); / glazing gap total resistance*/

$R_{-}$tot $=R_{\text {gap }}+R_{g_{-}} 1+R_{g_{-}} 2+$ Rout; $\quad / *$ total resistance of glazing window without blind $* /$

q_tot $=($ To-T1i)/R_tot; $\quad / *$ total heat transfer from outside to inside glazing surface $* /$

q out $=($ To-T2o)/Rout; $\quad / *$ total heat transfer from outside to outside 2nd glazing surface*/

q_gap $=(\mathrm{T} 2 \mathrm{i}-\mathrm{T} 1 \mathrm{lo}) / \mathrm{Rgap} ; \quad / *$ these heat transfer must/are equal*/

$q_{g} 1=(T 10-T 1 i) / R_{g} 1 ;$

$q_{L} g 2=(T 20-T 2 i) / R_{g} 2$;

$I^{*}$ for a given inner surface temp,update all temperatures

for new iteraton untill no change in temperature*/

$\mathrm{T} 2 \mathrm{O}=\mathrm{To}-\mathrm{q}$ tot * Rout;

$\mathrm{T} 2 \mathrm{i}=\mathrm{T} 2 \mathrm{o}-\mathrm{q}$ tot $* \mathrm{Rg}_{2}$;

$\mathrm{T} 1 \mathrm{o}=\mathrm{T} 2 \mathrm{i}-\mathrm{q}$ L tot $*$ Rgap;

q_rad_window $=$ q_tot $-h_{-}$inside *Aw*(Tli-Tamb); \} /*total radiation towards blind resistor network*/

else $\{$ counter $1=10000 ;\}$

\}

/* fprintf(fpp, "'lnT2o:\%gln T2i:\%gln T1o:\%glnq_tot:\%glnR_tot:\%gln",T2o,T2i,Tlo,q_tot,R_tot);

fprintf(fpp, "lnq gap:\%gln q out:\%glnq g2:\%gln q g1:\%g

fprintf(fpp,"InputhUnless otherwise specified, all temperatures are in (K), Area in $\left(\mathrm{m}^{\wedge} 2\right)$, Inheat transfer rates are in (W) $\left.\mathrm{ln}_{\mathrm{ln}} \mathrm{n}\right)$;

fprintf(fpp,"Windo Area:\%g ln",Aw);

fprintff(pp,"Tli:\%gltT_outside_surface:\%gltq_rad:\%gltq_tot:\%gln",Tli,Tlo,q_rad_window,q_tot);

fprintf(fpp,"h_inside:\%glnh_out:\%gln",h_inside,h_out);

fclose(fpp); *I

return(q_tot);

double window_Convection(double Tb,double Tambi,double TW, double Angle)

\{

double hw,Length, k,gr,pr,Ra, TB, Tamb,Tw, Tb_nodim;

double beta, Rho, viscosity, $T$ film,cp,T diff;

double $\operatorname{Ral[6],Rah[6],Rab[6],Ral45[6],Rah45[6],Rab45[6],Ral90[6],Rah90[6],Rab90[6];~}$

double $\mathrm{Ra}_{\text {_angle[6], }} \mathrm{Nu}$ _fidap;

int angle;

/*FILE *fiip = fopen("Window_convection.txt","w");*/

angle $=$ (int)Angle;

$\mathrm{Tw}=\mathrm{TW}$;

$\mathrm{TB}=\mathrm{Tb}$;

$T a m b=$ Tambi;

Tb_nodim $=$ (TB-Tamb)/(Tw-Tamb);

Length $=0.635$;

$T_{-}$film $=(T w+T a m b) / 2$;

$T_{-}$diff $=(T w-T a m b) ;$ 
$T_{-}$diff $=\operatorname{sqr}\left(\right.$ pow $\left(T_{-}\right.$diff, 2$\left.)\right)$;

beta $=1 /(T$ film);

if(T_film $>=250 \& \& T_{-}$film $\left.<=330\right)($

$c p=\left(3.4898964+0.0000511 * T_{-}\right.$film $) * 287041 \mathrm{e}$;

$k=0.003385+7.55 e-5^{*} T_{-}$film;

Rho $=101.325 \mathrm{e} 3 /\left(287.00^{\circ} \mathrm{T}\right.$. film $)$;

viscosity $=3.9975 \mathrm{e}-6+4.8250 \mathrm{e}-8 * \mathrm{~T}_{-}$film;

$\mathrm{pr}=\mathrm{cp} *$ viscosity $/ \mathrm{k}$;

gr $=9.806^{*}$ beta*T_diff*(Rho*Rho)*pow(Length,3)/(viscosity*viscosity);

$\mathrm{Ra}=\mathrm{pr}^{*} \mathrm{gr}$

$\mathrm{Ra}=\operatorname{sqrt}($ pow $(\operatorname{Ra}, 2))$;

\}

if(Tb_nodim $<0.1)\{$ Tb_nodim $=0.2 ;\}$

if $T$ Tb_nodim $>0.1 \& \&$ Tb_nodim $<0.2)$ (

$\operatorname{Ral}[1]=-27.5625 ; \operatorname{Ral}[2]=-49.3168 ; \operatorname{Ral}[3]=-75.6763 ; \operatorname{Ral}[4]=83.63004 ; \operatorname{Ral}[5]=-91.57687 ;$

$\operatorname{Rah}[1]=25.8276 ; \operatorname{Rah}[2]=-47.9998 ; \operatorname{Rah}[3]=-74.8214 ; \operatorname{Rah}[4]=82.95962 ; \operatorname{Rah}[5]=-90.98348 ;$

Ral4S[1] =-28.0054 ; Ral45[2] $=-49.51938 ; R a l 45[3]=-77.00298 ; R a 145[4]=-78.8918 ;$ Ral45[5]=0;

Rah45[1] $=26.3693 ; \operatorname{Rah} 45[2]=-48.5094 ; \operatorname{Rah} 45[3]=-76.6328 ; \operatorname{Rah} 45[4]=-78.59474 ; \operatorname{Rah} 45[5]=$;

Ral90[1]=-30.75823; Ral90[2]=58.06441; Ral90[3]=86.33443;Ral90[4]=-92.92174; Ral90[5]=102.5438;

$\operatorname{Rah} 90[1]=-29.27465 ; \operatorname{Rah} 90[2]=58.20088 ; \operatorname{Rah} 90[3]=84.98487 ; \operatorname{Rah} 90[4]=93.52098 ; \operatorname{Rah} 90[5]=-100.8468$

$\operatorname{Rab}[1]=\left(\operatorname{Ral}[1]^{*}(0.2-\mathrm{Tb}\right.$ nodim $)+\operatorname{Rah}[1]^{*}\left(T b_{-}\right.$nodim-0.1) $)(0.2-0.1)$;

$\operatorname{Rab}[2]=\left(\operatorname{Ral}[2]^{*}(0.2-\mathrm{Tb}\right.$ nodim $)+\operatorname{Rah}[2]^{*}(\mathrm{~Tb}$ nodim-0.1) $)(0.2-0.1)$

$\operatorname{Rab}[3]=\left(\operatorname{Ral}[3]^{*}\left(0.2-\mathrm{Tb}_{-}\right.\right.$nodim $)+\operatorname{Rah}[3]^{*}\left(\mathrm{~Tb} \_\right.$nodim- 0.1$\left.)\right)(0.2-0.1)$

$\operatorname{Rab}[4]=\left(\operatorname{Ral}[4]^{*}(0.2 \cdot \mathrm{Tb}\right.$ nodim $)+\operatorname{Rah}[4]^{*}(\mathrm{~Tb}$ nodim -0.1$\left.)\right)(0.2-0.1)$

$\operatorname{Rab}[5]=\left(\operatorname{Ral}[5]^{*}\left(0.2-\mathrm{Tb}_{\text {_nodim }}\right)+\operatorname{Rah}[5]^{*}(\mathrm{~Tb}\right.$ _nodim-0.1)$)(0.2-0.1)$;

$\operatorname{Rab45}[1]=\left(\operatorname{Ral} 45[1]^{*}(0.2-\mathrm{Tb}\right.$ nodim $)+\operatorname{Rah} 45[1]^{*}(\mathrm{~Tb}$ nodim -0.1$\left.)\right)(0.2-0.1) ;$

$\operatorname{Rab45}[2]=\left(\operatorname{Ral} 45[2]^{*}(0.2-\mathrm{Tb}\right.$ nodim $)+\operatorname{Rah} 45[2]^{*}(\mathrm{~Tb}$ nodim-0.1) $) /(0.2-0.1)$;

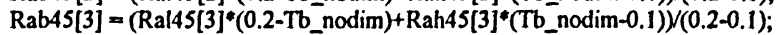

$\operatorname{Rab} 45[4]=\left(\operatorname{Ral} 45[4]^{*}(0.2-\mathrm{Tb}\right.$ nodim $)+\operatorname{Rah} 45[4]^{*}(\mathrm{~Tb}$ nodim -0.1$\left.)\right)(0.2-0.1)$

Rab45[5] $=\left(\operatorname{Ral} 45[5]^{*}\left(0.2-\mathrm{Tb}_{\text {_nodim }}\right)+\operatorname{Rah} 45[5]^{*}(\mathrm{~Tb}\right.$ _nodim-0.1) $)(0.2-0.1)$;

Rab90[1] $=\left(\operatorname{Ral90}[1]^{*}(0.2-\mathrm{Tb}\right.$ nodim $)+\operatorname{Rah} 90[1]^{*}(\mathrm{~Tb}$ nodim- 0.1$\left.)\right)(0.2-0.1)$;

Rab90[2] $=\left(\right.$ Ral90[2]*(0.2-Tb_nodim) + Rah90[2 ${ }^{*}\left(\mathrm{~Tb}_{\text {_ndim }}\right.$-0.1) $)(0.2-0.1)$;

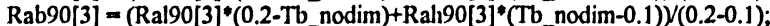

Rab90[4] $=\left(\right.$ Ral90[4]* ${ }^{*}\left(0.2-\mathrm{Tb}_{\text {_nodim }}\right)+\operatorname{Rah} 90[4]^{*}(\mathrm{~Tb}$ _nodim -0.1$\left.)\right)(0.2-0.1)$;

Rab90[5] $=\left(\operatorname{Ra} 190[5]^{*}\left(0.2-T_{0}\right.\right.$ nodim $)+R a h 90[5]^{*}(T b$ nodim -0.1$\left.)\right) /(0.2-0.1) ;$

if( angle $>0$ \&\& angle $<45)$ (

\begin{abstract}
Ra_angle[1] $=\mathrm{Rab}[1]^{*}(45-$ angle $) / 45+\mathrm{Rab} 45[1]^{*}$ angle/45;
$\mathrm{Ra}$ _angle $[2]=\operatorname{Rab}[2]^{*}\left(45\right.$ - angle) $/ 45+\operatorname{Rab} 45[2]^{*}$ angle/45;

$\mathrm{Ra}$ angle $[3]=\operatorname{Rab}[3]^{*}(45-$ angle $) / 45+\operatorname{Rab} 45[3]^{*}$ angle $/ 45$;

$\mathrm{Ra}$ angle $[4]=\mathrm{Rab}[4]^{*}(45-$ angle $) / 45+\mathrm{Rab} 45[4]^{*}$ angle/45

$\mathrm{Ra}$ _angle $[5]=\operatorname{Rab}[5]^{*}(45-$ angle $) / 45+\operatorname{Rab} 45[5]^{*}$ angle/45;
\end{abstract}

if( angle $>-45 \& \&$ angle $<=90)($

Ra_angle[1] $=$ Rab45[1]*(90-angle)/45+Rab90[1]*(angle-45)/45;

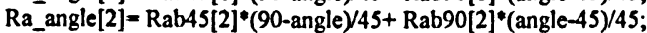

$\mathrm{Ra}$ angle $[3]=\mathrm{Rab} 45[3]^{*}(90$-angle $) / 45+\mathrm{Rab} 90[3]^{*}$ (angle-45)/45;

$\mathrm{Ra}_{\text {_angle }}[4]=\mathrm{Rab45}[4]^{*}(90$-angle $) / 45+\mathrm{Rab} 90[4]^{*}($ angle- -45$) / 45 ;$

$\mathrm{Ra}_{-}$angle $[5]=\mathrm{Rab} 45[5]^{*}(90$-angle $) / 45+\mathrm{Rab} 90[5]^{*}($ angle-45)/45;

if $(\mathrm{Ra}>1.0 \mathrm{e} 7 \& \& \mathrm{Ra}<1.0 e 8)$

$\mathrm{Nu}$ _fidap $=\mathrm{Ra}_{-}$angle[1]* $(1.0 \mathrm{e} 8-\mathrm{Ra}) /(1.0 \mathrm{e} 8-1.0 \mathrm{e} 7)+\mathrm{Ra}$ angle[2]* $(\mathrm{Ra}-1.0 \mathrm{e})(1.0 \mathrm{e} 8-1.0 \mathrm{e} 7)$

if $(\operatorname{Ra}>=1.0 e 8 \& \& R a<5.0 e 8)$

Nu_fidap - Ra_angle[2]*(5.0e8-Ra) $/(5.0 \mathrm{e} 8-1.0 \mathrm{e} 8)+\mathrm{Ra}$ _angle[3]* $(\mathrm{Ra}-1.0 \mathrm{e} 8) /(5.0 \mathrm{e} 8-1.0 \mathrm{e} 8)$;

if $(\mathrm{Ra}>=5.0 \mathrm{e} 8$ \& \& $\mathrm{Ra}<=7.0 \mathrm{e} 8)$

$\mathrm{Nu}$ _fidap $=\mathrm{Ra}$ _angle[3]*(7.0e8-Ra)/(7.0e8-5.0e8)+Ra_angle[4]* (Ra-5.0e8)/(7.0e8-5.0e8);

if $(\mathrm{Ra}>-7.0 \mathrm{e} 8$ \&\& $\mathrm{Ra}<=1.5 \mathrm{e} 9)$

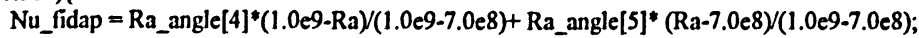

if $(\mathrm{Tb}$ nodim $>=0.2 \& \& \mathrm{~Tb}$ _nodim $<0.3)\{$

$\operatorname{Ral}[1]=-25.8276 ; \operatorname{Ral}[2]=-47.9998 ; \operatorname{Ral}[3]=-74.8214 ; \operatorname{Ral}[4]=-82.95962 ; \operatorname{Ral}[5]=-90.98348$;

$\operatorname{Rah}[1]=-24.1395 ; \operatorname{Rah}[2]=-47.3655 ; \operatorname{Rah}[3]=-75.09051 ; \operatorname{Rah}[4]=81.95538 ; \operatorname{Rah}[5]=-90.215 ;$ 


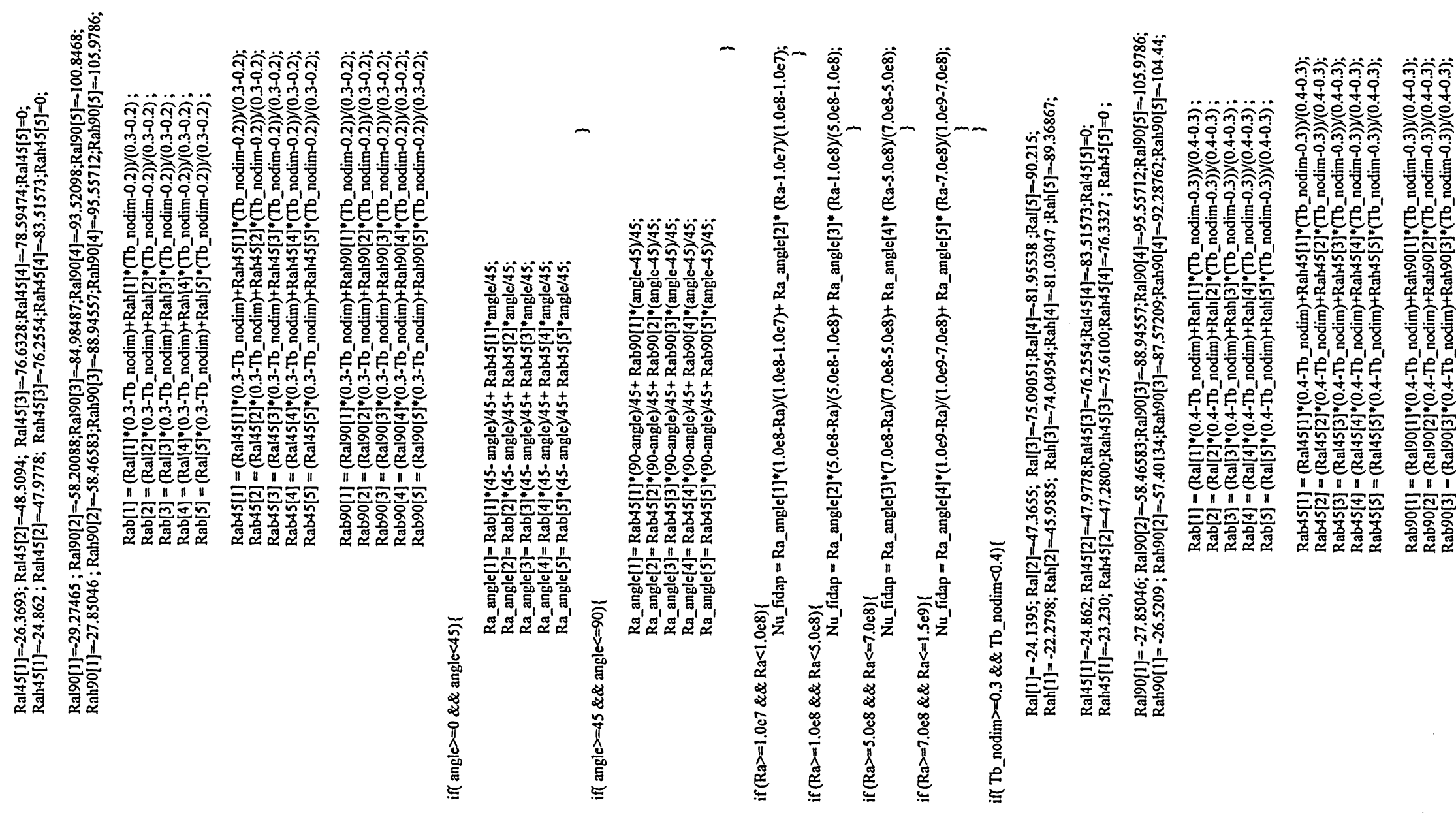


$\operatorname{Rab} 90[4]=\left(\operatorname{Ral} 90[4]^{*}\left(0.4-T b \_\right.\right.$nodim $)+\operatorname{Rah} 90[4]^{*}($ Tb_nodim- 0.3$\left.)\right) /(0.4-0.3)$; $\operatorname{Rab} 90[5]=\left(\operatorname{Ra} 190[5]^{*}\left(0.4-\mathrm{Tb}_{-}\right.\right.$nodim $)+\operatorname{Rah} 90[5]^{*}(\mathrm{~Tb}$ _nodim-0.3) $) /(0.4-0.3) ;$

if angle $>0$ \&\& angle $<45)$ (

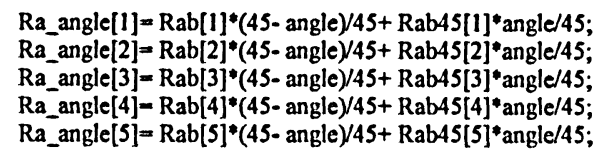

if( angle $>-45 \& \&$ angle $<=90)$ (

Ra_angle[1] $=$ Rab45[1]*(90-angle)/45+Rab90[1 $]^{*}($ angle-45)/45;

$R a_{-}$angle $[2]=R a b 45[2]^{*}(90$-angle)/45+Rab90[2]*(angle-45)/45;

Ra_angle[3]= Rab45[3]*(90-angle)/45+Rab90[3]*(angle-45)/45;

$\mathrm{Ra}$ _angle $[4]=\mathrm{Rab} 45[4]^{*}(90$-angle $) / 45+\mathrm{Rab} 90[4]^{*}$ (angle-45)/45;

Ra_angle[5] $=$ Rab45[5]* $(90$-angle $) / 45+\operatorname{Rab} 90[5]^{*}($ angle-45)/45;

if $(\operatorname{Ra}>-1.0 e 7 \& \& \quad R a<1.0 e 8)\}$

$\mathrm{Nu}$ _fidap $=\mathrm{Ra}_{-}$angle[1]*(1.0e8-Ra) $/(1.0 e 8-1.0 e 7)+\mathrm{Ra}_{-}$angle[2]* $(\mathrm{Ra}-1.0 \mathrm{e} 7) /(1.0 \mathrm{e} 8-1.0 \mathrm{e} 7)$;

if $(\mathrm{Ra}>=1.0 e 8 \& \& \mathrm{Ra}<5.0 \mathrm{e} 8)$ (

$\mathrm{Nu}$ _fidap $=\mathrm{Ra}_{-}$angle $[2]^{*}(5.0 \mathrm{e} 8-\mathrm{Ra}) /(5.0 \mathrm{e} 8-1.0 \mathrm{e} 8)+\mathrm{Ra}$ angle $[3]^{*}(\mathrm{Ra}-1.0 \mathrm{e} 8) /(5.0 \mathrm{e} 8-1.0 \mathrm{e} 8)$;

if $(\mathrm{Ra}>5.0 \mathrm{e} 8$ \& \& $\mathrm{Ra}<=7.0 \mathrm{e} 8)$ (

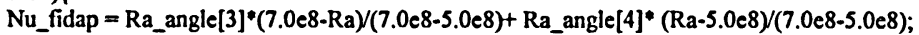

if $(\mathrm{Ra}=7.0 \mathrm{e} 8 \& \& \mathrm{Ra}<=1.5 \mathrm{e} 9)($

$\mathrm{Nu}$ fidap = Ra_angle[4]*(1.0e9-Ra)/(1.0e9-7.0e8)+Ra_angle[5]* (Ra-7.0e8)/(1.0e9-7.0e8);

if Tb_nodim $>0.4 \& \&$ Tb_nodim $<=0.5)($

$\operatorname{Ral}[1]=22.2798 ; \operatorname{Ral}[2]=-45.9585 ; \operatorname{Ra}[3]=-74.04954 ; \operatorname{Ral}[4]=81.03047 ; \operatorname{Ral}[5]=-89.36867 ;$

$\operatorname{Rah}[1]=20.4415 ; \operatorname{Rah}[2]=-44.615 ; \operatorname{Rah}[3]=-73.2151 ; \operatorname{Rah}[4]=-80.06841 ; \operatorname{Rah}[5]=-88.49633 ;$

$\operatorname{Ra} 45[1]=23.23 ; \operatorname{Ra} 145[2]=-47.28 ; \operatorname{Ra} 45[3]=-75.61 ; \operatorname{Ral} 45[4]=-76.3327 ; \operatorname{Ral} 45[5]=0$;

$\operatorname{Rah45}[1]=21.57 ; \operatorname{Rah} 45[2]=-46.1 ; \operatorname{Rah} 45[3]=-75.69 ; \operatorname{Rah} 45[4]=-82.88367 ; \operatorname{Rah} 45[5]=0$;

$\operatorname{Ra} 190[1]=-26.5209 ; \operatorname{Ra} 190[2]=-57.40134 ; \operatorname{Ra} 190[3]=-87.57209 ; \operatorname{Ra} 190[4]=-92.28762 ; \operatorname{Ra} 190[5]=104.44$; $\operatorname{Rah} 90[1]=25.20635 ; \operatorname{Rah} 90[2]=-57.6109 ; \operatorname{Rah} 90[3]=-87.55093 ; \operatorname{Rah} 90[4]=-97.85164 ; \operatorname{Rah} 90[5]=105.9913 ;$

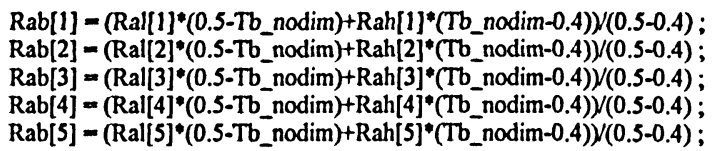

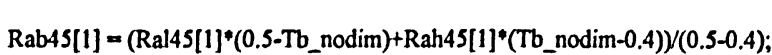

Rab45[2] $=($ Ral45[2]*(0.5-Tb nodim $)+R a h 45[2]^{*}\left(\mathrm{~Tb}^{*}\right.$ nodim-0.4) $)(0.5-0.4)$

$\operatorname{Rab} 45[3]=\left(\operatorname{Ral} 45[3]^{*}\left(0.5-\mathrm{Tb}_{\text {_nodim }}+\mathrm{Rah}_{45}[3]^{*}(\mathrm{~Tb}\right.\right.$ _nodim-0.4) $)(0.5-0.4)$;

Rab45[4] $=\left(\operatorname{Ral} 45[4]^{*}\left(0.5-\mathrm{Tb}_{\text {_nodim }}\right)+\operatorname{Rah} 45[4]^{*}(\mathrm{~Tb}\right.$ _nodim-0.4) $)(0.5-0.4)$;

Rab45[5] $=\left(\operatorname{Ral} 45[5]^{*}\left(0.5-\mathrm{Tb}_{\text {_nodim }}\right)+\operatorname{Rah} 45[5]^{*}(\mathrm{~Tb}\right.$ _nodim-0.4) $) /(0.5-0.4) ;$

Rab90[1] $=\left(\operatorname{Ral} 90[1]^{*}\left(0.5-T b \_\right.\right.$nodim $)+\operatorname{Rah} 90[1]^{*}($ Tb_nodim-0.4 $\left.)\right)(0.5-0.4)$;

Rab90[2] $=\left(\right.$ Ral90 $\left.[2]^{*}\left(0.5-\mathrm{Tb}_{\text {_nodim }}\right)+\operatorname{Rah} 90[2]^{*}\left(\mathrm{~Tb}_{\text {_nodim- }} 0.4\right)\right) /(0.5-0.4)$;

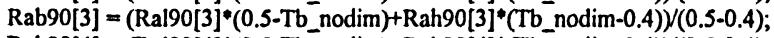

Rab90 $[4]=\left(\operatorname{Ral} 90[4]^{*}\left(0.5-\mathrm{Tb}^{-}\right.\right.$nodim $)+R a h 90[4]^{*}(\mathrm{~Tb}$ nodim-0.4) $) /(0.5-0.4) ;$

Rab90[5] - (Ral90[5]*(0.5-Tb_nodim)+Rah90[5]*(Tb_nodim-0.4))/(0.5-0.4);

if angle $>0$ \& \& angle $<45)$ (

Ra_angle[1]= $\operatorname{Rab}[1]^{*}(45-$ angle $) / 45+\operatorname{Rab} 45[1]^{*}$ angle/45;

$\mathrm{Ra}$ _angle[2]= $\mathrm{Rab}[2]^{*}\left(45\right.$ - angle)/45+ $\mathrm{Rab} 45[2]^{*}$ angle/45;

$\mathrm{Ra}_{-}$angle[3] $=\mathrm{Rab}[3]^{*}(45-$ angle $) / 45+\mathrm{Rab} 45[3]^{*}$ angle $/ 45$;

$\mathrm{Ra}$ _angle $[4]=\mathrm{Rab}[4]^{*}\left(45\right.$ - angle)/45+ $\mathrm{Rab} 45[4]^{*}$ angle/45;

$\mathrm{Ra}_{-}$angle $[5]=\operatorname{Rab}[5]^{*}(45$ - angle)/45+Rab45[5]*angle/45;

if( angle $>45 \& \&$ angle $<=90)($

Ra_angle[1]= Rab45[1]*(90-angle)/45+ Rab90[1]*(angle-45)/45;

Ra_angle[2] $=$ Rab45[2]*(90-angle)/45+ Rab90[2]*(angle-45)/45;

$R a$ angle $[3]=R a b 45[3]^{*}(90$-angle $) / 45+R a b 90[3]^{*}($ angle-45)/45;

$\mathrm{Ra}_{-}$angle[4] $=\mathrm{Rab} 45[4]^{*}(90$-angle)/45+ Rab90[4]*(angle-45)/45;

Ra_angle[5] $=\mathrm{Rab} 45[5]^{*}(90$-angle)/45+Rab90[5]*(angle-45)/45; 
$\mathrm{Ra}$ angle[2] $=\mathrm{Rab} 45[2]^{*}(90$-angle $) / 45+\mathrm{Rab} 90[2]^{*}($ angle -45$) / 45 ;$

Ra_angle $[3]=\operatorname{Rab} 45[3]^{*}\left(90\right.$-angle) $/ 45+\operatorname{Rab} 90[3]^{*}$ (angle-45)/45;

Ra_angle[4] $=\operatorname{Rab} 45[4]^{*}(90$-angle)/45+Rab90[4]*(angle-45)/45

Ra_angle $[5]=\operatorname{Rab} 45[5]^{*}(90$-angle $) / 45+\operatorname{Rab} 90[5]^{*}($ angle -45$) / 45$;

if $(\operatorname{Ra}>-1.0 \mathrm{e} 7 \& \& \mathrm{Ra}<1.0 \mathrm{c} 8)\}$

$\mathrm{Nu}$ _fidap $=\mathrm{Ra}_{-}$angle[1] ${ }^{*}(1.0 \mathrm{e} 8-\mathrm{Ra}) /(1.0 \mathrm{e} 8-1.0 \mathrm{e} 7)+\mathrm{Ra}_{-}$angle[2] ${ }^{*}(\mathrm{Ra}-1.0 \mathrm{e} 7) /(1.0 \mathrm{e} 8-1.0 \mathrm{e} 7)$;

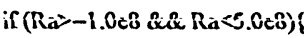

Nu_fidap $=$ Ra_angle $[2]^{*}(5.0 \mathrm{e} 8-\mathrm{Ra})(5.0 \mathrm{e} 8-1.0 \mathrm{e} 8)+\mathrm{Ra}$ angle[3]* $(\mathrm{Ra}-1.0 \mathrm{e} 8) /(5.0 \mathrm{e} 8-1.0 \mathrm{e} 8)$;

if $(\mathrm{Ra}>=5.0 \mathrm{c} 8 \& \& \mathrm{Ra}<=7.0 \mathrm{e} 8)$ (

$\mathrm{Nu}$ fidap $=\mathrm{Ra}_{-}$angle $[3]^{*}(7.0 \mathrm{e} 8-\mathrm{Ra})(7.0 \mathrm{e} 8-5.0 \mathrm{e} 8)+\mathrm{Ra}$ angle $[4]^{*}(\mathrm{Ra}-5.0 \mathrm{e} 8)(7.0 \mathrm{e} 8-5.0 \mathrm{e} 8)$;

if $(\mathrm{Ra}>=7.0 \mathrm{e} 8 \& \& \mathrm{Ra}<=1.5 \mathrm{e} 9)($

1

$\mathrm{Nu}$ _fidap $=\mathrm{Ra}_{-}$angle[4] $]^{*}(1.0 \mathrm{e} 9-\mathrm{Ra}) /(1.0 \mathrm{e} 9-7.0 \mathrm{e} 8)+\mathrm{Ra}$ _angle[5]* $(\mathrm{Ra}-7.0 \mathrm{e} 8) /(1.0 \mathrm{e} 9-7.0 \mathrm{e} 8)$;

$h w=-1 * N u \_$fidap $*\left(0.003385+7.55 e-5 * T_{-}\right.$film $)(0.635)$

if(T_film $<=249 \& \& T_{-}$film $\left.>=350\right)\{\mathrm{hw}=2.70$;

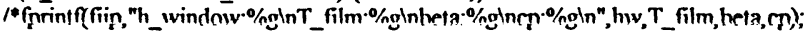

fprintf(fiip,"K_air:\%glnAir density:\%glnViscosity:\%gln",k,Rho,viscosity);

fprintf(fiip,"Prandtl no:\%glnGrashof's no:\%glnRayleigh no:\%gln",pr,gr,Ra);

fprintf(fiip,"NON_Dimensional BLIND TEMPERATURE $=\% \mathrm{~g}$ (nSlat Angle $=\% \mathrm{~g} / \mathrm{h}$,"Tb_nodim,angle);

fprintff(fip,"WINDDOW TEMPERATURE $=\% \mathrm{gK} \ln B L I N D$ TEMPERATURE $=\% \mathrm{gK} \ln "$,Tw,TB);

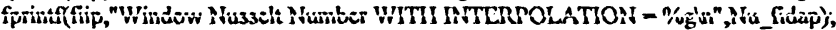

return(hw);

j

double blind_Convectlon(double Tb,double Tambi, double TW, double Angle)

l

1* Similar to Window Convection*/

)

double gan_Convection(double TB,double Tamb)

l

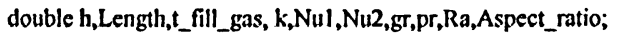

double beta, Rho, viscosity, T_film,cp,T_diff;

|"FILE *fos - fopen("Recult_gap_convection.tut","w");"!

Length $=0.635$;

$t$ fill gas $=12.70 \mathrm{e}-3$;

Aspect_ratio = Length/__fill_gas;

$T_{-} \pi m=(T B+T a n b) / Z$;

$\mathrm{T}_{-}$diff $=(\mathrm{TB}-\mathrm{Tamb})$;

$T_{-}^{-} \operatorname{diff}=\operatorname{sqt}\left(\right.$ pow $\left.\left(T_{-} \operatorname{diff}, 2\right)\right)$;

beta $=1 /(\mathrm{T}$ film $)$

if $\left(T_{-}\right.$film $>=250 \& \& T_{-}$film $\left.<=330\right)($

$\mathrm{cp}=\left(3.4898964+0.0000511 * T_{-} \text {film }\right)^{*} .287041 \mathrm{e}$;

$k=0.003385+7.55 e-5^{*} \mathrm{~T}$ film;

$R h o=101.325 \mathrm{e} 3 /\left(287.00^{-} \mathrm{T}_{\text {_film }}\right)$;

viscosity $=3.9975 c-6+4.8250 \mathrm{c}-8^{*} \mathrm{~T}$ film;

$\mathrm{pr}=\mathrm{cp}$ *viscositv/k:

$\mathrm{gr}=9.806^{*}$ beta*T_diff*(Rho*Rho)*pow(t_fill_gas,3)/(viscosity*viscosity);

$\mathrm{Ra}=\mathrm{pr}^{*} \mathrm{gr}$;

$\mathrm{Ra}=\operatorname{sqrt}($ pow $(\mathrm{Ra}, 2))$;

if $(\mathrm{Ra}>5 \mathrm{e} 4)$

if $R . a>$ le4 \&:\&: $R . a<=5 e$ )

if $(\mathrm{Ra}<=1 \mathrm{le})$

$\left\{\mathrm{Nul}=0.0673838^{*}\right.$ pow $\left.(\mathrm{Ra}, 0.33333333) ;\right\}$

$\mathrm{Nu} 2=0.242^{*}$ pow(Ra/Aspect_ratio, 0.272);

$\left\{\mathrm{Nul}=0.028154^{*}\right.$ pow $\left.(\mathrm{R} . \mathrm{g}, 0.4134) ;\right\}$

if $(\mathrm{Nul}>-\mathrm{Nu} 2)\left\{\mathrm{h}=\mathrm{Nul}{ }^{*} \mathrm{k} / \mathrm{t}\right.$ _fill_gas; $\}$

if $(\mathrm{Nul}<\mathrm{Nu2})\left\{\mathrm{h}=\mathrm{Nu2} * \mathrm{k} / \mathrm{t}_{-}\right.$fill_gas; $\}$

ii - surt $($ pow $(2,2))$;

if(T_film $<=249 \& \& T_{-}$film $\left.>=350\right)\{h=2.70 ;\}$

fclose(fgg); $* 1$

return(h);\} 


\title{
APPENDIX-E: SAMPLE OUTPUT FROM 1-D THERMAL RESISTANCE MODEL OF BLIND AND WINDOW SYSTEM
}

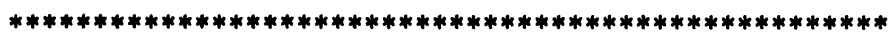 \\ Total Window Surface $=1$ \\ Blind Surface $=2$ \\ Blind Angle $=0$ degree $\quad$ Blind Emisivity $=0.1$ \\ Blind Temperature $=297.601 \mathrm{~K} \quad$ Indoor window Temperature $=300.831 \mathrm{~K}$ \\ Outdoor Temperature $=305.15 \mathrm{~K}$ Velocity $=3.35 \mathrm{~m} / \mathrm{s}$ \\ Total Heat flow $=13.51 \mathrm{~W} / \mathrm{m} \quad$ Balance $=0.00216414$ \\ Radiative Heat from window $=9.041 \mathrm{~W} / \mathrm{m} \quad$ Balance $=5.27578 \mathrm{e}-13$ \\ Radiative Heat from blind $=-0.951967 \mathrm{~W} / \mathrm{m}$ \\ Radiative Heat To Ambient $=-8.08903 \mathrm{~W} / \mathrm{m}$ \\ h_Blind $=1.45606 \mathrm{~W} / \mathrm{m}^{2} \mathrm{~K} \quad \mathrm{~h}$ window $=1.91124 \mathrm{~W} / \mathrm{m}^{2} \mathrm{~K}$ \\ $\bar{U}_{\text {_value }}=2.65944 \mathrm{~W} / \mathrm{C}$ Sq.m $\quad$ window Length $=0.635 \mathrm{~m}$ \\ ****************************************************
}

Total Window Surface $=1 \quad$ Blind Surface $=2$

Blind Angle $=10$ degree $\quad$ Blind Emisivity $=0.1$

Blind Temperature $=297.605 \mathrm{~K} \quad$ Indoor window Temperature $=300.841 \mathrm{~K}$

Outdoor Temperature $=305.15 \mathrm{~K}$ Velocity $=3.35 \mathrm{~m} / \mathrm{s}$

Total Heat flow $=13.4776 \mathrm{~W} / \mathrm{m} \quad$ Balance $=0.00397454$

Radiative Heat from window $=8.983 \mathrm{~W} / \mathrm{m} \quad$ Balance $=2.13163 \mathrm{e}-14$

Radiative Heat from blind $=-0.955482 \mathrm{~W} / \mathrm{m}$

Radiative Heat To Ambient $=-8.02752 \mathrm{~W} / \mathrm{m}$

h_Blind $=1.44762 \mathrm{~W} / \mathrm{m}^{2} \mathrm{~K} \quad$ h_window $=1.91598 \mathrm{~W} / \mathrm{m}^{2} \mathrm{~K}$

$\mathrm{U}_{-}$value $=2.65308 \mathrm{~W} / \mathrm{C} \mathrm{Sq} . \mathrm{m} \quad$ window Length $=0.635 \mathrm{~m}$

Total Window Surface $=1$

Blind Surface $=2$

Blind Angle $=20$ degree Blind Emisivity $=0.1$

Blind Temperature $=297.612 \mathrm{~K} \quad$ Indoor window Temperature $=300.875 \mathrm{~K}$

Outdoor Temperature $=305.15 \mathrm{~K}$ Velocity $=3.35 \mathrm{~m} / \mathrm{s}$

Total Heat flow $=13.3729 \mathrm{~W} / \mathrm{m} \quad$ Balance $=0.00281164$

Radiative Heat from window $=8.81319 \mathrm{~W} / \mathrm{m} \quad$ Balance $=1.06581 \mathrm{e}-13$

Radiative Heat from blind $=-0.972138 \mathrm{~W} / \mathrm{m}$

Radiative Heat To Ambient $=-\mathbf{7} .84106 \mathrm{~W} / \mathrm{m}$

h_Blind $=1.45249 \mathrm{~W} / \mathrm{m}^{2} \mathrm{~K} \quad$ h_window $=1.92649 \mathrm{~W} / \mathrm{m}^{2} \mathrm{~K}$

U_value $=2.63245 \mathrm{~W} / \mathrm{C}$ Sq.m window Length $=0.635 \mathrm{~m}$

Total Window Surface $=1 \quad$ Blind Surface $=2$

Blind Angle $=30$ degree $\quad$ Blind Emisivity $=0.1$

Blind Temperature $=297.62 \mathrm{~K} \quad$ Indoor window Temperature $=300.934 \mathrm{~K}$

Outdoor Temperature $=305.15 \mathrm{~K}$ Velocity $=3.35 \mathrm{~m} / \mathrm{s}$

Total Heat flow $=13.1926 \mathrm{~W} / \mathrm{m} \quad$ Balance $=0.00422907$

Radiative Heat from window $=8.52026 \mathrm{~W} / \mathrm{m} \quad$ Balance $=-5.24025 \mathrm{e}-13$

Radiative Heat from blind $=-1.0026 \mathrm{~W} / \mathrm{m}$

Radiative Heat To Ambient $=-7.51767 \mathrm{~W} / \mathrm{m}$

h_Blind $=1.47168 \mathrm{~W} / \mathrm{m}^{2} \mathrm{~K} \quad$ h_window $=1.94299 \mathrm{~W} / \mathrm{m}^{2} \mathrm{~K}$

U_value $=2.59696 \mathrm{~W} / \mathrm{C} \mathrm{Sq} . \mathrm{m} \quad$ window Length $=0.635 \mathrm{~m}$

Total Window Surface $=1$

Blind Surface $=2$

Blind Angle $=40$ degree $\quad$ Blind Emisivity $=0.1$

Blind Temperature $=297.63 \mathrm{~K}$ Indoor window Temperature $=301.021 \mathrm{~K}$ 
$\mathrm{h} \_$Blind $=1.50774 \mathrm{~W} / \mathrm{m}^{2} \mathrm{~K} \quad \mathrm{~h}$ wwindow $=1.96645 \mathrm{~W} / \mathrm{m}^{2} \mathrm{~K}$

$\mathrm{U}_{\text {_value }}=2.54415 \mathrm{~W} / \mathrm{C}$ Sq.m $\quad$ window Length $=0.635 \mathrm{~m}$

$* * * * * * * * * * * * * * * * * * * * * * * * * * * * * * * * * * * * * * * * * * * * * * * * * * * * *$

Total Window Surface $=1 \quad$ Blind Surface $=2$

Blind Angle $=50$ degree Blind Emisivity $=0.1$

Blind Temperature $=297.666 \mathrm{~K} \quad$ Indoor window Temperature $=301.129 \mathrm{~K}$

Outdoor Temperature $=305.15 \mathrm{~K} \quad$ Velocity $=3.35 \mathrm{~m} / \mathrm{s}$

Total Heat flow $=12.5911 \mathrm{~W} / \mathrm{m} \quad$ Balance $=0.00182254$

Radiative Heat from window $=7.45899 \mathrm{~W} / \mathrm{m} \quad$ Balance $=5.32907 \mathrm{e}-13$

Radiative Heat from blind $=-1.08855 \mathrm{~W} / \mathrm{m}$

Radiative Heat To Ambient $=-6.37044 \mathrm{~W} / \mathrm{m}$

h_Blind $=1.45522 \mathrm{~W} / \mathrm{m}^{2} \mathrm{~K} \quad$ h_window $=2.0307 \mathrm{~W} / \mathrm{m}^{2} \mathrm{~K}$

$\mathrm{U}_{\text {_value }}=2.47855 \mathrm{~W} / \mathrm{C}$ Sq.m window Length $=0.635 \mathrm{~m}$

******************************************************

Total Window Surface $=1 \quad$ Blind Surface $=2$

Blind Angle $=60$ degree Blind Emisivity $=0.1$

Blind Temperature $=297.735 \mathrm{~K} \quad$ Indoor window Temperature $=301.264 \mathrm{~K}$

Outdoor Temperature $=305.15 \mathrm{~K}$ Velocity $=3.35 \mathrm{~m} / \mathrm{s}$

Total Heat flow $=12.1741 \mathrm{~W} / \mathrm{m} \quad$ Balance $=0.0040989$

Radiative Heat from window $=6.59566 \mathrm{~W} / \mathrm{m} \quad$ Balance $=-4.583 \mathrm{e}-13$

Radiative Heat from blind $=-1.1185 \mathrm{~W} / \mathrm{m}$

Radiative Heat To Ambient $=-5.47716 \mathrm{~W} / \mathrm{m}$

$\mathrm{h} \_$Blind $=1.31858 \mathrm{~W} / \mathrm{m}^{2} \mathrm{~K} \quad$ h_window $=2.13408 \mathrm{~W} / \mathrm{m}^{2} \mathrm{~K}$

$\mathrm{U}_{-}^{-}$value $=2.39649 \mathrm{~W} / \mathrm{C}$ Sq.m window Length $=0.635 \mathrm{~m}$

******************************************************

Total Window Surface $=1 \quad$ Blind Surface $=2$

Blind Angle $=80$ degree Blind Emisivity $=0.1$

Blind Temperature $=297.938 \mathrm{~K} \quad$ Indoor window Temperature $=301.689 \mathrm{~K}$

Outdoor Temperature $=305.15 \mathrm{~K}$ Velocity $=3.35 \mathrm{~m} / \mathrm{s}$

Total Heat flow $=10.8575 \mathrm{~W} / \mathrm{m} \quad$ Balance $=0.0036588$

Radiative Heat from window $=4.14882 \mathrm{~W} / \mathrm{m} \quad$ Balance $=-3.16192 \mathrm{e}-13$

Radiative Heat from blind $=-1.20766 \mathrm{~W} / \mathrm{m}$

Radiative Heat To Ambient $=-2.94116 \mathrm{~W} / \mathrm{m}$

h_Blind $=1.05731 \mathrm{~W} / \mathrm{m}^{2} \mathrm{~K} \quad$ h_window $=2.32631 \mathrm{~W} / \mathrm{m}^{2} \mathrm{~K}$

U_value $=2.13731 \mathrm{~W} / \mathrm{C}$ Sq.m window Length $=0.635 \mathrm{~m}$

Total Window Surface $=1 \quad$ Blind Surface $=2$

Blind Angle $=90$ degree $\quad$ Blind Emisivity $=0.1$

Blind Temperature $=298.037 \mathrm{~K} \quad$ Indoor window Temperature $=301.838 \mathrm{~K}$

Outdoor Temperature $=305.15 \mathrm{~K}$ Velocity $=3.35 \mathrm{~m} / \mathrm{s}$

Total Heat flow $=10.3971 \mathrm{~W} / \mathrm{m} \quad$ Balance $=0.00418755$

Radiative Heat from window $=3.18277 \mathrm{~W} / \mathrm{m} \quad$ Balance $=-3.0731 \mathrm{e}-13$

Radiative Heat from blind $=-1.21495 \mathrm{~W} / \mathrm{m}$

Radiative Heat To Ambient $=-1.96783 \mathrm{~W} / \mathrm{m}$

$\mathrm{h}$ Blind $=0.944196 \mathrm{~W} / \mathrm{m}^{2} \mathrm{~K} \quad \mathrm{~h}$ window $=2.4223 \mathrm{~W} / \mathrm{m}^{2} \mathrm{~K}$

$\mathrm{U}_{-}$value $=2.04667 \mathrm{~W} / \mathrm{C}$ Sq.m window Length $=0.635 \mathrm{~m}$ 
In the current study, the radiation exchange between the window, blind and the indoor surroundings was computed using a four surface enclosure. To ensure the validity of this assumption, a grid study was performed. In this study, the blind was broken into sub-surfaces, and radiaosities at all surface were computed. Using these radiosities, the U-value of a double glazed window was computed for summer weather conditions and $d / L=0.043$. A comparison of the U-value variation with the louver angle $(\phi)$ for the five test cases is presented in Figure F-1. As seen in the Figure, dividing the blind surface into sub-sufaces has a minimal influence on the U-value of a double glazed window. For all cases, the U-value was found to be within $0.35 \%$ of the four surface enclosure defining the blind, window and the indoor surroundings.

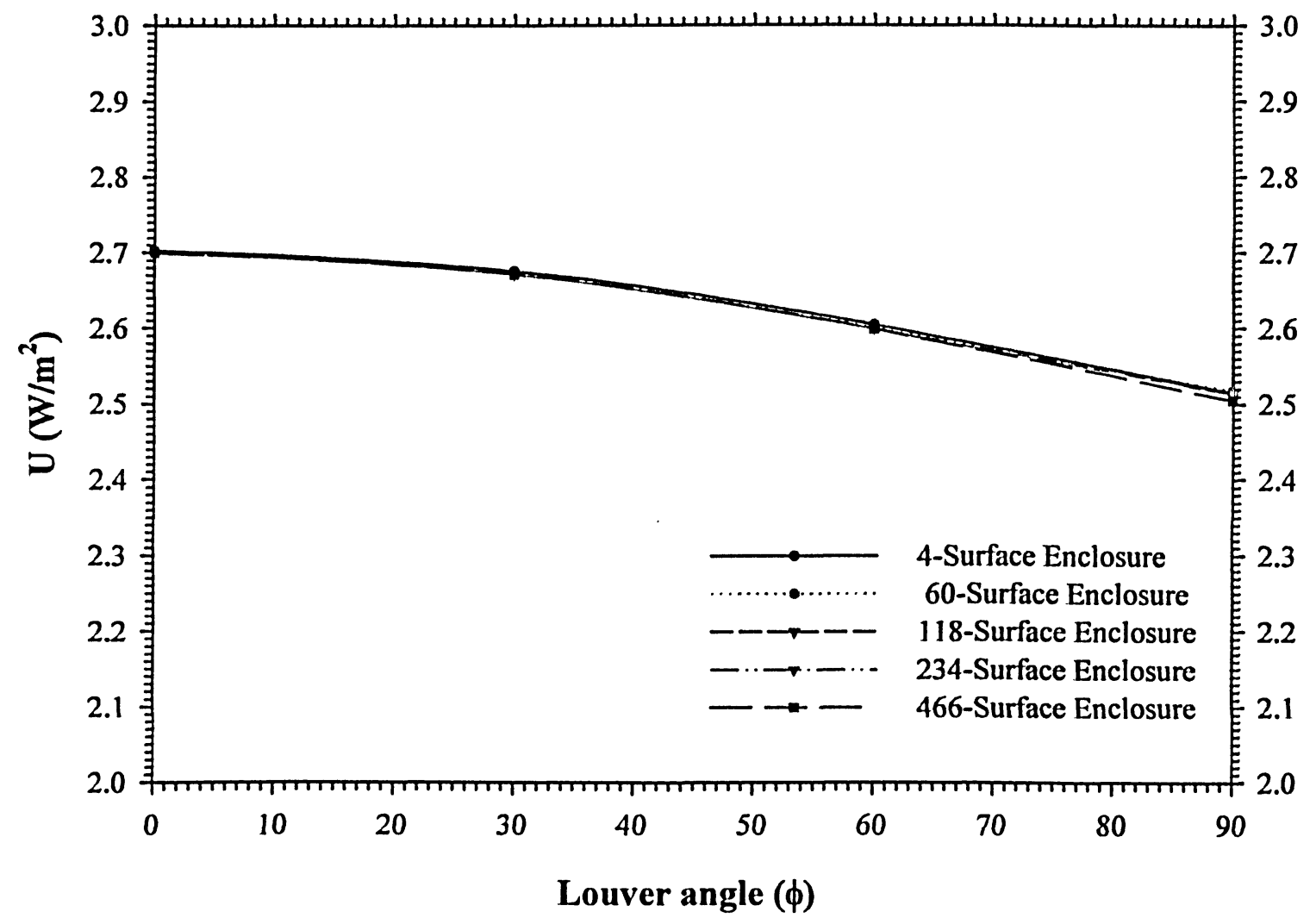

Figure F-1: Comparison of the U-value of a double glazed window for summer conditions, five different test grids, $\varepsilon_{\mathrm{b}}=0.8, \mathrm{~W} / \mathrm{ps}=1.14$. 


\section{APPENDIX-G: SAMPLE STREAMLINE AND TEMPERATURE CONTOURS PLOTS}

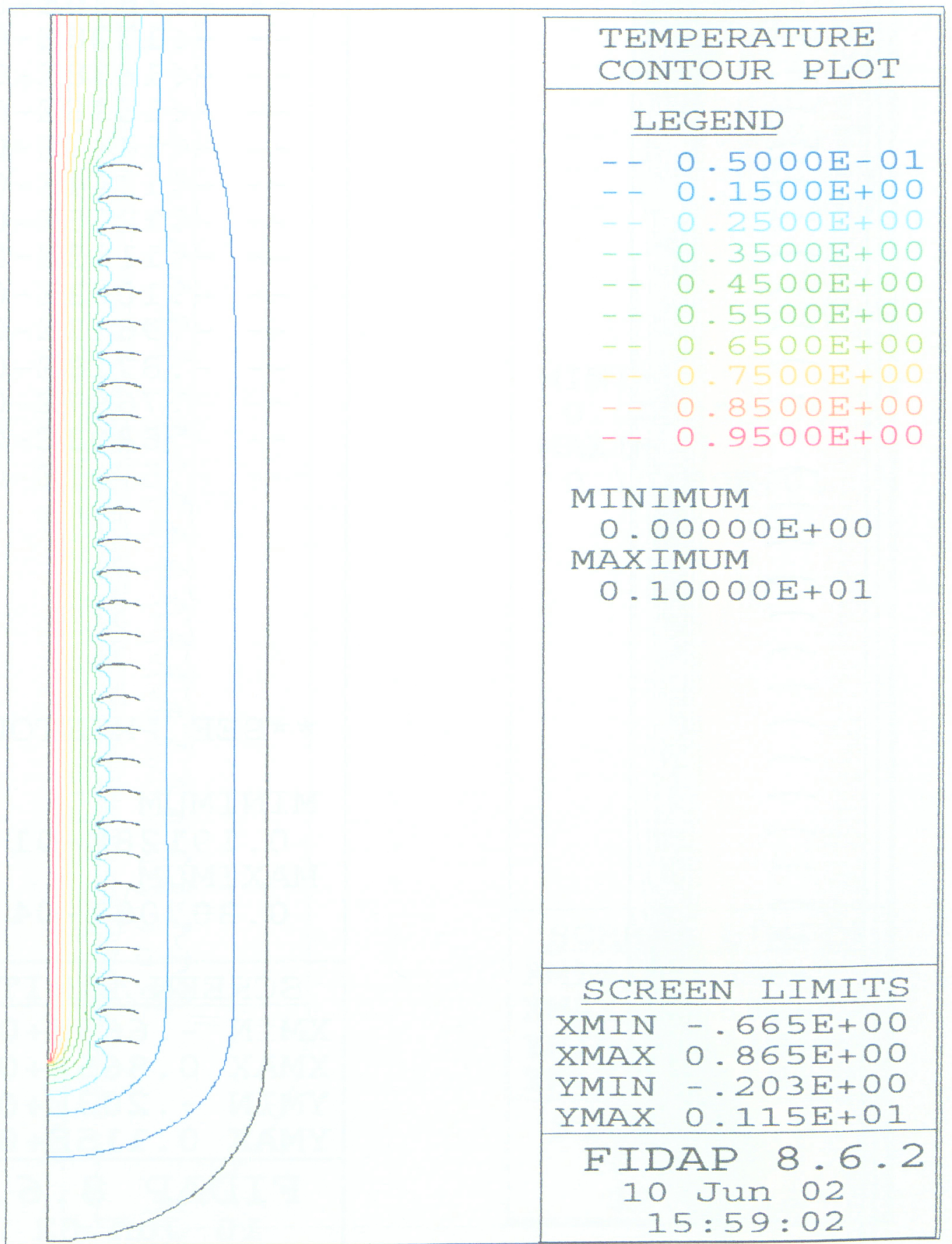

Figure G-1 $\phi=0^{\circ}$, blind tip-to-window spacing $\mathrm{d} / \mathrm{L}=0.043, \mathrm{~T}_{\mathrm{b}}{ }^{*}=0.3, \mathrm{Ra}_{\mathrm{L}}=10^{5}$ Refers to Figure 3.2 (a). 


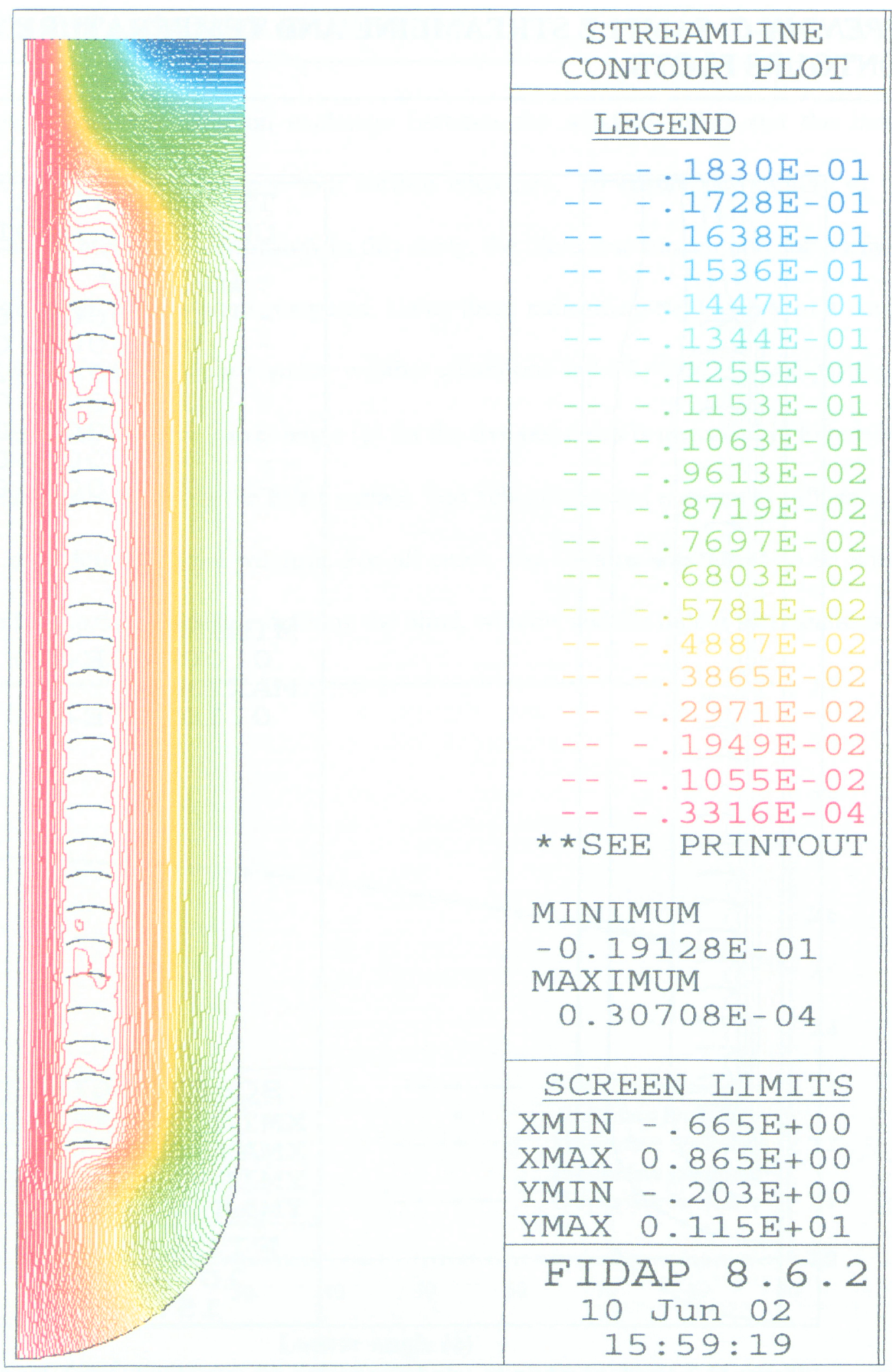

Figure G-2 $\phi=0^{\circ}$, blind tip-to-window spacing $\mathrm{d} / \mathrm{L}=0.043, \mathrm{~T}_{\mathrm{b}}{ }^{*}=0.3, \mathrm{Ra}_{\mathrm{L}}=10^{5}$ Refers to Figure3.3 (a). 


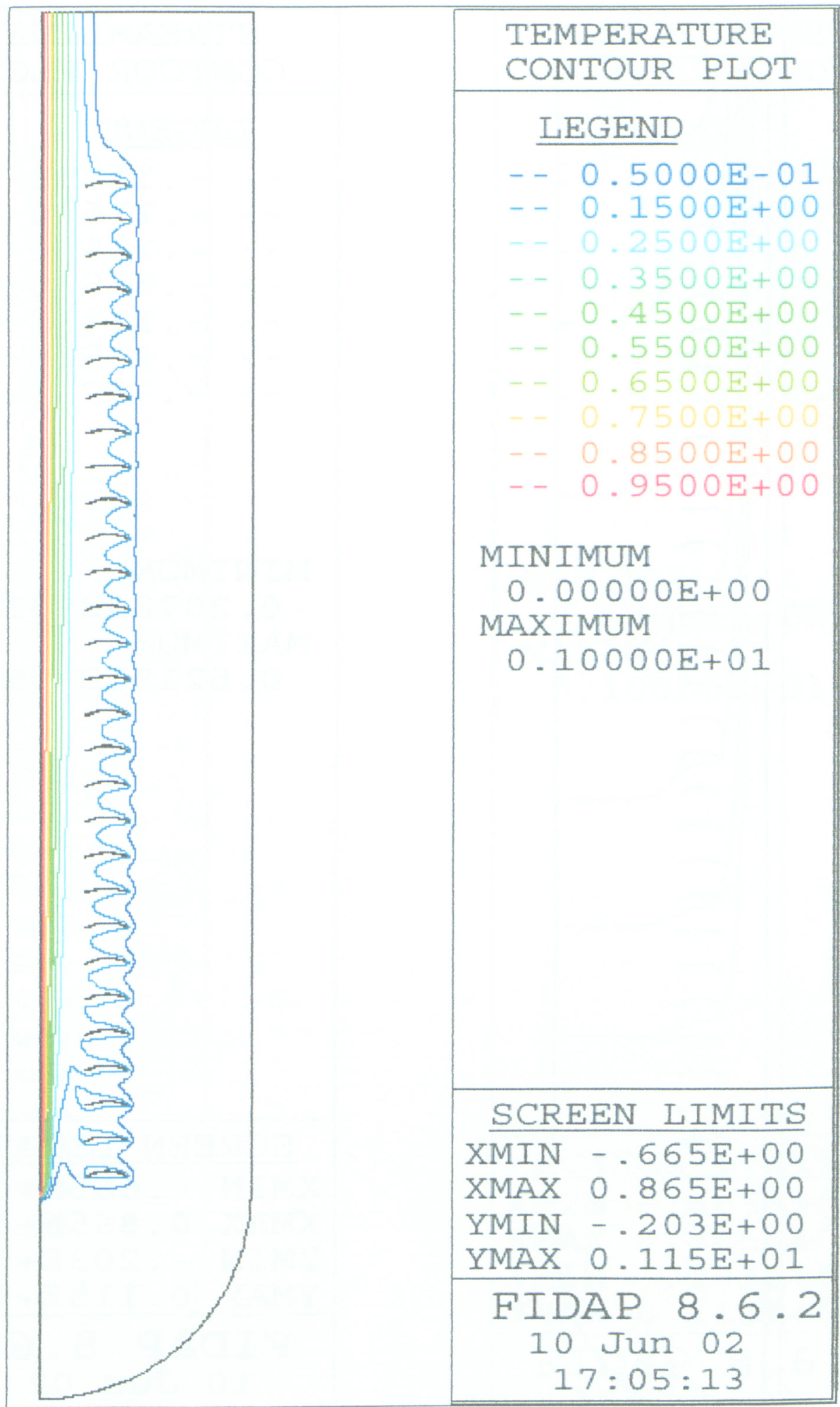

Figure G-3 $\phi=0^{\circ}$, blind tip-to-window spacing $\mathrm{d} / \mathrm{L}=0.043, \mathrm{~T}_{\mathrm{b}}{ }^{*}=0.3, \mathrm{Ra}_{\mathrm{L}}=10^{8}$ Refers to Figure3.2 (c). 


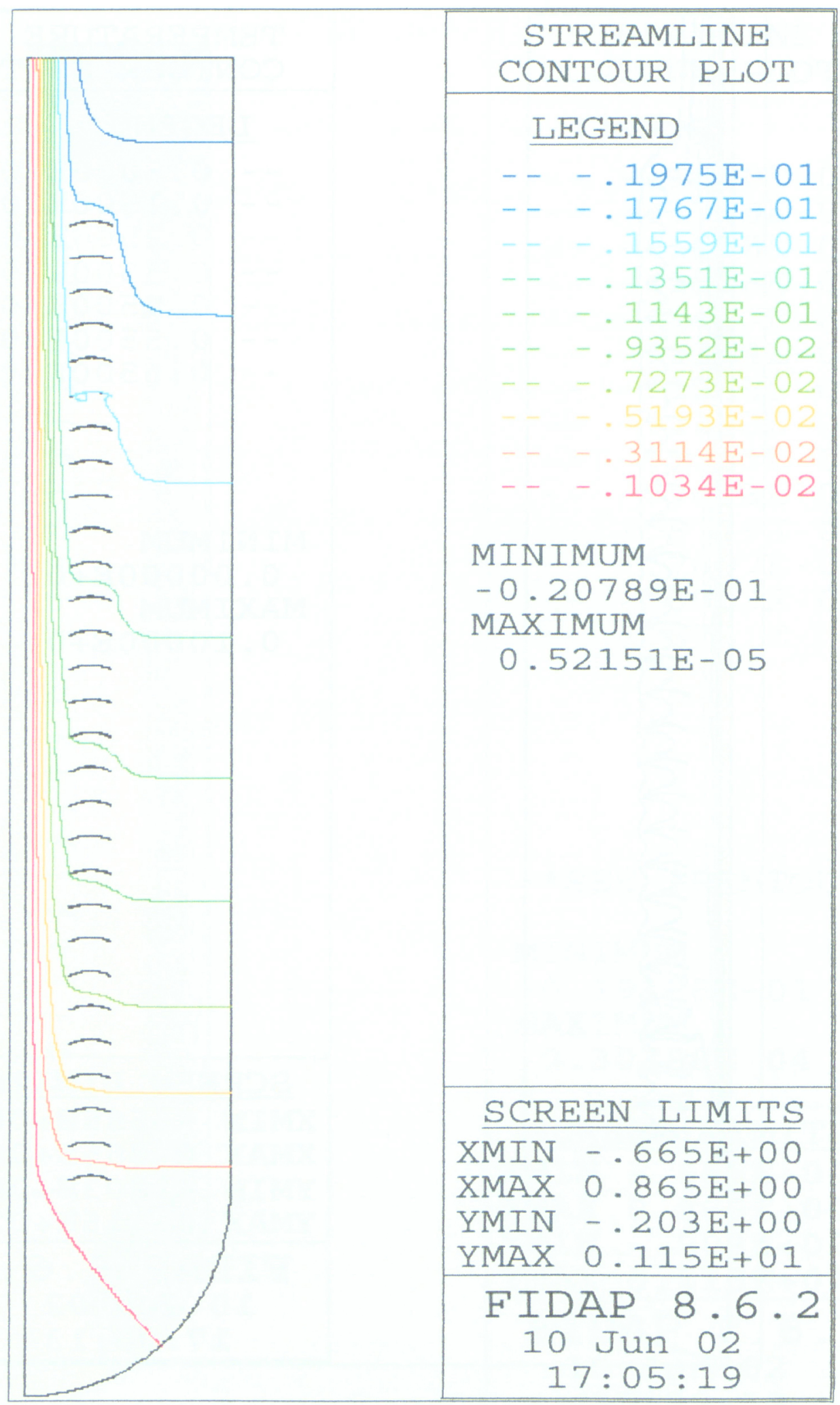

Figure G-4 $\phi=0^{\circ}$, blind tip-to-window spacing $\mathrm{d} / \mathrm{L}=0.043, \mathrm{~T}_{\mathrm{b}}{ }^{*}=0.3, \mathrm{Ra}_{\mathrm{L}}=10^{8}$. 


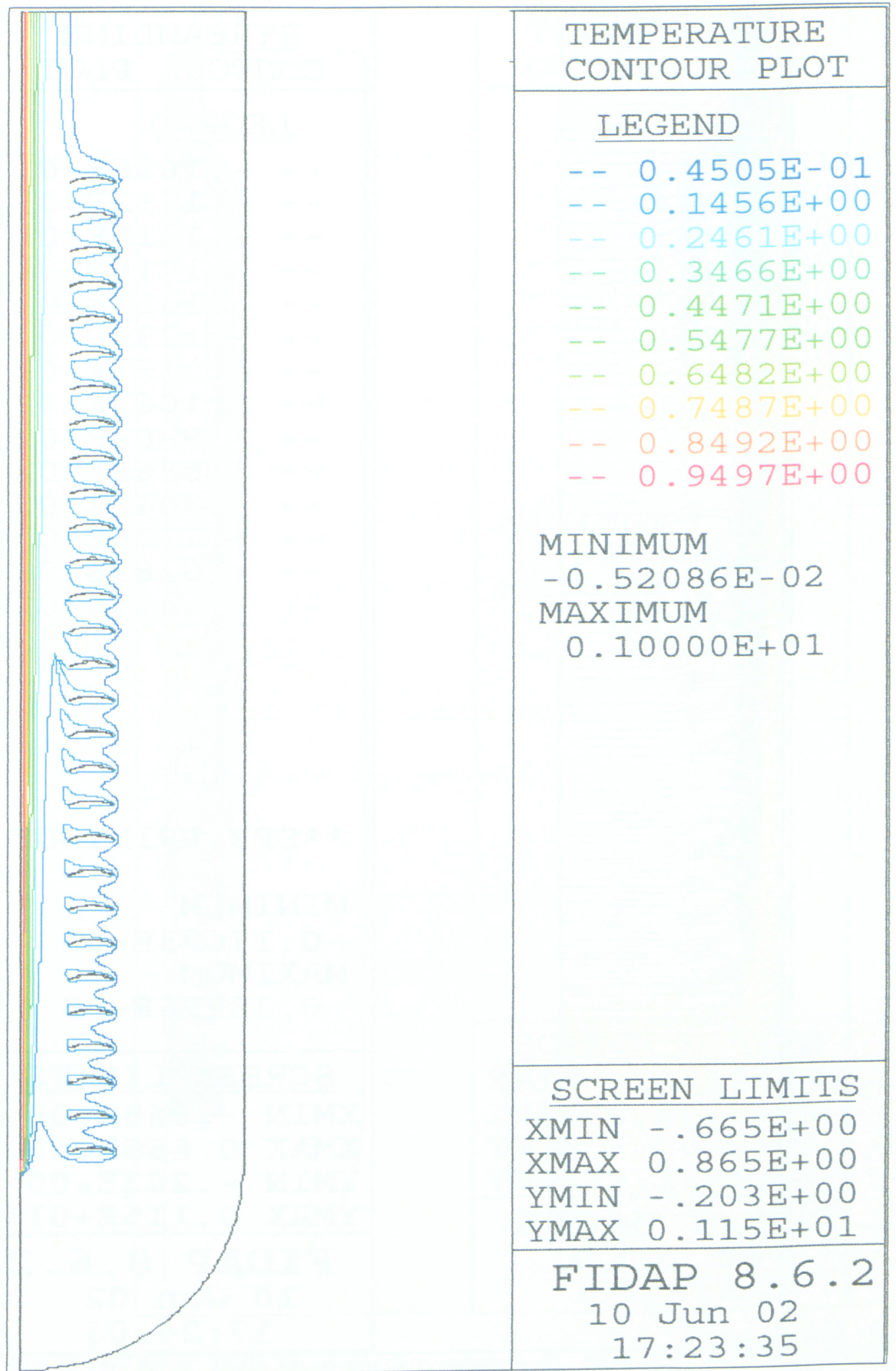

Figure G-5 $\phi=0^{\circ}$, blind tip-to-window spacing $\mathrm{d} / \mathrm{L}=0.043, \mathrm{~T}_{\mathrm{b}}{ }^{*}=0.3, \mathrm{Ra}_{\mathrm{L}}=5 \times 10^{8}$ Refers to Figure 3.2 (d). 


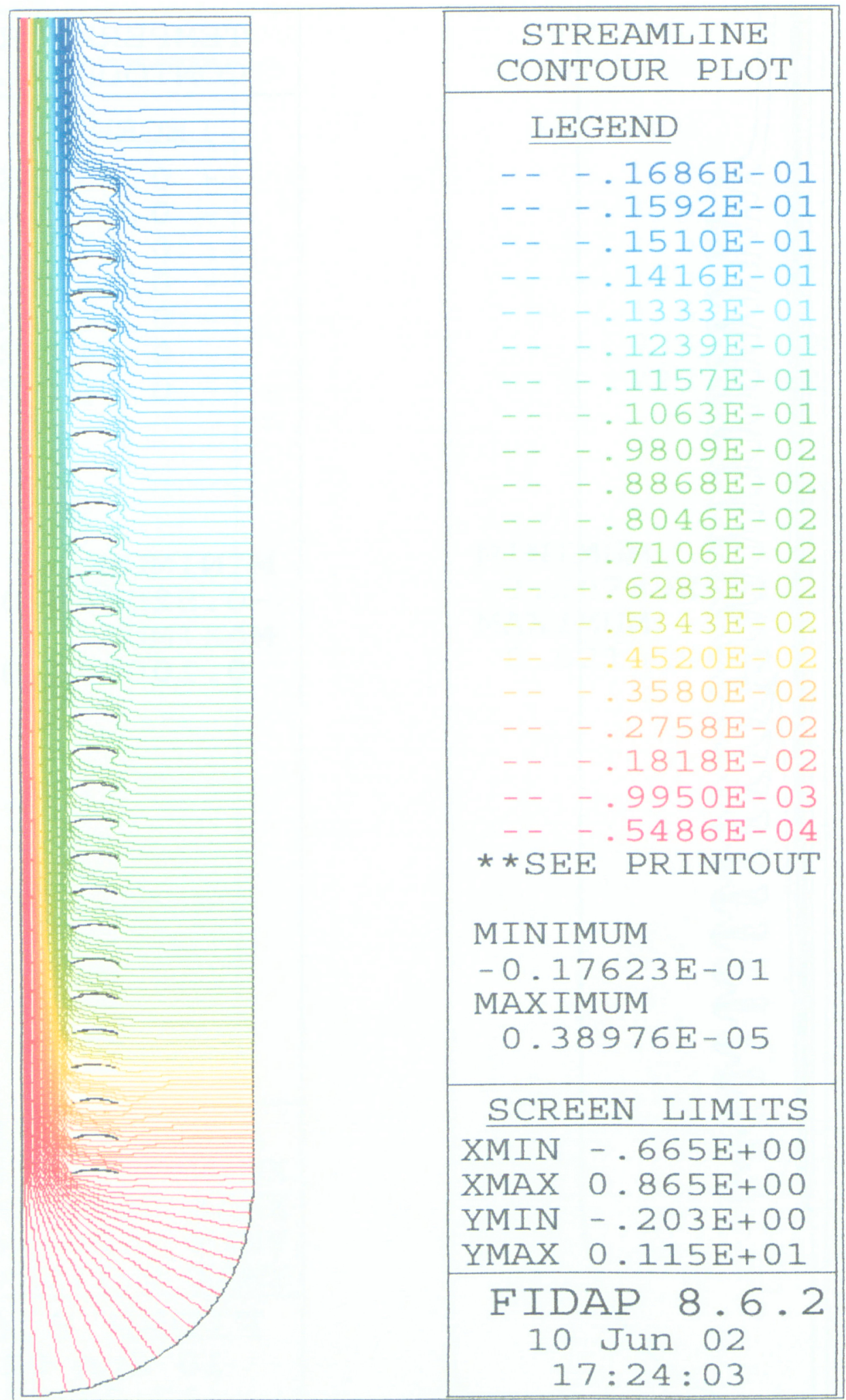

Figure G-6 $\phi=0^{\circ}$, blind tip-to-window spacing $\mathrm{d} / \mathrm{L}=0.043, \mathrm{~T}_{\mathrm{b}}{ }^{*}=0.3, \mathrm{Ra}_{\mathrm{L}}=5 \times 10^{8}$ Refers to Figure3.3 (c). 


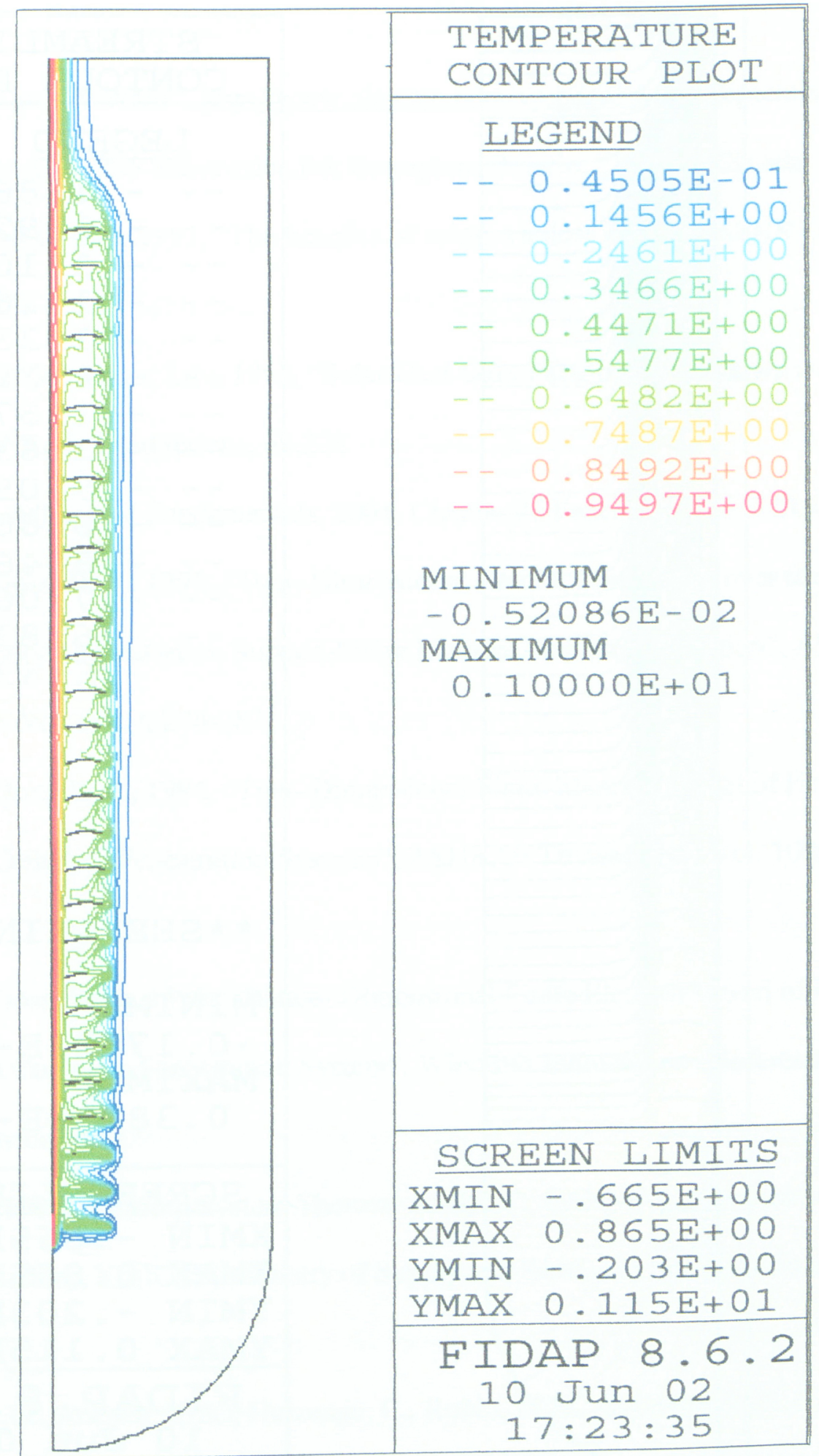

Figure G-7 $\phi=0^{\circ}$, blind tip-to-window spacing $\mathrm{d} / \mathrm{L}=0.043, \mathrm{~T}_{\mathrm{b}}{ }^{*}=0.3, \mathrm{Ra}_{\mathrm{L}}=5 \times 10^{8}$ Refers to Figure 3.7(a). 


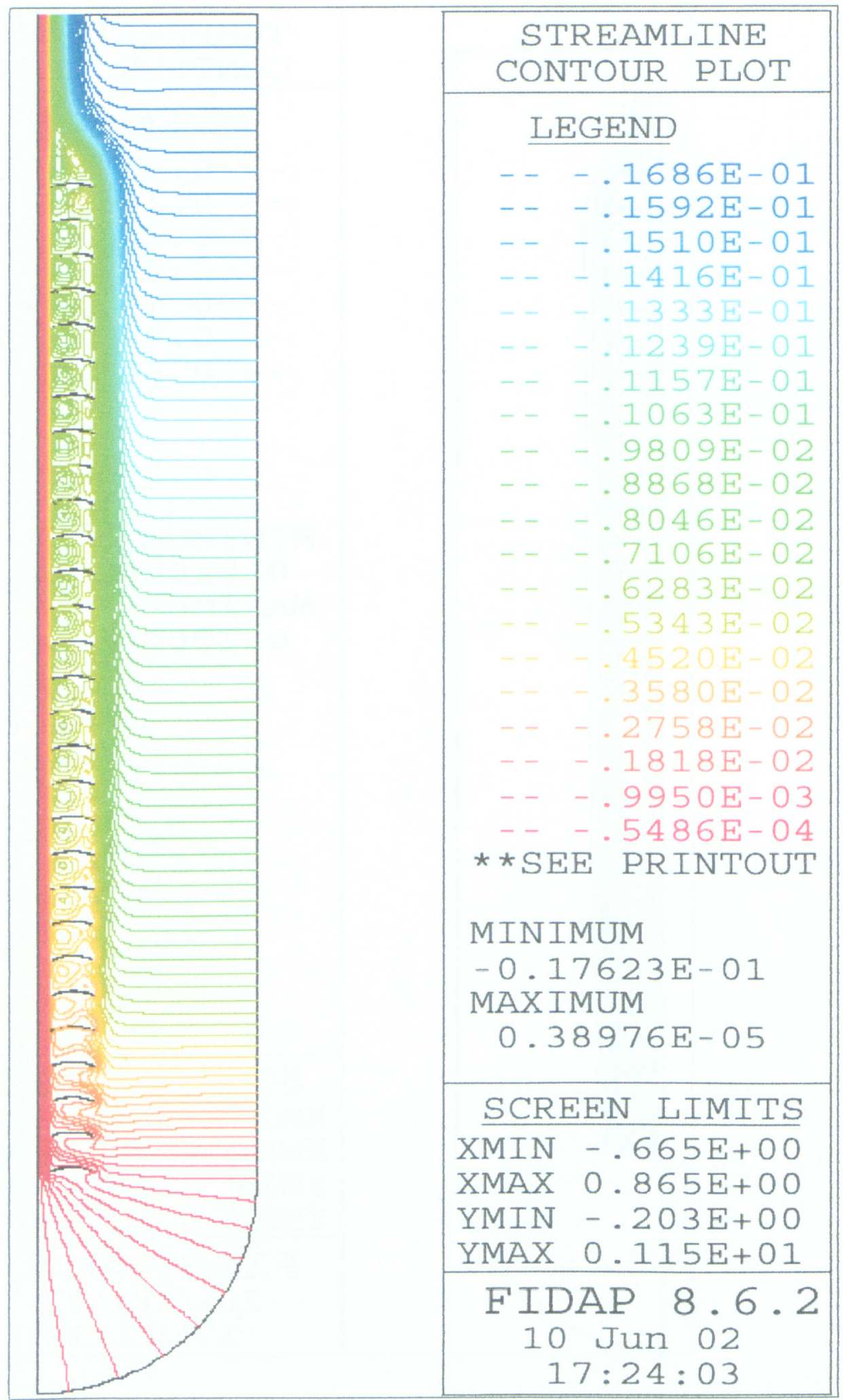

Figure $\mathrm{G}-8 \phi=0^{\circ}$, blind tip-to-window spacing $\mathrm{d} / \mathrm{L}=0.043, \mathrm{~T}_{\mathrm{b}}{ }^{*}=0.3, \mathrm{Ra}_{\mathrm{L}}=5 \times 10^{8}$ Refers to Figure3.7 (b). 


\section{REFERENCES}

1. "Better Than an RI9 Wall!", http://www.plastmo.com/vpipage1.html, September 17, 2003, Plastmo Ltd., 255 Summerlea Rd. Brampton, Ontario, L6T 4T8 Canada.

2. Mills, L.R., McCluney, 1993, "The benefits of using window shades", ASHRAE Journal, 20-27.

3. Ozisik, N. and Schutrum, L.F., 1960, "Solar Heat Gain Factors for Windows with Drapes", ASHRAE Transactions, 66:228

4. ASHRAE Handbook of Fundamentals, 2001, Chapter 30 Fenestration, ASHRAE, GA.

5. Curciji, D., Goss, W.P., 1993, "Two- Dimensional Natural Convection over the Isothermal Indoor Fenestration Surface-Finite Element Numerical Solution", ASHRAE Transactions, Vol. 99(1), 274-287.

6. Curciji, D., Goss, W.P., 1994, "Two- Dimensional Finite Element Model of Heat Transfer In Complete Fenestration Systems", ASHRAE Transactions, Vol. 100(2), $1207-1221$.

7. Curciji, D., Goss, W.P., 1995a, "Three- Dimensional Finite Element Model of Heat Transfer In a Complete Fenestration System", Windows Innovations Conference 95, Toronto, Canada, June.

8. Wright, J.L, 1992, "Glazing System Thermal Analysis", CANMET, Advanced Glazing System Laboratory, VISION3, Ministry of Supply and Services Canada, University of Waterloo.

9. Finlayson, E.U., Arasteh , D.K., Huizenga, C., Rubin, M.D., and Reily, M.S., "WINDOW 4.0: Documentation of Calculation Procedures", Energy and Environment Division, Lawrence Berkeley Laboratory, Berkeley, California. 
10. WinTherm 6.0, Thermoanalytics Inc, 2330 Airpak Blvd. Calumet MI.

11. Enermodal Engineering Ltd. 1991. "FRAME-- A Computer Program to Evaluate the Thermal, Performance of Window Frame Systems, Version 3.0." Waterloo, Ontario, Canada

12. Harrison, S.J., Barakat, S.A., "A Method for Computing the Thermal Performance of Windows", ASHRAE Transactions, Vol.89 (1).

13. Ede, A.J., 1967, “Advances in Free Convection", Advances in Heat Transfer, Vol. 4, Academic Press, New York, London, 1-62

14. Oberbeck, A., 1879, Ann. Phys. Chem. 7, 271.

15. Lorenz, L., 1881, Ann. Phys. Chem. 13, 582.

16. Schmidt, E., Beckmann, W., 1930, Tech. Mech. Thermodynamics 1, 341-391.

17. Saunders, O.A., 1939, Proc. Royal Society, A172, 55.

18. Schuh, H., 1948, Aerodynamics Versuchsanstalt Repts. \& Trans. 1007.

19. Ostrach, S., 1953, “An Analysis of Laminar Free-Convection Flow and Heat Transfer about a Flat Plate Parallel to the Direction of the Generating Body Force", NACA Technical Report 1111.

20. Sugawara, S., Michiyoshi, I., 1951, Transactions of the JSME 17, 109.

21. Sparrow, E.M., Gregg, J.L., 1958, Transactions of the ASME 80, 879.

22. Gebhart, B., 1962, Journal of Fluid Mechanics, 14, 225.

23. Le Fevre, E. J., 1956, Proc. $9^{\text {th }}$ International Congress of Applied Mechanics, Brussels 4, 168-174.

24. Wright, J.L. and Sullivan, H.F., 1989. "Natural convection in sealed glazing units; a review", ASHRAE Transactions, Vol. 95(1). 
25. Elsherbiny, S.M., 1980. "Heat transfer by natural convection across vertical and inclined air layers", Ph.D Thesis, Dept. of Mechanical Engineering, University of Waterloo, Canada.

26. Elsherbiny, S.M., Raithby, G.D. and Hollands, K.G.T., 1982, “Nusselt number distribution in vertical and inclined air layers", Transactions of the ASME, Vol. 105, 406-408.

27. Shewen, E.C., 1986, “A Peltier effect technique for natural convection heat flux measurement applied to the rectangular open cavity", Ph.D Thesis, Dept. of Mechanical Engineering, University of Waterloo, Canada.

28. Lee, Y., and Korpela, S.A. 1983, "Multicellular natural convection in a vertical slot", Journal of Fluid Mechanics, Vol. 126, 91-121.

29. Wright, J.L., and Sullivan, H.F., 1994, “A 2-D numerical model for natural convection in a vertical, rectangular window cavity", ASHRAE Transactions, Vol. 100(2).

30. Pennington, C.W., Smith, W.A., Farber, E.A., and Reed, J.C., 1964, “Experimental Analysis of Solar Heat Gain Through Insulating Glass With Indoor Shading",, ASHRAE Transactions Vol. 2, 54-68.

31. Rubin, I., Collins, L. and Tibbott, L., May 1978, "Window Blinds as a Potential Energy Saver-A case Study", NBS Building Science Series 112.

32. Mills, L.R., McCluney, 1993, "The benefits of using window shades", ASHRAE Journal, 20-27.

33. Rheault, S., Bilgen, E., 1989, "Heat Transfer Analysis in an Automated Venetian Blind Window System", J. of Solar Energy Engineering, Vol. 111, 89-95. 
34. Rheault, S., Bilgen, E., 1990, "Experimental study of full size-automated Venetian Blind Window System", J. of Solar Energy Engineering, Vol. 44(3), 89-95.

35. Cho, S.H., Shin, K.S., Zaheer-uddin, M., 1995, "The effect of Slat angle of windows with Venetian Blinds on Heating and Cooling loads of buildings in South Korea", Energy Vol. 20, (12), 1225-1236.

36. Garnet, J.M., Fraser, R.A., Sullivan, H.F. and Wright, J.L., 1995, “Effect of Internal Venetian Blinds on Center-Glass U-Values", In Proc. Of Window Innovations, 273279.

37. Fang, X.D., GE, X.S., April 1993. "Experimental Study of Overall Heat Transfer Coefficients of the Glass Window with a Venetian Blind", Journal of Solar Energy, Vol. 14, 138-142.

38. Klems, J.H., and Kelly, G.O., 1996, "Calorimetric Measurements of Inward-Flowing Fraction for Complex Glazing and Shading Systems", ASHRAE Transactions, 102 (1), 947-954.

39. Collins, M.R., Harrison, S.J., 1999, “Calorimetric Measurements of Inward-Flowing Fraction of Absorbed Solar Radiation in Venetian Blinds", ASHRAE Transaction, 105 (2), 1022-1030.

40. Collins, M.R., Harrison, S.J., Oosthuizen, P.H., Naylor, D., 2003, “Estimating the Solar Heat and Thermal Gain form a Window with a Interior Venetian Blind", ASHRAE Meeting, Chicago.

41. Collins, M.R., Harrison, S.J., Oosthuizen, P.H., Naylor, D., 2002, "Sensitivity Analysis of Heat Transfer from an Irradiated Window and Horizontal Louvered Blind Assembly", ASHRAE Transactions. 
42. Machin, A.D., Naylor, D., Oosthuizen, P.H., Harrison, S.J., 1998, “Experimental Study of Free Convection at an Indoor Glazing Surface with a Venetian Blind", Int. J. of HVAC \& R Research, Vol. 4(2), 153-166.

43. Ye, P., "Effect of Venetian Blinds on Overall Heat Transfer Through Window Systems: A Finite Element Numerical Solution", M.Sc. Thesis, Dept. of Mechanical Engineering, Queens University, Kingston, Ontario, Canada.

44. Phillips, J., Naylor, D., Oosthuizen, P.H., Harrison, S.J., 2001, “ Numerical Study of Convection and Radiative Heat Transfer from a Window Glazing with a Venetian Blind", Int. J. of HVAC \& R Research, Vol. 7(4), 383-401.

45. Shahid, H., Naylor, D., 2001, "The Effect of Vertical Louvered Blinds on the Thermal Performance of a Fenestration", $18^{\text {th }}$ Canadian Congress of Applied Mechanics Proceedings, Vol. 1, 135-136.

46. Bevans, J.T. and Dunkle, R.V., February 1960, "Radiation interchange within an enclosure", ASME Journal of Heat Transfer, 82(1):1-7.

47. Incropera, F.P., DeWitt, D.P., 1996, Introduction to Heat Transfer, by John Wiley \& Sons, Inc.

48. Siegel, R., Howell, J.R., 1972, Thermal Radiation Heat Transfer, McGraw-Hill, New York.

49. Hottel, H.C., 1967, Radiative Transfer, McGraw-Hill, New York.

50. Lokmanhekim, J. Ed., 1975, "Procedure for determining Heating and Cooling loads for Computerizing Energy Calculations: Algorithms for Building Heat Tranfer Subroutines", ASHRAE, New York. 
51. Oosthuizen, P.H., Naylor, D., 1999, Introduction to Convective Heat Transfer Analysis, McGraw-Hill, New York.

52. Wright, N.T. and Gebhart, B., 1994, "The Entrainment Flow Adjacent to an Isothermal Vertical Surface", Int. J. of Heat and Mass Transfer Vol. 37, 213-231.

53. FIDAP. 1989. FIDAP 8.5 Documentation Suite. Fluent, Inc. Evanston Illinois.

54. H. Shahid, D. Naylor, May 26-30, 2003, "Thermal Simulations of a Fenestration with Horizontal Venetian Blind", Proceedings of $3^{\text {rd }}$ International Conference on Computational Heat and Mass Transfer, Banff, Canada, 727-736. 